\title{
Manomin (Wild Rice) in the Kiji Sib̀̀ (Ottawa River) Valley: \\ An Exploration of Traditional Food, Development and Decolonization
}

\author{
by Geri Blinick
}

\author{
A thesis submitted to \\ the Faculty of Graduate and Postdoctoral Affairs \\ in partial fulfillment \\ of the requirements for the degree of \\ Master of Arts \\ in \\ Geography
}

Carleton University

Ottawa, Ontario

(C) Geri Blinick, 2012 
Library and Archives

Canada

Published Heritage

Branch

395 Wellington Street

Ottawa ON K1A ON4

Canada
Bibliothèque et

Archives Canada

Direction du

Patrimoine de l'édition

395 , rue Wellington

Ottawa ON K1A ON4

Canada
Your file Votre référence

ISBN: 978-0-494-93630-6

Our file Notre référence

ISBN: 978-0-494-93630-6
NOTICE:

The author has granted a nonexclusive license allowing Library and Archives Canada to reproduce, publish, archive, preserve, conserve, communicate to the public by telecommunication or on the Internet, loan, distrbute and sell theses worldwide, for commercial or noncommercial purposes, in microform, paper, electronic and/or any other formats.

The author retains copyright ownership and moral rights in this thesis. Neither the thesis nor substantial extracts from it may be printed or otherwise reproduced without the author's permission.
AVIS:

L'auteur a accordé une licence non exclusive permettant à la Bibliothèque et Archives Canada de reproduire, publier, archiver, sauvegarder, conserver, transmettre au public par télécommunication ou par l'Internet, prêter, distribuer et vendre des thèses partout dans le monde, à des fins commerciales ou autres, sur support microforme, papier, électronique et/ou autres formats.

L'auteur conserve la propriété du droit d'auteur et des droits moraux qui protege cette thèse. $\mathrm{Ni}$ la thèse ni des extraits substantiels de celle-ci ne doivent être imprimés ou autrement reproduits sans son autorisation.
In compliance with the Canadian Privacy Act some supporting forms may have been removed from this thesis.

While these forms may be included in the document page count, their removal does not represent any loss of content from the thesis.
Conformément à la loi canadienne sur la protection de la vie privée, quelques formulaires secondaires ont été enlevés de cette thèse.

Bien que ces formulaires aient inclus dans la pagination, il n'y aura aucun contenu manquant. 
Manomin (Wild Rice) in the Kiji Sibi (Ottawa River) Valley: An Exploration of Traditional Food, Development and Decolonization

\begin{abstract}
Manomin, or wild rice (Zizania sp.), is an ecologically significant wetland species, a highly nutritious food and a central food (culturally, spiritually and physically) for Anishinaabe people. The Ardoch Algonquin First Nation and Allies (AAFNA) is a community with strong ties to traditional ways of harvesting, processing, preparing and sharing manomin. AAFNA has also engaged in numerous oppositional stances to industrial developments throughout Algonquin territory.

This thesis examines how development has affected the Ardoch Algonquin's ability to maintain their responsibility for manomin, how AAFNA has responded to the challenges and/or opportunities of such developments, and highlights Algonquin-settler history and contemporary relations. The author concludes with a discussion about the implications for settler responsibilities in light of the research findings, underscoring the need for a commitment and action towards genuine engagement and honouring of historical agreements, towards relationships rooted in responsibility, respect, equity and justice, and towards decolonization.
\end{abstract}




\section{ACKNOWLEDGMENTS}

I would like to extend my warm appreciation to the many people who have supported this work. There are so many people who have offered their generosity, time and knowledge over the course of this project and to each of you I am so grateful.

Most importantly, I would like to recognize and thank the community who so warmly welcomed me and my questions, granting me the privilege to participate, share and learn from you. I would especially like to thank Harold, Mireille, Paula, Bob and Mitchell for welcoming me into your homes, your offices, your boats and your community gatherings and for taking the time to share your incredible insights Migwetch.

I would like to thank both of my co-supervisors, Patricia Ballamingie and Simon Brascoupé, for their wealth of knowledge and resources, their patience and their sustained support through the various junctures along the way. I am honoured to have been a recipient of their generosity. Patricia's guidance, encouragement, thoughtful and critical reflections and unwavering support have been invaluable throughout this entire learning

process. I am grateful to Simon for enabling this incredible opportunity for me to better understand Indigenous-settler relations. I have so appreciated his willingness to welcome me into his home and for opening so many doors for me to be able to better understand our collective histories, relationships and responsibilities.

I have been astounded with the generosity I have encountered throughout this learning journey and am grateful to everyone who took the time to share their knowledge and resources. I would like to express my gratitude to the many teachers I have 
encountered along the way who have helped to cultivate my curiosity and provide me with guidance.

I am eternally grateful to my parents for their encouragement and love from the very beginning. I am also most fortunate to have John as my partner, and to have had his support in all that I take on. Finally, I could not have done this without the humour, kindness and company of my friends and family. 
Manomin (Wild Rice) in the Kiji Sibì (Ottawa River) Valley: An Exploration of Traditional Food, Development and Decolonization

\section{TABLE OF CONTENTS}

Title Page

Abstract

Acknowledgments

ii

Table of Contents

iii

List of Acronyms

$\mathrm{v}$

List of Acrongms

ix

List of Figures

Preface

Chapter 1 - Substantive Context 2

1.1 The Anishinaabe and Algonquin Nations 5

1.2 Names, Terms and Identity in this Study $\quad 8$

1.3500 Years Later: Continuing Expansion, Novel Enclosures 10

An Era of Neoliberalism and Neoliberalization $\quad 12$

Food Today 14

Transnational Movements of Altereity, Creativity and Solidarity 19

Food Sovereignty and the Alternative Food Movement 20

1.4 Indigenous Resilience, Resistance and Revitalization of Traditional Foods 24

1.5 The Ecology of Manomin / Wild Rice (Zizania aquatica, and Zizania palustris) $\quad \mathbf{3 0}$

Manomin: a Local Gift, a Local "Resource", yet Globally Situated 35 
1.6 Ardoch Algonquin First Nation and Allies (AAFNA) and Ongoing Omàmiwinini Relations in the Valley of the Kiji Sibi

Manomin and the Ardoch Algonquin First Nation and Allies 41

Rice Wars (1979-1981) 42

Continuous Assertion of Algonquin Sovereignty and Jurisdiction by AAFNA

1.7 A Contingent Community?

1.8 A Resilient Community

\section{Chapter 2 - Conceptual Framework}

2.1 Deconstructing and Decolonizing the Production of Knowledge 60

2.2 Deconstructing Power, Domination, Resistance and Negotiation 66

Politicizing Ecology: A Short History $\quad 69$

A Critical Political Ecological Case Study $\quad 73$

Examining Discourse, Knowledge, Identity and Power: Poststructural Approaches

Theorizing Intersectional Oppressions, Shifting Nexuses of Power and Deconstructing Home: Some Critical Feminist Insights

Deconstructing Race and Identity: Decolonizing Academic Inquiry $\quad 87$

2.3 Theoretical Applications in this Research $\quad 89$

Deconstructing "Development" $\quad 89$

Deconstructing Resistance $\quad 92$

Working Across Scales $\quad 98$

Exposing Linkages Between the Workings of Capitalism and Colonial Relations

100

Understanding Nature as Socially Constructed 103

\section{Chapter 3 - Methodological Approach}

108

3.1 Methodologies guiding this study 108

Taking Account of Indigenous Intellectual Traditions: Indigenist and Decolonizing Methodologies

Examining the Production of Knowledge: Postcolonial

Methodologies

115

Researching through Reflexivity, Relationships and Attention to Particularity: Critical Feminist Methodologies 
Transformative Asset-Based Research: Critical Post-structural

Methodologies

Grasping multi-scalar interaction: Critical ethnographic methodologies

3.2 Practicing Research and Implementing Decolonizing Research Methods

Chapter 4: Algonquin-Settler Relations in the valley of the Kiji Sibi

4.1 Omàmiwinini-European Relations and Agreements in Omàmiwinini Territory: 1603-1867

4.2 Regulation of Indigenous Identity / Indian Status

4.3 Resisting Dispossession: Algonquin Petitions and the Algonquin Land Claim

4.4 Maintaining a Colonial Present through Judicial and Legal Processes in Canada

4.5 An Ongoing Colonial Order: Maintained Through "a great array of bayonets and cannons" (Thobani, 2007: 35)

Chapter 5: "Development" and Manomin - Current Challenges and/or Opportunities

5.1 Interpretation and representation of the research results

5.2 Manomin in Ardoch: A consequence of $19^{\text {th }}$ century "development" in the Ottawa Valley

5.3 Maintaining access to manomin at Mud Lake

Herbicide use in hydro-electric lines

Resisting the commercialization of manomin

Effects of motorboat activity and shoreline and hydrological management

Uranium exploration and mining in the Mississippi watershed: a threat to manomin, ecosystemic and community health

The Algonquin Comprehensive Land Claim and Manomin

The Contemporary Food System, Social Change and Manomin

5.4 Discussion 
6.2 Reviewing the Research Questions Guiding this Study

6.3 "Development" and the Ardoch Algonquin First Nation and Allies' access

225 to manomin

6.4 "It's in our blood": AAFNA Identity and Manomin

230

6.5 AAFNA's responses to the challenges of "development"

6.6 Where do non-Indigenous people fit in? Implications for Settler Responsibilities

6.7 Towards a decolonizing joumey 


\section{LIST OF ACRONYMS}

$\begin{array}{ll}\text { AAFNA } & \text { Ardoch Algonquin First Nation and Allies } \\ \text { AANDC } & \text { Aboriginal Affairs and Northern Development Canada } \\ \text { AFN } & \text { Assembly of First Nations } \\ \text { APTN } & \text { Aboriginal Peoples Television Network } \\ \text { CCAMU } & \text { Community Coalition Against the Mining of Uranium } \\ \text { CETA } & \text { Comprehensive Economic Free Trade Agreement } \\ \text { ERT } & \text { Environmental Review Tribunal } \\ \text { FAITC } & \text { Foreign Affairs and International Trade Canada } \\ \text { FVC } & \text { Frontenac Ventures Corporation } \\ \text { FAO } & \text { Food and Agriculture Organization } \\ \text { INAC } & \text { Indian and Northern Affairs Canada } \\ \text { IPSMO } & \text { Indigenous Peoples' Solidarity Movement of Ottawa } \\ \text { KI } & \text { Kitchenuhmaykoosib Inninuwug } \\ \text { LWR } & \text { Lanark Wild Rice } \\ \text { MOU } & \text { Memorandum of Understanding } \\ \text { MDNR } & \text { Minnesota Department of Natural Resources } \\ \text { NFU } & \text { National Farmers Union } \\ \text { NAFTA } & \text { North America Free Trade Agreement } \\ \text { OMAA } & \text { Ontario Ministry of Aboriginal Affairs } \\ \text { OMNR } & \text { Ontario Ministry of Natural Resources } \\ \text { OMNSIA } & \text { Ontario Métis and Non-Status Indian Association } \\ \text { OCAMU } & \text { Ottawa Coalition Against the Mining of Uranium } \\ \text { ONPP } & \text { Office of Nutrition Policy and Promotion } \\ \text { MNR } & \text { Ministry of Natural Resources } \\ \text { MRWMP } & \text { Mississippi River Water Management Plan } \\ \text { MVC } & \text { Mississippi Valley Conservation } \\ \text { PANAP } & \text { Pesticide Action Network Asia and the Pacific } \\ \text { PFPP } & \text { Peoples' Food Policy Project } \\ \text { RCAP } & \text { Royal Commission on Aboriginal Peoples } \\ \text { RCNE } & \text { Royal Commission on the Northern Environment } \\ \text { UN } & \text { United Nations } \\ \text { WRHA } & \text { Wild Rice Harvesting Act } \\ \text { WTO } & \text { World Trade Organization } \\ & \end{array}$




\section{LIST OF FIGURES}

Figure 1.1 Canadian Agri-Food Exports and Realized Net Farm Income From the 17 Markets: 1970-2006

Figure 1.2 Distribution of Manomin across Turtle Island 34

Figure 1.3 Airborne Gamma Ray Spectrometry Map of Eastern Ontario and 51 South West Quebec

Figure 1.4 Map of Uranium Mining Claims in North Frontenac County 52

Figure 4.1 Map of Eastern North America after Royal Proclamation of 1763, 145 According to British Crown

Figure 4.2 Map of Algonquin Nations in 1600s and the Royal Proclamation of 146 1763

Figure 4.3 Historic land cessions in current Algonquin land claim area

Figure 4.4 The Area Under Negotiation in the Algonquin Land Claim

Figure 5.1 Stands of Wild Rice in Ontario

Figure 5.2 Channels cut by motorized boat traffic through manomin fields on 192 Mud Lake, Mississippi River

Figure 5.3 Tourist camp

Figure 5.4 Mississippi River Profile near Mud Lake 198

Figure 6.1 Conceptual model of wild rice distribution 224

Figure 6.2 Developments that affect AAFNA's access to manomin on Mud Lake 227

Figure 6.3 AAFNA's responses to developments to protect manomin on Mud 240 Lake 


\section{Manomin (Wild Rice) in the Kiji Sibì (Ottawa River) Valley:}

An Exploration of Traditional Food, Development and Decolonization

\section{PREFACE}

This research begins where I currently stand, live, write and learn. I decided, very early on, that my research must be rooted in both the historical and current context of where I have chosen to plant my feet and set down roots. By engaging in research in this way, I have taken a journey through which I have come to more fully understand, recognize and acknowledge that I - a settler Canadian, a Canadian citizen of European decent - am rooted on Indigenous land, here, on Turtle Island. My story, my life, my research is thus embedded in the colonial history through which the Canadian state has come to be. My research begins with a strong sense of place, and an explicit acknowledgment that Carleton University (the institution through which I have pursued these present studies) and my current home are situated on unceded Algonquin (Anishinaabe) territory. 


\section{Chapter 1 - Substantive Context}

Manomin, also known as as the "food that grows on water" or wild rice (Zizania sp.), is a traditional food of Anishinaabe people. The situation of manomin - as a wetland species, as an example of one of many traditional Indigenous foods that has been central to many Anishinaabeg as a nutritious staple food and as a sacred food, as an example of a "commons" management and access scheme, and as a source of genetic material for domestication, commodification and the modification of other rice (Oryza sp) species presents a fascinating case study through which Indigenous-settler relations can be examined, particularly in the context of jurisdictional disputes over "natural resources" or "Gifts from the Creator". This thesis will focus specifically on a case study through which the situation of manomin will be examined in the context of the Ardoch Algonquin First Nation and Allies (AAFNA), a community which has engaged in numerous oppositional practices that challenge the legitimacy of expansion and "development" in the Valley of the Kiji Sibi (translations known as Great River; also known as the Ottawa River), traditional Algonquin territory. I present this study and the particular political ecological context of this case, with the hopes of illuminating the complexity and structural barriers that limit access to traditional foods, and Indigenous food sovereignty. By doing this I also hope to underline the significance for a broad movement towards decolonization. Throughout this paper the concept and processes of decolonization will be discussed in thorough detail, however a preliminary definition of decolonization is the process by which colonial histories are confronted and transformed through various practices including: education, activism and social-political change at various sites and 
scales - personal-political, national, institutional, and cultural spheres.

This research begins with where I stand and what I love. This research is grounded where I live, in Cantley, Quebec and where I study and work, in Ottawa, Ontario, which are all part of traditional Algonquin territory; land that is vast and beautiful and has never been ceded by its original people. My research also begins with my love of food and commitment to the belief that everyone should have access to healthy, sustainable and culturally-appropriate foods. In other words, this research comes from the conviction that not only is access to enough food monumental, but also that our food should sustain our bodies, our senses, our sense of community, our cultures and must sustain and respect the environment and the creatures that we share this space with.

I came to this area of research through my interest to learn more about sustainable communities and sustainable community development, particularly in the context of natural resource-dependent economies. I have been interested and active in food politics in various capacities for several years and began to hear more about the unique concerns surrounding Indigenous foods through my involvement with Food Secure Canada (a national food security organization). In one discussion about Indigenous Food Sovereignty it became apparent to me that if such a concept became respected in policy and development, a fundamental shift would necessarily have to occur in Canadian economic, political, social and environmental relations. I had learned of the Ardoch Algonquin First Nation shortly after my arrival in Ottawa, as the uranium mining protests and the incarceration of Robert Lovelace (discussed further below) had happened just months earlier. Additionally, through a directed study with Simon Brascoupé I was able 
to become more fully acquainted with Indigenous teachings and history, the colonial history of Canada, decolonial literature and specific cases of Indigenous communities or organizations that were developing more sustainable and cooperative economic endeavours.

This research focuses on the case of a particular community in the valley of $K i j i$ Sibi (Ottawa River) who have successfully maintained cultural, spiritual, as well as physical connections to a traditional food that has grown in the region for generations that is the Ardoch Algonquin First Nation and Allies and the manomin (wild rice) that has sustained community members and neighbours for generations. Manomin, in the context of the Ardoch Algonquin First Nation and Allies, provides an opportunity to understand how access and responsibility over food (or food sovereignty) is maintained and defended in a contemporary context in the face of various "industrial" developments which encroach upon, despoil and contaminate the very systems that support such traditional food systems. I chose to examine one particular and narrow case study (as opposed to examining the entire landscape of traditional foods of significance to AAFNA, Algonquin or Anishinaabeg people) in order to tease out the complexity of what is involved when groups of people assert their right to food, or, perhaps more appropriately, when people assert their responsibility to maintain their food security, food democracy and food sovereignty and their responsibility to maintain their access to healthy, nutritious, nourishing, sustainable, delicious and local foods.

This chapter will present the broad context in which the case study is situated, beginning with a brief overview of the history of the Anishinaabe and Algonquin Nations 
in Section 1.1. Following this a brief overview of terms used throughout this thesis will be explained in Section 1.2. In Section 1.3, the study will then be contextualized in the contemporary environment of enclosure and dispossession, with a discussion of neoliberalization in Section 1.3.1. A discussion of food follows in Section 1.3.2, outlining food as a frontier for enclosure and as a site of transnational resistance movements. In Section 1.3.3, the alternative food movement is discussed, and in Section 1.3.4 food sovereignty is introduced as a political agenda around which thousands of people are mobilizing worldwide. In Section 1.4 Indigenous food sovereignty is discussed to further contextualize the unique position of Indigenous foods in the wider food movement, particularly in Canada. Manomin is then introduced through an overview of its ecological, cultural, spiritual, economic and political situation throughout Section 1.5. Finally, in Section 1.6 the Ardoch Algonquin First Nation and Allies are introduced, first by briefly discussing the continuous relations that Algonquin people have had in the Kiji Sibi valley (the Ottawa River valley), then by providing a brief and partial overview of the political history of the community, including the Rice Wars of 1979-1981.

\subsection{The Anishinaabe and Algonquin Nations}

What is today known as the Ottawa River watershed has been the traditional territory of the Algonquin (Omàmiwinini) Nation since time immemorial ${ }^{1}$. Greg Sarazin, chief of the

1 The phrase "since time immemorial" is in common usage among many Anishinaabe people, including scholars, Elders and various government officials and institutions (Lovelace, n.d.; McGregor, 2004; Johnson in Sherman, 2007) to discuss the historical presence of Anishinaabe people on Turtle Island (North America) and in the valley of the Kiji Sibi (Ottawa River). According to Hessel (1993), 
Algonquins of Pikwàkanagàn First Nation from 1987 - 1989 explains:

The Algonquin Nation was never a newcomer to its territory. Our occupation and use of an identifiable tract of land goes beyond the limits of what is now called history. The Algonquins have been in the valley of the Ottawa River, at least as long as the French have lived in France or the English have lived in England. Before there was a Canada, before Cartier sailed his small ship up the great river, Algonquins lived in, occupied, used and defended their home in the Ottawa Valley (Sarazin, 1989 quoted in Majaury, 2005: 1).

The Algonquin Nation is part of a larger group of nations, known as the Anishinaabe Nation, which means "original man or peoples" (Gehl, 2010: 10).

Anishinaabe peoples have lived throughout the Great Lakes region to the present day, share similar culture and language, and include "the Algonquin, Chippewa, Delaware, Mississauga, Nipissing, Odawa, Ojibwa and the Potawatomi" (Gehl 2010: 10). Paula Sherman (2007), an Omàmiwinini scholar and former co-chief of the Ardoch Omàmìinini First Nation, cites oral history throughout her account of Omàmìinini creation and migration to demonstrate that Omàmìinini people had participated in the Anishinaabe migration, which is thought to have begun from the salty waters of the Gaspé Peninsula and ended along the tributaries of Kiji Sibi. It is through this migration that Omàmiwinini people received the teachings and prophecies of the

archacological records indicate occupation of parts of Quebec and Ontario as early as 9000 BCE, however it is hypothesized that Anishinaabe people were not descendants of these early occupants, and can trace their lineage through archaeological evidence of Indigenous groups of the Laurel culture, dating to approximately $1000 \mathrm{BCE}$. This account of Anishinaabe presence is however problematic as it refers to a Eurocentric conception of time and relations with place. Paula Sherman (2007) posits that

the past does not exist in isolation from the present and future within the epistemologies of Indigenous peoples. For example, Kanien'kehá:ka scholar Deb Doxtator has argued for the existence of temporal continuity within the North American continent $[\ldots]$ The ancestors who greeted Champlain when he arrived in the valley of the Kiji Sibi would not have been thinking that the event took place in the seventeenth century; for them time would have been constructed differently and would have been based on complex relationships that extended past the physical world into the metaphysical (41-42). 
Seven Fires that formed part of the Omàmiwinini epistemology, and the basis for the relationships of Omàmiwinini people with the Natural World to achieve the good life (or Mino-Pimaadiziwin) (Sherman, 2007).

A central part of the Anishinaabe migration story is the account of manomin, or wild rice, as a gift of the Creator to the Anishinaabe people. Elder Erma Vizenor, Ojibwa Elder recounts:

Wild rice, or manoomin, is a sacred food and medicine integral to the religion, culture, livelihood, and identity of the Anishinaabeg. According to our sacred migration story, in the long ago a prophet at the third of seven fires beheld a vision from the Creator calling the Anishinaabe to move west (to a land previously occupied long ago) until they found the place "where food grows on the water." The Anishinaabeg of the upper Mississippi and western Great Lakes have for generations understood their connection to anishinaabe akiing (the land of the people) in terms of the presence of this plant as a gift from the Creator (Erma Vizenor, quoted in Minnesota Department of Natural Resources, 2008).

Manomin is therefore a sacred food for Anishinaabe people, as well as a historicallysignificant staple food for many communities (this is described in more detail in Section $1.5)$.

This study will focus on the contemporary context of manomin the Kiji Sibì as recounted by some members of the Ardoch Algonquin First Nation, in order to explore the implications of maintaining access and the responsibility to care for this culturally significant food today. 


\subsection{Names, Terms and Identity in this Study}

It is important that I draw attention to my choice of words in describing Algonquin people and Indigenous peoples in Canada more broadly. I have chosen to use the word 'Indigenous peoples' throughout most of this study to refer to the original inhabitants of lands that have been settled or colonized. I use this term in order to acknowledge the existence of numerous and diverse Indigenous nations, or separate and distinct peoples, particularly in the context of Turtle Island (or what is today known as North America) where Indigenous peoples includes both status and non-status people. Use of the words Aboriginal and Indian are used to indicate a legal context, wherein these are the terms used to identify Indigenous individuals who have particular traits as understood and ultimately determined by the Canadian state (where Aboriginal people includes First Nations, Métis and Inuit groups; and "Indians" is a term used to refer to First Nations who are recognized by the federal government to have legal "Indian status" and thus accrue particular benefits and are recognized to posses particular rights). I do this with the full awareness that Indigenous peoples in Canada refer to themselves in numerous ways and that the use of English terms to describe a group of people differently than how they would have named themselves is incredibly problematic.

Algonquin people historically referred to themselves as Omàmìinini, though the term Algonquin had begun to be used in the early $17^{\text {th }}$ century by Samuel de Champlain and then later gained popularity "and became the main linguistic designation for various peoples who were not all members of the Anishinabek Nation"' (Sherman, 2007: 26) (i.e., the Algonquin language family). The word Algonquin is also used to identify 
Omàmiwinini people (Algonquins) in Ontario and Québec. Paula Sherman (2007) in her dissertation posits that renaming and reclassifying the land and people was a central part of the process employed by the French to possess the land. She explains: "In the case of the Omàmiwinini people, French exploration and missionary discourses involved the erasure of Omàmiwinini cultural and spiritual designations of identification with the valley of the Kiji Sibi, and the implementation of a renaming policy that suited the economic and political goals of the French Crown" (26). She cites the contemporary use of the word Algonquin by Omàmiwinini people as an example of the effectiveness and impacts of "cognitive colonialism" (Sherman, 2007: 27). Sherman (2007) further elaborates: "Omàmiwinini translates as the people of the Kiji Sibi. It reminds us of the relationships that we have with the Natural World" (151). I have chosen to use both Omàmiwinini and Algonquin throughout the paper because Omàmiwinini is not, in my experience, in common usage amongst many Omàmiwinini people, and as Gehl (2010) suggests, the dominant use and status of the term Algonquin may serve to contribute to existing scholarship.

I have chosen to use some Algonquin words [such as manomin (wild rice) and Kiji Sibi (Ottawa River)] to recognize the existing and ongoing relationships of the Algonquin people within this territory. By doing so, I also hope to undermine, in this small way, colonial acts of dispossession of Indigenous peoples by erasure and misrepresentation through language [as "wild rice" is not "wild", but a managed food crop (Cizek, 1992); and the Ottawa River was not the territory of the Ottawa nation, but of the Anishinaabe people (Hessel, 1993)]. In this thesis, I replicate the spelling for these words that is used 
by the leadership of the Ardoch Algonquin First Nations, the community with whom this research has been conducted (though in quotations there may be variations of these spellings based on how the word is written in the original texts). I italicize these words to differentiate them from English words and to show respect.

\subsection{Years Later: Continuing Expansion, Novel Enclosures}

Over the course of more than 500 years of European presence on Turtle Island, a great shift in political, ecological and social relations has occurred. In Chapter 4, I examine the history of Indigenous-settler relations and settler expansion in the valley of Kiji Sibì in detail. In this section I outline the current political economic context in which the case study is situated.

Presently, processes of enclosure and accumulation by dispossession - the very same processes through which Canada was colonized and established as a white settler state (discussed in Chapter 2 of this thesis) - are expanding through both seemingly benign and violent tactics (including everyday consumerism, military action, and displacement of people), in ongoing and escalating privatization of the Commons. David Harvey (2003) discusses the novel processes at play in the privatization and commodification of life systems and human ingenuity, noting the role of state governments in facilitating such developments: 
Wholly new mechanisms of accumulation by dispossession have also opened up. The emphasis upon intellectual property rights in the WTO negotiations [the so-called TRIPS (Trade-Related Aspects of Intellectual Property Rights) agreement] points to ways in which the patenting and licensing of genetic material, seed plasma, and all manner of other products can now be used against whole populations whose practices had played a crucial role in the development of those materials. Biopiracy is rampant and the pillaging of the world's stockpile of genetic resources is well under way to the benefit of a few large pharmaceutical companies. The escalating depletion of the global environmental commons (land, air, water) and proliferating habitat degradations that preclude anything but capitalintensive modes of agricultural productions have likewise resulted from the wholesale commodification of nature in all its forms. The commodification of cultural forms, histories, and intellectual creativity entails wholesale dispossessions [...]. The corporatization and privatization of hitherto public assets (such as universities), to say nothing of the wave of privatization (of water and public utilities of all kinds) that has swept the world, indicate a new wave of 'enclosing the commons'. As in the past, the power of the state is frequently used to force such processes through even against popular will. The rolling back of regulatory frameworks designed to protect labour and the environment from degradation has entailed the loss of rights. The reversion of common property rights won through years of hard class struggle (the right to a state pension, to welfare, to national health care) to the private domain has been one of the most egregious of all policies of dispossession pursued in the name of neo-liberal orthodoxy (147-148).

In addition to novel enclosures, there is continuing economic dependence on more traditional resource exploitation (mining, forestry, hydrological management and damming) on Indigenous lands the world over, and on Turtle Island in particular. The Canadian economy is very much based on the natural resources sector. In 2008 , natural resources (including energy, mineral and timber resources) accounted for $65 \%$ of all goods exported, while "the direct and indirect output of resource output was equivalent to $22 \%$ of all GDP, while natural resources accounts for only $7 \%$ of Canada's share of employment" (Statistics Canada, 2008). As commodity prices rose from 2002 to 2008, there was increasing investment in the mineral and energy sectors, resulting in increasing 
investment in resource exploration, drilling and extraction, including mining activities, off-shore oil drilling and the continued development of crude bitumen in the Alberta oil sands. Forestry, mining and energy development, and unsustainable food systems (such as industrial agriculture and industrial fisheries) are often highly ecologically destructive activities, and are the back bone of the Canadian natural resources economy.

Furthermore, the processing and distribution of these materials through the expansion of trade routes (including natural gas pipelines, highways and rail transportation) often encroach upon traditional Indigenous territories.

These ongoing processes (through which common properties of Indigenous communities and nations are becoming increasingly privatized, commoditized, despoiled and encroached upon) are central to the focus of this thesis, which seeks to understand the consequences of these processes for Indigenous livelihoods, particularly with respect to access to traditional foods and the continuation of cultural practices.

\subsubsection{An Era of Neoliberalism and Neoliberalization}

As mentioned above by Harvey (2003), neoliberal policies have been adopted by, and have been imposed upon governments to encourage the privatization of public goods and services in the name of economic growth and efficiency. Tickell and Peck (2003) advocate for an understanding of neoliberalism that is fluid, dynamic and geographically significant. Undertaking a historical analysis of the evolution of neoliberalism, they demonstrate that it is a process, dependent upon socio-political contexts, reworkings and negotiations. Thus the authors argue "neoliberalization, like globalization, should be 
thought of as a contingently related process, not as an end-state or 'condition"' (Tickell and Peck, 2003: 165; emphasis in original edition). They continue that neoliberalism is not a uniform monolith: "there is no pure form neoliberalism, only a range of historically and geographically specific manifestations of neoliberalization-as-process" (Ibid, 165). The hybridity of neoliberalism is a necessity; it always conforms to local social, political, cultural and environmental norms, histories and organizations, while challenging and shaping these processes in turn. Neoliberalization is a restructuring process in a political economic sense, not to be conflated with institutional outcomes (Tickell and Peck, 2003). Tickell and Peck (2003) define neoliberalization as "the mobilization of state power in the contradictory extension and reproduction of market (-like rule)"; it involves new forms of governance ("statecraft") to encourage the expansion of markets, and blurring of boundaries between state and markets. Neoliberalism emerged in direct opposition to the Keynesian welfare state, in which social programs mediated the contradictions of capitalistic polarization. Roll-back neoliberalism prioritized the following policies: "minimize the size of government, make space for competitive forces, enlarge the scope and reach of the private sector, (re)distribute wealth on the basis of market principles" (Tickell and Peck, 2003: 173). Roll-out neoliberalization, features two distinct characteristics. The first is the "partial depoliticization" of neoliberal ideology and policy. The second is the increasing re-emergence of institution building, however, in this historical instance, state and supra-national institutions are consolidating to encourage global market viability and expansion. I therefore situate this study in a neoliberal era in which food, and local resources more broadly, have come to be 
understood and treated as commodities to be exploited and subjected to the logic of the "free" market, through state and supra-national apparatuses (such as the World Trade Organization and bilateral trade agreements). As mentioned by Tickell and Peck (2003) neoliberalization is a highly contingent process; this study will therefore shed some light on how this process is negotiated in the context of this case study.

\subsubsection{Food Today}

The broad political ecological situation of food today is highly relevant to this case study, as manomin, like many other foods, is subjected to the logic of neoliberalization and industrialization. Manomin is increasingly commodified through industrial production, harvesting and processing practices in Canada and northern U.S.A, and through paddy production in California. As is discussed below, the stands of manomin managed and shared collectively by AAFNA were licensed by the Ontario Ministry of Natural Resources for private harvesting in 1979. Furthermore, manomin is being researched for its "genetic potential", while most genetically modified organisms are patented by private industries. Unfortunately, the issue of genetic manipulation and commodification of manomin is beyond the scope of this research, however it remains a highly significant development.

The context of neoliberalization and increasing industrialization of economies and life systems has resulted in two distinct food systems. Blay-Palmer and Donald (2008) characterize industrial food production regimes as those that engage with food as a commodity, emphasizing quantity and large-scale production, dependence on capital, 
labour and technology, international trade and vertical integration in processing, distribution, retail and food services. They characterize the alternative food system as one that engages with sustainable food provisioning with a focus on decentralized, local production, diversity, re-framed relationships between farmer and consumer, the dissipation of externalities and restraint of resource use. The authors stress that food systems are in fact hybridized and that "it is important to acknowledge the need to avoid false dualisms", which mistakenly conceptualize the food system as polarized. However, they also argue that there is value in articulating well-defined differences between the two systems in order to distinguish more sustainable practices which oppose or offer a distinct alternative to industrial practices.

Increasingly, the industrial food system (whether viewed at a local scale or otherwise) is under astoundingly concentrated control by very few corporations and their subsidiaries, such as Cargill, Bayer, Dow, Syngenta and Monsanto, who represent a massive portion of the market share for some or many of the following sectors of the food system: the means to (food) production (through large-scale landholdings, quotas, heavy machinery and the capital necessary for large-scale, intensive, industrial agriculture); production of chemical inputs and pharmaceuticals; patenting of seeds and biotechnology; food processing; food distribution and retailing (ETC Group, 2009). The ETC Group is an international civil society action group focused on erosion, technology and concentration. They (amongst others who offer similar critiques of the industrial food system) characterize the industrial food system as an oligopoly in which very few corporations have control of the entire food system from field to table through vertical 
integration of the food supply chain and control over life systems.

National food policies the world over are regulated by free trade agreements which privilege export-oriented agricultural practices (that are dominated by large-scale foreign interests) over local needs, including the needs of the farmers, fishers, hunters, wild crafters and citizens themselves.

Canada is no exception, while the average size of farm is increasing, the number of farms and farm owners is decreasing, with a loss of almost 80,000 farms since 1988 (NFU, 2010). Farmers are also experiencing a cost-price squeeze where the cost of inputs has risen significantly, while farm product prices have dropped resulting in decreasing profit margins for farmers, while retail prices (often controlled by large multinational corporations through vertical integration of processing, transportation and retail) have risen. This is often referred to as the farm (or small farm) crisis. The National Farmer's Union (NFU), a direct-membership national farm organization comprised of farming families and supporters, presents the declining net incomes of farmers as a consequence of free trade agreements which create fierce competition amongst farmers at an international scale, and favour transnational corporations which have the power to out-compete local businesses and create global monopolies through vertical integration in areas such as oil and gas exploration and development, pharmaceutical development, farming inputs, heavy machinery and equipment, transportation, processing and retail. Figure 1.1 demonstrates the correlation of increasing exports with steadily decreasing farm income. 
Figure 1.1: Canadian Agri-Food Exports and Realized Net Farm

Income From the Markets: 1970-2006

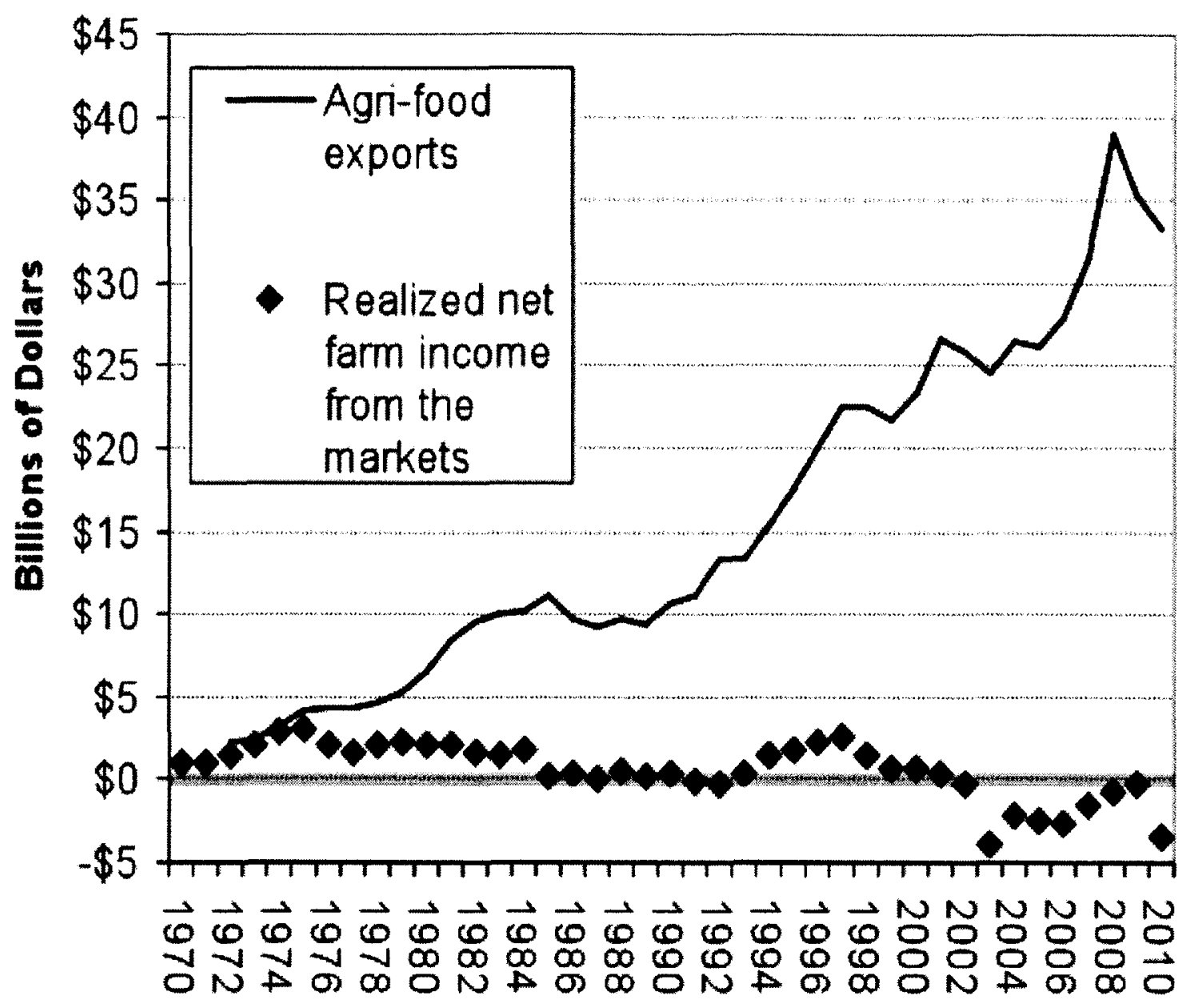

Source: NFU, 2010

Note: Prices are not adjusted for inflation, thus realized farm net income is in effect much lower. Also, realized net farm income from the market does not correct for the effect of publicly funded support programs, which masks even greater net farm income losses.

In addition to agriculture, other food sectors are also adversely affected by neoliberal, free trade policies. Canadian fisheries are increasingly imperiled due to unsustainable fishing practices in order to maximize harvests, mainly for export-oriented 
trade. Additionally, adequate habitat to support the hunting, harvesting and collection of "wild" foods is continually under pressure from encroaching urbanization and industrial activities such as forestry and mining, the products of which are integrated into the global market. Amidst increasing exports, parts of Canada are found to be highly food insecure despite having viable lands for food production. Ontario is highly reliant on food imports, where it imports $\$ 4$ billion of food more than what is exported (Metcalf Foundation, 2008).

Canada is a signatory to the following free trade agreements: Canada-United States Free Trade Agreement; North American Free Trade Agreement (NAFTA), the Canada-European Free Trade Association and the Agreement on Agriculture of the World Trade Organization (WTO). With the failure of large bloc free trade agreements, such as the Free Trade Area of the Americas, Canada has increasingly focused on bilateral trade agreements. Canada has established bilateral free trade agreements with Chile, Israel, Costa Rica, Japan, Jordan, Colombia, Peru and Panama and is in the process of negotiating several others (FAITC, 2012). The Comprehensive Economic Free Trade Agreement (CETA) between Canada and the European Union is currently being negotiated which will have major consequences for the Canadian economy and the environment for small enterprises.

The consequence of the current political economic environment is a food system that privileges export-oriented production and externalizes costs to social-ecological systems through industrial agricultural practices (including the heavy use of toxic synthetic inputs, irrigation and/or monocultures), long-distance food supply chains, and 
oligopolies of power. The result of this includes a concentration and polarization of wealth and power, significant emissions of greenhouse gases and other pollutants, depletion of aquifers, erosion and loss of top soil, loss of biodiversity (in terms of onfarm and off-farm ecologies), a rural farm crisis and increasing pressure on, encroachment upon and despoliation of Indigenous territories.

This raises serious concerns regarding the state of food security in Canada. Accordingly, the alternative food movement has emerged as not only one that is focused on more localized and sustainable food production, distribution and access, but it is highly mobilized around the complex politics of food, economy and trade.

\subsubsection{Transnational Movements of Altereity, Creativity and Solidarity}

The blurring of state policies with corporate agendas has not gone uncontested. Recent years have seen the largest mass mobilizations of people in public demonstrations, rallies and protests in recorded history. Grassroots groups and civil society organizations are utilizing new technologies, and innovative and creative means to communicate, connect and mobilize to creatively protest the increasing militarization, corporatization and privatization of public goods, community lands, and livelihoods. In recent years there has been a rise of the organization of people through mobile phone and Internet-based social networking, mass protests and strikes, peoples' assemblies and World Social Forums. Moreover, numerous groups are forming coalitions and alliances to put forward a collective vision of alternative worlds and possibilities, creating unique and diverse mass movements committed to countering the dominant neoliberal narrative with visions 
of social justice, equity and fairness. In numerous instances, local struggles have become transnationalized through the creation of networks of support and mobilization adding international pressure to local struggles (the Zapatista rebellion being amongst the first instances of such ways of organizing, the Occupy movement and Arab Spring being more recent manifestations of such forms of organizing) (McNally, 2006). Amongst these mass movements are the transnational mobilizations of peasants, Indigenous people, farmers, eaters and many others organizing to demand and cultivate food justice, democracy and food sovereignty.

\subsubsection{Food Sovereignty and the Alternative Food Movement}

Across the globe there has been significant mobilization around the concept of food sovereignty. Food sovereignty generally refers to reclaiming decision-making power in local food systems, thus democratizing food so that it is more sustainable, accessible, nutritious, acceptable, fair and responsible. The concept of food sovereignty recognizes the political barriers that limit local control of food and promotes communities to assume responsibility over their food (PFPP, 2012). Consequently, the concept of food sovereignty provides a political framework in that it challenges the domination of global transnational trade organizations and industrial agribusiness that limit the democratization of food systems. Food sovereignty is a policy framework that creates opposition to neoliberal commodification, marketization and control of food and seeks to ensure local control of foodscapes to serve the interests of members of local communities: 'the people' and producers who have often been marginalized and are increasingly excluded by 
contemporary food policy the world over (PANAP, 2004). Johnston, Biro and MacKendrick (2009) define a foodscape as "a social construction that captures and constitutes cultural ideals of how food relates to specific places, people and food systems" (512).

Food sovereignty represents an alternative means through which local and national policies, which target issues of poverty and malnutrition globally, can be designed and implemented by focusing on the innovation and strengths of the livelihood strategies of food producers and harvesters and the agency of those who experience hunger and malnutrition (Windfuhr and Jonsen, 2005). The term was coined by La Via Campesina, a global peasant/farmers' movement, and presented in 1996 at the World Food Summit of the United Nations Food and Agriculture Organization (FAO). It is important to emphasize that this is a concept and a term that was coined by a transnational movement comprised of peasants, small farmers, Indigenous peoples, fisherfolk, herders, landless peoples, migrant workers, women, youth, environmental and urban movements and many others.

There are manifold interpretations of the principles of Food Sovereignty that have arisen from numerous dialogues, conferences and publications amongst members of $L a$ Via Campesina, NGOs and civil society organizations. However the basic principles of food sovereignty are neatly summed up in The Declaration of Nyéléni -drafted by members of La Via Campesina in 2007 in Sélingué, Mali: 
Food sovereignty is the right of peoples to healthy and culturally appropriate food produced through ecologically sound and sustainable methods, and their right to define their own food and agriculture systems. It puts those who produce, distribute and consume food at the heart of food systems and policies rather than the demands of markets and corporations. It defends the interests and inclusion of the next generation. It offers a strategy to resist and dismantle the current corporate trade and food regime, and directions for food, farming, pastoral and fisheries systems determined by local producers. Food sovereignty prioritises local and national economies and markets and empowers peasant and family farmer-driven agriculture, artisanal fishing, pastoralist-led grazing, and food production, distribution and consumption based on environmental, social and economic sustainability. Food sovereignty promotes transparent trade that guarantees just income to all peoples and the rights of consumers to control their food and nutrition. It ensures that the rights to use and manage our lands, territories, waters, seeds, livestock and biodiversity are in the hands of those of us who produce food. Food sovereignty implies new social relations free of oppression and inequality between men and women, peoples, racial groups, social classes and generations (Forum for Food Sovereignty, 2007: $8)$.

Food sovereignty offers a policy framework through which local needs are prioritized over transnational trade agreements, thus challenging the ubiquitous logic of the industrial commodified food chain. The six pillars of food sovereignty include: a focus on food for people; value for food providers; localization of food systems; local control; building of knowledge and skills; and working with nature (Forum for Food Sovereignty, 2007: 76). More recently, a seventh pillar has been added through the creation of the Peoples' Food Policy Project in Canada: food is sacred (PFPP, 2012).

Canadians have been active members of the global alternative food movement, and have also established a considerable movement at local, provincial, regional and national levels. Within the alternative food movement in Canada there has been mobilization around food sovereignty. Food sovereignty organizations and grassroots groups (such as the National Farmers' Union, the Toronto Food Policy Council, Food 
Secure Canada, the Peoples' Food Policy Project and numerous regional, provincial, municipal and community-based, farmer, consumer, and citizen groups) often focus on inclusion, peoples' democracy, respect, and multiple and multidimensional approaches to work towards food sovereignty. Within the conceptualization of food sovereignty in the many different arms of this movement in Canada, there is an explicit recognition of the importance of Indigenous food sovereignty in creating a food web that has integrity in its responsiveness to the needs of consumers and producers at a local level.

Indigenous food sovereignty is an integral part of the food sovereignty movement, and refers, in part, to the unique position of Indigenous peoples in protecting and maintaining responsibility for their sacred foods sources that are often based upon hunting, gathering, farming, fishing and wildcrafting. It also acknowledges that Indigenous peoples hold in common the source of much of the biodiversity that is the foundation of contemporary food production (including much diversity of seeds of agricultural crops) ${ }^{2}$. In Canada, food sovereignty can be particularly relevant to Indigenous peoples who, both traditionally and currently, have unique foodscapes,

2 It is important to note that Indigenous Food Sovereignty is a concept that has been conceptualized in Canada as a means to emphasize the unique situation of Indigenous food systems relative to broader food sovereignty movement in Canada. As mentioned above, the Declaration of Nyéléni, which serves as a founding document for elaborating upon the meaning of food sovereignty, was drafted by various Indigenous peoples from around the world, in addition to peasants, small farmers, fisherfolk and others. Thus food sovereignty, as initially conceptualized, was drafted to be inclusive of the contexts and concerns of Indigenous people. At the same time, many Indigenous people in Canada may not frame their discussions of traditional foods through the framework of Indigenous Food Sovereignty, but may make appeals to the more commonly used term food security. I have chosen to frame the case study in the concept of food sovereignty as it is a concept with which I have much familiarity and that has a large transnational network of support through La Via Campesina. Furthermore, I argue that although many groups may not frame their struggles in terms of food sovereignty, it does provide a very relevant framework through which to understand this particular case study, particularly due to the emphasis of food sovereignty on political processes and the development of policy to transform food systems to be inclusive and accountable to all people, particularly those who are often subordinated through the industrial food system (including low income people, small farmers and peasants, fisherfolk and Indigenous peoples). 
traditions and practices relating to food, such that it is an integral part of many Indigenous peoples' identities. It is argued that Indigenous people struggle acutely over sovereignty issues and food policy due to the high levels of food insecurity across most of the Indigenous population, and the increasing climate of enclosure of traditional knowledge(s) through biopiracy (the patenting and manipulation of genetic material, such as seeds), and neoliberal trade which increasingly commodifies and markets the symbols, materials, information and common property of Indigenous people the world over (Shiva, 2000; LaDuke, 2005). Moreover, food sovereignty has been identified as "the newest and most innovative approach to addressing the complex issues impacting the ability of individuals, families and communities to respond to their own needs for healthy culturally adapted Indigenous foods" (Morrison, 2008: 11). Elements of Indigenous food sovereignty as outlined by the Working Group on Indigenous Food Sovereignty (of the B.C. Food Systems Network) extend to include sacredness, self-determination, participation and policy (Morrison, 2008: 12). Indigenous food sovereignty therefore provides a body of literature and political thought that is located in a contemporary global movement while simultaneously rooted in local contexts. This concept therefore provides a forum in which to situate discussions of traditional foods and decolonization.

\subsection{Indigenous Resilience, Resistance and Revitalization of Traditional Foods}

The discussion that follows aims to situate the case study within the broader contemporary decolonization movement to revitalize traditional practices surrounding Indigenous foods, celebrate the resilience of ongoing traditional food practices, and 
defend the deterioration of Indigenous food systems. Prior to first European contact, Indigenous communities in Turtle Island (North America) were self-sufficient and healthy (Cajete, 1999b, Milburn, 2004; LaDuke, 2005). Across the continent, diverse foodscapes have existed for millennia, which reflect(ed) both the natural endowments of the local ecology and the ingenuity of the numerous, diverse and distinct cultural groups who further select(ed), manage(d) and protect(ed) the biological diversity in complex systems of agroecology and co-evolution (Cajete, 1999a; Morrison, 2008). These foodscapes ranged in character from hunting, gathering, fishing and gardening in forest, plains and arctic environments, to systems of advanced agriculture. However, processes of colonization were and are multi-faceted and include(d): displacement from, and despoliation of, traditional territories and livelihoods; denigration of Indigenous worldviews, customs, economies and values; and implementation of policies of assimilation and genocide (Churchill, 1997; LaDuke, 2005; Bodirsky and Johnson, 2008). The destruction of traditional food systems (including practices of gathering, hunting, fishing and farming) was both a means and a consequence of the above processes of colonization. Today this has manifested in many Indigenous peoples' dependence upon the global industrial food system, which has been shown to result in multiple, adverse health consequences (including disproportionately high rates of food related illness such as diabetes, obesity and heart disease) (Milburn, 2004; Adelson, 2005; Reading, Kmetic and Gideon, 2007; Bodirsky and Johnson, 2008). Moreover, loss of traditional foodways - the cultural practices surrounding the production, preparation and presentation of food (Brien, 2009) - has eroded and continues to erode cultural values, knowledge and 
traditions and creates distance between Indigenous peoples and their traditional foods, medicines and the land (Cajete, 1999a; Milburn, 2004; Bodirsky and Johnson, 2008).

There is a growing contemporary revitalization of traditional food systems and parallel reinvigoration of creativity to resist ongoing oppression facing Indigenous peoples in order to reverse the adverse health effects, and address systematic poverty and cultural erosion, caused by colonialism, dispossession and marginalization. Indigenous foodways are understood as an integral part of sustainable, culturally-appropriate livelihood strategies, a necessary element of Indigenous economies that may either be integrated within or separate from the market capitalist economy (Morrison, 2008). By reclaiming food production and the right to traditional foods, Indigenous peoples are both engaging in decolonization strategies and resisting industrial, economically-driven ecological exploitation (whether through protection and use of forests and waterways or through sustainable agriculture practices).

One of the many ways that food is being promoted in Indigenous communities is as a social determinant of health and well-being (LaDuke, 2005; Reading, Kmetic and Gideon, 2007). The approaches that link Indigenous foods to health vary from strategies that are adopted from a nutritional and dietary perspective, to approaches stemming from more holistic understanding of healing, health, community and relationships (between and amongst people, plants, animals, the land and spirits). In Decolonizing Diet: Healing by Reclaiming Traditional Foodways, the authors write: 
The reconstitution of traditional Indigenous foodways is a precondition to healing the many traumas of colonization, including unhealthy attitudes toward food and diet that were learned through Western institutions. In this sense, perhaps one of the best methods of reclaiming culture and treating the modern epidemics of obesity, diabetes, and cardiovascular disease affecting many Indigenous people is to attend to their root causes by supporting the revitalization of traditional Indigenous knowledge and foodways (Bodirsky and Johnson, 2008: 12).

In a comprehensive review of traditional foods and contemporary health problems, Milburn (2004) explains that many traditional, wild foods are higher in vitamin and mineral content than similar cultivated foods. The fat content of wild meats and fish is often more nutritionally well-balanced than farm-raised meat and fish. Furthermore, traditional lifestyle patterns foster(ed) high levels of physical activity (Milburn, 2004: 424). Milburn also argues that the knowledge encoded in Indigenous nutrition (which has been developed through Indigenous science and ways of knowing) “offers solutions for modern health problems, crucial technology for a sustainable agriculture, and important approaches and tools for ecosystem management" (421).

In a cross-cultural study, Baskin (2008) demonstrates how food is deeply connected to Indigenous identity of youth from Elsipogtog First Nation (New Brunswick) and youth from Pankararu and Pataxo communities (in the interior of Brazil). She writes that: "Food and food security can provide a conduit for recovering identities and preserving the cultures of Indigenous peoples, especially when youth are empowered to participate in reaffirming pride in their traditions" (Baskin, 2008: 6). Baskin explains that food is a holistic element of sustainable Indigenous livelihoods: "Food is not only a structural determinant of health, but also has cultural and spiritual meanings for Indigenous people worldwide" (Baskin, 2008:1). 
In many Indigenous cultures food is understood as both a source of nourishment and as medicine. Thus, many authors argue that a reconnection with food, ceremony, land and traditional livelihoods in some forms is a necessary component of the path towards individual, family and community healing and decolonization. LaDuke (2005) explains:

The recovery of the people is tied to the recovery of food, since food itself is medicine: not only for the body, but for the soul, for the spiritual connection to history, ancestors, and the land. The sustainability of landbased life rests on the biodiversity of traditional agriculture, the life stuff for pollinator diversity, and the web of life itself (210).

Elaborating upon the potential of traditional foods to link with processes of decolonization, Clayton Brascoupé (1999), Director of the Traditional Native American Farmers Association, demonstrates that farming (particularly in the context of traditional farming cultures such as the Iroquois and the Pueblo) helps to lend more meaning to spiritual and religious practices, affirms traditional educational approaches, nourishes healthy interpersonal social relationships within families and the community, and reenforces linkages with elders, ancestors, ritual and prayer (155). Thus food becomes a link to the assertion of sovereignty and a revitalization of cultural identity. Corntassel (2008) also argues that food is of great importance to "regenerating Indigenous nations" holistically and sustainably (105): 
Indigenous connections between well-being and food security/livelihoods are critical to the realization and practice of a sustainable selfdetermination. When such relationships are severed, "the knowledge, worldviews, values and practices about these relationships and about other aspects of their food and agro-ecological systems, commonly erode over time as well." In other words, disruptions to indigenous livelihoods, governance, and natural-world relationships can jeopardize the overall health, well-being, identity, and continuity of indigenous communities (emphasis in text, 118, quoting Woodley et al., 2006: 3).

Brascoupé (1999) further explains that growing food is a political act: "We are asserting sovereignty, an area of self-sufficiency, by growing foods for ourselves and our community" (155).

The reclamation of traditional foodways must be understood as a deep political act given the contemporary climate of ongoing systemic racism against Indigenous people in Canada and parallel struggles for self-determination by Indigenous peoples. There are continuing policies and acts of theft specifically targeting Indigenous cultural property (including the domestication of wild foods and concomitant patenting of knowledge and genetic information). The relatively small proportion of Indigenous territory that is legally recognized as such by the Canadian government and its institutions is continually threatened by the by-products of 'development', including pollution, resource extraction and despoliation of ecosystems that sustain Indigenous livelihoods.

The political landscape of traditional foods can therefore be situated within discussions of food sovereignty, which both encompasses and goes beyond food security. Food security is of great relevance to marginalized and low-income populations - such as many Indigenous peoples across Turtle Island, who are more vulnerable to food insecurity than the rest of the Canadian population (Power, 2005; ONPP, 2007; Baskin 
2008). Food security is often described in terms of access, sufficiency, safety, nutrition and acceptability (Baskin, 2008). Alternatively, the concept of food sovereignty is far more political in that it directly challenges the domination of global transnational trade organizations and industrial agribusiness that limit the democratization of food systems and seeks to re-embed decision making power in food systems in the hands of those who produce, hunt, gather, fish and eat.

In an effort to understand the complexity surrounding efforts by various peoples to protect, maintain or work towards food sovereignty, I turn to the case of a particular community in the valley of Kiji Sibi who have successfully maintained cultural, spiritual, as well as physical connections to a traditional food that has grown in the region for generations - that is the Ardoch Algonquin First Nation and Allies and the manomin (wild rice) that has sustained community members and neighbours for generations. By examining this case study, I hope to understand the opportunities and struggles that arise in maintaining access to healthy, nutritious, nourishing, sustainable, delicious and local foods. ${ }^{3}$

\subsection{The Ecology of Manomin / Wild Rice (Zizania aquatica, and Zizania palustris)}

Manoomin (wild rice) is a staple food source at the centre of Anishinaabeg culture (extending across Eastem North America - from New Brunswick to Manitoba in Canada) (DeLisle, 2001). It has been found to predate the arrival of First Nations (from both oral history accounts and western scientific research): "Manoomin is a gift given to the

3 This thesis does not intend to confine Indigenous peoples to traditional diets and foodways, rather, it seeks to understand the challenges and opportunities that exist for one community that has explicitly articulated its commitment to traditional foods. 
Anishinaabeg from the Creator", writes LaDuke (2005: 168). At the same time, First

Nations have managed and propagated wild rice for millennia (DeLisle, 2001). LaDuke has written prolifically about the nutritional, cultural, spiritual and political significance of wild rice. She explains its value and importance:

Wild rice is a centerpiece of our community's sustenance. Wild rice offers amino acids, vitamins, fiber, and other essential elements, making it one of the most nutritious grains known to exist. The wealth of wild rice has ensured that we have not starved over many a cold winter. It is this profound and historic relationship that is remembered in the wild rice harvest on the White Earth and other reservations - a food that is uniquely ours, a food used in our daily lives, our ceremonies, and our thanksgiving feasts. It is that same wild rice that exemplifies the worldwide debate on issues of biodiversity, culture, and globalization (LaDuke, 2005:168-9)

In addition to its cultural, spiritual, political and nutritional value, manomin is historically and currently an economically important grain that has been used in trade for millennia, with grains of manomin found in archaeological sites as far west as present day British Columbia (Delisle, 2001). It has more recently been domesticated and is today grown in paddies in California as well as in lakes which are commercially harvested in Minnesota, Saskatchewan, Manitoba and Ontario. Manomin is also being researched for its genetic potential for various uses in biotechnology (La Duke, 2006).

Manomin is an emergent annual wetland grass species, found in depths of water ranging from $0.5-3$ feet. It is found in bodies of moving water, such as rivers, flowages and shallow lakes with inlets and outlets. Wetlands are defined as "land that has the water table at, near, or above the land surface or which is saturated for a long enough period to promote wetland or aquatic processes as indicated by hydric soils, hydrophytic vegetation, and various kinds of biological activity that are adapted to the wet 
environment" (Tamocai, 1980 quoted in Cox, 1993: 8), in other words, areas that are submerged in water for most or all of the time, neither dry land nor open bodies of water. Wetlands provide unique and invaluable "ecosystem services" (of benefit to human ecosystems and socio-economic systems), which sustain healthy watersheds. Ramsarthe Convention on Wetlands of International Importance - highlights ten essential ecosystem services provided by wetlands (although the extent of these services depends on the particular ecosystem). These ecosystem services include: "flood control; groundwater replenishment; shoreline stabilisation and storm protection; sediment and nutrient retention and export; water purification; reservoirs of biodiversity; wetland products; cultural values; recreation and tourism; and climate change mitigation and adaptation" (Ramsar, n.d.). Wetlands are particularly vulnerable to development as they are often drained or encroached upon for agriculture, industrial uses, urbanization, energy development, amongst other land uses. According to Zedler and Kercher (2005) wetlands cover a global area in the range of 5.3 to 12.8 million $\mathrm{km}^{2}$ (the area is not well documented and also fluctuates with climatic conditions), or what amounts to approximately $9 \%$ of the Earth's land area. The authors note that wetlands provide a far greater contribution to essential ecosystem services than is relative to their small land area, particularly with respect to biodiversity, water quality, flood abatement, and carbon management. It is estimated that approximately half of the global wetland area has been lost. It is further estimated that Canada has more than 1.4 million $\mathrm{km}^{2}$ of wetlands, which store $60 \%$ more carbon than that of Canadian forests (including biomass and soil) (Roulet, 2000). 
There are three species of wild rice in North America, all in the genus of Zizania. Zizania aquatica and Zizania palustris are the two annual species of manomin that are harvested in more northern climates of North America and are referred to interchangeably in this study as manomin or wild rice. Historically, the range of wild rice is quite broadly distributed, across the Great Lakes region in North America ranging from present day Manitoba to New Brunswick (Figure 1.2). Zizania sp. have particular requirements for growth including: a limited hydrological regime (i.e. water depth), sediment characteristics, nutrient profiles of water and soils, water quality and temperature. As such, manomin and its affiliated macrophyte community have been found to be highly sensitive to various effects of development, as is discussed in Chapter 5 and 6 of this thesis. 
Figure 1.2: Distribution of Manomin across Turtle Island

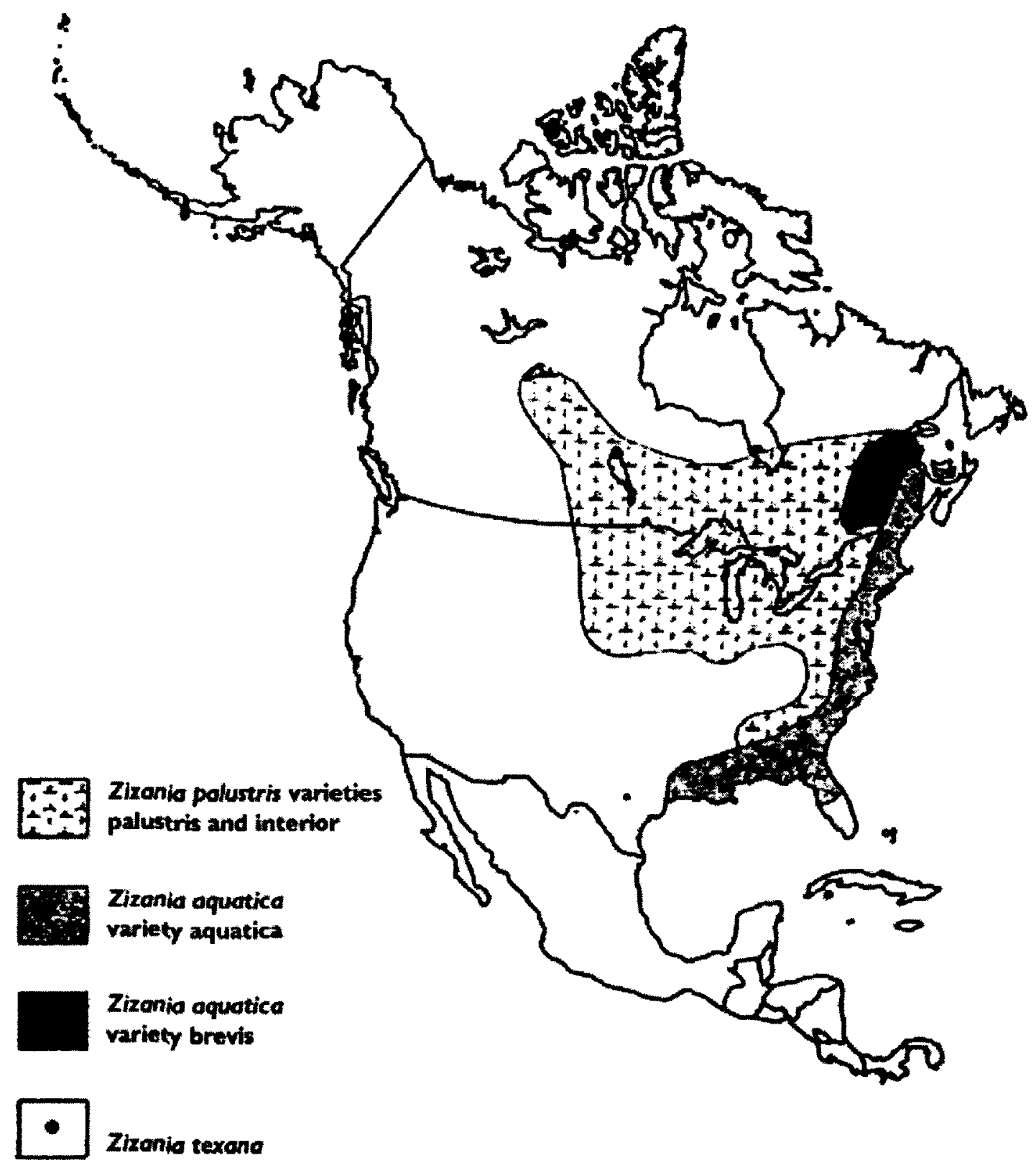

Source: Oelke, Bloom, Porter, Liu, 1999. 
Manomin has been observed by to be an important food source and source of shelter for numerous wildlife species, particularly waterfowl. Manomin habitat is also used by numerous species for reproduction and foraging. Its abundant and nutritious seeds are an important source of food for waterfowl during fall migrations, and it has been found to be amongst the most important food sources for many duck species in various studies (MDNR, 2008). Other parts of wild rice are also valuable as nesting material, brood cover, food for large herbivores and for various insects and invertebrates which are preyed upon by various birds, small fish and amphibians. Manomin is an emergent wetland plant, providing shoreline protection, stabilizing soils, providing natural windbreaks and habitat for fish. It is also a sink for nutrient loads of phosphorous and nitrogen in the spring and summer (during periods of rapid growth), limiting potential for algal growth and lake turbidity (MDNR, 2008).

\subsubsection{Manomin: a Local Gift, a Local "Resource", yet Globally Situated}

Given the ecological, cultural, spiritual, economic and political situation of manomin, numerous debates and struggles have arisen with regards to protection of manomin stands and its associated communities, and jurisdiction over the capacity to care for, manage and harvest manomin. Manomin therefore provides a means to examine social, ecological, and political consequences of the various issues outlined above. In both of their studies, Kinew (1995) and Delisle (2001) explain that the case study of access to and jurisdiction over manomin is symbolic and representative of contradictions and conflicts that underlie relations of Indigenous people and settler governments. Delisle (2001) writes of the case 
study of the Mud Lake conflict of 1979-1982 in Ardoch, Ontario: "This story, while local in scope, and insignificant in the larger dealings of resource concerns, provides a focal point into the issues that pervade Aboriginal/State relationships over natural resources in Canada" (3). In her thesis examining manomin in the context of the Treaty \# 3 Anishinaabeg, Kinew (1995) explains that:

Manomin focuses on the central conflict between indigenous and provincial governments within Canada: natural resources as a (provincial) crown resource or a treaty and aboriginal right? Manomin also serves as a continuing example of Indigenous forms of government in action, even through generations of suppressed sovereignty under the federal lndian Act and provincial wildlife legislation.

Manomin serves another useful function in this thesis. It is a metaphor to explain the Anishinaabe version of Anishinaabe or original rights. According to Treaty \#3 Anishinaabeg, manomin is a gift from the Great Spirit; its use and development given to the people through legend and ceremony $[. .$.$] The drowning and life-threatening conditions of$ manomin symbolize the suppressed sovereignty of the Anishinaabeg. (8-9)

In this study, I will attempt to extend the above discussions of manomin, by documenting the relations that are embedded in a case study regarding access to and jurisdiction of manomin in southeastern Ontario. The current debates and struggles over wild rice exemplify the issues discussed above, including the interconnections between traditional foods, decolonization, community health, well-being, sustainability and food sovereignty. Manomin can also shed light on ecological conflicts and control of environmental processes, as manomin is a plant sensitive to water levels, pollution and other disturbance. Manomin can be understood in the context of struggles between Indigenous peoples and settler governments, as is done by both Kinew (1995) and Delisle (2001) in exploring conflicts surrounding the question "is wild rice a natural resource owned by the Crown or a gift from the Creator given to the Anishinaabe?" (Kinew, 1995, ii). In what is 
today known as eastern Ontario, the story of wild rice provides a focal point through

which to explore the above issues, situated globally, but highly significant locally.

\subsection{Ardoch Algonquin First Nation and Allies (AAFNA) and Ongoing Omàmiwinini Relations in the Valley of the Kiji Sibi}

This research is based upon a case study that seeks to understand the contemporary political ecology of manomin within the Kiji Sibi from the perspective of some Omàmiwinini of the Ardoch Algonquin First Nation and Allies (AAFNA). This section therefore introduces AAFNA by providing a brief outline of AAFNA's history, governance and political engagements.

Paula Sherman is a former co-chief and Family Head on Ka-Pishkawandemin, the traditional Council of AAFNA. She describes the Ardoch Algonquin in her book, Dishonour of the Crown: the Ontario Resource Regime in the Valley of the Kiji Sibi:

Ardoch Algonquin First Nation is a community of related Algonquin families whose members are the descendants of Shawanepenesi's community ${ }^{4}$. Ardoch Algonquin families have historically occupied and related within the lands of the Tay, Mississippi and Rideau watersheds, all of which connect to the Ottawa and St. Lawrence Rivers through ground and surface water. The marshes and wetlands that became the permanent home of Algonquin communities such as Ardoch were always the traditional hunting, trapping and harvesting areas of extended Algonquin families. The need for our ancestors to locate themselves permanently in the region was a direct result of colonial actions on the part of the English who appropriated the best lands within the Algonquin homeland for themselves (Sherman, 2008: 33).

4 Shawanepenesi and his people (comprising 80 people) were granted a license of occupation for two thousand acres of land in 1843 in the townships of Bedford and Oso. These lands were to be protected by the Crown. This "reservation" was created in response to his petitions reminding the Crown of their relationship and responsibilities, without land cessations by Algonquin people, but because of encroachment by settlers. By 1846 loggers had moved into the area to cut the forest and build homes. Despite further petitions by Shawanepenesi nothing was done by the Crown Lands Department. As an outcome of the Bagot Commission, Algonquin people were encouraged to move to Manitoulin Island. 
Robert Lovelace (n.d.), former chief of the Ardoch Algonquin First Nation explains on the AAFNA website that AAFNA "is non-status; that is, it is not designated as an Indian

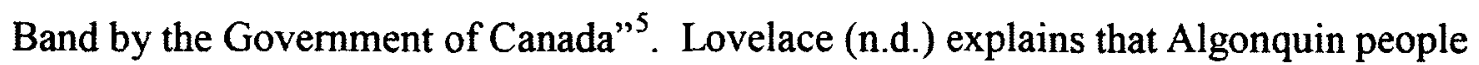
have always been Algonquin, whether recognized as status Indians at Golden Lake (Pikwàkanagàn), or not:

Federal recognition of the Golden Lake Reserve provided structure and resources that were desperately needed for the well being of that community. Other Algonquin communities at Matawa, Whitney, Lake St. Peter, Calabogie and many other locations did not have a protected land base. Non-Algonquins had long settled the land that had been once "protected" for the Ardoch Algonquin families at Bob's Lake. These communities did not stop being Algonquin communities when they were overrun by European settlement. They did not stop being Algonquin communities when the trees were cut and burned or when racism forced the people to the bottom of the social order. They did not stop being Algonquin communities when they survived and found a measure of prosperity on their own. Their children did not stop being Algonquin when they went to the city to support their families. They certainly did not stop being Algonquin communities when the Federal Government recognized Golden Lake as a Federally controlled Indian Band.

AAFNA has a traditional governance structure, known as Ka-Pishkawandemin. Sherman (2007) explains Ka-Pishkawandemin as "a system of social and political operation [...] [it] is a system in which extended families appoint an individual to represent them in a community or nation council. The purpose of this Council is to reach consensus on matters that will benefit or impact the whole community or nation" (187).

\footnotetext{
$5 \quad$ As discussed above, there are various means by which a person could become a non-status Indian, however in the case of the Algonquin people in Ontario, the only "status community" is Algonquins of Pikwàkanagàn First Nation (formerly Algonquins of Golden Lake First Nation), which is a status Band, based on a reserve, with a Council as defined in the Indian Act. AAFNA is a non-status First Nation, as it is an off reserve community and does not adhere to Indian Act regulations, but some members may be registered under the Indian Act and therefore be "status Indians" (Koschade, 2003).
} 
As a community independent of the Indian Act (i.e. non- status) all of AAFNA's funds are secured through fundraising and personal contributions to community actions and programs.

In her thesis, "Land of Which the Savages Stood in No Particular Need": Dispossessing the Algonquins of South Eastern Ontario of their lands, 1760-1930, Marijke E. Huitema (2000) documents in detail the continuous history of the Ardoch Algonquin First Nation and Allies in the Ottawa River Valley, as descendants of the nuclear and extended family of Joseph Whiteduck Jr. during the period of settlement and intensive logging. However, as Lovelace (n.d.) describes, it was after "the Rice Wars" of 1981 in Ardoch, Ontario, that “Algonquins from Sharbot Lake, Bob's Lake, the Fall River, Eel Lake, Eagle Lake, the Big Rideau, the Tay River, Mattawachen, Calabogie and Ottawa [came] to claim the name Ardoch as their own"6. After more than ten years of research and community organizing:

... [i]n June of 1992 [Harold Perry and Bob Lovelace] called together all of the Algonquin families of the region and established the Ardoch Algonquin First Nation and Allies (AAFNA) [...] This was not a new organization. AAFNA was the contemporary continuance of the federation of families that had worked together in times past" (Lovelace, n.d.).

The Ardoch Algonquin First Nation is a community that has survived over 200 years of assault on their traditional lands and their livelihoods. Paula Sherman (2008) writes:

6 The wild rice conflict is discussed in more detail below. 
There is a long history of interaction with our homeland that goes back for thousands of years. There are also numerous sacred and cultural sites within our homeland that have particular importance for us as they were left to us by our ancestors and other spiritual beings in Creation. Our ancestors passed on their knowledge and interactions with those places so that we would always have the ability to maintain our relationships and responsibilities with our homeland. The extended families that make up Ardoch Algonquin First Nation have struggled over the past two hundred years to hold on to our community lands and have begun to shake off the colonial oppression and assimilation that has kept us quietly contained and controlled. We have managed to find our voice once again and have begun to rebuild our relationships with the Natural World. This is difficult given the destruction that has occurred over the past two hundred years, but we have found ourselves again and have reinstituted our own laws and traditions within our homeland and our lives. We understand and recognize the fact that our identity as people and our autonomy within our homeland is dependent upon our ability to main our relationships and responsibilities (34).

The Ardoch Algonquin First Nation is a community that continuously exemplifies resistance to ongoing encroachment and despoliation of their Indigenous territory, and the ongoing assimilation and control of Indigenous peoples by the Canadian government.

Specifically, the Ardoch have a history of activism that has been in opposition to "development", or industrial despoliation of the land, water and creatures for the sake of economic gain. Sherman (2008) explains:

Omàmiwinini families have begun the process of envisioning an alternative relationship within our homeland that is based upon the Anishinaabe theory of Pimaadiziwim, which situates human beings within a collective that includes the Natural World and all other parts of Creation. Elders such as William Commanda, Harold Perry, Edna Manitowabi, Shirley Williams, and Doug Williams have made real differences in the lives of various Algonquin people, which have facilitated a deeper connection to the land and wasterscapes within the Kiji Sibi. While some Omàmiwinini people continue to find it difficult to make that connection, others have entirely transformed their lives as a result of the recognition that they have responsibilities as human beings within our homeland. Opposition to development has been one of the outcomes of this re-envisioning of Algonquin relationships with the land (16-17). 
Following below is a brief overview of recent AAFNA history with a focus in particular on ecological relations within Algonquin territory, or stated another way, natural resources conflicts and negotiations. ${ }^{7}$

\subsubsection{Manomin and the Ardoch Algonquin First Nation and Allies}

In the Mississippi River, a tributary of the Kiji Sibi, there are fields of manomin that have sustained local families for generations and have been the site of conflict in more recent years. As is documented in oral and local history, the manomin at Mud Lake was planted by one of the grandmothers of Harold Perry (current manomin steward), who brought the seeds from Rice Lake, at Alderville (a Mississauga community). Since then it has been managed and harvested by descendants of the Whiteduck family. It has been harvested by and shared with non-status Algonquin people, status Mississauga relatives from Alderville and Curve Lake, and non-aboriginal residents (Delisle, 2001; Lovelace, n.d.).

There is a long history of management of the wild rice. During the 1950s, the manomin beds began to diminish. Harold Perry notes that at the same time there was spraying around the hydro lines about one mile from the Mississippi River and the hydro workers told Perry that they were spraying 2,4-D (2-4 dichlororphenoxyacetic acid), and 2,4,5-T (2,4,5 trichlorophenoxyacetic acid) (Agent Orange - a well known herbicide used during the Vietnam War) in order to control the vegetation, (Delisle, 2001, 89). For the following twenty years, until the early 1970s, Harold Perry and his father Richard

7 This focus necessarily excludes an outline of other significant historical moments for the Ardoch Algonquins including assertion of rights as non-status Algonquin people to government programs and benefits extended to status Algonquins. 
Perry worked to re-seed, rest and rejuvenate the manomin (not harvesting until the early 1970s). In 1978, the manomin began to thrive again and people began to take the rice again (Delisle, 2001). However, it was just after the rice fields had re-established that they once again came under threat.

\subsubsection{Rice Wars (1979-1981)}

In the summer of 1979 , residents of Ardoch, Ontario learned that Lanark Wild Rice had been granted a commercial license to harvest all of the stands of manomin at Mud Lake, under the Ontario Ministry of Natural Resources (OMNR) Wild Rice Harvesting Act (WRHA). As discussed by Susan B. Delisle (2001) in her thesis which examined the history of this conflict ${ }^{8}$, there were two competing management schemes at play, the first being the "long-term local authority structure" (still practiced) under which a manomin steward monitors the manomin and controls the harvest to ensure that the beds are adequately reseeded. The second management scheme was that of the OMNR under the WRHA which required applications to the OMNR for permits of access and also sought to maximize the profitability and efficiency of the wild rice harvest and industry in Ontario for the good of all Ontarians. Purportedly, both parties were unaware of the other, thus explaining why a license was issued to a harvester from outside the community while there was an existing moratorium on new license issuances (though Delisle provides documentary evidence which supports that this was in fact not the case

8 In her thesis Coming out of the shadows: Asserting identity and authority in a layered homeland: The 1979-82 Mud Lake wild rice confrontation Delisle (2001) contextualizes the Rice war of Mud Lake within a broader history of resource dispossession and conflict between Aboriginal peoples and federal and provincial governments. Her thesis focuses on key policies which served to establish provincial jurisdiction over Aboriginal lands and resources, and includes an analysis of the development and execution of the Wild Rice Harvesting Act. 
and employees at the OMNR would have been aware of the ricing activities of local residents at Mud Lake). Due to the protests of local residents (including Harold Perry, the manomin steward of Mud Lake) and support from the township of Clarendon and Miller, a license for harvesting the Mud Lake wild rice was not issued the following year (1980).

In the summer of 1981 , community members learned that Lanark Wild Rice (a private company) would be issued a license to harvest a portion of the wild rice beds and members of the community mounted a campaign against the commercial harvest. This campaign was supported by Aboriginal organizations, two regional townships, the Mississippi Valley Conservation Authority, political leaders and numerous individuals. When Lanark Wild Rice was issued a license on August 19, 1981, Indigenous and nonIndigenous people announced that they would begin a 24-hour patrol of the site and mounted a media campaign to publicize the conflict and the intention of the members to halt the operation non-violently, through legal, political and civil disobedience (Delisle, 2001).

Robert Lovelace (n.d.), an active participant at the time, explains the "Rice Wars" on the AAFNA website: 
In August and September of 1981 the people of the Ardoch Algonquin First Nation and their allies from Alderville, Tyendinaga, Curve Lake and Hiawatha fought a 27-day stand-off against Ontario to protect their jurisdiction and responsibility for the manomin (wild rice) which grows in the Mississippi River near Ardoch. The wild rice at Ardoch has been shared for over a hundred and thirty years with pickers from Alderville and Curve Lake. It is the manomin that was preserved from Rice Lake when the Trent Canal destroyed its habitat there. On August 30 the Ontario Provincial Police and the Ministry of Natural Resources invaded the Ardoch community with over 50 police cruisers. They brought boats, paddy-wagons, tow trucks and helicopters. Hundreds of police and MNR were employed in the operation. All of this force was used to escort one commercial air boat to the shores of Mud Lake. Although people were threatened, arrested and pushed to the ground the air boat never made it to the water. The next morning on August 31 the community dug up the road entrances to the Lake and liberated a part of the Algonquin homeland for 27 days. Harold Perry now an Elder and the Honourary Chief of the Ardoch Algonquin First Nation led the battle and the subsequent court cases that followed. In 1982, Alan Pope the Minister of Natural Resources admitted that there was an unsettled question of jurisdiction and that the Province had no right to impose its authority over the manomin. No subsequent Provincial government has threatened to lay claim to the rice.

Thus, as discussed above, it was after the conflict surrounding manomin that a coalescing of non-status Algonquins began under the name of Ardoch Algonquin First Nation and Allies.

\subsubsection{Continuous Assertion of Algonquin Sovereignty and Jurisdiction by AAFNA}

Since the Rice Wars, the Ardoch Algonquin First Nation and its members have taken numerous stances that demonstrate Algonquin autonomy and jurisdiction in their traditional territory, or have taken stances against various projects that serve to limit Algonquin autonomy and jurisdiction and/or despoil the lands and waters in the valley of the Kiji Sibi. Some of these instances are outlined below, including AAFNA's refusal to participate in the Algonquin Land Claim; their assertion of Aboriginal rights and 
sovereignty in traditional activities as "non-status Indians"; their protection of the Tay

River from industrial overextraction; their assertion of access to "Crown", or Algonquin

lands; and their resistance to uranium mining exploration in Frontenac County.

The Algonquin Comprehensive Land Claim is currently being negotiated with the acknowledgment of the Algonquin assertion that Algonquin territory is unceded, that is it has never been surrendered through treaty, sale or conquest (OMAA, 2009). While the land claims process had been officially initiated in 1991 under the leadership of the Algonquin of Golden Lake First Nation (described above), AAFNA decided to withdraw from the process in 1994. Robert Lovelace (n.d) explains AAFNA's reasoning:

In 1991 the Government of Canada approved an application on the part of the Algonquins of Golden Lake to begin a Comprehensive Land Claims to settle Algonquin title south of the Ottawa River. With almost no preparation the Chief and Council at Golden Lake began a process that quickly spiraled out of control. The non-Algonquin backlash was intense. The Band entered into a hunting agreement with Ontario, which undermined their claim to Algonquin Park resources and territory. They miscalculated or ignored the real numbers of Algonquins off reserve and attempted to impose control by establishing puppet governments in nonstatus Algonquin communities. These "area committees" were intended to be satellites of the Reserve. Legitimate leaders like Harold Perry tried to provide representation for their communities and guidance to the process. Harold Perry quickly realized that he was only a convenient figurehead for the Land Claims industry that had sprouted at Golden Lake. Struggling for equality and recognition for non-status Algonquins Harold Perry led the first break with the Golden Lake Land Claim process. He was tired of being told that his rights flowed from the Federal Government and only a land claim would provide him with the recognition that he needed to be an Algonquin. In his heart he knew this was not true. He knew that it was wrong. In the summer of 1994 AAFNA withdrew its support for the Algonquins of Golden Lake Land Claim.

The Algonquin land claim and its relation to jurisdiction in the Kiji Sibi and manomin more specifically is discussed in further detail in Chapters 5 and 6 of this study. 
By partaking in traditional Indigenous activities, such as hunting, fishing and trapping, without seeking permits from Ontario, AAFNA leadership have asserted their rights as Aboriginal people, despite being "non-status Indians". Harold Perry defended his rights as an Algonquin to hunt migratory birds and moose in various court cases, which he won. In one case, he challenged Game and Fish Act, R.S.O. 1990, c. G.1, and Migratory Birds Regulations made under the Migratory Birds Convention Act, R.S.C. 1985, c.M-7 on behalf of Ardoch Algonquin First Nation and Allies, when he was charged with contravention of the Acts as an unrecognized Indigenous person due to nonIndian status, and hunting and fishing without a permit and license, respectively. His appeals were successful in that he was not charged with a criminal offense for hunting and fishing without a license, however, the successful appeal for recognition of Aboriginal people (rather than only status Indians) in the Interim Enforcement Policy of the Government of Ontario was later overturned by the Ontario Court of Appeals. ${ }^{9}$

Lovelace (n.d.) on the AAFNA website explains other efforts by members of the community to protect and maintain Indigenous livelihoods:

Hunting and wild rice have not been AAFNA's only interests. In 1996 Randy Cota successfully fought a case to ensure that Aboriginal trappers could hold both a buyers license and a trappers license at the same time. He challenged this policy knowing that it might seriously jeopardize his trapping income and affect his professional career.

According to Perry, it was the case related to duck hunting that established legal recognition of Ardoch Algonquin First Nation (Pawlick, 2009).

In addition to the above court cases, AAFNA leadership have also participated in

9 See Perry v. Ontario [1997] 33 O.R. (3d) 705 
an Environmental Review Tribunal to contest the overdrawing of water from the Tay River. In August, 2000, the Ministry of Natural Resources allowed Omya, a multinational firm that "produces dry ground calcium carbonate [...] used by the paint, plastics and building industry" (Omya, 2010), to draw 4.2 million litres of water a day from the Tay River watershed to process its product, beginning in January, 2001. After two years of organized resistance by AAFNA, an Environmental Review Tribunal (ERT) was established to examine the issue. Paula Sherman (2007) explains that over the course of the environmental tribunal hearing, held from July to October of 2001, community members from Ardoch participated in the hearing through daily attendance, provision of testimony and the submission of evidence.

As documented in the tribunal hearing and in the thesis of Bettina Koschade (2003), the tribunal served as a forum to assert Algonquin responsibility in the watershed of the Kiji Sibi and as a means to establish the legitimacy of jurisdiction of Algonquin people within the territory. In the space of the Environmental Review Tribunal expert knowledge came into question and Algonquin knowledge was also asserted as a legitimate form of expertise and knowledge.

During the hearing, the ERT Board imposed limitations on AAFNA's discussions of Aboriginal rights to consultation and Algonquin jurisdiction in the area, as established in constitutional agreements (the Royal Proclamation of 1763 and the Constitution Act 1982). The ERT board argued that it was beyond the scope of the tribunal to interpret these agreements and AAFNA should only present testimony on Traditional Ecological Knowledge regarding the water extractions. Consequently, discontinuities and 
inconsistencies between provincial and federal legislation were discussed and highlighted, where "there is no mention of Aboriginal peoples in provincial legislation", thus AAFNA could only refer to constitutional law in asserting their jurisdiction and the duty to consult regarding the Tay River watershed, but was restricted from doing so by the ERT board. Eventually, AAFNA withdrew from the tribunal as a "party" participant in order to be able to discuss these inconsistencies on record.

As a result of the tribunal hearings, Omya was ultimately limited to daily withdrawals of 2.3 million litres at the end of the hearing. Paula Sherman (2007), an active resistance organizer during this process, explains that "[a]s with the manomin movement and other resistance movements in the past, Omàmiwinini people were successful in their challenge to alter the behaviour of some newcomers in ways that made a real difference for the survival of the watershed [...] In the end, Omàmiwinini autonomy was compromised, but not extinguished altogether" (309).

AAFNA has also asserted its sovereignty in the region by asserting access to unceded Algonquin/Crown lands. In 2003, the Ardoch Algonquin began to clear a site on Pine Lake, a small lake near Ardoch, Ontario. This was done on what is considered to be Crown land, for which the Ministry of Natural Resources is responsible. AAFNA began the clearing without seeking permission as a gesture to articulate "its position with the Ministry of Natural Resources with respect to our right to build a community centre on our lands near Ardoch" (Sherman, 2008: 19). The site has been envisioned to provide a space for cultural programs and social services for the community (including linguistic programming), as well as to serve as the Pow-wow grounds for the annual AAFNA 
Manomin Festival. Fundraising activities and construction were stalled in 2006, though the plans remain to build the centre at Pine Lake.

AAFNA's ongoing commitment to upholding their responsibilities in the valley of Kiji Sibi have most recently been demonstrated through their efforts to prevent uranium mining and drilling in Frontenac County. In November of 2006, AAFNA was informed by a non-Algonquin neighbour that "our community lands may have been staked for mineral exploration" (Sherman, 2008: 19). This news was confirmed and it was learned that Frontenac Ventures Corporation (FVC) had staked 30,000 acres overall around Crotch lake, "26,000 of which was on Algonquin land that had not been surrendered to the Crown through any treaty or negotiation process" (Sherman, 2008: 19). Lovelace (2009) explains that the claims were registered by the Ministry of Mines and Northern Development and leases for much of the public lands were issued by the MNR. From the on-set, an alliance was established between non-Aboriginal or neighbouring settlers and the Ardoch Algonquin First Nation and Allies, as the Ontario Mining Act allowed for staking mineral claims on both private and public lands (thus leaving private landowners unprotected and without means to legal redress), however much of the land was "Crown" or unceded Algonquin land, under a contemporary land claims process. ${ }^{10}$ By neglecting to consult with Aboriginal communities in the area, the Province ignored legal precedence established by the Supreme Court of Canada for the duty to consult Aboriginal communities:

10 Members of AAFNA have written extensively on this issue. Refer to: Sherman, 2008; Lovelace, 2009; Sherman, 2010a 
The Algonquin homeland and Ontario's claim to jurisdiction overlap in eastern Ontario without any historical treaty or land cession. When Ontario acted unilaterally, without consulting our community, the Province broke the law. Consultation is required before development is contemplated where jurisdictions are shared or in dispute. Along with consultation there must be comprehensive and reasoned accommodation of Aboriginal rights and cultural need. These principles have been confirmed by the Supreme Court of Canada as necessary in preserving the honour of the Crown in relations with Aboriginal communities and nations ${ }^{11}$ (Lovelace, 2009: $\mathrm{x}$ ).

As a further affront, it was learned that no environmental assessment was required for the work of FVC (Sherman, 2008).

Community collectives were organized around the issue of uranium exploration. First the Community Coalition Against the Mining of Uranium (CCAMU) was formed, followed by the Ottawa Coalition Against the Mining of Uranium (OCAMU). As Sherman (2008) explains: "[a]ll of these community organizations focused on the issue as it related to private landowners, while also supporting our position as Algonquin people" (20-21). Consequently a significant regional movement was established, centered on the rights and responsibilities of Algonquin people and supportive community organizing by non-Indigenous neighbours and supporters. AAFNA established an alliance with the Shabot Obaadjiwan (Shabot) (another non-status Algonquin community with historical ties to AAFNA, that chose to continue with the land claims process when Ardoch withdrew). This alliance was contentious due to past and ongoing disagreements, but was effective (to a point) in forging a united Algonquin movement against uranium mining in Omàmìinini territory. Sherman (2010) explains: "under Omàmìwinini law,

$"$ The duty to consult with First Nations was established in the Supreme Court of Canada cases of the Haida Nation and Taku River Tlingit First Nation; see Haida Nation v. British Columbia (Minister of Forests), [2004] 3 S.C.R. 511, 2004 SCC 73 and Taku River Tlingit First Nation v. British Columbia (Project Assessment Director), [2004] 3 S.C.R. 550, 2004 SCC 74 
we had a responsibility to restore and maintain the ecological balance within the Natural

World as much as possible. Uranium exploration and mining carried huge negative impacts that were known around the world" (119). ${ }^{12}$ Their resistance was therefore founded on Omàmiwinini law and the fact that they had neither been notified nor consulted about the proposed explorations and mining. Below are two maps published on the CCAMU website (Figure 1.3) and the AAFNA website (Figure 1.4) illustrating uranium in the region.

Figure 1.3: Airborne Gamma Ray Spectrometry Map of Eastern Ontario and South West Quebec

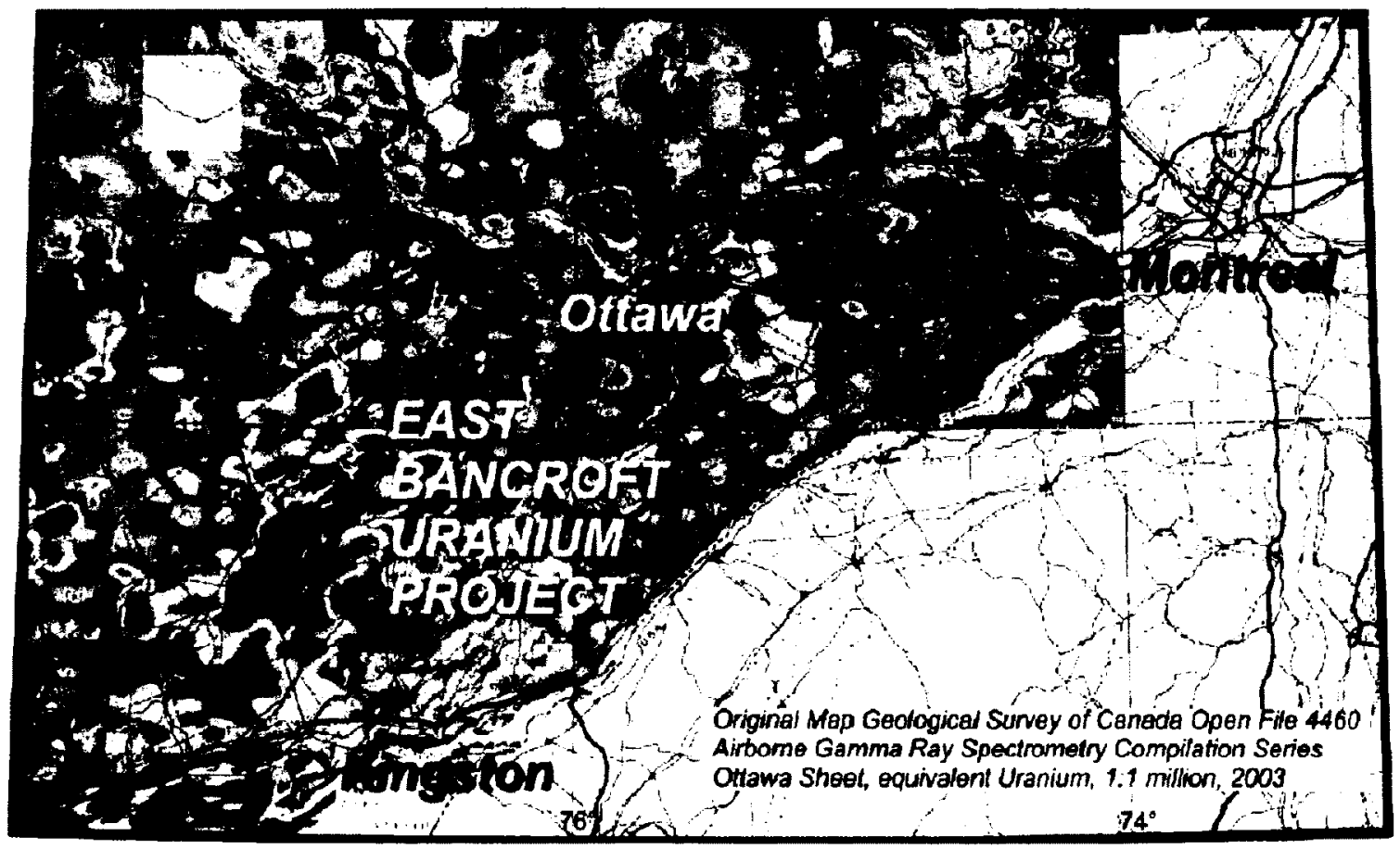

Source: Kittle, 2009.

Note: A high concentration of uranium deposits can be noted north of Kingston and in Western Quebec north of the Ottawa River.

12 Some of these impacts are discussed in Chapters 4 and 5, and are discussed throughout Sherman's (2008) Dishonour of the Crown. 
Figure 1.4: Map of Uranium Mining Claims in North Frontenac County

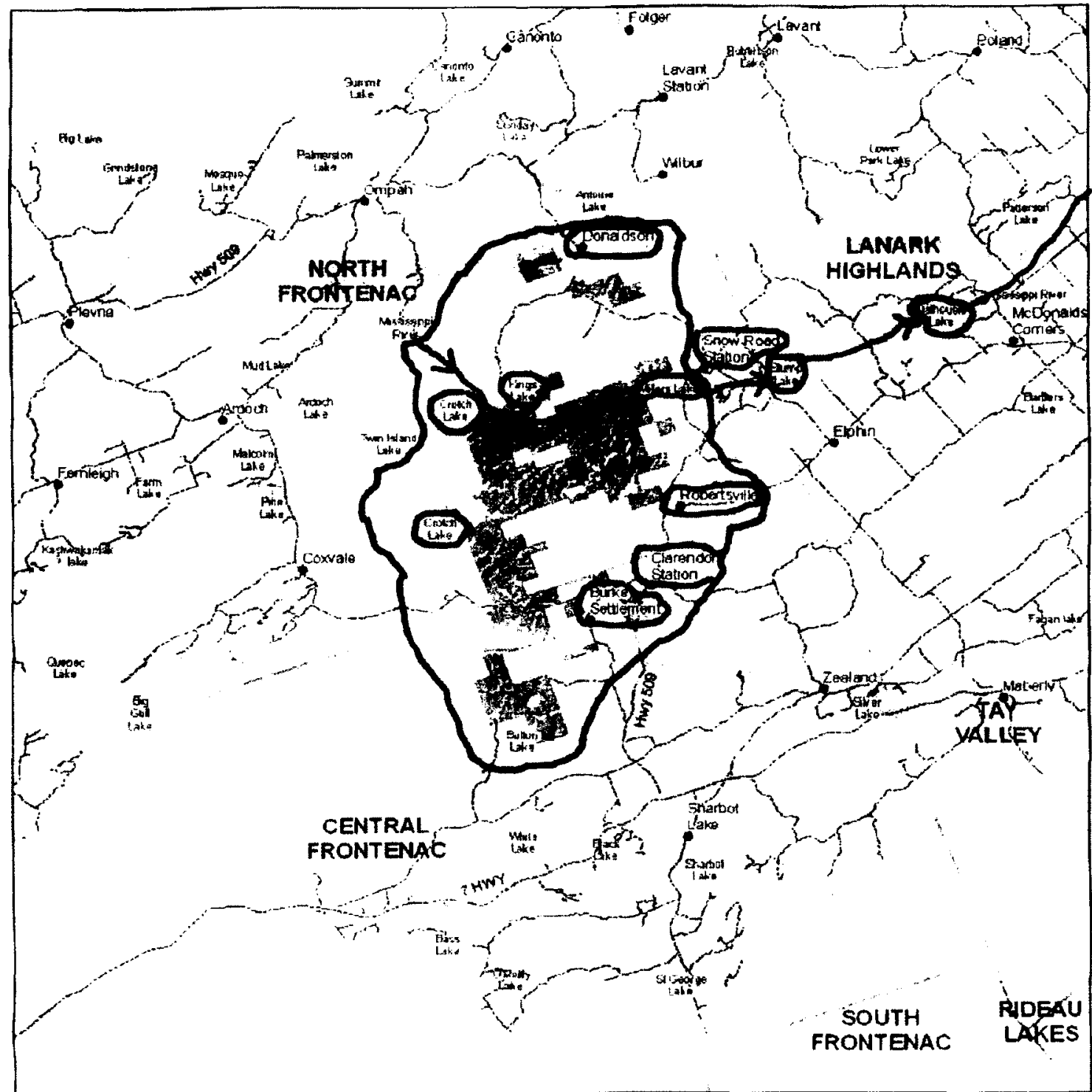

Legend

2 for Fronlenac ventures Claims

Oher Claims

Watershed Boundary

Mining Claims in Frontenac County

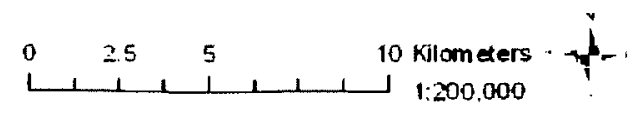

Source: AAFN, 2008.

The above map encircles the area most affected by mining in black. The red line indicates the flow of the Mississippi river towards the Ottawa River. Towns and lakes circled in blue are predicted to suffer from surface and groundwater contamination from uranium by-products. 
maintain the security camp. In October, 2007, Ardoch entered into mediated talks with the Province for eight weeks, but the mediations were ultimately based on the preconditions of the Province that consultations would begin with choosing drilling sites, rather than challenging the validity of the staking of claims. Consequently, AAFNA walked away from the consultations and contempt charges were issued.

After a series of decisions in the Ontario Court relating to the lawsuit and contempt charges, Justice Douglas Cunningham criminalized the leadership of AAFNA, ordaining six-month jail sentences and fines for $\$ 25,000, \$ 15,000$ and $\$ 10,000$. Robert Lovelace spent 104 days in a "super maximum security" prison. Lovelace's case was mirrored by that of six leaders from Kitchenuhmaykoosib Inninuwug (KI), known as the KI Six, who also received a six month sentence for refusing "to obey a court order prohibiting them from interfering with mining in their territory" (Kitchenuhmaykoosib Inninuwug and Ardoch Algonquin First Nation, 2008). On May 28, 2008, Lovelace was released after a successful appeal of his sentence and AAFNA was awarded costs of the trial. The appeals decision "set important precedents for courts in dealing with political dissent and the inclusion of Aboriginal law in the Canadian legal system" (Lovelace, 2009: xix).

In June of 2008, Shabot Obaadjiwan began to negotiate independently with the Government of Ontario. In late November, 2008, Shabot Obaadjiwan (who faced over $\$ 109,000$ in legal fees and the $\$ 77$ million dollar lawsuit), Snimikobi (Ardoch) First Nation (the splinter group that also goes by the name of Ardoch First Nation) and the Algonquins of Ontario signed an agreement of accommodation, leading to a 
Memorandum of Understanding (MOU) with FVC and Ontario, allowing FVC access to complete drilling for exploration in a limited area as set out in the agreement (Lovelace, 2008). Paula Sherman (2008) writes: “Ardoch Algonquin people reject this agreement and do not recognize the authority of Shabot Obaadjiwan or the land claims negotiations table to allow access to our community lands" (129). In March of 2008, it was discovered that the drilling had already been in process while Shabot was in negotiation with FVC (despite assurances with FVC that drilling had not yet occurred) and furthermore, that FVC had discovered a large new zone of uranium with more drill sites than what was permitted in the Memorandum of Understanding. Consequently, Shabot Obaadjiwan withdrew from the MOU.

Paula Sherman (2010a) explains that AAFNA continues to seek a political solution to the issue, through consultations with Ontario, however "Ontario will only agree to a consultation process that allows drilling" (127). In October 2009, Ontario approved and assented the new Ontario Mining Act, which was revised due to pressure from the public after public outcry over the jailing of Robert Lovelace and the KI 6. Important changes in the Act included wording that acknowledges the need for consultation with Aboriginal people, however, the wording has been criticized as vague and does not include the right to Free, Prior and Informed Consent, also known as the right to say "no", which is also affirmed in the United Nations Declaration on the Rights of Indigenous Peoples. Furthermore the duty to consult has been assigned to mining companies when it is a provincial responsibility, established through the courts (Mining Watch Canada, 2010). 
Currently FVC has stopped its operations due to the economic climate in which prices for uranium on the world market have dropped to one third of the prices of 2007. Consequently FVC is having difficulties securing funders (Green, 2010). Thus, at the time of research, AAFNA was not engaged in major legal engagements.

\subsection{A Contingent Community?}

As members of AAFNA have articulated their positions throughout a short history with much complexity and adversity, as outlined above, membership within the community has changed, resulting in community and family divisions characteristic of the outcome of 'divide and conquer' tactics used in colonial contexts. In 1996, after Ardoch Algonquin First Nation had withdrawn from the land claims process, some families from AAFNA decided to form under a new council in order to participate in the land claims process, forming the Sharbot Mishigama Algonquin Anishnabe First Nation, who are today known as the Shabot Obaadjiwan. As outlined above in the discussion of uranium mining exploration, AAFNA and Shabot Obaadjiwan have formed strategic alliances but both maintain distinct paths in political choices. In the first years of 2000 , another split in Ardoch Algonquin First Nation took place during negotiations in the land claims process to elect Algonquin Negotiations Representatives who were to sit on the Algonquin National Tribal Council (ANTC), an Algonquin non-status negotiating body separate from the Algonquins of Pikwàkanagàn. Randy Malcolm, who was purportedly representing AAFNA in the ANTC, was given a letter rescinding his mandate to represent AAFNA. Since that time, there are two communities claiming the name of 
Ardoch Algonquin First Nation, though more recently the group with Randy Malcolm as Chief goes by the name Snimikobi (Ardoch) Algonquin First Nation. Randy Malcolm is a Algonquin Negotiations Representative for the Snimikobi (Ardoch) Algonquin First Nation.

Both of the above splits are considered to be betrayals, as is published on the AAFNA website (Lovelace, n.d.). The Ardoch Algonquin First Nation, therefore appears to be a flexible community that is historically and politically contingent. This study will not focus on the politics of community membership and identity, rather it will focus on community members and spokespeople who identify as the Ardoch Algonquin First Nation and Allies under the honourary leadership of Harold Perry and the current leadership of former co-chiefs Paula Sherman and Mireille Lapointe. Throughout this thesis reference to the Ardoch Algonquin First Nation, or Ardoch is a reference to Ardoch Algonquin First Nation and Allies (AAFNA).

\subsection{A Resilient Community}

Robert Lovelace (2009) offers reflections on the struggle for environmental justice in the article "Notes from Prison: Protecting Algonquin Lands from Uranium Mining". He explains AAFNA's strategy to address the threat of uranium exploration and mining as a four-pronged approach that includes research, community education, legal action and direct action. Lovelace (2009) writes: "the four-pronged approach was needed to achieve a successful outcome, one in which not only exploration for uranium would be stopped but also existing legal precedents would be strengthened and potentially the long-term struggle for acceptance of Aboriginal rights and title would be advanced" (xii). While 
writing from the Central East Correctional Centre - after having served seventy-one days of a six month sentence for contempt of court, for AAFNA's refusal to respect the injunction and maintenance of the security barrier to block Frontenac Venture's uranium exploration activities - Lovelace emphasizes the importance of all aspects of AAFNA's strategy. Below are some excerpts of his reflections on the value of direct action in particular:

Shifting colonial ideology from its present foundations in Canadian law requires much more than changing the words [...] Action, doing, becoming growing - these are the vital processes that bring about lasting change. Such processes of change cannot be imposed but rather must emerge at a local level and represent the innate principles of living cultures from which they find ascendancy. This is the power of direct action. Often mistaken as impromptu, violent exhaustion, or last-resort anger, direct action is able to draw attention to a cause. However, to be effective, direct action must not be an end in itself for the attention, then it works against those who use it. Direct action must be considered, planned, purposeful, and controlled [...] Like other initiatives in the four pronged strategy, direct action should be integrated throughout all activities. It is the primary tool for building momentum and often the signature of the underlying philosophy of a movement.

[...] For a variety of reasons, Aboriginal people's direct action more often than not has taken on the characteristics of resistance [...] However, as indigenous people who must oppose colonialism to protect our homelands and way of life we run the risk of becoming largely cultures of resistance or, worse, perpetual victims. The very essence of living in harmony with the environment, sharing with others, and reducing conflict is undermined by persistent defence of these values. Because of this, strategic direct action should be mindful not only to project Indigenous values but to enliven them as well. Indigenous activists need to stay close to the land and community to draw continuing insight and energy, and to reinforce traditional attitudes and beliefs. Direct action should take its shape and purposes from the intrinsic goodness embedded in indigenous epistemologies" (Lovelace, 2009, xvi-xvii).

This study will explore the following research questions: "How has the Omàmiwinini of the Ardoch Algonquin's access to manomin been affected by 'development'?" and 
"How have the Omàmiwinini of the Ardoch Algonquin responded to the challenges and opportunities of 'development' with respect to wild rice harvesting and production?" As such, this research will look at manomin (a healthy, ecologically significant, and culturally important food) in its contemporary context, as it pertains to the everyday lives of some community members, to understand how manomin is situated within AAFNA's history and recent oppositional stances activities (what I consider to be both resilience and resistance). By exploring these questions I also hope to critically examine contemporary "development" in unceded Algonquin territory and examine implications for non-Indigenous people, or settler responsibilities.

In order to explore the questions guiding this research Chapter 2 begins by explicitly discussing the conceptual framework (the theoretical underpinnings) that inform how this research is approached. Chapter 3 presents the methodological framework which guides the practice of research and choice of research methods. A historical overview of relations between Algonquin people and settlers is offered in Chapter 4 to make explicit the foundations upon which current Algonquin-settler relations exist. Chapter 5 presents the ways that developments throughout the valley of the Kiji Sibi have affected AAFNA community members' access to manomin. The thesis is concluded with a discussion of how AAFNA have responded to the challenges or opportunities of development with respect to their ability to maintain access and responsibility to manomin, and further explores the implications of the research findings for settler responsibilities. 


\section{Chapter 2 - Conceptual Framework}

In this chapter, I explain the theoretical and conceptual bodies that underpin and inform my research. I do so with the hopes of explicitly stating the perspectives and positions that inform my approach to research, including the methodologies and methods used to obtain data, as well as the conceptual framework used to analyze data. Chapter 2 begins with a discussion of the imperative to decolonize academic inquiry and research by deconstructing the production of knowledge and being attentive to the landscape of power that is complicit in research and writing. Section 2.2 situates the main approach of the thesis within the field of critical political ecology, where an outline of the theoretical foundations of political ecology and a brief outline of the history of its development is provided. Sections $2.2 .3,2.2 .4$ and 2.2 .5 elaborate on other disciplinary insights that inform emerging political ecological studies; thus an overview of poststructural, critical feminist and postcolonial/decolonizing literature is presented. Finally, in Section 2.3 an explanation of how the above theoretical groundings will be applied throughout the research is offered through deconstructions of "development" and resistance, through a multiscalar analysis, by exploring the connections and mutually constitutive nature of capitalism and colonialism, and by using social nature theory.

\subsection{Deconstructing and Decolonizing the Production of Knowledge}

As discussed in the previous chapter, this research is situated in the Canadian context, with a specific focus on food and, thereby, environmental and ecological issues (based on land and water "resources"), thus bringing questions of jurisdiction, ownership, territory and power to the fore. I have chosen to explore food and resource-use as intertwined 
with Indigenous history, culture, spirituality, knowledge and innovation. The case of manomin (wild rice) and the Ardoch Algonquin First Nation is further situated in a history of resistance and conflicting claims to jurisdiction, as explained in the previous chapter. Thus the colonial history and ongoing colonial reality in Ontario and Canada more broadly is at the forefront of this research.

This paper is most firmly rooted in a decolonizing framework, through which an "unmapping" of the landscape will be undertaken in order to undermine colonial legitimacy and make explicit ideological and material struggles that arise as a consequence of domination and exploitation that characterize Canada as a White settler state. Sherene Razack (2002) in Race, Space and the Law: Unmapping a White Settler Society explains the project of unmapping as making visible the discrimination, racism and violence upon which Canada has been founded and maintained - recognizing that a large part of establishing and maintaining a colonial order was and is achieved through spatial ordering and re-ordering according to settler ideologies. Unmapping therefore provides a means of disrupting the national mythology of the superiority, equality and fairness of establishing a White settler society through the erasure of its original peoples (through conceptions of space as "empty land" or terra nullius, through colonial violence, displacement and genocide), and through the policing, control and discrimination against immigrants, refugees and people of colour. Razack (2002) writes:

To contest white people's primary claim to the land and to the nation requires making visible Aboriginal nations whose lands were stolen and whose communities remain imperiled. It entails including in the national story those bodies of colour whose labour also developed this land but who are not its first occupants. It is to reveal, in other words, the racialized structure of citizenship that characterizes contemporary Canada (5). 
By approaching research in this way, I hope to contribute to a body of knowledge that reconceptualizes Canadian history and politics (with particular reference to Indigenoussettler relations) as understood through and recounted in dominant discourse, in order to move towards a more just future for all who live on this land, breathe this air and depend on this water.

The production of knowledge - created by history that is told and re-told, by the place names used to describe geographical features, the language used to communicate ideas or describe objects, the way that research is undertaken to analyse, understand and characterize a given situation or object of study - is highly complicit in both decolonizing projects, and projects that serve to maintain a colonial order. Thus this research is attentive to the production of knowledge through the approach to research, and by a critical examination, deconstruction and selection of literature which challenge the dominant narrative that (re)produces a social order based on hierarchy, discrimination and exploitation. This research is rooted in the recognition that it is embedded in a history of academic and historical inquiry and accounting which was (and in many cases continues to be) highly complicit in establishing imperial legitimacy through erasure and silencing of Indigenous histories, through the perpetuation of half truths and nationalist mythologies and through Eurocentric and often racist, sexist, discriminatory approaches to research (see Said, 1993; Battiste, 2000b; Henderson, 2000a; Tuhiwai Smith, 2000; Hart, 2004; Mihesuah and Wilson, 2004; Sherman, 2007).

Cree Scholar, Winona Wheeler (2000), explains the importance of academic engagements in decolonization: 
A large part of decolonization entails developing a critical consciousness about the cause(s) of our oppression, the distortion of history, our own collaboration, and the degrees to which we have internalized colonialist ideals and practices. Decolonization requires auto-criticism, selfreflection, and a rejection of victimage. Decolonization is about empowerment - a belief that situations can be transformed, a belief and trust in our own peoples' values and abilities, and a willingness to make change. It is about transforming negative reactionary energy into the more positive rebuilding energy needed in our communities (quoted in Wilson, 2004: 71).

However, educational institutions have not traditionally been sites of decolonization. In a panel discussion entitled Decolonizing the Academy? The Status of Indigenous Peoples and Scholarship, Joyce Green (2009) posits that "the University has been the place where élite knowledge and élite social classes come together, perpetuating privilege and worldviews along with specific knowledges". Rauna Kuokkanen (2009) in the same panel states:

As an institution the academy supports and reproduces certain systems of thoughts and knowledge and certain structures and conventions that rarely reflect or represent Indigenous worldviews. To a large extent the academy remains founded on epistemological practices and traditions that are selective and exclusionary, and that are reflective of and reinscribed by the enlightenment, colonialism, modernity, and in particular, liberalism. These traditions, discourses and practices have little awareness of other epistemologies and ontologies and offer them only heavily restricted space at best.

Taiaiake Alfred (2004) has identified universities as sites of colonial knowledge processes. He argues that universities "accomplish the acceptance and normalization of Western ideas, the glorification of Western societies as the highest form of human organization, and promote the emulation of North American culture to the next generation of citizens" (96). Alfred further posits universities as "microcosms of the larger societal struggle" in which Indigenous people are perpetually resisting assimilation (88). 
Consequently, engagements within universities also require a warrior approach to scholarship, "to change the places we live and work from sites of imperialism into spaces of resistance, of regeneration, and of human freedom" (Alfred, 99). Similarly, Green (2009) argues that the university remains an institution worth transforming rather than abandoning, and that possibilities for decolonizing and indigenizing the academy remain.

The analysis and imperative of decolonizing academe, or indigenizing academia, is most often forwarded by Indigenous academics, or other historically colonized peoples. While I am not an Indigenous person, I also argue that the commitment towards transforming praxis and knowledge production in universities and educational institutions is the responsibility of all who strive for a more just and equitable future and are part of an academic community. In light of this, throughout my studies, I have engaged with my positionality in order to be critically aware and engaged with the problems and consequences of my research: as a settler Canadian, as a White person (and Canadian of European descent), as a woman, as a person of Jewish decent, as an academic and as a researcher, and in the various other ways that I experience both privilege and subordination. ${ }^{14}$

My research has been informed, not only by scholarly, text-based studies, but through lived experience, and practical and political engagement. More specifically, my research has been informed by my continual involvement and participation in activist and grassroots organizations that work, beyond the realm of research and writing, to challenge, disrupt and change the current context of exploitation, injustice and inequality in local and global contexts. Thus, this research represents a linking of theory and

${ }^{14}$ Positionality is discussed in greater detail in Chapter 3 of this thesis. 
practice with the goals of working towards decolonization through academic and other political avenues. I have also reflected deeply upon how I would actually do my research: my methodological approach (including my research design) and the methods through which I would undertake my research (discussed in Chapter 3) have been chosen as an attempt to design and carry out research in such a way that challenges traditionally oppressive, extractive or colonial research designs, methods and dissemination. It is a commitment to research as a decolonizing process that has informed my approach to research, and the theoretical grounding I have used to understand this case study.

I approach this chapter with some trepidation, as a central aspect of decolonizing academic pursuits is challenging the élitism, and the inaccessibility of academic writing. Throughout my studies, I have learned to read, understand and speak the academic language that has given me access to an incredible depth of analyses and critical thought. The academic ideas, arguments, logic and insights that I have come across during this research have been, for the most part, absolutely central to my intellectual, analytical and political growth, and increasing critical awareness and insight. There is, no doubt, incredible value, substance and depth in the wide range of academic writing that I have come across. However, I do fear that in communicating theoretical concepts, as is my purpose in this chapter, there can be a loss of the 'groundedness' of the theory, of how the theory fits within a real world context outside of the university and off of the paper.

The theories I describe in this chapter (political ecology, poststructuralism, critical feminism and postcolonialism) serve to contextualize my research, within the history of research, academic pursuits and the production of knowledge in Euro-American societies. 
The above theories also serve to explicitly explain my approach to understanding my research question, by laying out the foundations that inform my analysis - the lens through which I will examine the case study. It is my goal here, to explain how my research fits in within these areas, without losing the meaning in academic jargon and distance from reality. I find it to be a great challenge, as most theories are written in a language that is not in common usage and thus not accessible to most people. Thus, this chapter reflects my tensions with the effort to engage in decolonizing research, while also producing a legitimate, nuanced and critical piece of academic work in the university as it stands today.

\subsection{Deconstructing Power, Domination, Resistance and Negotiation}

Ultimately, this research is based on a commitment to contribute towards practical, meaningful studies that present an alternative, or counter-hegemonic account of socialecological relations to point to a more equitable, sustainable, just and fair way forward, while also documenting the contradictions, injustices and casualties of the dominant neoliberal capitalist industrial development agenda. Counter-hegemony refers to Gramci's (1971) account of the contestation of capitalist hegemony, where, according to Alan Hunt (1990), hegemony is the ideological and political domination by a fundamental group or historical bloc, "through the formation of popular consciousness or common sense" (310) by "an active process involving the production, reproduction, and mobilization of popular consent" (311). In other words, hegemony comprises the dominant assumptions and perspectives that are taken as objectives truths but are rooted 
in particular ideologies and political orientations. Counter-hegemony is therefore "the process by which subordinate classes challenge the dominant hegemony and seek to supplant it by articulating an alternative hegemony" (Hunt, 1990,312). The project of "unmapping" (Razack, 2002), discussed above, is central to counter-hegemony. This thesis represents a study of hegemony and counter-hegemony through an examination of manomin, a community commons that has come under threat of privatization and commoditization, yet has also been defended and maintained as a community commons for which Algonquin people have responsibility and jurisdiction.

This study is concerned with the political situation of manomin - understood both as a Gift from the Creator, as well as a natural resource and commodity by different actors - within a complex ecological community. Thus, a central component of this project is to deconstruct the operations of power, domination and subordination, as well as resistance, contestation and negotiation, through the examination of this particular case study with the hopes of illuminating how both environmental and social change and conflict in a local context are embedded in various networks of interaction.

The foundations of research are therefore well situated within the literature of political ecology (see Bryant, 2001; Braun, 2002; Paulson, Gezon and Watts, 2003; Watts and Peet, 2004; Robbins, 2005). Political ecology is a broad field of inquiry with a focus on social interactions with respect to access and control of natural resources and life systems. The main value of political ecology is its approach to understanding environmental or ecological studies with recognition of the implications of the socialpolitical sphere and power relations in the shaping of ecological dynamics. Therefore, 
nature is understood to both shape and be shaped by social relations, particularly through the exercise and contestation of power. Furthermore, political ecology approaches its subjects of analysis with an explicit agenda, which is to uncover more sustainable and just forms of interaction (Watts and Peet, 2004; Robbins, 2005).

In an overview of political ecology, Robbins (2005) notes that there is no single definition of political ecology amongst political ecologists, and that the definition of political ecology and its questions or themes of inquiry that have been emphasized have changed over the course of time. However, he does argue that there is coherence among the numerous political ecological analyses which can be classified into four themes or narratives of political ecological inquiry, identified as: degradation and marginalization; environmental conflict; conservation and control; and environmental identity and social movements.

As discussed by Paulson, Gezon and Watts (2003), political ecology studies identify

politics of difference and power within specific sites and pursue links with political and economic relationships and systems that extend beyond those sites. They also consider discourse and representation in analyzing environmental outcomes and offer new possibilities for engaging with power and political processes (212).

As is noted by Watts and Peet (2004) and Robbins (2005), political ecology operates with a normative imperative to understand social and environmental changes with a dual role: to "critically [explain] what is wrong with dominant accounts of environmental change, while at the same time exploring alternatives, adaptations, and creative human action in the face of mismanagement and exploitation" (Robbins, 2005: 12). This study 
aims to do exactly that by examining contemporary challenges and opportunities presented by 'development' with respect to access, production and harvesting of manomin (wild rice), and to document how the Ardoch Algonquin First Nation and Allies have responded to such challenges and/or opportunities.

A brief recounting of the history of political ecology serves to further explain the theoretical groundings of this approach to analysis.

\subsubsection{Politicizing Ecology: A Short History}

Political ecology was a term coined in the 1970s by Alexander Cockburn (journalist), Eric Wolf (anthropologist) and Grahame Beakhurst (environmental scientist):

... as a way of thinking about questions of access and control over resources (that is to say the toolkit of political economy), and how this was indispensable for understanding both the forms and geography of environmental disturbance and degradation, and the prospects for green and sustainable alternatives (Watts and Peet, 2004: 6).

It is a broad field of inquiry which draws strength from a multitude of theories from various disciplines including anthropology, geography, postcolonial studies, political economy, critical feminism and poststructuralism. An overview of the history of this field follows below. ${ }^{15}$

As outlined by Paulson, Gezon and Watts (2005), political ecology has its roots in anthropological studies that have long explored debates regarding "the relationships of people in their material environments" (18). Anthropological theories ranged from social evolutionary theories (which assumed universal, hierarchical progressions of social

15 A detailed account of the origins of political ecology is provided by Paulson, Gezon and Watts (2005) in their chapter "Politics, Ecologies and Genealogies", pp. 17-40 
development through the use and adaptation of technologies) to culture-area and possibilism theories in which people, through cultural practices, were understood to be shaped by culture, rather than by environmental limitations, or environmental determinism. In the 1920 s, the culture-area theory was refined by a dialectical understanding of the relationships among people and the environment, noting that culture was influenced by environmental conditions, but also shapes the environment. In the mid-twentieth century Julian Steward (1972 [1955]) coined the term 'cultural ecology'a theory grounded in materialist assumptions that similar environments produced similar socio-cultural characteristics. In response to critiques of cultural ecology, Andrew Vayda and Roy Rappaport (1967) developed the field of human ecology, otherwise known as ecological anthropology, which established an ecosystem model in which people were understood as one of many species in a given environment, linking cultural practices and environmental change. However, cultural ecology also has been criticized for its lack of attention regarding differentiation of power, and for failing to account for extra-local influences such as colonialism and the effects of global economic forces (Paulson et al., 2005: 19).

In geography, cultural geography emerged in the mid-twentieth century as a means to situate landscape change within environmental and cultural diffusion and the domestication of plants and animals through the studies of Carl Sauer (1952) and the Berkeley School of Cultural Geography. The work of William M. Denevan (1989) and students from the University of Wisconsin also combined geographical and anthropological inquiry in which cultural ecology approaches were applied in efforts to 
understand the interaction of knowledge systems, sustainable production, and trade flows (Paulson et al., 2005: 21). In the 1970s, cultural ecology came to require a sophisticated engagement with questions rooted in political economy through studies which demonstrated cultural adaptations to the environment and which explored how adaptive capacities were undermined by integration with the global economy. Interdisciplinary research into responses to hazards and disasters, conducted during the Cold War era, further emphasized that, "disaster prevention, preparation and responses to it were highly political" (Paulson et al., 2005: 23). Thus, the stage was set for a more politicized analysis of human-ecological relations.

The 1960s and 1970s saw a re-emergence of political economy through a proliferation of peasant studies, critiques of colonialism and renewed focus on Marxist analysis in the social sciences (Paulson et al., 2005: 23). Watts and Peet (2004) note the important shift in which cultural ecology and ecological anthropology were challenged by examining not isolated or subsistence communities in harmony with their physical environment, but rather peasant societies marked by the presence of the markets, social inequalities, conflict and forms of social and cultural disintegration associated with their integration into a modern world system (9).

Consequently, studies began to emphasize the relevance of social relations, production and growth to understanding environmental analyses. Political ecology of the 1970s and 1980s, though innovative in its connections of Marxist political economy with questions of resource access, control, management and use, is criticized for a number of shortcomings including studies not informed by gender nor deep political engagement seeking to explain ability or barriers to control or access resources or define property 
rights negotiated in multiple political arenas and at various scales (Watts and Peet, 2004; Paulson et al., 2005).

Bryant (2001) also emphasizes that political ecology in the 1970 s and 80 s was a critical response to neo-Malthusian analyses of poverty and environmental crises in developing countries, which grounded causality in demography and environmental degradation at the local scale. Political ecologists on the other hand emphasized uneven economic development, and resource exploitation in the South for export to Northern countries, drawing on Marxism and dependency theory, thus extending analyses to the interaction of "non-place-based forces" with "place-based activities" (Bryant, 2001: 153).

Thus, political ecology today came to be situated at the juncture of ecological anthropology, cultural geography and political economy. As such, it serves to bridge debates of structure (or materialist explanations) versus agency (or symbolic or social explanations), recognizing both the politicized interactions of local environments with global economic influences, and the significance of social and environmental imaginaries in shaping cultural-ecological relations and responses to environmental change (Paulson et al, 2005).

As political ecology has progressed since its inception in the 1970 s, political ecological studies have moved beyond geography, anthropology, political economy and development studies to theories extending from more disciplines. Since the 1990 s, political ecology has been "marked by creative cross-fertilization among [...] diverse approaches and by the interrogation of assumptions in intellectual traditions that were institutionalized in nineteenth century science" (Paulson et al., 2005: 25). Thus, political 
ecology also integrates analysis from feminist studies, poststructural studies and postcolonial studies. Watts and Peet (2004) explain that contemporary political ecology is more robust in its theorizing of development and environment spurred "by the realities

of the new social movements themselves, and by the intellectual developments associated with green Marxism, cultural and social theory, discourse theory and poststructuralism"

(5). This research therefore reflects the more recent developments of political ecology by examining the networks of power and opposition relating to access, use, jurisdiction and control of "resources," by integrating insights from multiple disciplines.

\subsubsection{A Critical Political Ecological Case Study}

This research responds to emerging directions of political ecology as set forth by Watts and Peet (2004), Paulson, Gezon and Watts (2005) and Robbins (2005). As such, this study will attempt to be a "practical political engagement with new movements, organizations and institutions of civil society challenging conventional notions of development, politics, democracy and sustainability" (Watts and Peet, 2004: 6) examining both the new transnational social movements, through the lens of Indigenous sovereignty, and food sovereignty and La Via Campesina, and the uniquely local struggle of the Ardoch Algonquin First Nation in the Ottawa Valley that "may not warrant the term 'movement"' but is indicative of important local social actors asserting jurisdiction and responsibility (Watts and Peet, 2004: 5).

Recognizing that "struggles over resources lie at the center of struggles over power" (Watts and Peet, 2004: xiv), the study of manomin is situated within the 
understanding that evoking discourses of traditional and local knowledge(s) and Indigenous jurisdiction and responsibility to legitimate access to Indigenous foods are used as an alternative or counter-hegemonic strategy to assert power and jurisdiction. This research will therefore, in part, focus on local and traditional knowledge(s) and study how, in the context of wild rice and conflicting "developmental" interests, these knowledges are asserted, legitimated or contested. Watts and Peet (2004) note that, "central to the new political ecology is a sensitivity to environmental politics as a process of cultural mobilization, and the ways in which such cultural practices - whether science, or 'traditional' knowledge, or discourses or risk, or property rights - are contested, fought over and negotiated" (6). This particular aspect will be explored through postcolonial theory.

Furthermore, Watts and Peet (2004) argue that relevant work in contemporary political ecology lies no longer in how to think (using poststructural analyses to deconstruct the operation of power), but what to think about, arguing for "primitive accumulation and enclosure as a starting point for understanding the relations between environment and development...as an ongoing process of dispossession as the market, and private property relations, enter new arenas [...] [driven by] techno-scientific innovation" (xvi). This research will also have a focus on property rights in terms of the nature of property in the case study, particularly in reference to property rights and jurisdiction claimed by various actors (including the state, Algonquin people and private property owners), and property rights held in common, with a focus on the communities and ecosystems that support manomin. This research examines some of the implications 
of the commodification of manomin. Further research could discuss the implications of the domestication of wild rice, and the implications of biotechnological genetic development of wild rice germplasm, thus further addressing the continuing and expanding climate of enclosure characteristic of capitalism (as discussed in Chapter 1 and below).

Therefore, research on manomin provides a means to examine a number of contemporary political ecological subjects including: Indigenous rights and sovereignty (self-determination and access to territory and resources to support livelihood activities); food security and food sovereignty; the interaction of food, diet, nutrition, culture, identity, health and well-being; access to and control over water rights and aquatic ecological communities; power struggles over contested discourses and perceptions of 'development' including those of economic progress and sustainable development, ecological pollution and contamination, and resource exploitation and degradation; and the continuing enclosure of the commons through privatization and patenting of genetic material and manipulation of property rights. This research is situated within contemporary political ecological debates, particularly by inquiring into the politics of knowledge, identity, counter-hegemonic struggles and by exploring ecological democracy [in which local autonomy over natural wealth is maintained through engagement with politics, justice and governance (Watts and Peet, 2004)].

In order to continue forward in political ecology, there is an ongoing need to account for critical social theory developed in other disciplines. Thus, below is an overview of insights from poststructural, postcolonial and critical feminist theory, which 
will be used within the political ecological framework to further expose the workings of power and oppositional forces in the case study of the Ardoch Algonquin First Nation and manomin.

\subsubsection{Examining Discourse, Knowledge, Identity and Power: Poststructural}

\section{Approaches}

As discussed previously, in addition to drawing on political economy, ecological anthropology and cultural geography, political ecology since the 1990s has also come to draw on insights from critical feminism, critical post-structuralism, and post-colonialism, all of which are fields that themselves are quite cross-fertilized and complementary. By also framing the research within critical poststructural geography, issues around the politics of identity, Indigeneity and authenticity, knowledge creation and dissemination, and power, are brought to the fore of analysis. Poststructural and postcolonial approaches are complementary and overlapping and form the backbone of contemporary political ecology. They form the foundation from which to question apparent truths (such as the principles and ideologies of a modernist worldview) and provide modes of inquiry which can open doors to the realms of the possible and becoming by challenging inherent assumptions of hegemony (Barron, 2000; Braun, 2002; Butler 2004; Gibson-Graham, 2006). Post-structuralism is radically anti-essentialist and anti-foundationalist, thus, meanings do not exist in objects themselves - they are constructed through historical, social processes which are closely tied to power and authority over knowledge creation. Deconstruction and discourse analysis are poststructural techniques that I will employ 
throughout my research to interrogate binaries, uncover hidden meanings, expose silences and bring to light the operation of power through knowledge creation (Harrison 2006; Wylie, 2006).

Arturo Escobar (1996) explains poststructural discourse analysis as both a linguistic theory and a social theory, where social relations are constructed through language. Escobar defines poststructuralism as

a theory of the production of social reality which includes the analysis of representations as social facts inseparable from what is commonly thought of as "material reality." Poststructuralism focuses on the role of language in the construction of social reality; it treats language not as a reflection of "reality" but as constitutive of it (46).

Derek Gregory (2001) explains the use of discourse analysis in postcolonial studies:

Postcolonial theory often seeks to map the circuits through which culture underwrites power and power elaborates culture by working with the concept of discourse. A discourse is a specific, collective series of representations, practices, and performances through which meanings give the world its particular shapes - their forms and norms [...] Discourses have their own rules and protocols about what can properly be regarded as knowledge, but these conventions are grounded. By this I mean that they are encased in apparatuses - in books and journals, in instruments and equipment, in interactions and procedures - which are produced and reproduced through interlocking networks of individuals and institutions, and their physicality, materiality, and durability help to naturalize particular ways of being in and acting in the world (86, emphasis in original text).

By critically examining the discourses that are mobilized to legitimate particular knowledge(s) and subject positions, a process of deconstruction can occur which underlines the contingent nature of that which may appear to be self-evident and "true". Deconstruction is described as a method to undermine, denaturalize and destabilize what is given as "truth, certainty and authority" by making visible the erasures and silences behind what is readily apparent (Wylie, 2006: 299). 
Closely related to discourse is the poststructural understanding of identity construction, through which particular subjects, group identities and communities mobilize particular discourses to communicate their aims. In Contested Grounds, Amita Baviskar (2008) accuses political ecology of neglecting to account for the construction of political identities, thus arguing for attentiveness to culture as part of a political agenda. Baviskar (2008) argues that establishing and maintaining "stable regimes of extraction" (3) - a necessarily expansionary, imperial project - requires consensus in addition to brute force, so that people will be willing participants. Achieving consensus that legitimizes particular projects of conquest, interference and outright theft (and alternatively, effectively opposing such projects) thus requires the mobilization of particular discourses, narratives and rationales that are inherently political. This discursive manoeuvering underlines the significance of cultural politics. Hornborg and Kurkiala (1998) note that discourses (particularly oppositional arguments or positions) exist on a plain of credibility through which the acceptance of particular and competing narratives (reflecting differing views or experiences of "truth") is based upon the perceived legitimacy of the participants. Thus, the ability to assert "traditional ecological knowledge", Indigenous knowledge, or Algonquin knowledge is contingent upon the ability to construct, or perform an identity that is accepted as legitimate, much as the ability to assert rational, scientific knowledge is also based on the ability to construct an identity that is accepted as legitimate. Baviskar (2008) explains: 
A cultural politics of natural resources treats identities, interests and resources, not as pre-determined givens, but as emergent products of the practices of cultural production and reproduction. By emphasizing power, process and practice, this approach treats 'culture itself as a site of political struggle'. The analytic draws attention to the cultural work involved in reproducing and challenging inequalities and exclusions around resources [...] While cultural politics shares political ecology's commitment to understanding the asymmetric workings of power it argues for a greater appreciation of the complex and contingent conditions under which people make history (7).

The politics surrounding the ability to assert a persuasive subject position are acknowledged as significant, however, discussions exploring the identity politics and internal dynamics (or the politics of Indigeneity) of the Ardoch Algonquin First Nation and Allies is not discussed in detail in this paper. ${ }^{16}$ Alternatively, the politics regarding the ability of settlers (in the form of governments, organized groups or individual actors) to assert jurisdiction and control over Indigenous "resources", such as manomin and its associated ecological community, are the main focus of this paper, and are further discussed below, in Section 2.3.5 in which social nature is discussed.

In discussions of Indigenous-settler relations, a discourse of difference and distinctiveness is implied between the two groups, and is arguably necessary in order to recognize the unique histories, cultures, interests, priorities and responsibilities of each. However, various authors have discussed that the construction of Indigenous identities as

16 I acknowledge that deconstruction of community politics, that is an analysis interrogating community as a constructed, politically motivated group of people, is an important body of work within poststructural approaches to social research. I also acknowledge that there is controversy surrounding community politics and the politics of identity with respect to the Ardoch Algonquin First Nation and Allies. I have outlined briefly in Chapter 1 some of the history and complexity of the community over time, thus noting the contingency of the community based on political orientation and motivations. I furthermore outline the complex history of the Indigenous-settler and Algonquin-settler relations in Chapter 4 of this thesis. However, it is beyond the scope of this thesis, and beyond my comfort level given my positionality, to theorize further upon the identity politics involved in the formation, continuity and political engagements of the Ardoch Algonquin First Nation. 
fixed, unchanging and essential has been a central colonizing tactic and remains problematic in the representation of Indigenous peoples in particular coalitions, such as alliances between Indigenous sovereignty and environmental activists (Hornborg and Kurkiala, 1998; Barron, 2000, Braun 2002; Thobani, 2007). Barron (2000) notes that such representations often "end up limiting the practical possibilities for justice and [...] self-determination" (Barron, 2000: 94), through the requirement to appeal to common understandings of "authentic Indigeneity", tradition and cultural difference. This argument is also echoed by Braun (2002). Barron (2000) argues that these problems of representation, particularly in reference to solidarity work (and more specifically in reference to coalitions between environmental and Indigenous groups) can be mediated through a "politics of articulation" - through which "neither the identities of political actors nor the meanings of any given struggle exist a priori; rather, they are constituted discursively through the political process - i.e., the definition of interests and the elaborations of strategies" (102). Thus, a commitment to a poststructural approach to research and coalition building can provide a more meaningful way of forging alliances.

While poststructural approaches help to reveal the contingent and constructed nature of social and ecological relations, critical feminist theory provides a body of literature through which relations of power and opposition can be investigated using different though complementary approaches. This is highly relevant given the objective of this research: to elaborate upon the nature of settler-Indigenous relations in contemporary eastern Ontario, in the Kiji Sibi Valley through an examination of manomin. 


\subsubsection{Theorizing Intersectional Oppressions, Shifting Nexuses of Power and}

\section{Deconstructing Home: Some Critical Feminist Insights}

Contemporary critical feminism provides a vast body of literature that can contribute to the increasing robustness of political ecology (Watts and Peet, 2004), through insights in intersectional and multidimensional theory, coalition or transversal politics, examinations of White privilege and critical analyses and accounts of home. While this research is not a gendered study, in that an analysis of gender dynamics is not part of the research, this thesis is very much informed by feminist theoretical insights. Critical feminists draw on the critiques of earlier feminist theorists, who were accused of essentializing gender, reflecting the idea of a fixed experience of gender oppression, and neglecting race and other axes of social differences amongst women. Early feminists were therefore accused of reflecting the experience of White, able-bodied, heterosexual, socio-economicallyprivileged women, and thereby subordinating the experiences of women who experienced gender oppression differently (Lorde, 1984; Frankenberg, 1993; Collins, 2002; Mohanty, 2002; Froc, 2010). Thus, insights from Black, Third World, postcolonial, and queer feminists (amongst others) have invigorated and opened up conceptualizations of feminism that recognize differences among women, and take account of multiple forms of oppressions beyond sexism or gender oppression.

Intersectionality is a feminist concept derived from such considerations.

Intersectionality is based on the experience that multiple oppressions intersect in a "matrix of domination" - wherein various oppressions operate simultaneously in particular historic, social, cultural contexts that are unique to the local situation - and 
result in differing realities (Collins, 2002). Thus, the experience of gender oppression for women of colour is connected to the experience of racism, poverty and other forms of oppression, in complex ways that are not simply an addition to gender oppression (Lorde, 1984; Collins 2002; Mohanty, 2002). Kerri Froc (2010) argues that intersectional theory views oppressions as discrete, identifiable and interconnecting, and offers multidimensionality theory as a more appropriate way to conceptualize the operations of multiple oppressions by further complicating how multiple axes of oppression are seen to interact. She draws on an analogy from the movie The Matrix in which systems of oppression constitute an invisible matrix whereby

oppressions are composed of a vast network of complex, overlapping, interactive, and mutually reinforcing systems that constitute everyone's reality. The systems have real, material effects that are more devastating and acutely felt by some than by others, but no one is left untouched. However, those living within the matrix are deceived into thinking that the illusion, the world the systems create, is the natural world ("the way things are") (Froc, 2010: 23, emphasis in original text).

Consequently, understanding or even having awareness that such a system exists in the first place is difficult; teasing out how multiple oppressions interact can be confusing, complex and messy. However, Froc (2010) argues that "one can expose the operation of the systems by looking at a specific site where certain systems are known to be operating (e.g., homophobia, white supremacy) and considering the contradictions or 'unexplainability' of the circumstances based on the 'known' systems alone" (3). Patricia Hill Collins (2002) argues that while the organization of matrices of domination differs across time, place or societies, the experience of "intersecting oppressions through diverse local realities" is universal (228). Thus, critical feminist work is characterized by 
an intersectional or multi-dimensional approach to analysis that acknowledges the interplay of multiple systems of oppression.

This study is therefore well situated within the above critical feminist approaches. Throughout this thesis, I will examine the intersection and multi-dimensionality of colonialism, race and identity, the production of knowledge, economic "development" and ecological dispossession and despoliation, in the case of manomin and the Ardoch Algonquin First Nation. ${ }^{17}$

Political ecologists draw on other critical feminist insights, including how power, position and privilege are conceptualized. In general, identity is understood in feminist literature as complex, and extends beyond binary thinking (for example male/female; gay/straight; Black/White; oppressed/privileged); ideas of hybrids, spectra, or shifting identities have been developed by many feminists on the basis of sexuality, biology, intersectional oppressions, and coalition building (Butler, 1990; Fausto-Sterling, 2000; Butler 1992; Collins, 2002). Collins' (2002) conceptualization of transversal politics is demonstrative of feminist theorizations of shifting, relational, non-essential identities. . Transversal politics are based upon coalition building between groups of "political actors", with empathy as a basis for coalition. Collins (2002) argues that in coalition building between groups, examining group histories as interdependent and relational is needed in order to reveal "painful contradictions" (247). These contradictions demonstrate that domination and resistance are not absolute and allow for the recognition of shared experiences of victimization amongst groups, thus building empathy, while also

17 The works of Razack (2002), Lawrence (2004) and Thobani (2007) are all exemplary works which investigate the interaction of gender, race, nationalism, and to a certain extent, class in highly critical and informative works. 
recognizing the responsibility in the oppression of other groups (for example, White women may experience gender oppression, but they may also be complicit in violence against people of colour in general, and women of colour in particular). Thus, Collins (2002) states: "In this model, there are no absolute oppressors or victims. Instead, historically constructed categories create intersecting and crosscutting group histories that provide changing patterns of group participation in domination and resistance to it" (248). That is not to say that experiences of domination or resistance are also therefore equivalent, but that is to say that there is room for creating contingent coalitions amongst various groups that can inform a novel agenda for justice. Biddy Martin and Chandra Talpade Mohanty (1986) provide a relevant analysis of Minnie Bruce Pratt's (1984) essay, "Identity: Skin, Blood, Heart" (a reflective essay examining her shifting experience as a victim and a beneficiary of oppression). They write:

Pratt's essay on feminism, racism, and anti-Semitism is not a litany of oppression but an elaboration, indeed an enactment of careful and constant differentiations which refuses the all-too-easy polemic that opposes victims to perpetrators. The exposure of the arbitrariness and the instability of positions within systems of oppression evidences a conception of power that refuses totalizations, and can therefore account for the possibility of resistance. 'The system' is revealed to be not one but multiple, overlapping, intersecting systems or relations that are historically constructed and recreated through everyday practices and interactions, and that implicate the individual in contradictory ways (209).

Thus feminist accounts of subordination/domination allow for a complicated understanding of shifting relations and complex systems through which oppression and resistance are enacted.

In examining both my own positionality as an outsider and a researcher, and the struggles, negotiations and coalitions of the Ardoch Algonquin First Nation and Allies, 
the above feminist conceptualizations of identity, power, and transversal politics become highly relevant.

Another body of literature that is only just emerging in political ecology, but is more established in critical theory and feminist thought is that surrounding the notion of "white privilege" and "whiteness" studies. White privilege is described by Ruth Frankenberg (1993) as a:

[...] position of structural advantage, associated with 'privileges' of the most basic kind, including, for example, higher wages, reduced chances of being impoverished, longer life, better access to health care, better treatment by the legal system, and so on. (Of course access is influenced by class, sexuality, gender, age, and in fact, 'privilege' is a misnomer here since this list addresses basic social rights) (54).

Peggy McIntosh (1988) describes white privilege as "an invisible package of unearned assets that I can count on cashing in each day, but about which I was 'meant' to remain oblivious. White privilege is like an invisible weightless knapsack of special provisions, maps, passports, codebooks, visas, clothes, tools, and blank checks" (1). Privilege is the other side of the coin of dispossession or marginalization, and is often less willingly acknowledged, however, is a critical tool as McIntosh argues that recognition of white privilege establishes accountability to lessen one's unearned privilege. This concept is highly relevant to this research in reference to critically examining my own positionality and privilege as a White researcher, as well as in contextualizing academia (historically a racially privileged/discriminatory site) and the production of knowledge (particularly with respect to historical accounts, or references to histories written by European explorers and/or White settlers).

Relating to white privilege are critical accounts of home, also generally developed 
by feminist theorists and also relevant to this study and to emergent critical political ecology more generally. Notions of family, community and home are recognized to be bound up with rhetoric and ideology that is antithetical to other feminist pursuits of equality, fairness and justice. Particularly, White, middle-class homes, representing safety, unity, boundedness and security, are founded upon exclusions and repressions (Weir, 2008: 5). Traditional (European) ideals of home are noted to be oppressive towards women generally, confining women within traditional conceptualizations of female identity (Young, 1997; Weir, 2008), and are arguably founded upon histories of exclusion, which have legitimated the systematic oppression of "others" (i.e., through segregation and policing). Martin and Mohanty (1986) write: “'Being home' refers to the place where one lives within familiar, safe, protected boundaries; 'not being home' is a matter of realizing that home was an illusion of coherence and safety based on the exclusion of specific histories of oppression and resistance, the repression of differences even within oneself" (196). Samah Sabra (2008) argues for the value of critical memory work in examining idealized reflections on home - a critical analysis of nostalgia, asking: what is longed for, what has been lost? Sabra (2008) writes:

We need to use critical memory work to remind ourselves that the current social conditions of most (oppressed) peoples - exiles in both the literal and the metaphorical sense - have been results of selective memory, which has been made possible by and used to construct/maintain particular power relations. If this is our starting point, then it may be possible to begin to integrate critical memory work into our attempts to rework these power relations in favour of more equitable ones. (Postcolonial and feminist scholars have been arguing this for some time now). Critical memory work may thus be used to empower or to give a sense of hope: specifically, when the historical events/conditions of one's current social location are made visible/audible, then one has a place from which to begin. In some sense, then, memory work may itself provide one with a discursive home, a site 
from which to begin to argue for social change and redress (98).

In this thesis, I will provide a critical examination of my home, in the sense of my home as a Canadian national, and my home in traditional Algonquin territory where I currently reside and study. Through this I aim to examine and expose the selective collective memory that sustains my (our) occupation of this land as a settler Canadian, while also providing a more inclusive account of the history of this land. I engage in this critical memory work as a means to work towards a more inclusive, accurate and fair account of home - one which honours the history and agreements that enabled my family to come here and contributed to my ability to live a life of incredible privilege, to the exclusion, displacement and subordination of others.

Critical feminism provides numerous bodies of literature that have informed political ecology since the 1990s, such as feminist conceptions of power and identity. Other streams of feminist theory provide the means for a more engaged political ecology and critical inquiry into discussions of production of knowledge, positionality and socialpolitical relations.

\subsubsection{Deconstructing Race and Identity: Decolonizing Academic Inquiry}

This research is firmly rooted within a postcolonial, anti-racist framework.

Postcolonialism is the term that encompasses ongoing academic engagement with decolonization. Tuhiwai Smith (2000) introduces postcolonialism speaking from the voice of a colonized people: "The collective memory of imperialism has been perpetuated through the ways in which knowledge about indigenous peoples was collected, classified 
and then represented in various ways back to the West, and then, back to those who have been colonized" (1). Barnett (2006) explains that colonization is understood as not only "economic [social and environmental] exploitation and political subordination" but as "the exercise of cultural power to denigrate the traditions of non-western cultures, and to celebrate the superiority of particular versions of western culture" (147). Thus, after colonization there remains the project of "decolonizing the mind" in which one must conscientiously engage with the psychologies, assumptions, patterns of thought and deeply embedded values of colonization in order to counter naturalized notions of normality and superiority (Barnett, 2006). Catherine Nash (2004) further explains: "postcolonialism explores the complex and effective relationships between issues of power, inequality and exploitation" (105). Many of the theoretical techniques discussed in the above sections are informed by postcolonial analyses and insights, and will inform the project of unmapping discussed in Section 2.1.

Central to this study will be a countering of commonly held understandings of the context of natural resource issues in the Kiji Sibi (Ottawa River) Valley through a process of unmapping, in which the history of Indigenous-settler relations will be discussed, including colonial violence and Indigenous responses. This research can therefore be situated in a postcolonial, or more appropriately, decolonizing ${ }^{18}$ framework as a result of: the explicit engagement with critical memory work and unmapping in exploring the context of the case study; the commitment to sharing and learning from the perspectives, insights and experiences of the members of the Ardoch Algonquin First Nation; and the

18 I prefer to use the term decolonizing as it connotes efforts to confront colonial legacies as an ongoing process rather than an already achieved end-state implied by the term postcolonial. 
process of research design and implementation (discussed in greater detail in Chapter 3). Thus, Indigenous history, knowledge and experience, and the history, knowledge and experience of the Ardoch Algonquin more specifically, will be woven throughout this thesis in an attempt to make visible the implications of a colonial history and a neocolonial present in resource conflicts.

\subsection{Theoretical Applications in this Research}

The above theoretical underpinnings thus inform the main approaches to research situated in political ecology. Consequently, the research will be approached with the objectives of deconstructing "development" and resistance, working across scales, exposing the linkages between capitalism and colonialism, and will examine the implications of nature as a social construction in the case study of manomin and the Ardoch Algonquin First Nation.

\subsubsection{Deconstructing "Development"}

Development is a term that is used by numerous actors in numerous fields, most often invoked in reference to an idea of linear progress towards a state of improvement and greater ability, such as in reference to physical, emotional and intellectual development; economic, technological and industrial development; or international development. In the context of this case study, the logic of technological, industrial and capitalist development was evoked to justify many of the projects that members of the Ardoch Algonquin had opposed, such as the issuing of a license to allow commercial harvesting 
of the wild rice on Mud Lake, the water extraction for the production of calcium carbonate by Omya, and the uranium exploration in Frontenac County. By deconstructing "development", I intend to undermine the naturalized logic of industrial, capitalist development to demonstrate the adverse, often unintended or unpredictable, destabilizing effects of development, and its implications in neo-colonial relations.

In the Power of Development, Jonathan Crush (1995) explains that the idea of development not only has much purchase and longevity, but also lacks consistency and clarity in development studies and in its application over time. It is important to note the various interpretations of development offered by some academics, as they are highly at odds with development understood in its more common usage. Esteva and Prakash (1998) argue that development is one of many colonial tools used to justify the control and domination of others: "Colonialism always implied a kind of moral and political violation, something imposed by the brute force of the physically strong, with different kinds of ideological emblems used to legitimate such violation. The Cross coming with the Sword took different shapes - like development or democracy in the postwar era" (125). Thus, they understand development as part of the ongoing project of colonialism which seeks to impose a particular, historically and culturally mediated social-political economic regime under the guise of universality, growth and progress. Cindi Katz (2004) describes development as the result of capital flows from place to place. She writes: 
Development - always uneven - is less a process imposed by one place on another than the uneven motion of capital finding, producing, and reproducing places and people in particular and differentiated relation to peculiar strategies of accumulation [...] Development is the iterative flux of capital moving across space in time, making and unmaking particular places; structuring and restructuring social relations of production and reproduction; and being met, engaged, and countered by social actors whose own histories and geographies enable and call forth broad and differentiated material social practices (xi)

Watts and Peet (1994), Crush (1995) and Escobar (1995) argue for the value of understanding development as discourse and exploring the discourse of development, defined as "the forms in which it makes its arguments and establishes its authority, the manner in which it constructs the world" (Crush, 1995: 3). Crush (1995) argues that central to projects of development is the construction of objects of development as primordial, static, and unchanging - in need of injection of expertise and technology in order to progress towards naturalized and linear notions of modernity based on the experience of many northern countries. Escobar (1995) explains that "development" has also been a tool to imagine or construct the underdevelopment of the "Third World" (and I would extend this argument to the "Fourth world"19 as well). Similarly, Crush (1995) argues: "Development is thus fundamentally about mapping and making, about the spatial reach of power and the control and management of other peoples, territories, environments, and places" (7). However, he also notes that development is not only formative, but reactive as well; it is responsive to the reactions and resistances of its subjects.

By documenting the ways in which access, production, jurisdiction and control of

19 Hornborg and Kurkiala (1998) define the Fourth World as "marginalized enclaves of indigenous peoples in the midst of affluent nations" (7). 
manomin have been affected by development, this thesis aims to illuminate the contradictions of the industrial development rationale. Gillian Hart (2004) cautions against understanding development through "the 'impact model' through which inexorable forces of capitalism bear down, albeit unevenly, on passive 'locals"' (91). Consequently, an examination of the responses to the consequences of development by the Ardoch Algonquin First Nation and Allies serves to complicate the discussion of development. By also documenting the responses to development, I hope to identify oppositional practices that serve to transform the adverse effects of development, in a similar approach to that used by Katz (2004):

In teasing out how "development" transformed the grounds on which these young people came of age, I hope to provide a textured analysis of the meaning of knowledge and the consequences of knowing in an economic, political-ecological, and cultural context in the throes of significant change. In tracing the effects of and responses to capitalist development over a generation, I found several creative strategies that people used to stay afloat and even reformulate the conditions and possibilities of their everyday lives $(\mathrm{x})$.

\subsubsection{Deconstructing Resistance}

As mentioned above, I situate the Ardoch Algonquin First Nation within counterhegemonic social (civil society) movements, given their extensive history of challenging encroachment and exploitation of local "natural resources" for capitalist expansion and accumulation, for production and economic development on traditional Algonquin territory (see Section 1.6). The nature of Ardoch Algonquin responses to various "development" issues is at the heart of this research, as is reflected in the research questions: "How has the Omàmiwinini of the Ardoch Algonquin's access to manomin 
been affected by 'development'?" and "How have the Omàmiwinini of the Ardoch Algonquin responded to the challenges and opportunities of 'development' with respect to wild rice harvesting and production?" Based upon the primary data collected through the research process as well as some secondary literature, I will analyze contestations of capitalist and industrial "development" through the use of Katz's (2004) framework of resilience, reworking, resistance and revanchism (to be explained, shortly), with adaptations from insights from Simon Brascoupé (2010).

In her longitudinal study examining children's lives in the face economic restructuring and development in both a Sudanese village and in New York City, Katz (2004) proposes a framework though which a more complex understanding of responses to global economic capitalism can be used, beyond the broad classification of resistance. She argues that:

[...] [a]ll over the world 'development' driven by global economic restructuring produces similar contradictions between resources available and possibilities engendered, leaving people scrambling to make themselves viable in the face of relentless, uneven development that is the hallmark of capitalism.

These circumstances call for and create a range of responses. Just as there are ties and similarities in the local forms and manifestations of global economic process in Harlem and Howa, so, too, are there in the nature, style, and effects of the responses at both sites (Katz, 2004: 240).

Consequently, Katz offers three "fluid and overlapping" categories: resilience, reworking and resistance, "each carried out at a range of scales and by a number of differently situated actors" (241). Katz also appends the category of revanchism to the three 'R's listed above. She explains: 
When almost anything can be constructed as an 'oppositional practice,' I find myself bored and unconvinced. In what ways do such practices respond effectively to the massive disruptions in productions of space, nature, and social life that pierce people's everyday lives in the course of capitalist development? When it comes down to it, feeling good, even when it is called something as fancy as 'reconstituting one's subjectivity in the face of power,' through all manner of discursive practices and independent readings is simply not enough to transform the social relations of oppression and exploitation that are the comerstone of so many people's daily lives. Autonomous, even 'counterhegemonic' agency is just the beginning. Yet it is so often presented as an end.

To make fruitful ends of such beginnings, I have tried to delineate between the admittedly overlapping material social practices that are loosely considered 'resistance' to distinguish those whose primary effect is autonomous initiative, recuperation, or resilience; those that are attempts to rework oppressive and unequal circumstances; and those are intended to resist, subvert, or disrupt these conditions of exploitation and oppression. The way I have laid out these overlapping responses is obviously toward stronger forms of oppositional practices, but they are interwoven and mutually sustaining. Acts of resilience and instances of reworking often provide the groundwork for stronger responses, but so too, can an organized oppositional movement, for instance, create the political space or opportunity for various autonomous initiatives - the restorative and strengthening acts of what I am calling resistance (Katz, 2004: 242, emphases in original text).

Katz situates the responses of resilience, reworking and resistance within the context of revanchism, borrowing the term from Neil Smith's (1996) account of the "material social practices of meanness and revenge" (Katz, 2004: 243) in response to a class-based, gendered, sexualized, racialized and national terror faced by those in power who are confronted with an "Other" outside of control. Katz notes that revanchism policies are enacted both in the north and the global south through the demonization, policing and oppression of the poor. Importantly, revanchism exists in dialectical opposition to those who contest such practices through the realignment of privilege and redistribution of wealth, thus shaping and responding to practices of resilience, reworking and resistance. 
This framework is adaptable to an understanding of Indigenous history and forms of opposition, according to Simon Brascoupé (2010). Brascoupé (2010) suggests that it is appropriate to understand Indigenous history through three distinct phases: Pre-contact; Contact; and Decolonization. He also suggests that these same phases can be mapped on to Katz's concepts of resilience, reworking and resistance, respectively, thus expanding the framework beyond an analysis of capitalist and economic flows. As Katz (2004) notes however, the oppositional responses are overlapping and mutually reinforcing. Katz's concepts are described and the relationship with Brascoupé's (2010) conceptualization of Indigenous history and oppositional practices is elaborated in further detail below .

Resilience is characterized by Katz (2004) as practices and acts that sustain people in the face of predatory revanchist policies and that (re)make social identities and collectivities. In her case study of Howa, Sudan, she posits that practices that sought "new forms and sources of knowledge, as well as [conserved] and [found] new grounds for the expression of existing skills and knowledge" exhibited resilience (Katz, 2004: 249). For Brascoupé (2010) resilience is connected with pre-contact history through the continual practice of traditions that preceded European settlement and colonization, in a contemporary context.

Reworking is characterized by projects that attempt to redistribute access and control of resources and (re)constitute people as "political subjects and social actors" (Katz, 2004: 247). Brascoupé (2010) associates Katz's idea of reworking with the contact period, during which Indigenous peoples negotiated with European settlers as 
sovereign Nations - the lack of European recognition of Indigenous sovereignty from the mid-1800s onward (discussed in Chapter 4), and the encroachment upon Indigenous territory by settlers have required substantial negotiations, assertion of Indigenous subjectivity and legitimacy and instances of reworking by Indigenous actors. In her case studies, Katz (2004) found that instances of reworking were characterized by projects that were not counter-hegemonic per se, but that demonstrated a recognition of what was privileged by hegemonic social forces.

Resistance is associated with an oppositional, critical consciousness and actions that directly assert a counter-hegemonic stance against the subordinating tendencies of economic restructuring and capitalist development. Katz (2004) distinguishes "tactics" of resistance as isolated oppositional acts rather than acts that serve to build a larger subversive consciousness. Brascoupé (2010) asserts that decolonization can be associated with Katz's notion of resistance. However, Katz's conceptualization of resistance is in strict political economic terms, and therefore cannot be perfectly mapped onto the concept of decolonization, which must also take cultural, racial, gendered and other hierarchies or hegemonies into account. Therefore in this study resistance will be framed in a political economic framework and in a broader sense, through a lens of decolonization. It is problematic to map decolonization onto Katz's (2004) framework, as her framework distinguishes between oppositional practices that may all be understood as decolonizing by different actors. For example, traditional practices (that have been exercised prior to European contact) might be understood as decolonizing due to the importance of (re)learning and (re)asserting Indigenous knowledges and practices that 
may be very different from Euro-Canadian knowledges and practices. Brascoupé (2010) does also associate decolonization with revitalization and reclaiming, in addition to resistance. This conceptualization therefore opens up Katz's framework, to potentially be more responsive to Indigenous perspectives on oppositional practices.

The logic for elaborating the above categorizations of oppositional practices, Katz (2004) argues, is to better inform praxis - the doing of contestation, negotiation, subversion, resistance, and ultimately, transformation. Thus, I hope that my application of Katz's theory of resistance, including adaptations by Brascoupé, to the responses to development by the Ardoch Algonquin First Nation with respect to manomin will permit a greater and more nuanced understanding of oppositional responses to capitalist and industrial development in the context of traditional Indigenous foods and allow for a more critical understanding of responsibility and solidarity for settlers sharing the land and its many gifts.

Both Braun (2002) and Jennifer Barron's (2000) discussions about oppositional practices, Indigenous solidarity and environmental movements, and politics of representation offer important insights into the connections between identity construction and representation, resistance and power. Both authors note that reliance on discourses of resistance that assert the existence of "pure" or "authentic" spaces or voices outside of the reaches of colonialism rely on problematic representations of Indigenous identity and ultimately detract from discussions of Indigenous sovereignty. Thus, Barron (2000) argues that in oppositional movements, the way that communities and coalitions are discursively mediated (whether as essential, natural and fixed, or as contingent, particular 
and negotiated) influences the effectiveness of opposition and solidarity. This will be taken into consideration in analyzing oppositional stances taken by members of the Ardoch Algonquin, but also through attentiveness to the way in which I represent the oppositional practices of the community.

\subsubsection{Working Across Scales}

This case study will also be explicitly examined through a multi-scalar analysis, taking into account the networks of interaction that influence "development" initiatives that affect access to manomin by the Ardoch Algonquin. A central feature of political ecology, postcolonialism and critical feminism is working across scales, or understanding local processes as embedded in a globalized context, and understanding globalization as shaped by actors and social movements rooted in a localized context (Collins, 2002;

Mohanty 2002; Nagar, Lawson, McDowell and Hanson, 2002; Nash, 2004; Watts and Peet, 2004; Paulson et al., 2005; Robbins, 2005). In other words, histories, discourses and power exist in multiple and overlapping networks that extend across multiple scales from domestic, to regional, national, and transnational spheres - and are enacted in various arenas, including the household, the community, the state, and transnational spaces and organizations. Inherent in this idea is the notion that globalized forces, such as global capitalism and neoliberalization, are not monolithic and uniformly imposed from above, rather they are negotiated, contested and hybridized by engaged and innovative actors in a socially-, geographically-, and historically-contingent process. It is this very nature that locates the "political" in political ecology, that is extending analyses 
of social, political and economic influences beyond the sites of ecological study (Paulson, Gezon and Watt, 2003). Gezon and Paulson (2005) explain that global embeddedness in local processes necessarily requires an extension of focus, not only spatially, but also temporally, thus analyses need to account for historical and contemporary connections as well.

Robbins (2005) presents a criticism of political ecology - the tendency to rely on misleading "chains of explanation", or causal hierarchy, to analyze extra-local interactions with local phenomena:

By always following explanation 'upwards' from produced environments, through producers, and on to increasing scales of interaction (typically the community, the state and the global economy), a conceptual hierarchy of power and causal force is imposed on political ecological problems that is empirically unfounded, and perhaps politically undesirable (210).

According to Robbins (2005), there are various producers of nature, beyond those who interact with the environment directly, including non-human actors; thus, he presents conceptualizations of networks as more useful for explaining multi-scalar, and multiple actor interactions:

Networks organize and are organized by a range of human and non-human actors, through systems of accumulation, extraction, investment, growth, reproduction, exchange, cooperation, and coercion. While diverse, each network is by no means unique. Common patterns of exploitation and environmental change reflect common network morphologies and common processes. By explicating networks, therefore, we come to a better understanding of recurrent socio-natural situations, especially undesirable ones. Rather than manipulating or waiting for changes in global political economy to trickle down to a chain, a network allows a range of places for progressive political action and normative change (212).

Through an historical analysis, critical ethnography and other primary and secondary research methods, this study will seek to make visible the various networks of interaction 
that influence the political ecology of manomin in the Kiji Sibi Valley. Chapter 4 of this study outlines the historical networks of actors that situate the current context of manomin and the Ardoch Algonquin First Nation, Chapters 5 and 6 examine manomin in the current context of the Ardoch Algonquin community and the consequences of development. It is my hope that my separation of analyses into distinct chapters does not collapse the overall analysis into one of causal hierarchy and chains of explanation. Rather, I hope to demonstrate the workings of various actors in this elaborate network in order to better understand the context of manomin in this case study, and identify "places for progressive political action and normative change" (Robbins, 2005: 212).

\subsubsection{Exposing Linkages Between the Workings of Capitalism and Colonial}

\section{Relations}

The situation of this research in its examination of responses to "development" in the context of an Indigenous community (AAFNA) requires explicit engagement with the workings of capitalism and its complicity in perpetuating colonial relations. In this thesis, capitalism and colonialism (including the appropriation, despoliation and exploitation of land, knowledge, technologies and creations of Indigenous peoples) will be shown to be mutually constitutive. Political economic writings that explore the origins of capitalism reveal that the conditions in which a small elite was able to acquire capital, the means of production and the means to exploit the labour power of the majority are rooted in the violent dispossession and enclosure of common lands - known as primitive accumulation. David Harvey (2003) describes Marx's basic explanation of primitive 
accumulation as that which "entailed taking land...enclosing it, and expelling a resident population to create a landless proletariat, and then releasing the land into the privatized mainstream of capital accumulation" (149). Marx (1990 [1867]) himself recognized in Capital, Volume I the interdependence of colonialism and capitalist exploitation, noting that primitive accumulation required the exercise of brute force that was supported by the State and society.

Capitalism and colonialism have deep connections and have always been mutually-constitutive, for it was capitalist aspirations and activities that legitimized colonialism from the outset, and it was colonialism which permitted economic expansionism in North America and elsewhere (through the exploitation of the natural riches tied to the land and water such as the fisheries, the forests and the furs). Harvey (2003) explains how expansionary capitalist logic arose in conjunction with nationalism following a wave of nation-state formation that occurred during the latter half of the nineteenth century in Europe as a result of over accumulation (involving both labour and capital surpluses) in Europe. Consequently,

... a variety of nation-based and therefore non-bourgeois imperialisms evolved (British, French, Dutch, German, Italian). Industrially driven but non-bourgeois imperialisms also arose in Japan and Russia. They all espoused their own particular doctrines of racial superiority, given pseudoscientific credibility by social Darwinism, and more often than not came to view themselves as organic entities locked in a struggle for survival with other nation-states. Racism, which has long lurked in the wings, now moved to the forefront of political thinking. This conveniently legitimized the turn to [...] 'accumulation by dispossession' (of barbarians, savages and inferior peoples who had failed to mix their labour properly with the land) and the extraction of tribute from the colonies in some of the most oppressive and violently exploitative forms of imperialism ever invented (Harvey, 2003: 45). 
It is noteworthy that it was during this same time period when settler expansion in the Ottawa Valley became significant and resulted in ecological destruction (through logging and forest fires) and the retreat of Algonquin families and communities to more remote areas of the Kiji Sibi watershed (discussed in more detail in Chapter 4).

Harvey notes that Marx neglected to account for the ongoing and persistently predatory nature of capitalism, and thus offers the concept of 'accumulation by dispossession' to emphasize the continuity of 'primitive' or 'original accumulation', as Marx had conceptualized it. In the New Imperialism, Harvey (2003) explains that:

A closer look at Marx's description of primitive accumulation reveals a wide range of processes. These include the commodification and privatization of land and the forceful expulsion of peasant populations; the conversion of various forms of property rights (common, collective, state, etc.) into exclusive private property rights; the suppression of rights to the commons; the commodification of labour power and the suppression of alternative (indigenous) forms of production and consumption; colonial, neo-colonial, and imperial processes of appropriation of assets (including natural resources); the monetization of exchange and taxation, particularly of land; the slave trade; and usury, the national debt, and ultimately the credit system as radical means of primitive accumulation. The state, with its monopoly of violence and definitions of legality, plays a crucial role in both backing and promoting these processes and $[\ldots]$ there is considerable evidence that the transition to capitalist development was and continues to be vitally contingent upon the stance of the state.

All the features of primitive accumulation that Marx mentions have remained powerfully present within capitalism's historical geography up until now. Displacement of peasant populations and the formation of a landless proletariat has accelerated in countries such as Mexico and India in the last three decades, many formerly common resources, such as water, have been privatized (often at World Bank insistence) and brought within the capitalist logic of accumulation, alternative (indigenous and even, in the case of the United States, petty commodity) forms of production and consumption have been suppressed. Nationalized industries have been privatized. Family farming has been taken over by agribusiness. And slavery has not disappeared (particularly in the sex trade) (145-146).

Harvey (2003) therefore notes that effective proletariat struggle must move beyond a 
class struggle (arising out of "expanded reproduction") to one that also includes an understanding of accumulation by dispossession and the continuing expansionism and exploitation that it entails. By examining the connections of contemporary capitalism to colonial relations, current crises relating to food and the enclosure of other vital resources (commons) by private interests can be understood as a continuation of the logic and tactics through which Turtle Island was colonized and Canada was founded.

\subsubsection{Understanding Nature as Socially Constructed}

The maintenance of a capitalist, colonial order in Canada has been found to be contingent upon the ability to convincingly assert European, and later, Canadian jurisdiction over lands and "resources" used and managed by Indigenous peoples for millennia, prior to the arrival of settlers (Gregory, 2001; Braun, 2002; Baviskar, 2008). As mentioned above, political ecology has come to engage in post-structural analyses linking discourse, power, knowledge production, and the ability to shape resource access, use and control. A central focus of political ecology today extends from poststructural insights which emphasize the socially constructed or produced nature of the environment. It is posited that material nature is produced through discourses (narratives and ideas) enacted by various actors working within a landscape of power. Thus nature (the physical environment) itself is understood to be contingent upon power dynamics that influence which interpretations of nature are dominant.

In this study, I will deconstruct ideas of nature, property and resources in order to theorize these physical entities and ideas in a political ecological context. Therefore, this 
research will draw on aspects of social nature theory, in which nature is understood as an inherently social construction (Castree, 2001: 5). Within social nature theory, nature is understood not as something outside of or external to humanity and culture, but rather it is understood as hybridized, integrated into social processes, or as Bruce Braun (2002) argues, it is socially produced. Noel Castree (2001) illustrates that the physical constitutions of nature are socially contingent upon discourses and conceptualizations of nature. Castree (2001) notes: "all claims about nature are discursively mediated. Knowledge and language are tools we use to make sense of a natural world that is both different from us and yet which we are a part of" (12, emphasis in text).

Throughout The Intemperate Rainforest, Braun (2002) similarly demonstrates how constructions of nature are closely linked with social relationships of power and domination. More specifically, he uncovers how the externalization of nature serves to erase the presence and sovereignty of First Nations in Clayoquot Sound, British Columbia. Braun (2002) argues that the implications of understanding nature as socially produced requires a shift in how ecological problems are approached, wherein "natural environments" are not simply given, but are embedded in histories of production which have generated environments that are found (created, seen, constructed) today. Braun and Castree (2001a) and other contributors to Social Nature: Theory, Practice and Politics demonstrate that such a conceptualization allows for other understandings of nature to be articulated which can nurture alternative ecological relationships to those of the status quo of modern industrial society. Braun and Castree (2001b) pose the following question: 
[...] what counterhegemonic definitions are currently available to us (in geography and beyond) and what kind of a world - socially, economically, politically, and culturally - do they allow us to envisage? This question is saturated with political promise as [...] 'de-naturalizing nature' allows us to glimpse not just a different ecological future but a future where class, gender, 'race' and interplace relations might be configured along more just and equitable lines (xiii)

The ability to assert alternative constructions of nature (such as those embodied in the worldviews of Indigenous peoples), as well as efforts to challenge modem industrial assumptions, are inherently linked to opposition and resistance to ongoing colonialism and the corresponding processes of decolonization. Henderson (2000b) argues that a key element of decolonization, or human empowerment, can only come from engaging with, and deconstructing, the assumptions of the modernist worldview that have justified the use of terror, violence and subjugation to institute rule and law. He further argues that the modernist worldview stems from an artificial construction of nature that is contingent on certain values and their related discourses, as was set out in Hobbes' 'state of nature' theory:

Hobbes' vision of the state of nature remains the prime assumption of modernism, a cognitive vantage point from which European colonists can carry out experiments in cognitive modeling and engineering that inform and justify modern European scholarship and systematic colonization. Indigenous people have experienced this concept as slavery, colonization, and imperialism, as well as liberalism, socialism, and communism. These derivatives of Hobbes' vision are the source of our difference, our suffering, and our pain, and it is our experience of them that unites us against continued domination and oppression (Henderson, 2000b: 11).

Given the above analysis, Henderson argues that processes of decolonization and human empowerment lie mainly in revealing the assumptions of modernism and the state of nature. He further asserts alternative conceptions of nature rooted in Indigenous 
teachings offer possibilities for envisioning alternative relations:

We are seeking to challenge and transform the modernist vision of the state of nature and to replace it with an extraordinary context-breaking vision that relies on Indigenous teachings about our place in nature. All major aspects of human empowerment or self-assertion depend on our success at diminishing the distance between context-preserving routines (law) and context-transforming conflict. Human empowerment relies on people's ability to invent institutions and practices that manifest contextrevising freedoms. From an understanding of artificial contexts, Indigenous people can understand how to inspire alternative contexts to end the domination and oppression that are the residue of colonialism. A constructive understanding of contexts also gives us greater mastery in reconstructing a more equitable society and more equitable human relationships (Henderson, 2000b: 14).

Braun (2002) also argues that the implications of understanding nature as socially produced requires a shift in how ecological problems are approached, wherein "natural environments" are not simply given, but are embedded in histories of production which have generated contemporary environments.

This research seeks to leam from alternative constructions of ecological, social, political and economic relationships that are more harmonious, rather than more destructive, exploitative and dominating relationships. Such alternative conceptualizations will be explored through the study of manomin as a traditional food, its role in food sovereignty for the Ardoch Algonquin First Nation and its links to decolonization. The struggles through which local and/or traditional knowledge(s) are legitimated over competing claims will be studied in order to engage with the politics relating knowledge, power and resource access and control, and the production of "nature". As Braun (2002) explains, social nature: 
[... ] brings society and ecology together into a single analytic field, allows us to critically examine and evaluate the many ways that nature is socially produced and draws attention to the ways in which nature's production including its preservation - is always entangled with much more than nature, including questions of class, race, gender, and sexuality (14).

This research is therefore approached using the conceptual framework outlined above, which provides a nuanced understanding of the workings of power, domination, subordination, contestation, resistance and negotiation in the case of manomin and the Ardoch Algonquin First Nation and Allies. 


\section{Chapter 3 - Methodological Approach}

Chapter 3 outlines the methodologies used to inform the design, data collection, analysis and dissemination of this research. While Chapter 2 outlined the conceptual and theoretical framework to broadly situate this thesis, Chapter 3 will explain the frameworks that influence how the research practice is carried out (the methodologies) and the particular research methods used that reflect the methodological insights and concerns. Research methodology:

[...] entails the broader reflections and debates concerning the overall 'principles of reasoning' which specify both how questions are to be posed (linking into the concepts of the discipline) and answers are to be determined (pertaining to how specific methods can be mobilized to provide findings which can meaningfully relate back to prior concepts) (Cloke, Cooke, Crang, Goodwin, Painter, Philo, 2004: 5).

Research methods are the techniques used to collect data. Both methodologies and methods were thoroughly contemplated such that this study could be carried out responsibly and respectfully. Section 3.1 introduces the methodologies underpinning the research practices of this study. Section 3.2 outlines the specific research methods used to design the research, and collect and analyze the data. And finally, Section 3.3 explains the limitations of this research.

\subsection{Methodologies guiding this study}

Given the breadth of the conceptual framework underpinning the analysis of this study, the research practice is also rooted in diverse methodological frameworks including: Indigenist and decolonizing, post-colonial, critical feminist, critical post-structural and critical ethnographic methodologies. 


\subsubsection{Taking Account of Indigenous Intellectual Traditions: Indigenist and}

\section{Decolonizing Methodologies}

Though not an Indigenous person myself I will attempt to the best of my abilities to engage in Indigenist research methods (Simpson, 2004). Simpson (2004) elaborates upon Churchill's (1996) concept of an "Indigenist outlook" as:

[...] one that not only takes the rights of Indigenous Peoples as the highest priority but that also draws upon the tradition and intellect of Indigenous Peoples to advance critiques to the present social, political, economic, and philosophical status quo. 'Indigenist' in this context is not synonymous with 'Indigenous'. Indigenous scholars may not work from an Indigenist or decolonizing theoretical framework; similarly using this definition, it is possible for a non-Indigenous scholar to work from within an Indigenist framework (382).

Thus, a critical adoption of post-colonial methodologies involves engaging with alternative worldviews and modes of communication that de-centre Western ways of knowing and being. Marie Battiste (2000a) argues that the public education system in Canada - including elementary, secondary and post-secondary - is a form of cognitive imperialism which devalues and delegitimizes knowledge(s) and values that are different from that of the dominant culture and presents the other cultural knowledge(s) as inferior. Battiste (2000a) explains:

Validated through one's knowledge base and empowered through public education, [cognitive imperialism] has been the means by which whole groups of people have been denied existence and have had their wealth confiscated. Cognitive imperialism denies people their language and cultural integrity by maintaining the legitimacy of only one language, one culture, and one frame of reference (198).

Thus, I understand the educational system itself to be very much implicated in processes of colonization and domination. Consequently, I would like to situate my research within 
the realm of cooperative and collaborative research practices in which I will attempt to carry out and disseminate my research in a way that is sensitive to the ways of knowing and communicating particular to community norms of the Ardoch Algonquin First Nation and Allies.

These practices are centered in theories of decolonized research methods, some elements of which are outlined by Tuhiwai Smith (2000):

Indigenous methodologies tend to approach cultural protocols, values and behaviours as an integral part of methodology. They are 'factors' to be built into research explicitly, to be thought about reflexively, to be declared openly as part of the research design, to be discussed as part of the final results of a study and to be disseminated back to the people in culturally appropriate ways and in a language that can be understood (15).

My research, therefore draws on the insights of numerous Indigenous scholars (Battiste 2000b; Tuhiwai Smith, 2000; Simpson, 2004; Sherman, 2007) and takes into account appropriate and culturally-sensitive protocols throughout the entire research process (discussed in further detail in Section 3.2).

Most of the literature I have encountered thus far regarding decolonization processes in the context of academia is written by Indigenous people for Indigenous people, in order to engage in research itself as a process of decolonization for individuals, communities and/or nations (Battiste, 2000b; Tuhiwai Smith, 2000). I employ some of the methodological considerations offered in this literature throughout my engagement in research with the Ardoch Algonquin First Nation and Allies; however, I also draw on literature centered on cooperative relationships and relationships of solidarity amongst Indigenous peoples and non-Indigenous researchers (Barron, 2000; Simpson, 2004; Sherman, 2007; Bell, 2008; Davis, 2010), as I do believe that such research can be 
mutually beneficial and critical to a broad decolonization agenda. Therefore, my research will also explore concepts surrounding decolonization processes and responsibilities for non-Indigenous (settler) North Americans as an integral part of the research process.

Leanne Simpson (2004) provides insight as to how such aims can be approached. She writes:

Academics who are to be true allies to Indigenous Peoples in the protection of our knowledge must be willing to step outside of their privileged positions and challenge research that conforms to the guidelines outlined by the colonial power structure and root their work in the politics of decolonization and anticolonialism (Simpson, 2004: 381 ).

As outlined in the previous chapter, academic norms do not often conform to Indigenous ways of communicating, thinking, knowing or being, and often delegitimate Indigenous history and epistemology. Therefore engaging in research that is respectful and responsive to Indigenous community norms and protocols, often places academic researchers in a position that requires active negotiation with the norms and standards of the university (see Mihesuah, and Wilson, 2004).

Bonita Lawrence and Enakshi Dua (2005) argue that the project of decolonization must be central for all anti-racist and anti-oppression projects. They explain that in order to truly decolonize projects towards anti-racism, inclusion of an analysis of colonialism, or of Aboriginal voices, is not enough. Rather, they posit that an analysis of colonialism must be foundational to all anti-racism and postcolonial projects. They write: "The failure of Canadian antiracism to make colonization foundational has meant that Aboriginal peoples' histories, resistance, and current realities have been segregated from 
antiracism", thus limiting antiracism analyses by failing to take account that all settlers, including settlers of European decent, newcomers and people of colour, are complicit in the ongoing oppression of Indigenous peoples (Lawrence and Dua, 2005: 132). Lawrence and Dua (2005) offer suggestions for further exploration, including that: "Within academia, antiracist theorists need to begin to make ongoing colonization central to the construction of knowledge about race and racism. They must learn how to write, research, and teach in ways that account for Indigenous realities as foundational" (137). This research is therefore designed as a response to the above arguments, such that Indigenist methodologies are integrated throughout: from research design, to research methods, analysis and dissemination.

In order to sincerely engage in processes of decolonization, both non-Indigenous and Indigenous Canadians must engage in, acknowledge and learn from Indigenous ways of knowing, and alternative accounts of both history and contemporary political ecological struggles. As Paula Sherman (2007) explains, this is the responsibility of both Indigenous peoples and settlers, as a part of honouring the agreements through which European settlers were welcomed in the valley of the Kiji Sibi (discussed in detail in Chapter 4). Sherman (2007) argues for a commitment, by Indigenous peoples and settlers alike, to decolonization by producing "scholarship that articulates the autonomy and jurisdiction of Indigenous peoples" (157). Sherman (2007) explains that false historical accounts have been a central means of legitimizing the colonization and ongoing occupation of Turtle Island (North America) and Omàmiwinini (Algonquin) territory in particular. She explains that "If we are to facilitate change in the attitude and 
behaviour of governments and corporations toward Indigenous peoples, then they must be socialized to the histories in which Indigenous peoples exist as human beings with agency" (Sherman, 2007: 328). I agree with Sherman (2007) that this must be a project of both Indigenous peoples and non-Indigenous peoples as part of a mutually liberatory and decolonizing process.

Given my position of relative privilege - as an academic of European descent researching with an Indigenous community, across (arguable) landscapes of difference there remains an opportunity for numerous problems to arise in terms of cultural 'othering' and essentializing. As introduced in the previous chapter, in her discussion surrounding "the politics of solidarity", Barron (2000) provides a framework through which partnerships between different groups can be forged, sustained and represented responsibly. I recognize my position within the politics of solidarity is, at least partially, as a non-Indigenous person concerned both with issues of Indigenous sovereignty and ecological integrity. Furthermore, I acknowledge that my research question itself can set up the very "Native-Earth equivalence" van Wyck (as cited in Barron, 2000: 93) and Braun (2002) criticize, where Indigenous people are represented to have an inherent and natural affinity and relationship with "pristine nature" that ultimately limits various Indigenous peoples as a result of perceived notions on "Native authenticity", or culturalist and essentialist discourses (Barron, 2000: 93). As a result, my research rests in a critical position bordering on potentially perpetuating colonial practices of representing Indigenous peoples according to my own needs or ideals.

Representation is inherently mis-representational as it is always an abstraction 
from reality, but representation is also unavoidable (Barron, 2000: 94). Barron demonstrates how representation of Innu struggles for land claims by environmentalist allies limited the political possibilities of the Innu by appealing to selective characteristics and symbols, which were inconsistent with the diverse identities within the community, making particular goals that community members wanted to pursue illegitimate. Consequently, Barron advances the politics of articulation in opposition to the politics of representation (discussed briefly in Section 2.2.3). Articulation is an active process by which the goals of allies are constantly negotiated, as Barron (2000) asserts: "neither the identities of political actors nor the meanings of any given struggle exist $a$ priori; rather they are constituted discursively through the political process - i.e., the definition of interests and the elaboration of strategies" (102). Through articulation, the contingency of alliances, identities, and support are recognized and the ability to change affinities or politics becomes less problematic. According to Barron, articulation allows for: multiple subject positions and contradictions or heterogeneity within groups; processes of active decision-making, negotiation and choice amongst interest groups; and active engagement within one's own spheres of interaction and influence.

My research is situated within a particular case study in which the political ecological situation of manomin is examined; this very process represents an articulatory negotiation, as discussed by Barron (2000). My own choices to study this case have been stated explicitly. As I have outlined in Chapter 2, I situate myself within the body of political ecology theory because my analysis of social justice is inevitably linked to an analysis of resource use, access and control. My support for the political aims of the 
Ardoch Algonquin First Nation in the case of manomin, and in numerous other endeavours pursued by the community, is based not on a natural affinity based on their Indigeneity and my environmental background. Rather, my support is based on an initial understanding of AAFNA politics and struggles; as I have learned more about the political orientations and activities of members of AAFNA, my desire to support these struggles has deepened and evolved. Similarly, as I understand it (based on negotiations in the preliminary stages of research discussed in Section 3.2), the relationship of AAFNA members with me, as a researcher, is highly contingent upon my political orientation, which also is not static, thus reflecting the contingent nature of the research relationship. Brascoupé (2012) describes this negotiated relationship as a healing journey.

\subsubsection{Examining the Production of Knowledge: Postcolonial Methodologies}

Aside from situating this research in Indigenist and decolonizing research methodologies, this research can also be situated within postcolonial methodologies. Postcolonial methodologies share numerous approaches and techniques with decolonizing and Indigenist methodologies; the differences between the approaches are nuanced but important.

Like decolonizing methodologies, postcolonial methodologies are particularly attentive to how traditional and contemporary research practices reproduce colonial relations. Robbins (2005) explains that the term postcolonial can be taken to mean "the theorization of a historical period 'after' formal colonization and the geographic spaces 
experiencing and negotiating decolonization, with their persistent experience of unequal power relations", or "a methodology to interrogate the colonial logics and practices of Euro-American cultural/scientific hegemony, both historically and contemporarily" (314). Postcolonialism is not in this research, used to indicate the period after formal colonization, rather it is used to refer "to a complex process of disengagement from the colonial power that often preceded and continues long after independence" (Nash, 2004: 114). I make this distinction because some scholars do not believe we are in a postcolonial period because colonial laws and policies still exist (Churchill 1996; Esteva and Prakash, 1998; Tuhiwai Smith, 2000; Razack 2002; Nash 2004; Lawrence and Dua 2005; Robbins, 2005; Thobani 2007; Gehl 2010). Postcolonial literature is more wellestablished than Indigenist or decolonizing literature, and therefore postcolonial methodologies have been more widely adopted by Indigenous and non-Indigenous people alike.

In addition to being a study situated in postcolonial theory (as discussed in Section 2.2 .5 ), this research will be inherently postcolonial by virtue of the research process itself, which aims to employ critical research methods attentive to the politics of knowledge production. Kobayashi (1994) speaks to this point:

This is not to say that we can 'move unheralded into just any field situation and become an effective part of its struggle for change just because we believe in its political ends'... There needs to be critical and reflexive questioning of what the research/researcher hopes to accomplish, why a particular area was chosen, and for whom we are working. There also needs to be a recognition that some historical and material realities are beyond our personal and social reach. Such reflexive analysis requires that we link larger-scale political objectives to smaller-scale methodological strategies which break down hierarchical objectivistic ways of knowing in the field (quoted in Nast 1994: 58). 
Radical, anti-oppressive, progressive research methods are fundamental to practicing politics effectively and holistically. Interrogating the ways in which research questions are framed, language is used, and subjects and participants are chosen, is of monumental importance as each choice carries political implications and is embedded in historicallyconstructed social norms (Hoggart, Lees and Davies, 2002; Hart, 2004; Nash, 2004;Cameron and Gibson 2005). The communication and dissemination of research findings is equally political and can be a process of reinforcing privileged access to information or alternately, it can be a process that serves to democratize knowledge(s) (Kindon, 2005).

The adoption of postcolonial methodologies does not negate the problems of research. Robbins' (2005) chapter entitled "Research is Theft: Environmental Inquiry in a Postcolonial World" examines the conundrum faced by researchers using postcolonial analyses, namely, that all research is colonial in nature due to the very simple argument that "recording, interpreting, and analyzing the world is a way to appropriate and control it", regardless of whether research is approached with explicitly normative agenda or not (Robbins, 2005: 311). Robbins posits that research is theft, by appropriating both local voices, through representational and interpretative acts by researchers, and local resources, by the establishment of élite researchers as experts who are able to determine the most appropriate use of resources. Thus, the question inevitably arises: Why then, continue with the research tradition? Robbins examines how to contend with the inherent postcolonial contradiction of research, by examining the logic of 'staying at home', which he argues is neither completely anti-colonial (as 'home' is imbued with political 
histories and interactions), nor is it useful since multinational firms, international environmental organizations, foreign armed forces, transnational organizations and the migrant labour force will not stay at home. Accordingly, Robbins supports a postcolonial approach to research that is self-aware of the inherent contradictions and problems of engaging in postcolonial, normative research, through "a serious attention to methodology", examining how research is done. Thus, while exploring empirical environmental questions, such as that of this thesis (How has manomin been affected by development and how have members of the Ardoch Algonquin First Nation responded?), Robbins advocates for a critical assessment examining the power of science and the production of truth and knowledge. Robbins (2006) concludes:

A necessary step for any such project is the establishment of politically viable alliance - those that might impact pernicious policy and practice with other participants in the struggle over nature, whether these are farmers, herders, or foresters. By sharing results, by allowing research questions to be modified and diverted in consultation, and by arguing over the application of research to policy advocacy, the act of research becomes more complex, though really no more or less political. Admitting that the interests of these players, including the geographer, the forest range officer, and the raika pastoralist, do not and cannot entirely coincide, such alliances are necessarily fluid, temporary and strategic. Even so, productive research to help reinvent the world will require robust and extensive research conducted in just such complex political networks - mutual exploitation, mutually agreed upon. Anything else is theft (322).

While this research does draw on post-colonial theoretical and methodological insights, as mentioned above it draws more heavily on decolonizing and Indigenist methodological implications in order to further centre the commitment to Indigenous self-determination and be explicit about the decolonizing agenda as an ongoing process both as a simultaneously personal and political project. 


\subsubsection{Researching through Reflexivity, Relationships and Attention to Particularity: Critical Feminist Methodologies}

I also intend to situate myself and my research using feminist methodologies, in order to make my positionality as a researcher as transparent as possible, and to undertake research that is attentive to particularity, locality and place by examining traditional Indigenous foods and development through the case study of manomin and the Ardoch Algonquin First Nation and Allies. Many feminist theorists advocate for approaching research through a process of "transparent reflexivity" wherein a researcher must explicitly ground his or her position in a landscape of power and social relations (see Nast, 1994; Rose, 1997; Moeckli and Braun, 2001; Nagar et al., 2002). It is theorized that by doing this the researcher can then know and state their positionality, defined as "a researcher's social, locational, and ideological placement relative to the research project and to other participants in it" (Hay, 2005: 290). By doing this, it is argued, researchers can confront 'the god trick', where researchers (traditionally white and male) claim to operate from a position of truth, clarity and objectivity, while simultaneously producing value-laden analyses and studies that serve to delegitimize other ways of knowing and understanding.

Gillian Rose (1997) argues that feminist methodologies must extend beyond reflexivity and positionality to situate the research in a more productive manner. She critiques the feminist idea of situating research and knowledge through the project of "transparent reflexivity" by illuminating that one's positionality is necessarily mired in social complexity and dynamism. Rose argues that such an approach can be problematic 
in that it enacts the "goddess trick", claiming to know the impossible - that is "a transparently knowable self separate from its transparently knowable context" (314) and thus mirroring the 'god trick' so highly criticized by feminist researchers. Rose argues that research highly focused on positionality creates distance between the researcher and the researched through a landscape of power and an emphasis on difference. Reflexivity must therefore engage in a process of negotiation that bridges relations of difference, that understands research as a process of identity construction both for the researcher and the research participant. Rose (1997) reminds her audience of the "political aim of situating academic knowledge[...]: to produce nongeneralizing knowledges that can learn from other kinds of knowledges" (318). Consequently, research is understood as performative, constitutive and transformative, with unknowable outcomes in terms of the identities and subjectivities of the researcher and the research participants, and thus must be understood as a relational project, in that "what we research is our relation with the researched" (Rose, 1997: 315).

While this research responds to Rose's argument that researcher reflexivity should not be myopically focused on the landscape of power and difference that exists between researcher and research participant, I do maintain that an attempt at reflexivity - to make transparent at least some of the researchers' theoretical, political and normative position is useful and important. In making explicit a limited account of the researchers' situatedness and positionality, the contingency of the production of knowledge is highlighted and, as is true (though not readily evident) for all and any research, it becomes more evident that it is a partial and limited account - an interpretation. Thus the 
conceptual framework outlined in Chapter 2 and the methodology outlined here serve to underline the contingent nature of this research, which is limited (at least in part) by the questions I have chosen to ask, the relationships forged between myself and members of the Ardoch Algonquin First Nation and Allies, and the individuals with whom I have sought to (and have been able to) work.

Feminist research is also concerned with particularity, locality and place in order to counter universalized and exclusionary narratives that often do not account for the experiences, struggles and resistance of marginalized groups, particularly of marginalized women. Chandra Mohanty’s (2002) essay “'Under Western Eyes' Revisited" examines transnational and cross-cultural feminism, and is particularly relevant to this research methodology by forwarding an agenda to link local experience with broader political economic processes. Mohanty's (1986) preceding essay, "Under Western Eyes: Feminist Scholarship and Colonial Discourses" sought to decolonize feminist scholarship through a critique of feminist discourse which, she argued, was Eurocentric and universalizing, and was ultimately a colonial endeavour by effectively erasing the varied experiences of oppression, struggle and resistance of diverse communities of women. Mohanty (1986) therefore explains that critical feminism needs to be mindful of the particularities of place and the relationship to universal and global values:

My most simple goal was to make clear that cross-cultural feminist work must be attentive to the micro-politics of context, subjectivity, and struggle, as well as to the macro-politics of global economic and political systems and processes...Thus I argued for grounded, particularized analyses linked with larger, even global economic and political frameworks (quoted in Mohanty 2002: 501).

She further explains that her intent was to outline a vision of "feminist solidarity across 
borders" based on a common feminist political project that was attentive to politics of location, "common differences" and the interplay of power dynamics. She argues that noting difference allows for the theorization of universal values to be more inclusive and appropriate for women of diverse communities and identities (Mohanty, 2002: 505). With attention to all of these considerations, Mohanty (1986), in "Under Western Eyes", set out a vision for coalition-building and solidarity that is egalitarian and noncolonizing.

Mohanty (2002) notes that while many of her arguments presented in 1986 remain relevant, the context since writing "Under Western Eyes" has changed dramatically such that the feminist agenda must now take into account a deep critique of global capitalism and its values that are recolonizing people everywhere. She argues that the links between political economy and culture, through a "race-and-gender conscious historical materialism", still need to be at the centre of feminist analyses and frameworks (as she had argued in 1986); however, she notes that: "global economic and political processes have become more brutal, exacerbating economic, racial and gender inequalities, and thus they need to be demystified, reexamined, and theorized" (509). She also explains that, "political shifts to the right, accompanied by global capitalist hegemony, privatization, and increased religious, ethnic, and racial hatreds, pose very concrete challenges for feminists" (508). Therefore, Mohanty (2002) argues for the imperative of a feminist critique of capitalism and globalization that focuses on marginalized communities of women, particularly those who are racialized:

This analysis begins from and is anchored in the place of the most marginalized communities of women - poor women of all colours in 
affluent and neocolonial nations; women of the Third World/South or the Two-Thirds World. I believe that this experiential and analytic anchor in the lives of marginalized communities of women provides the most inclusive paradigm for thinking about social justice. This particularized viewing allows for a more concrete and expansive vision of universal justice (510).

This methodology, that focuses on marginalized women, makes visible power dynamics (including those embedded in the production of knowledge) that are often hidden and offers the most "inclusive viewing of systemic power" (Mohanty, 2002: 511). She argues that a particular focus on the lives, struggles and bodies of women and girls reveals the workings of capitalism as a system that exacerbates sexism and racism, and further allows for effective envisioning of collective antiglobalization and anticapitalist resistance (Mohanty, 2002: 514).

While this research does not focus specifically on the lives and bodies of marginalized women and girls, it does focus on the lives and livelihoods of members of an Indigenous community in Canada, who as a broad demographic are collectively amongst the most disproportionately marginalized groups at a national level (according to numerous indicators including quality of life, poverty, health status, unemployment, criminalization, violence against women and children, access to infrastructure, social services and basic services) (Adelson, 2005; Reading, Kmetic and Gideon, 2007; Amnesty International, 2009). Therefore feminist methodologies are used in this research to document the context of access to traditional food for the Ardoch Algonquin First Nation by focusing specifically on manomin, with the hope of shedding light on broader political and economic processes that simultaneously interact at regional, national, transnational and global scales. 
Proponents of feminist methodologies are also highly committed to participatory research models that are attentive to the research processes and the relationships formed between research participants and the researcher (particularly with respect to power relationships) (Cotterill, 1992; Ballamingie and Johnson, 2011). Pamela Cotterill (1992), like Rose (1997), explains that feminist methodologies therefore aim "to produce nonhierarchical, non-manipulative research relationships" (594). This participatory approach is also supported by various Indigenous methodologies (Brascoupé, 2012). Thus participatory research methods were central to this research.

\subsubsection{Transformative Asset-Based Research: Critical Post-structural}

\section{Methodologies}

As discussed in Chapter 2, my research can be situated within a critical poststructural conceptual framework, with a focus on discourse, identity, representation, power relations and social constructions of nature. Consequently, this research can also be situated within literature on post-structural approaches to community-based research through a constructive lens of possibility and hope.

Cameron and Graham (2005) explain that their focus on an assets-based approach to community development research, as opposed to a needs-based approach "was prompted by commitment to the view that social research is an explicitly political intervention that not only represents, but constitutes reality" (316). Their approach is based upon a poststructural understanding of identity and subjectivity wherein "the subject is understood as always in the process of becoming, of being shaped in a 
multitude of ways by various discourses and practices" (Cameron and Graham, 2005:

317). Thus, participatory action research (PAR) can then become attentive not only to the broad or macro political agenda of research (in the context of this thesis - Indigenous food sovereignty and decolonization) usually characteristic of PAR, but "to another micropolitical dimension that is part of the process of transforming subjects" (Cameron and Graham, 2005: 328). Thus Cameron and Graham (2005) argue post-structural methodologies or orientations in community-based research can further the emancipatory goals of the research project by also illuminating possibilities of becoming for those involved.

The Assembly of First Nations speaks to the ethical and real (as opposed to theoretical) importance of focusing on assets:

First Nations peoples in North America are very critical of research for many reasons and seek to create assurances from researchers and public health scientific investigators that their research and surveillance activities will lead to improved health, not the structural characterization of ill health which, in the long term, is thought to be a significant barrier to improved health and well being.

Innovative research now directs effort at meaningful engagement of communities in the research process, building capacity among community, translating research results into policy and programs and the call for proposals that emphasize factors that can assist vulnerable communities to become strong. The tension is real when research fails to reveal community resiliencies demonstrated by First Nations peoples, as they endure many significant obstacles to achieve a reasonable standard of living. Innovative research strives to counter impressions by First Nations communities, best expressed in the widely used phrase, that they have been 'Researched to Death' by transforming their role from research subjects to researchers themselves (Reading, Kmetic and Gideon, 2007: 8).

I have therefore attempted to adopt a focus on community assets and success stories, and aim to communicate, celebrate, nurture and encourage diverse hopes, dreams and visions 
for the future. I had approached the Ardoch Algonquin First Nation and Allies as research participants precisely because I admire, respect and wanted to learn from the resistance strategies used by the community and the epistemologies that inform their strong, oppositional stances against destructive activities in traditional Algonquin territory.

\subsubsection{Grasping multi-scalar interaction: Critical ethnographic methodologies}

This research will employ elements of critical ethnographic methodologies. Hoggart, Lees and Davies (2002) explain that through ethnography "the researcher tries to understand the world through the eyes of the participants in a social situation" (251). Similarly to Cameron and Graham (2005), Hart (2004) posits that critical ethnographic research has the potential to contribute to the deconstruction of capitalism as the dominant economic assumption. By refusing to focus on development in terms of the "impact model" of capitalism, which victimizes those being studied, Hart suggests a concentration on political economic history as articulated through a dialectical, mutually constitutive process. Hart (2004) writes:

[...]sorting out capitalist from non-capitalist elements - or deconstructing 'the economy' to demonstrate its parasitic character - become far less interesting than the question of how multiple forces come together in practice to produce particular dynamics or trajectories, as well as possible alternatives.

Flowing directly from this observation is the central importance of critical ethnographies - not as case studies of the 'impact of globalization' but as windows into constitutive processes, and a means for reconfiguring understandings and practices (97).

Thus, critical ethnography, according to Hart, engages studies of globalization not 
through the binaries of local and global, nor through discrete identities, places or events, but rather, through the aim of attempting to grasp multi-scalar interaction, by focusing on processes through time and across space. Such a perspective is also in agreement with Indigenous worldviews that are described as holistic, dynamic, and process-oriented (Henderson, 2000a; Little Bear, 2000). Furthermore, Hart (2004) argues that a focus on a particular case study is of value in grounding theory in the concrete, as opposed to the abstract [relating to Mohanty's (2002) discussion arguing for feminist valuation of particularities of experience rooted in place].

This research is attentive to Hart's critiques of the "impact model of development". While this thesis does seek to understand how manomin and community access to traditional foods have been affected by development, the community responses are also central to this research. Consequently, there is also a focus on opposition, resistance, contestation and negotiation, as outlined in Chapter 2 of this thesis, and an overall emphasis on the interactions and processes of development through a multi-scalar analysis rooted in this particular case study.

Lila Abu Lughod (1993) advocates for "writing against culture". She explains that through ethnographic studies, culture is created whereby communities are represented as unified, coherent, homogeneous and timeless, making differences between ethnic groups seem more pronounced, and enabling 'othering' to occur more readily through an emphasis on difference that creates hierarchies between peoples. Abu Lughod (1993) explains: "Generalization can make these 'others' seem simultaneously more coherent, self-contained and different from ourselves than they might be" (7). She 
continues: "the effort to produce general ethnographic descriptions of people's beliefs or actions risks smoothing over contradictions, conflicts of interest, doubts, and arguments, not to mention changing motivations and historical circumstances" (9). Henderson (2000a) echoes the above by noting how Eurocentric ethnographies were both a tool of domination and 'othering': "Eurocentric thought was created on a negative vision of Aboriginal thought and life. It stressed the dissimilarities between Europeans and Aboriginal people, and it used this distinction to create barriers to Aboriginal rights and solidarity" (253). He further explains that Indigenous worldviews offer a means of approaching culture that opposes emphasis on difference: "Aboriginal thought emphasizes coherent wholes or shared patterns at the expense of unique processes of change and internal consistencies, conflicts, and contradictions. Aboriginal thought honours the diversity of life and never developed any single theory or view of culture, which knowing observers have attributed to it" (Henderson, 2000a: 254). In this research, I intend to "write against culture" - a feminist, postcolonial, post-structural tactic which sets to question assumptions that assimilate individuals into cohesive groups; it involves a focus on particularity, exploring how ideologies, or institutions are experienced as lived. Therefore, my thesis includes the opinions, insights, experiences and stories of research participants in order to focus on the particularities of individuals' experience in reference to the case study. Importantly, Abu-Lughod (1993) notes that such "decolonizations on the level of text" are only reformist in nature and do not alter "the basic configuration of global power" in which anthropology (or geography in this case) is constituted (26). 


\subsection{Practicing Research and Implementing Decolonizing Research Methods}

The previous sections have outlined the methodological grounding that has informed the research design, implementation, methods and dissemination. Indigenist, decolonizing, postcolonial, feminist, poststructural and critical ethnographic insights have informed the diverse research methods that are explained below.

At the very heart of the research methods used in this study are participatory research principles. As Rachel Pain (2004) explains, participatory research is a negotiated, collaborative and (potentially) non-hierarchical process through which research subjects are engaged as participants "in some or all stages of research, from problem definition through to dissemination and action" (652). Participatory research provides a strategy, through the research process itself, to counter exclusion and social marginalization of peoples. Caitlin Cahill (2007) extends the potential of participatory research to one in which participatory research can create new knowledge(s) and new ways of knowing, thus being transformative for research participants, and revealing the potential for perpetual becoming, or cultivating new subjectivities and transformative learnings.

With this in mind, participatory research methods were employed from the outset of research. In fact, my original research proposal had outlined my research design very loosely, as I hoped to have most of the research designed as a co-research project in partnership with youth from AAFNA. Consequently, I approached my research with flexibility and the intent to collaborate. From the outset the research was based on 
practices of collaboration and consensus with AAFNA through Ka-Pishkawandemin, the Family Heads Council. At first I had asked AAFNA leadership (specifically co-chief a the time, Paula Sherman) if there was any research that was sought by AAFNA that I could do. However, Sherman suggested to independently craft my research question and design, get university approval and then approach the Family Heads Council. After submitting the research proposal to the Department of Geography and Environmental Studies and the Research Ethics Board at Carleton University and receiving approval, I then brought my research to the Family Heads' Council for approval. My application package was first submitted by e-mail and preliminary comments and conditions of research were set out. Interestingly, this preliminary step proved to be highly politicized as it did involve changing the scope of my original proposal, which sought to work with youth from both AAFNA and another non-status Algonquin community in the area. The proposal, as formulated, did not prove acceptable to AAFNA council, thus requiring me to choose which community I wanted to research with, and ultimately leading to my decision to commit to working with AAFNA only, due to their strong political stances, in the context of uranium exploration and mining protests, and in the past with respect to the Rice Wars. I further had to negotiate my intellectual freedom, in promising to forward any royalties resulting from this research to the community, but maintaining my liberty to submit my final thesis to AAFNA Family Heads Council for comments which I can consider for revisions, but not for complete editing power on the part of AAFNA, which was originally requested.

In the secondary step of participatory research design, I attended a $\mathrm{Ka}$ - 
Pishkawandemin (Family Heads Council) meeting to present my research in person and ask for permission to proceed with active research with community members and at community events, an important step in adhering to community protocol for research. At the beginning of the meeting, I presented the co-chiefs with a tobacco offering (as is customary in Anishinaabe tradition). During the Council meeting, my intent, scope of research, and proposed approaches were questioned by those present. Specifically, one community member expressed concern with regards to my relationship with a council member of another Algonquin community, the Shabot Obaadjiwan, which I explained was professional in nature, and would not involve any communication of my research results to that individual. Concern was also expressed with regard to the fact that an examination of manomin alone does not provide a full account of food sovereignty issues in the community. I maintained that an examination of manomin specifically provides a reasonable scope for this research (which is limited), but that my examination of manomin will aim to illuminate sovereignty issues with respect to other traditional, culturally significant, or important foods for AAFNA, thus providing insight into a more complete understanding of food sovereignty issues. There was also concern expressed that the research must take account of how the current Algonquin land claim has a very large potential impact on food sovereignty for AAFNA. Consequently, I included a question in the interview guide that takes into account the implications of the Algonquin land claim. From the very outset, I approached my research with sensitivity and adherence to community protocols for decision-making.

Ultimately, it proved unfeasible to undertake research as I had initially 
conceptualized, as my access to members of the broader community and the youth within the community was limited for a number of reasons, outlined below and in the discussion of research limitations in Section 6.1. While the interview questions took account of concerns and issues that were raised during the Council meeting, I ultimately designed them as the sole researcher (as opposed to designing research methods through a partnership process with youth).

As part of my commitment to using Indigenist and decolonizing research methods, I have approached learning through what many authors identify as Indigenous ways of knowing, sharing and transferring knowledge: through relationship-building, listening to Elders, experiential learning and reciprocity (Battiste, 2000b; Cajete, 2000; Oakes, Riewe, Edmunds, Dubois and Wilde, 2003; Simpson, 2004; Anderson, 2008). By researching the practices of Aboriginal women health practitioners, healers and health researchers, Anderson (2008) outlines traditional ethical research practices used by Indigenous women across the Canadian landscape. Her research indicates two components are central to Indigenous health research: "relationships to the Natural and Supernatural worlds"; and "the importance of respect and reciprocity" (8). Anderson (2008) writes of the insights of one research participant: 
In terms of how we might better govern ourselves as researchers, Be'sha Blondin's description of how she works as a healer is directly applicable. Ultimately, there needs to be respect. The fundamental principle of reciprocity must be respected, as mutual exchange must take place to ensure successful results in healing and in research. As Blondin explained, one cannot simply go to the people and say 'I'm going to do this for you.' In order to gain knowledge through research, we must give something first. If we look at the example of storytelling, we must earn the right to tell a story, and each time this will involve a different process of relationship-building. If research is viewed as a process of gathering and retelling stories, these same principles can apply. In talking about not being 'there for your own ego,' Be'sha Blondin inspires us to remember to always consider our intent. The way in which we govern our work is directly tied to the way in which we govern ourselves (11).

Many authors explain that Indigenous worldviews are centered upon relationships (interpersonal, ecological, kinship-based, spiritual) ( Henderson, 2000b; Little Bear 2000; Cajete, 2002), therefore, I had hoped that approaching research through relationshipbuilding, participatory and Indigenist methods would open up and deepen my relationship with members of AAFNA. In reflecting upon his experience conducting research on fisheries in a First Nations community, Gallagher (2003) writes: "Arriving in a community and asking questions will only provide a portion of traditional knowledge but will completely neglect the experience and the relationships" (189). Thus, I attended numerous community events both prior to and during research including: Pray for the Land (2009) (a yearly gathering at the Robertsville mine site to pray for the healing of the earth); AAFNA Manoomin Festival (August 2009 and 2010) (the annual Pow-Wow); Culture Camp at Mazinaw lake (July 2010); Silver Lake Pow-Wow (August 2010); Algonquin Sharing Day (June 2011). At each of the events, celebrations or gatherings, I was able to meet and get to know various community members and participants, who, for 
the most part, welcomed my participation warmly and generously ${ }^{20}$. I contributed to the gatherings by bringing small gifts such as fruits and other foods to share, as a small contribution to the many meals (and conversations) so generously shared with me. I also took opportunities to contribute to the gatherings by looking after children and youth for short periods of time, and by helping with food preparation and clean-up. By contributing to community events in these small ways, I was able to establish meaningful relationships with some AAFNA community members and demonstrate my intentions to approach research in a respectful and meaningful way. ${ }^{21}$

I also went ricing with manomin steward and Elder, Harold Perry. We paddled to the manomin fields and harvested manomin using the traditional canoe and stick method in late August 2010. In October 2010, I went with Harold again to see the manomin in the fall and simply to be out on the water together.

Participatory Action Research (PAR) is a subset of participatory research methods which is aimed explicitly at informing praxis, or action, through research, and informing research through praxis, activism, and embodied experience (Kindon, 2005). Henderson (2000b) explains that the linking of theory and practice is also a central component of Indigenous epistemologies, expressed in Indigenous languages that are based more on verbs than nouns. I engaged in PAR in a number of ways. First and foremost, my

20 I am particularly indebted to Mireille Lapointe and Paula Sherman, co-chiefs of the Ardoch Algonquin First Nation who always made a great effort to make me feel welcome and introduce me to other community members, despite often being very busy with their families, their community, and their work.

21 Interestingly, reflecting on the research process in this way, outlining the ways in which I intended to approach my relationship with AAFNA and community members through reciprocity, seems to take away from the sincerity of these small acts. Though I was very conscious at times of needing to follow appropriate and respectful community protocols, it was not with an intent to necessarily further some abstract research goals, rather to learn and participate with the community where I was welcome in "a good way". 
research was informed and grounded in a variety of experiences outside of theoretical explorations. Throughout my studies, I have simultaneously been involved with community organizing and activism in both Indigenous solidarity work, and in the alternative food movement. I began working with the Indigenous Peoples' Solidarity Movement of Ottawa (IPSMO) shortly after beginning my studies. IPSMO "is a grassroots organization that directly supports indigenous peoples in diverse struggles for justice. We also work within communities to challenge the lies and half-truths about indigenous peoples and colonization that dominate Canadian society" (IPSMO, n.d.). IPSMO engages in direct action, popular education, and support work for a number of Indigenous communities, including the Ardoch Algonquin. My involvement with IPSMO provided me with hands-on experience in the doing of Indigenous solidarity work, through a community organizing context in Ottawa, and greatly enhanced my understanding of Indigenous sovereignty issues for many peoples in and around Ottawa, across Turtle Island and around the world. In the alternative food movement, my work involved volunteering with an on-campus, volunteer-run food collective (the Garden Spot) as an organizer, coordinator, cook and gardener, and committing to my own household level of food sovereignty (to the best of my abilities). I have also participated in various non-academic projects, including kitchen table talks for the development of food policy in Ottawa (Just Food's Food For All Campaign).

My research for this thesis was therefore approached using multiple methods, to triangulate data collection in order to thoroughly study manomin in the valley of the Kiji Sibi in the context of development. By participating in the community events outlined 
above, I engaged in over 32 hours of participant observation, which provided the benefits already mentioned and also improved my contextual understanding of community relations. I also attended public presentations, teachings, workshops and lectures given by community leaders, of which one was transcribed (with permission) and included approximately 2 hours of discussion with three community members and an open discussion period.

I also conducted semi-structured interviews with five research participants, each interview lasting between half an hour to two hours, for a total of 8.5 hours of interviews (that were taped and fully transcribed). The semi-structured format of interviews permitted me to ask probing questions for clarification of meanings and allowed the interview participants to delve deeper into subjects that I had not anticipated discussing prior to the interview. The interviews were conducted in person at the location of choice for the interview participants, thus allowing for more comfortable conditions and increasing convenience for research participants. All of the interviewees were key informants within the community with respect to the relationship between development, manomin and Algonquin self-determination. All interviewees are active (or have been in the recent past) in the leadership of the Ardoch Algonquin First Nation and Allies. I was able to connect with these five community members through introductions from the cochiefs of AAFNA at that time, Mireille Lapointe and Paula Sherman.

I also reviewed popular media and literature, government documents [including Canadian Legal Information Institute (CanLII) full-text court decisions] and scholarly literature for an overview of narratives produced around Algonquin jurisdiction in the 
valley of the Kiji Sibi, with particular reference to the Ardoch Algonquin First Nation and Allies and manomin. I focused particularly on historical narratives and analyses that presented Indigenous and Algonquin accounts of Indigenous-settler relations and histories. Additionally, two members of AAFNA [Paula Sherman ( $\mathrm{PhD}$ and professor at Trent University) and Robert Lovelace (professor at Queen's University and Fleming College)] have both published works in academic texts; this thesis also draws on the analyses and insights conveyed in their writings.

As an integral part of this research project, the contents of the interviews are inevitably interpreted and represented (and possibly, misrepresented) by me (the researcher) with the aim of answering the research question through an analysis of the data collected. As mentioned above, the research is substantiated through a process of triangulation, whereby multiple methods were used for data collection and data analysis for a more encompassing analysis, greater than the sum of its parts. Therefore, extracts from interviews are presented alongside popular and scholarly literature, discourse analysis, and select field notes.

I have designed my research to be accountable to the community through a number of mechanisms. Research design was a participatory and iterative process (described above) in which I forwarded my preliminary research proposal (including both the academic and ethics proposal) to the AAFNA Family Heads' Council for review, negotiated the orientation and terms of the research, and returned to the Family Heads' Council anew for approval to do my research within the community. During the interviews, I sought oral consent from interviewees (rather than ask them to sign a 
consent form) and also gave them a signed letter of promise, which outlined my commitments and promises to them as a researcher, making these very accountability mechanisms known and transparent to research participants. Full interview transcripts were returned to interviewees to review, revise and edit their transcripts within a three week time frame. Only one research member chose to edit their transcript. Photos taken of research participants, or photos taken during activities with them were also submitted to them with the option of withdrawing the photos from the research and having the photos destroyed. I also brought a draft of the thesis to the AAFNA Family Heads' Council for comments. A final copy of the thesis will be given to AAFNA for their records and to be accessed for future use. Finally, I have committed to return to the community to present the research findings in a presentation to supplement the written thesis.

The following chapters (Chapters 4, 5 and 6) represent the results of having implemented the research methods discussed above to answer the questions: How has access to manomin been affected by development? How have the Ardoch Algonquin First Nation and Allies responded to the challenges and/or opportunities of development? What are the implications for settler responsibilities? What I hope has become clear throughout this chapter, is that the practice or doing of research (guided by the conceptual framework of Chapter 2 and the methodological considerations outlined above) is a highly important, reflexive, challenging and negotiated piece of the overall project of answering the research questions that guide this study. 


\section{Chapter 4: Algonquin-Settler Relations in the Valley of the Kiji Sibi}

If we are to facilitate change in the attitude and behaviour of governments and corporations toward Indigenous peoples, then they must be socialized to the histories in which Indigenous peoples exist as human beings with agency.

- Paula Sherman, former Co-Chief of the Ardoch Omàmìinini, 2007: 328

The Anishinaabe agreed to incorporate the Newcomers into already existing social, spiritual and political systems of relating to each other as components of Creation. As William [Commanda, late Omàmiwinini Elder] articulates, 'it was inconceivable to them that the enormous resources of the land would not sustain them all'. The prophecies also led them to believe that relationships with the Newcomers could lead to positive things on both sides. Indigenous peoples, however, were to remain at the centre of the relationship, as the original peoples, holding the relationship together.

- Sherman, 2007: 240-241.

Chapters 4, 5 and 6 represent the results and analysis of my research. In Chapter 4, I present a historical overview of Omàmiwinini (Algonquin) relations with settlers (including settler governments) in the valley of the Kiji Sibi (also known as the Ottawa River). In (re)constructing the history below I draw mainly on the works of contemporary Indigenous scholars, and on scholars who convey the oral histories and historical accounts of Indigenous and Algonquin peoples. I do this to further contextualize the case study of manomin (an Anishinaabe traditional food) as it pertains to the Ardoch Algonquin First Nation and Allies. The current climate of relations between Indigenous peoples and the Canadian government, neighboring settlers and other actors in the region (such as government agencies and private corporations) in unceded Algonquin territory is built upon the foundation of history of relations since contact (represented in the creation and interpretations of agreements, documents, records and subsequent policies and legislation, and the accounts of events, interactions and 
impressions).

Thus, Chapter 4 presents a brief account of Algonquin-settler relations in the Ottawa Valley. Section 4.1 outlines this history from early French explorations in 1603 until 1867 with the formation of the Dominion of Canada through the passing of the British North America Act (also known as the Canadian Constitution Act 1867). Section 4.2 introduces the history of the legislation and regulation of "Indian" identity, through which Indigenous nations and communities have been divided according to British and Canadian law. Section 4.3 provides an overview of the history of Algonquin petitions to the Crown since 1772, documenting the ongoing assertion of Algonquin jurisdiction in the territory up until present day (specifically, with the negotiation of, and resistance to, the Algonquin land claim). Section 4.4 outlines how Canadian laws are founded on colonial relations and also serve to entrench ongoing colonial relations. Chapter 4 concludes with a description of the various techniques through which a colonial present is maintained in a settler state in Section 4.5.

\subsection{Omàmìwinini-European Relations and Agreements in Omàmìwinini}

\section{Territory: 1603-1867}

As introduced in Chapter 1, oral history indicates that Omàmiwinini (Algonquin) people have lived in the valley of the Kiji Sibi since "time immemorial". Written records from European explorers indicate that at the beginning of the $17^{\text {th }}$ century Algonquin people occupied "the entire watershed of the Ottawa River in Ontario and Quebec" (Hessel, 1993: 1). Hessel (1993), an Ottawa Valley historian writes: "For thousands of years their domain was the vast territory that stretched roughly from the present city of Montreal 
almost as far west as Lake Nippissing, and from the Rideau Lakes to the distant headwaters of the Ottawa River and its tributaries" (1). The tributaries of the Kiji Sibi include the following rivers, currently commonly known as: South Nation, Rideau, Mississippi, Madawaska, Bonnechere, Indian, Barron, Petawawa and Mattawa rivers (all in present day Ontario), and Rivieres Rouge, de la Petite Nation, Blanche, Lievre, Gatineau, Coulonge, Noire, Temiscamingue, and des Outaouais rivers (all in present day Québec) (Gehl, 2010).[did anyone talk about the migration from the east to the land of the manomin, which can be found on rock art in Anishinabeg territory]

Thus, as discussed in Chapter 1, Algonquin people have occupied and lived throughout the vast territory of the valley of the Kiji Sibi for millennia, including through European exploration and settlement, until present day. In her dissertation, Lynn Gehl (2010) notes several historians who acknowledge that the Algonquin nation played a central part in the history of North America but that this history has largely been neglected and is not well documented. However, Gehl's (2010) work, entitled Maan Piinde'eng: A Debwewin Journey Through the Algonquin Land Claims and SelfGovernment Process, offers a comprehensive account of Algonquin history and the land claims process beginning from European contact period to present day. Sherman (2007) also explains that recorded Algonquin history is embedded with racism and accounts that were manipulated to serve colonial interests, particularly in reference to earlier historical records from explorers and missionaries, thus drawing attention to the problems of more contemporary research that has drawn on these documents. Sherman (2007) therefore offers a thorough account of Omàmiwinini history in the valley of Kiji Sibi, outlining 
Omàmiwinini epistemological foundations, relations with Haudenosaunee (Iroquois) people, and the resistance to violations of foundational agreements between Omàmiwinini people and settler governments. A very brief recounting of a lesser-told history that accounts for Indigenous perspectives is offered below.

Early Aboriginal-European relationships are characterized by J.R. Miller (1991) as generally harmonious in the context of New France. He explains various reasons for this, including that the French did not pose a serious threat to Indigenous livelihoods as they rarely encroached upon their territories of high use and occupancy since the French economy was based more on commerce than agrarian expansion. There were also mutually beneficial outcomes for the French and Indigenous peoples (through economic exchanges in the fur trade - including pelts for iron products and firearms; and through military alliances which secured French 'sovereignty' with respect to other European powers in the area and protected Indigenous peoples' way of life and lands from the more aggressive and agrarian Americans and British). Lastly, Miller (1991) notes that although the Indigenous population far outnumbered that of the European newcomers, they did not drive away the Europeans but also shared their knowledge, land and gifts from the Creator as a consequence of their pre-existing epistemologies and ethic for sharing. Sherman (2010a) explains "the principles and protocols for relating among Indigenous peoples also applied to relations with European empires when they arrived in the lands of Indigenous peoples" (114). Sherman (2007) explains that Anishinaabe people welcomed the French due to the Seven Fires Prophecies, which have been passed down through oral history for generations and anticipated the arrival of the newcomers. She explains: 
The Anishinaabe agreed to incorporate the Newcomers into already existing social, spiritual and political systems of relating to each other as components of Creation. As William [Commanda, Omàmiwinini Elder] articulates, 'it was inconceivable to them that the enormous resources of the land would not sustain them all'. The prophecies also led them to believe that relationships with the Newcomers could lead to positive things on both sides. Indigenous peoples, however, were to remain at the centre of the relationship, as the original peoples, holding the relationship together (Sherman, 2007: 240-241).

This understanding was recorded in the Wampum belt ${ }^{22}$ of Friendship and Sharing (or Welcoming Belt), according to the late Algonquin Elder William Commanda, which was created to record the Friendship Treaty of 1701 between the Omàmiwinini, the French and the English. The Wampum belt depicts three figures, representing the Omàmiwinini in the centre, and the French and English on either side. Sherman (2007) explains: "The placement of Indigenous peoples in the centre of the belt represents the special position that Indigenous peoples have as central figures of autonomy within the landscape of North America" (240). This understanding of the relationship between Algonquin people and settlers persists to this day, as is exemplified in the telling and retelling of this history by Algonquin Elders (such as William Commanda), leaders (such as former Ardoch Algonquin co-chief Paula Sherman) and scholars (such as Lynn Gehl).

Over time, the responsibility to uphold the relationship between the Omàmiwinini, French and English was appropriated by the newcomers. In 1763, the Treaty of Paris was signed at the end of the Seven Year War in which France formally ceded all title and claims in North America - which did not belong to France (Gehl, 2010) - to Great Britain, who thus acquired control of all Indian territory on Turtle Island (according to

22 As Sherman (2010a) explains, wampum belts were, and continue to be, exchanged amongst Indigenous peoples as a means of establishing, maintaining and restoring relations. They are "a symbol of truth, honesty, and integrity" (114), and as such reflect the sacredness of an agreement. 
European law). On October 7, of that same year, the Royal Proclamation of 1763 was issued, after Indigenous rebellions led by Odawa Chief Pontiac severely undermined the British presence in the Great Lakes region. The Royal Proclamation of 1763 divided the territory into the four colonies of Quebec (Canada), East Florida, West Florida and Grenada, and a separate Indian territory (Gehl, 2010), as shown in Figure 4.1, below. Hence, Algonquin territory was divided into the colony of Quebec and Indian territory along the border created by the Kiji Sibi, which remained divided after the formation of Ontario and Quebec (see Figure 4.2). As discussed above, the Ottawa River watershed was, and continues to be Algonquin territory; the jurisdictional divide created by the Royal Proclamation of 1763 has therefore had a significant and long-lasting impact in dividing the Algonquin Nation (Majaury, 2005).

The Royal Proclamation of 1763 set to define the relationships between Aboriginal peoples and the Crown. There is debate - amongst those who support the British colonial account, written in the declaration and those who support Indigenous accounts, transmitted through oral history - about the significance of the terms of agreement of the Royal Proclamation. 
Figure 4.1: Map of Eastern North America after Royal Proclamation of 1763, According to British Crown

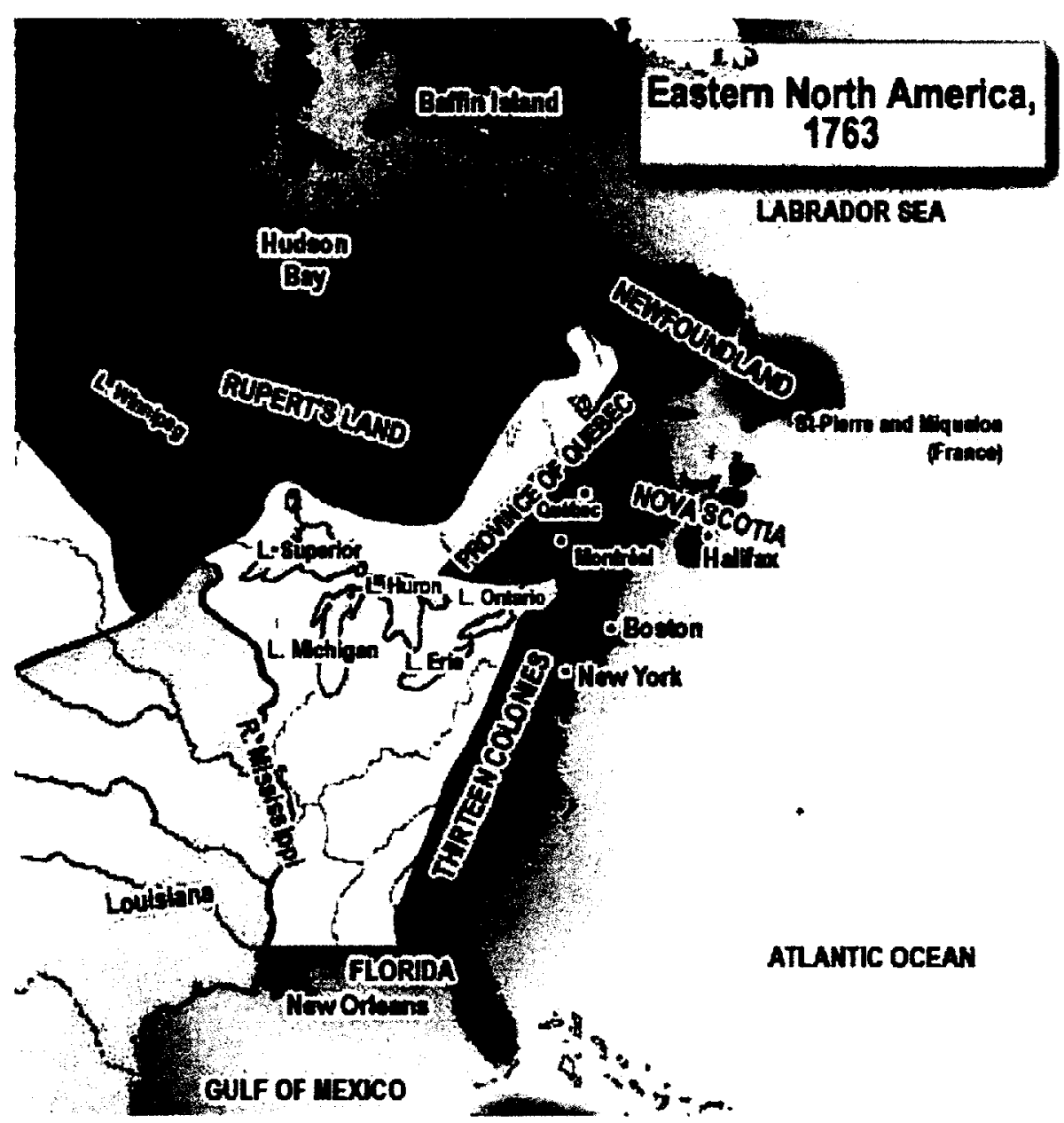

Source: Bron and Houle, 2001.

Note: The yellow land on the above map was designated as Indian territory. 
Figure 4.2: Map of Algonquin Nations in 1600s and the Royal Proclamation of 1763

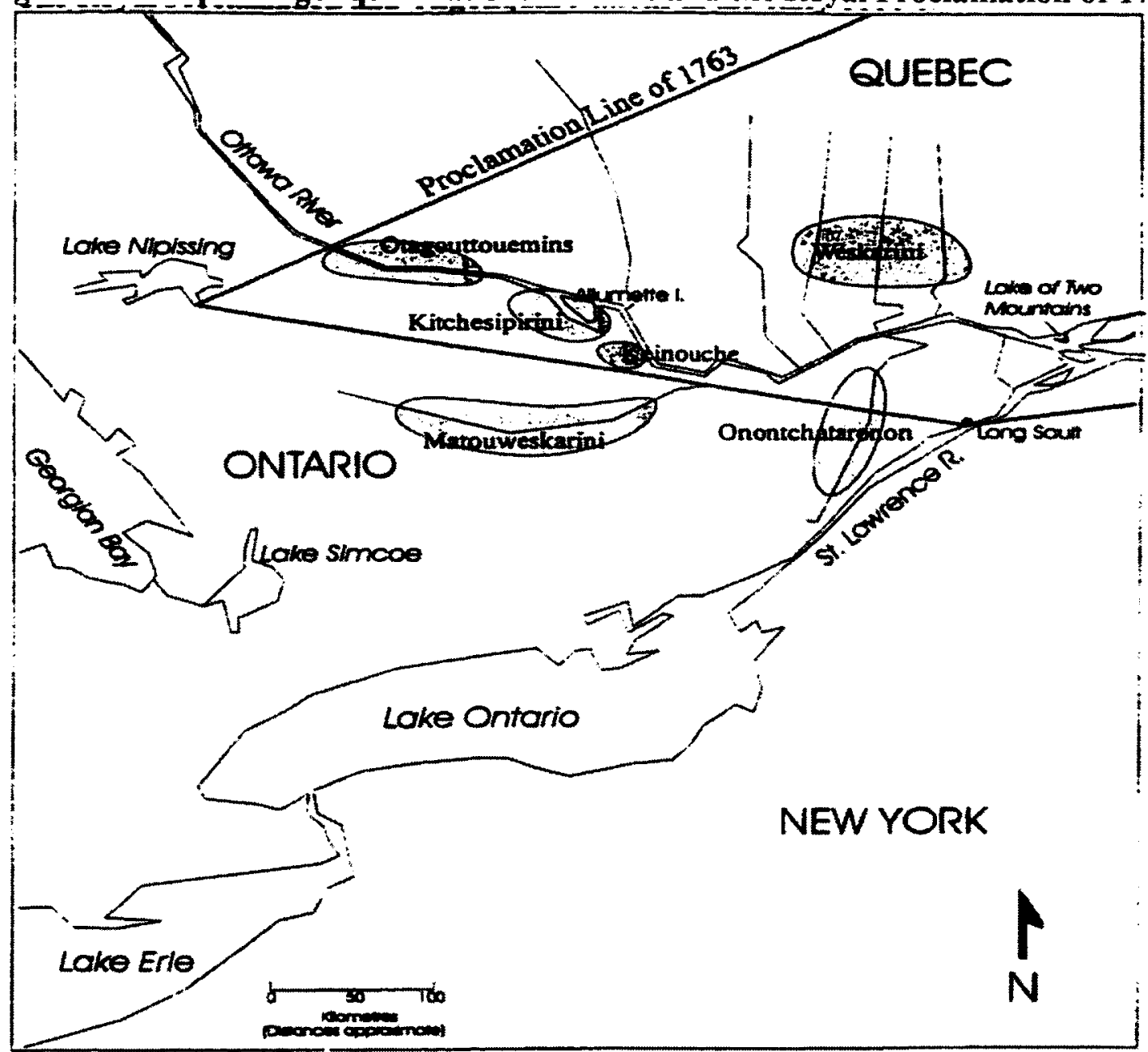

Source: Huitema, 2000: 27

The Government of Canada, through the Department of Indian and Northern Affairs Canada (INAC), [now Aboriginal Affairs and Northern Development Canada (AANDC)] explains the significance of the proclamation in which: 
[...] guidelines for the government's relationship with Aboriginal people were set. These are still relevant today. The Royal Proclamation describes the basis for the historical and modern day treaties. The Royal Proclamation of 1763 recognized that: Aboriginal people lived on traditional lands; interest in those lands belonged to groups and nations, not individuals; only the Crown could buy or accept Aboriginal lands; the Crown generally required an agreement to obtain lands for Aboriginal people; Aboriginal people were under the Crown's protection (Ina $\mathrm{Ca}$ 2010a).

Alternatively, Gehl (2010) argues that the consideration of the Royal Proclamation with the Treaty of Niagara of 1764 serves to further contextualize and clarify the agreements enshrined in this process, as it was understood by both Indigenous peoples and the British. The Royal Proclamation of 1763 was ratified at the Treaty of Niagara, which was attended by over 2000 Chiefs representing twenty-four Indigenous nations (Gehl, 2010: 131), during which Wampum belts were exchanged between both the British and the twenty-four Indigenous nations ${ }^{23}$. Taking into account the Treaty of Niagara, the Royal Proclamation can then be understood as a nation-to-nation agreement between various Indigenous nations and the British Crown, which recognized, guaranteed and protected the autonomy and independence of Indigenous nations and their territories (Sherman, 2007; Brascoupé 2010; Gehl, 2010).

It is important to note however, that the contents of the Royal Proclamation of 1763 alone, though enshrining the rights of Indigenous nations to self-government, to autonomy over Indigenous lands (by preventing encroachment by settlers) and to Indigenous livelihoods (through access to hunting grounds), also served to dispossess Indigenous nations of their rights through contradictions in the document (such as the

23 See Gehl (2010), pp. 131-133 for an overview of the Wampum belts that were exchanged and the agreements that were recorded. 
duality established of Indigenous Nations, as both Nations and tribes) (Gehl, 2010). The Royal Proclamation of 1763 is a foundational document that is often invoked to clarify the extent of Indigenous rights through Canadian courts. Therefore, there are important implications for Indigenous rights, depending on which account of the spirit of the agreement is taken into consideration.

As is discussed below in section 4.3, Algonquin people "assert that the Algonquins of Ontario never surrendered its territory by treaty, sale, or conquest and have made such claims since 1772" (OMAA, 2009a) (i.e., that the territory is unceded). ${ }^{24}$ As such, the Royal Proclamation of 1763 remains one of the most important colonial documents outlining the terms of the relationship between Algonquin people and settlers, particularly with respect to jurisdiction of "traditional lands" and access to "natural resources", such as manomin (wild rice).

Gradually settler governments came to assert greater authority and jurisdiction over the affairs and lands of Indigenous peoples on Turtle Island. John S. Milloy (1991) outlines how from the issuance of the Royal Proclamation of 1763 until 1860, when the responsibility for Indian Affairs was transferred to the government of the United Canadas, "Indian tribes were, de facto, self-governing. They had exclusive control over their population, land and finances" (146). Bonita Lawrence (2004) notes that the crucial moment in which the government of then colony of Canada asserted the "legislative authority over any member or citizen of an Indigenous nation" occurred in 1850 by

24 While the Algonquins of Ontario legally refers to the body of Algonquin communities that are currently negotiating the Algonquin land claim, I intend for this quotation to demonstrate that Algonquin territory in Ontario was never ceded by any Algonquin community in Ontario. Furthermore, it is generally argued, and accepted, that all traditional Algonquin territory is unceded territory, in that Algonquin people in Ontario and Quebec never made any formal agreements to cede any part of their territory. 
passing its "first law arrogating itself the authority to define who was or was not a member of an Indigenous nation - designated in generic terms as 'Indian'"' $(27)^{25}$. Shortly thereafter, the legality of federal control of Indigenous peoples and lands (reserves) was formally established through the passing of the British North America Act (the Canadian Constitution Act 1867), thus transferring the regulation and control of Indigenous governance, identity and rights to the Canadian government. Susan Delisle (2001) notes that at the same time:

[...] section 109 of the [British North America] Act awarded ownership of land and resources to the Provincial governments. Thus reserve lands came under Federal jurisdiction, while all other ceded lands (those currently viewed as Provincial territories) became the property and jurisdiction of the Provinces. In addition, section 109 provided for the interest of the Crown in Crown lands, mines, minerals, or royalties stating that they belong to the Provinces but are subject to existing trusts and interests. Sections 92(5) and 92(13) awarded Provincial governments the authority to legislate concerning management and sale of public lands and resources. Also section 88 made Provincial laws applicable to Aboriginal peoples. Thus legislation regulating resource use on Provincial Crown lands impeded Aboriginal access to off-reserve resources regardless of the promises provided in the Robinson Treaties. It is worthy to note that neither government was assigned responsibility over Aboriginal use of natural resources. This set the stage for Provincial control of Aboriginal lands, and the gradual degradation of land and resource rights (19).

Similarly, Bettina Koschade (2003) argues that the Constitution Act 1867 further eroded Aboriginal rights, title and jurisdiction to their lands by specifying the jurisdiction of federal and provincial governments and remaining silent on the jurisdiction and responsibilities of Aboriginal peoples, leaving Aboriginal peoples to establish recognition of their rights and responsibilities. Thus, with the legal formation of Canada in 1867, Indigenous self-determination became severely limited by both federal and provincial

25 An Act for the Better Protection of Lands and Property of the Indians in Lower Canada, s.c. 1850, c.42 
jurisdiction of Aboriginal affairs and territories.

While British policy was based more on nation to nation governance with the objective of Indigenous self-governance, Canada had changed policy direction to assimilation through the Indian Act (Brascoupé, 2012). Koschade (2003) explains that through the Constitution Act 1867, and the Indian Act of 1876, Aboriginal people came to be seen by the Canadian Government as "wards of the state rather than as political communities" (40). Moreover, Merrell-Ann Phare (2009) explains the significance of the Constitution Act 1867 in enshrining deeply uneven, dominating and colonizing relations between settlers and Indigenous peoples:

When the Constitution drafters could have acknowledged the rich and critical contribution Indigenous Nations made to the creation of Canada, and affirmed Canada's commitment to seeing them remain strong and vibrant, the drafters instead placed them under the care and supervision of those who had every interest in ensuring that they ceased to exist. To say that this was immoral and unethical is to understate and simplify the matter greatly. Addressing the consequences of this act, along with the mindset that motivated it, has been a continuing battle that is fought daily by First Nations all across the country (26).

\subsection{Regulation of Indigenous Identity / Indian Status}

The regulation of Indigenous identity by the Canadian state represents one of its most insidious means of control of Indigenous peoples. Beginning with the Royal Proclamation of 1763, racial difference between "Indians" and European settlers began to be encoded in law, through the recognition of differentiated land title for Indians and nonIndians (Thobani, 2007: 47). In 1850, the British sovereign began to legislate and control the racialized "Indian" by asserting authority over who was a recognized Indigenous person who therefore held particular legally entrenched rights and restrictions through 
their status as Indians, as determined by agents of the (settler) state. In 1869, the Gradual Enfranchisement Act was passed and Indian status was legally defined through patrilineage. This marks the beginning of the official Canadian policy to systematically annihilate Indigenous juridical subjects, just two years after the foundation of Canada through the British North America Act (the Canadian Constitution 1867), which as discussed above, established the exclusive jurisdiction of the Federal Government of Canada "over the administration of Indians and lands reserved for Indians" (Stevenson, 1999: 65). The Indian Act was passed in 1876 and remains the primary body of legislation pertaining to "status Indians" in Canada today.

Several authors discuss the incredible significance of the process of asserting legal control over Indian identity. In "Real" Indians and Others: Mixed-Blood Urban Native people and Indigenous Nationhood, Bonita Lawrence (2004) lays out in detail the construction of "status" and "non-status" "Indians" in North America and its profound consequences for Indigenous nations and individuals. ${ }^{26}$ She explains that the Indian Act has been the main means of control of Indigenous people in Canada. In her book, Lawrence (2004) explores the meaning of Indigeneity in a contemporary context, in which Aboriginal peoples have been subjected to over five hundred years of assimilationist tactics. She also uncovers how identity policies have created a large portion of the Canadian population who are "Mixed-blood" Native people who "have been continuously, legally externalized from Indianness" (Lawrence, 2004: 26). These

26 Lawrence's (2004) account is thorough, detailed, poignant and accessible and she explains far more than I could possibly hope to in this brief synopsis. I am indebted to the author for the insights she relayed through her writing and I strongly encourage the reader to turn to this book for insight into Canadian history. 
are people who may themselves identify as Indigenous (or have ancestors who did), but who are not recognized by the state as Indigenous peoples with specific rights. Hence, these individuals have often been forced to leave their traditional homelands, territories and reserves, and many now live in urban settings. Lawrence argues that recognition and inclusion of these urban Mixed-blood Native peoples in conceptualizations of contemporary Indigeneity is paramount to the decolonization process for Indigenous nations.

There were various mechanisms through which a person could be excluded from Indian status over the course of the history of legislation and regulation of Indian identity by the Canadian government. These included: refusing to move onto a reserve, enfranchisement, marrying a non-status or non-Aboriginal man (in the case of status Indian women - known as the exclusion of matrilinear descent of status), or being a descendant of anyone who had lost their status. Thus, Aboriginal peoples were divided and accorded different rights and entitlements, based upon the laws and criteria of the Canadian government and its agents. The implications of this division amongst Aboriginal peoples is monumental in terms of the power that was seized by the Government of Canada and in terms of the resulting demographics of status Indians and the exclusions of non-status Indians from many Indigenous communities and nations. There have been profound cultural, social, economic and ecological effects. Koschade (2003) explains:

The way the Indian Act was administered gave some Aboriginal people legal status and did not give this status to others. The discrepancy between the two was not dependent on the individuals' lifestyle or ancestry; it was dependent on legal administration of bands and treaties, on the compilation 
of government lists, and sometimes, during the periods when enfranchisement was not forced on some Aboriginal people, non-status was a choice individuals made. In effect, the government created two classes of Indian people. The non-status Indians were not included in consideration for reserves, for being officially part of bands for band voting, for government funding, or for Aboriginal hunting and fishing rights (39).

Lawrence (2004) considers identity legislation to be a discourse of domination and thus a form of governmentality, in the Foucaultian sense, of producing subjectivities through control:

The Indian Act, in this respect, is much more than a body of laws that for over a century has controlled every aspect of status Indian life. It provides a conceptual framework that has organized contemporary First Nations life in ways that have been almost entirely naturalized, and that governs ways of thinking about Native identity (25).

Since the regulation of Indian identity began, numerous Indigenous people have been forcefully evicted from their communities, in many cases denying them, their families and their descendants a concrete identification with their historical communities and cultures, particularly in the context of racism and discrimination amongst the settler population which served to further alienate Indigenous people. Lawrence and Anderson (2005) characterize the exclusion of matrilineal decent of Indian status as genocidal:

Over the past one hundred and twenty-five years, approximately 25,000 women and their descendants were expelled, by colonial legislation, from their homes and communities. The most conservative estimates suggest that these women had between half-a-million and one million descendants, within two generations of first losing status. With the exception of 127,000 who were reinstated in 1985, almost all of these individuals were permanently lost to their nations; the numbers approach two million if the third generation is taken into account. Indeed, by the time the Indian Act was changed in 1985, there were only 350,000 Status Indians still listed on the Department of Indian Affairs Indian Register (3).

As discussed in Chapter 1 (Section 1.6) and in more detail in the following 
section, the Ardoch Algonquin First Nation is a non-status community - it is not a federally designated "Indian Band", it is not based on reserve, and it does not adhere to Indian Act regulations. Most Algonquin communities in Ontario are non-status; the only Algonquin community with status is Algonquins of Pikwàkanagàn First Nation (formerly Algonquins of Golden Lake First Nation), which is a federally designated status Band, based on the only Algonquin reserve in Ontario, with a Council as defined in the Indian Act. This is very unique in Eastern Canada. A discussion of the genealogy (or historical roots) of status Indians is highly relevant to this case study of manomin, as Ardoch Algonquin First Nation's independence from the Indian Act and Indian Band status both enables and limits particular stances, governance structures, financial opportunities, and ultimately, self-determination, as will be discussed below and in Chapters 5 and 6 .

\subsection{Resisting Dispossession: Algonquin Petitions and the Algonquin Land Claim}

As the Ottawa Valley became increasingly settled, Algonquin people did not idly accept encroachment upon their traditional territory (Sherman, 2007; Gehl, 2010). Since 1772, Algonquin people have submitted 28 petitions to the British and Canadian governments (Gehl, 2010). The content of most petitions indicated that Algonquin territory, which was to be protected by the Royal Proclamation of 1763 and the Treaty of Niagara of 1764 , was increasingly occupied by settlers who were encroaching on the Omàmiwinini land base, thus dispossessing them of their livelihoods and sustenance and violating the terms of those agreements. As Huitema (2000) explains: "historical documents and contemporary writings have shown that many of these complaints and entreaties were 
ignored, misinterpreted, or manipulated by the government" (20).

The increasing encroachment into Omàmiwinini territory was legally justified through the Crawford Purchase (1783), the Rideau Purchase (1819) and the Williams Treaty (1923) which were negotiated between the colonial government and Mississauga people, however, Omàmiwinini land was included in these agreements without consent or negotiations with Algonquin people (see Figure 4.3). Numerous petitions were submitted to the government in light of these unlawful land cessions referencing the responsibility of the British and its agents to honour the Royal Proclamation of 1763 (Huitema, 2000; Sherman, 2007; Gehl, 2010). 
Figure 4.3: Historic land cessions in current Algonquin land claim area

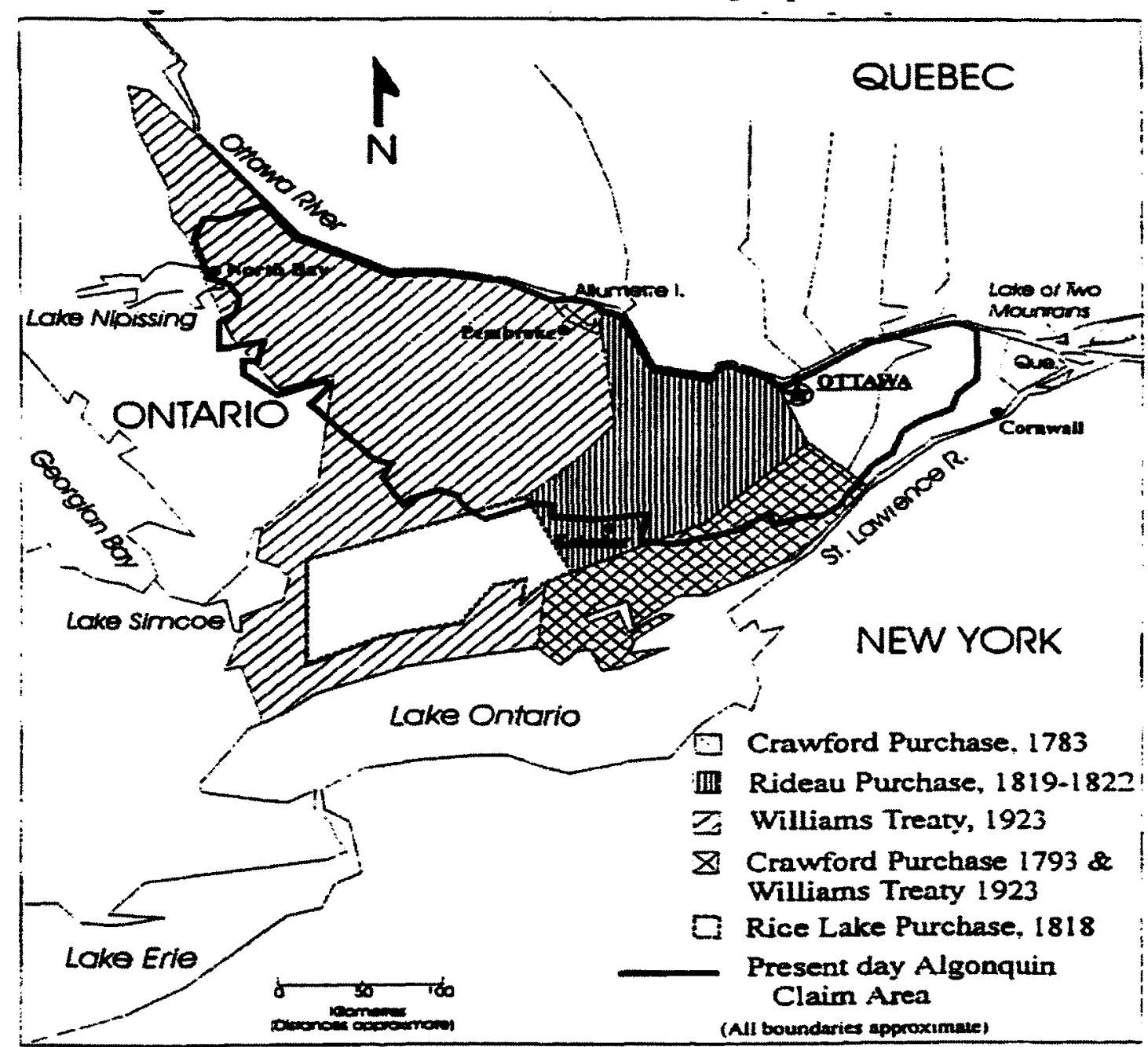

Source: Huitema 2000: 75

In the mid- $19^{\text {th }}$ century the government responded to various petitions by setting

aside and purchasing land to create Algonquin reserves. Lynn Gehl (2010) writes that:

[...] in 1857, two tracts of land were set aside for Algonquin people. These tracts consisted of 15,360 hectares at Temiscaming in present-day western Quebec, and 18,300 hectares at River Desert also in Quebec. Not all Algonquin wanted to go to these two locations. Thus, in that same year five families near Golden Lake petitioned the Governor General (88).

The requests by the families near Golden Lake for eighty hectares per family (the size of free land grants available to white settlers) was refused through racist logic that allowed 
white settlers to access free homestead grants, or claim squatters rights or preemptory rights, but denied Algonquin people the ability to acquire property.

In 1864,624 hectares were purchased for $\$ 156.10$ by the Indian department using Indian funds for the land that became the Golden Lake reserve (today known as Pikwàkanagàn) (Gehl, 2010). Gehl (2010) explains the significance of this purchase:

This system of establishing a reserve through purchasing lands with Indian funds was indeed novel. Most reserves were established through the treaty making process. It seems the Algonquin were special. As I have been arguing, the Algonquin Nation has never established a treaty with the Crown (88).

Koschade (2003) explains that Algonquin families who lived outside of the three reserves continued to petition the government for their own land grants, but their rights continued to be restricted and reserves remained limited, with only one in Ontario. Eventually, Algonquin people living in Golden Lake were granted "Indian status" (and by default, those Algonquin people who lived off-reserve became "non-status Indians").

Sherman (2007) offers extensive documentation of the petitions submitted to the Crown demonstrating the understanding of Omàmiwinini people that the Royal Proclamation of 1763 set the grounds for the relationship between them and English people, and that the terms of the agreement were not being honoured by the Crown through increasing encroachment on Omàmiwinini hunting grounds and traditional lands by settlers, while Omàmiwinini people continued to honour their commitment to the agreement. These petitions were continuous and offer extensive documentation of assertion of Algonquin jurisdiction in the territory and how their rights to the lands were being abused. 
In 1983, Algonquin people added yet another petition as part of the newly formulated comprehensive land claims procedure, though it was not responded to by the federal government or the Government of Ontario for four years (in violation of land claims procedure) (Gehl, 2010). In 1991, the Algonquin land claim was accepted by the provincial government and in 1992 it was accepted by the federal government. Gehl (2010) explains:

Thus, the Algonquin land claims to their traditional territory was finally accepted by the governments of Canada 220 years after the first Algonquin petition was submitted in 1772 . This was a total of 230 years after the Algonquin Nation facilitated The Treaty at Niagara of 1764 where The Royal Proclamation of 1763 was ratified (64).

Over twenty years since the process began, the Algonquin land claim is still in negotiation today.

The claim is being negotiated with the intent to agree upon a settlement which will result in an Algonquin treaty that will address the following considerations: “ownership of lands, rights and management obligations regarding natural resources (e.g., hunting, fishing, trapping and gathering rights, etc.), compensation, jurisdiction, economic opportunities, and/or other initiatives to promote the survival of Algonquin culture" (Tanakiwin, 2009). The land claim covers an area of 36,000 square kilometers (8.9 million acres), within the Ottawa and Mattawa River watersheds, in Ontario (see Figure 4.4). The Ontario Ministry of Aboriginal Affairs (OMAA) explains that the claim area includes most of Algonquin Park, Canadian Forces Base Petawawa and the National Capital Region, including Parliament Hill. As mentioned, the goal of the land claim is to reach a final settlement "which will provide certainty of legal title to lands in the region 
and will give legal force to a lasting and comprehensive settlement of all outstanding issues related to this Aboriginal claim" (OMAA, 2009b).

Figure 4.4: The Area Under Negotiation in the Algonquin Land Claim
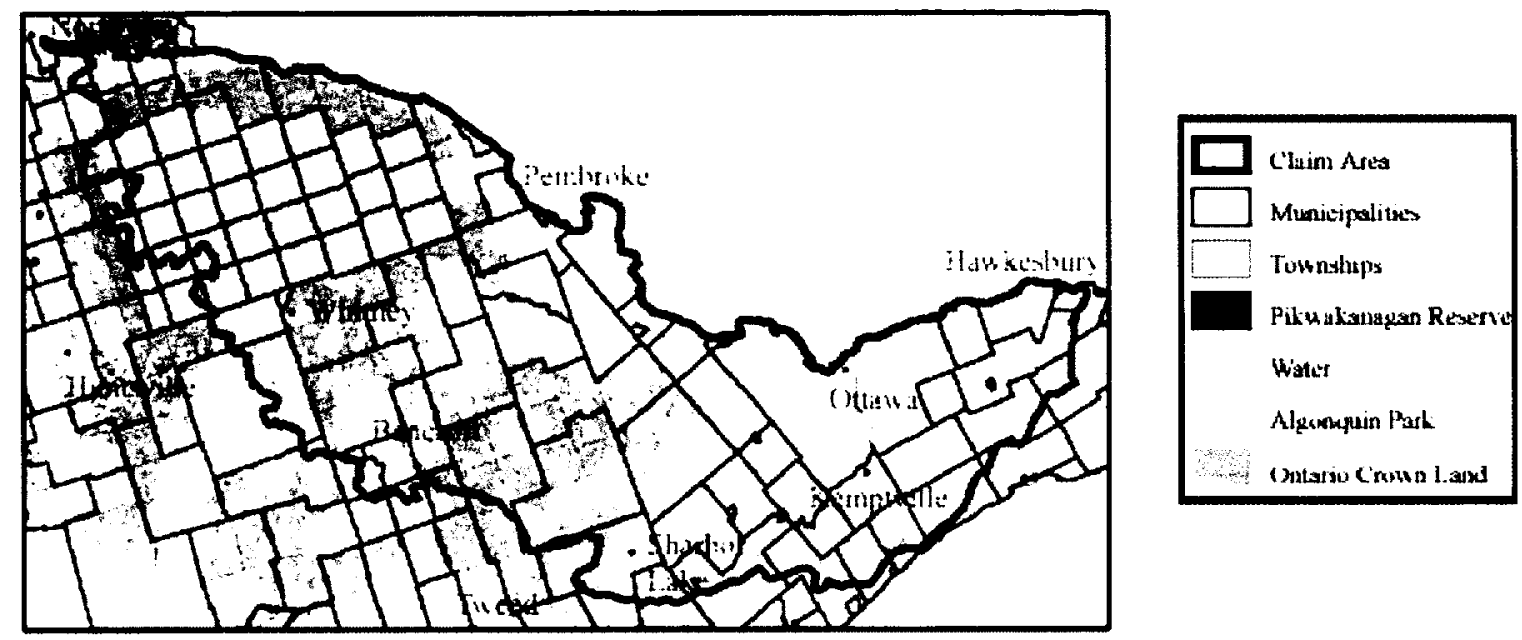

Source: OMAA, 2012.

The land claim is being negotiated by the federal Government of Canada, the provincial Government of Ontario and the Algonquins of Ontario, which at the time of writing include the Chief and Council of Pikwàkanagàn and Algonquin Negotiations Representatives from the following off-reserve Algonquin communities: Antoine, Snimikobi (Ardoch), Bancroft, Bonnechere, Greater Golden Lake, Mattawa/North Bay, Shabot Obaadjiwan (Sharbot Lake) and Whitney. The land claims process has been very divisive in terms of delineating power between status and non-status Algonquin communities (Majaury, 2005; Sherman, 2007; Gehl, 2010), and also between Algonquin people in Ontario and Quebec (Gehl, 2005). There have also been Algonquin 
communities that have completely withdrawn from the process, including the Ardoch Algonquin First Nation, the Ottawa Algonquin First Nation and Kichesiperini First Nation (Green, 2007).

\subsection{Maintaining a Colonial Present through Judicial and Legal Processes in Canada}

As illustrated in the above discussion, French, British and Canadian legislation have been central to the colonization and settlement of Indigenous traditional territory throughout what is now known as Canada. Various authors have discussed how the current legal order is upheld by colonial foundations, including racial hierarchy and discrimination (Monture-Angus, 1995; Razack, 2002;Thobani, 2007; Lovelace, 2009). It is through these analyses that the incongruity between Canadian laws (including the Constitution) and Indigenous sovereignty and self-determination (as established in the United Nations Declaration on the Rights of Indigenous Peoples, for example) can be understood. In a letter originally written from prison after his incarceration for blockading the Robertsville uranium mine site in Algonquin territory, Lovelace (2009) explains the processes through which colonial law is maintained by regulating Indigenous peoples lives, land and governance: 
Canadian governments are divided into three separate legal orders. Parliament and legislatures create law, cabinets administer law, and the judiciary decides how laws can be applied.[...] Contrary to popular opinion, the courts are not very useful in deciding issues relating to Aboriginal people. Poor decisions affect subsequent rulings, building layers of harmful precedent into a tide of history. It can take decades to remedy inadequate decisions made by ill-informed judges. The court process is extremely costly and accentuates the disparity between indigenous communities and colonial governments. Canadian jurisprudence is historically prejudiced in favour of colonial values and aspirations. Finally, although Canadian law has its foundations in the doctrine of continuity in regard to the Aboriginal right of self-governance, Canadian courts are restricted by letter and politics to acknowledge only colonial law (xiv)

Patricia Monture-Angus (1995), late legal academic and Mohawk woman, in her discussion of the rigid structure of law, its exclusionary language and the foreclosure of participation by "outsiders" explains that Canadian law is not reflective of Indigenous values or governance traditions and has been imposed upon Indigenous peoples without consent, as part of ongoing colonial oppression and dispossession. She writes:

Our understanding of law is not represented within the structure of the Canadian legal system. We experience that system, particularly the criminal justice system, as racist and oppressive. We, as individuals, did not participate in the process whereby the legal system was formed. We did not participate in the process of agreeing to the assumptions and values reflected in the system. Further, we have been excluded as Peoples in participating in the formation of that system. More importantly, First Nations Peoples have never consented to the application of the Canadian legal system to any aspect of our lives. It is important to note that the issue of consent is different from the issue of inclusion. These realities are continually ignored by the Canadian government, the legal profession and the judiciary. Only by understanding the history of the Canadian legal system can we then understand why the result of this system is not justice but exclusion and force (34-35).

In her book, Exalted Subjects: Studies in the Making of Race and Nation in

Canada, Sunera Thobani (2007) illustrates how Canada maintains a racialized and 
gendered order based on the exaltation of particular conceptualizations of Canadian nationals and the marginalization and exclusions of "the other" - including Indigenous peoples, people of colour, and immigrants. Thobani offers a detailed and rich account of the violence that upholds the lawfulness of Canada as a sovereign nation. In both of this books Lawrence (2004) and Thobani (2007) illustrate how Canadian legislation is founded on a colonial order of racialized and gendered violence. Thobani argues that the Canadian subject is conceived of the colonial violence that was necessary to establish the juridical order and she argues that in turn, the notion of legality under which the nation was founded, has been essential in the construction of national identity. Monture-Angus (1995), Lawrence (2004) and Thobani (2007) present lawmaking as an assumption of power and a simultaneous suppression and negation of previously existing Aboriginal governance and as such, a necessarily violent process, both as means and ends.

Thobani (2007) draws on Mbembe's theory of the historical implementation colonial violence, of which there are three kinds of violence: founding violence; authorizing violence; and maintaining sovereignty. Founding violence, according to Thobani, was rooted in the rationale of religious, cultural and racial superiority, which established the right of Europeans to occupy inhabited lands and to kill. It consists of material and physical practices that were used to decimate Indigenous populations.

Authorizing violence was enacted through laws that were invented, created and performed in order to legalize the violent oppression of Indigenous peoples (first by applying medieval Christian law to peoples in foreign lands, such as the Papal Bull "Inter Caetera" of 1493 and the Doctrine of Discovery, and later through British Common Law 
which established the Crown's title over all land both in Britain and abroad). Authorizing violence, as conceptualized by Thobani, is established by the authorizing authority - it is the circular logic used that lawfully established the British Crown (and later the Canadian government) as the rightful sovereign nation. Thobani deconstructs the Royal Proclamation of 1763 and illustrates the central paradox of British sovereignty, whereby the lawfulness of the Crown is established by the Crown itself and it is therefore both inside and outside of the law. Thobani (2007) explains that legal legitimacy was necessary in the international context: "European sovereigns understood that the question of legality of colonial rule was to play a critical role in the maintenance of colonial relations, as well as in legitimizing their own claims of sovereignty over these lands against those of other European powers who coveted the same" (43). Consequently, "European powers constituted themselves as law-upholding entities at the international level by forging a secular law that was to enable, and sustain their racial domination of colonial peoples" (Thobani, 2007: 44). By establishing European law as the legitimate sovereign law governing relations in Canada, Thobani (2007) argues that "law became the rule of race" (45).

The third form of violence, maintaining sovereignty, was and is enacted through racialized and gendered apartheid through the Indian Act and reserve system which legally defined 'Indians' as separate from 'Nationals', and continues to exist today. The violence of maintaining sovereignty, Thobani (2007) argues, was and is also enacted by settlers who realize(d) the authority of the Canadian sovereign nation on the ground through the subjugation and violent displacement of Aboriginal peoples. Furthermore, 
the legitimacy of Canadian sovereignty was and is created through national mythologies of the inferiority of Aboriginal people as uncivilized, and vis-à-vis the concept of the empty land or terra mullius [reinforced, for example, through conceptions and depictions of Canadian pristine wilderness (Braun, 2002; Lawrence, 2004; Mackey, 2005)].

There are notable and very positive legal amendments and decisions set by the Canadian courts and the Canadian government that represent positive changes in relations between the Canadian government, settlers and Indigenous peoples. Most notably, in 1982, the Canadian Constitution was amended, and in Section 35 of the Constitution Act, 1982 , "the existing aboriginal and treaty rights of aboriginal peoples of Canada" (s. 35) were recognized and affirmed. This decision has completely changed the terms of Indigenous-settler relations, to a politics of recognition, rather than explicit assimilation policies and treatment of Indigenous peoples as wards of the state. Phare (2009) explains that:

With this decision, Indigenous Nations' legal status became unique in the world. More importantly, it opened the door to a reconciliation of the past based upon respect, dignity and honour [...]

This recognition is also important because with it comes the highest level of protection a country can give to rights held by a citizen, higher than any other law which that country has (29-30).

Unfortunately, delineating exactly what does and does not constitute Aboriginal rights has been a complex, evolving and long-standing process, involving time-consuming and expensive legal proceedings in the Canadian courts. Phare (2009) notes there is not yet one concrete definition of Indigenous rights. In an important distinction, Aboriginal rights are recognized as valid by Canada, only "once they are acknowledged by a court or the government itself' (Phare, 2009: 36). On the other hand, Phare (2009) explains that 
Indigenous rights are understood as inherent to Indigenous identity:

Indigenous peoples, however, refer to their rights as being inherent in their Nations, given and limited by the Creator's laws and responsibilities, including the laws of stewardship and reciprocity with nature. These principles cannot be altered or narrowed by other humans, their governments or their laws, and this includes all Canadian governments $(36-37)$

Thus, a significant contradiction remains with respect to the very basic conceptualization of Indigenous rights, despite important and progressive changes to Canadian legislation. These contradictions become readily apparent in the following chapters, as I examine how the Ardoch Algonquin First Nations and Allies' access to manomin has been affected by various "development" initiatives, and how they have protected and maintained their access to and responsibility for manomin and its supporting ecosystems.

\subsection{An Ongoing Colonial Order: Maintained Through "a great array of bayonets and cannons" (Thobani, 2007: 35)}

A survey of critical feminist studies illustrates how the colonial nation mobilizes various strategies (in addition to the law) to establish itself rightfully, legitimize its presence and maintain a particular social order grounded in racial and gendered hierarchy in a space already inhabited by independent and autonomous nations (Razack, 2002; Lawrence, 2004; Mackey, 2005; Thobani, 2007). Settling a land that was and continues to be inhabited by other sovereign nations, as is the case with Turtle Island, or what we now call North America and more specifically Canada today, has been and continues to be a multi-faceted and complex process that is enacted in multiple spheres of socio-politicalhistorical influence, or as Thobani (2007) puts it though "a great array of bayonets and 
cannons" (35). These spheres of influence include: the law; regulation of Indigenous governance (as discussed by Lawrence and Anderson, 2005); art (Mackey, 2005); historical spectacles which help to invent history (McClintock, 1997); and the media (Vukov, 2003).

Canada is a country rife with contradictions, particularly with respect to selfrepresentation as an open multicultural nation with exemplary democracy and civil liberties, with often conflicting realities on the ground. An examination of settlerIndigenous relations is one way to uncover these inconsistencies and half-truths upon which the national mythology is based and maintained. For instance, on June 11, 2008, the Prime Minister of Canada, Stephen Harper, issued the "Statement of Apology - to former students of Indian Residential Schools", an apology on behalf of the Government of Canada to residential school survivors, their families and communities for the policies of assimilation through education and separation from families, and for the neglect and abuse that occurred in these schools for over 100 hundred years for over 150,000 Aboriginal children (Harper, 2008). It would seem that the Government had taken responsibility for past wrongdoings and acknowledged a shameful colonial history. Astonishingly, only one year later, at the close of the G20 Summit in Pittsburgh, Pennsylvania, on September 25, 2009, while expounding the virtues of the Canadian economy and the stability of Canadian democracy, Harper was quoted as saying: "We also have no history of colonialism. So we have all of the things that many people admire about the great powers but none of the things that threaten or bother them [...] Canada is big enough to make a difference but not big enough to threaten anybody" 
(Ljunggren, 2009). How the same leader can present such very different perspectives is confounding.

Canada had also voted against the adoption of the United Nations Declaration on the Rights of Indigenous Peoples (UNDRIP) in 2007, along with Australia, New Zealand and the United States of America (all white settler states), while it was endorsed by the support of 143 countries and adopted by the UN General Assembly on September 13, 2007 (Inaction 2010b). It was not until November 12, 2010 that Canada issued an official statement to endorse UNDRIP, which was welcomed by the Assembly of First Nations as a positive step towards "faimess and justice" (AFN, 2010). Canada has endorsed this declaration with the clarifications that the document is a "non-legally binding aspirational document" (INAC, 2010b). The reasons issued for not supporting the declaration were explained by John Duncan, Indian Affairs Minister and parliamentary secretary, in 2009: "We are not prepared to sign on to this non-binding document because it is inconsistent with our Constitution, the Canadian Charter of Rights and Freedoms, the National Defence Act, Supreme Court rulings, policies under which we negotiate treaties and does not account for third-party interests" (APTN National News, 2010). UNDRIP was drafted by Indigenous peoples from around the globe over the course of 20 years. The declaration contains 46 articles, some highlights of which include: the right to self-determination and self-government; the right to freedom, peace and security; the right to practice traditional customs and traditions without discrimination; the right to establish and control educational institutions; the right to maintain relationships with traditional lands (UN, 2008). The implications of Canada's 
endorsement of the declaration as a "non-legally binding aspirational document" (INAC, $2010 \mathrm{~b}$ ) remain to be seen.

The above discussions serve to illustrate the ongoing colonial present, so frequently overlooked in mainstream Canadian discourse. The relations between Indigenous peoples and the Canadian government, settlers and other actors are entrenched in a complex socio-political and ecological history, which sets the terms for acceptable actions, which often serve to further dispossess and marginalize Indigenous peoples and compromise Indigenous self-determination. By closely examining the case of access to wild rice (manomin) by the Ardoch Omàmiwinini many of the contradictions of Canada as a fair, democratic, multicultural and post-colonial state become apparent. This thesis therefore serves to illustrate current relations between the Canadian government, settlers (and other non-Indigenous actors) and Indigenous peoples through an examination of settler-Algonquin relations in the valley of the Kiji Sibi. 


\section{Chapter 5: "Development" and Manomin - Current Challenges and/or Opportunities}

Chapter 5 presents the results and analysis of the preliminary portion of the research question guiding this thesis: What are the challenges and opportunities of 'development' with respect to the Omàmiwinini of Ardoch's capacity to maintain access to manomin (wild rice)? This chapter therefore outlines and documents which developments have occurred in the area that have affected manomin, whether by improving access to manomin, or by inhibiting and creating barriers that limit access to manomin. In Section 2.3.1, development is discussed as: an idealized linear progression, in this case towards improvement through economic and industrial transformation; as a discourse used to construct relations of difference that sustain the logic of domination of one group over another; as a result of the flows of capital; and as part of the ongoing, culturally mediated social, political and economic regime of western colonialism. The results presented in this chapter aim to reflect the research participants' understanding of development and how it has affected manomin and/or access to it.

The results presented in both Chapters 5 and 6 are the outcome of the qualitative research methods and methodologies described in Chapter 3 of this thesis. The research data includes the primary data collected, in the form of recorded and fully transcribed semi-structured interviews, and the secondary data derived from existing literature that further discuss how particular developments and processes have affected the ecology of wild rice, or Indigenous peoples' access to this traditional food.

This chapter begins with an overview of how the research data was collected and analyzed in Section 5.1. Section 5.2 discusses the historical connections between the 
manomin at Ardoch and settler development in the area through the logging industry of the $19^{\text {th }}$ century. Section 5.3 outlines the various developments that have affected maintaining access to manomin since its establishment. Developments discussed in Section 5.3 include: the use of herbicides to maintain hydro-electric lines; attempts to commercialize and commodify the manomin at Mud Lake and recreational activities on the Mississippi River. Other developments that have affected AAFNA's access to manomin that are also discussed include: hydrological management of the river; uranium exploration and mining in the region; the Algonquin comprehensive land claim; and, the contemporary food system. In Section 5.4, this chapter concludes with a discussion of the various factors responsible for developments in the region that affect access to manomin, as well as an overview of the AAFNA perspectives on "development" as it pertains to manomin.

\subsection{Interpretation and representation of the research results}

It is important to explain how the interview data have been interpreted and represented, in order to emphasize and make explicit once again the role of the researcher, myself, in shaping this research, from design and implementation to analysis and discussion, while also emphasizing the methodological rigour of qualitative research methods. As discussed in further detail in Section 3.2, the semi-structured interviews with five key informants from the Ardoch Algonquin First Nation and Allies, and one public workshop were taped and fully transcribed. The transcripts were returned to the participants to ensure the opportunity to review, edit and/or withdraw their statements, though the 
participation rate in this opportunity was low with only one research participant choosing to edit their interview transcript. Each transcript was coded for analysis, using both 'invivo codes' [defined by Peter Jackson (2001) as "terms used by informants themselves that the researcher regards as significant" (202)] and analytical or constructed codes, which are "abstracted from the data by the researcher" (Jackson, 2001: 202). Thus references to development, manomin, community identity, Indigenous and/or Algonquinsettler relations, resistance, resilience and oppositional practices were deemed significant, coded and grouped according to themes. After coding each individual transcript, all of the codes were compiled according to themes in order to allow for reading and analysis across the interviews, rather than within each individual interview (Jackson, 2001). This technique effectively allows for polyvocality, or difference amongst community members, to emerge (Ley and Mountz, 2001).

Section 1.6 of this thesis provides an overview of the history, governance and political activities of the Ardoch Algonquin First Nation and Allies (AAFNA). As discussed in Section 2.3.1, many of AAFNA's political activities have resulted from their strong oppositional stance to encroachments into traditional Algonquin territory in the Kiji Sibi watershed that have been justified through the logic of technological, industrial and capitalist "development". This chapter serves to document and analyze if and how these developments (and others) are connected to the continued access to manomin by Ardoch Algonquin community members. 


\subsection{Manomin in Ardoch: A consequence of $19^{\text {th }}$ century "development" in the}

\section{Ottawa Valley}

The manomin at Mud Lake, near Ardoch, Ontario is unanimously acknowledged by all research participants to have been planted by the ancestors of Harold Perry (AAFNA elder and current manomin steward) who came from Alderville (Alderville First Nation is a Mississauga First Nation in southern Ontario). The reason that manomin was brought from people at Alderville to the Algonquin people at Ardoch is directly attributed to the encroachment of settlers and the logging industry practices that were so prevalent in the Ottawa Valley in the mid-1800s.

Robert Lovelace (2010a), former chief of AAFNA, explains the significance of the lumber mill that Philemon Wright had established in present day Ottawa-Gatineau:

From the time he [Philemon Wright] set up that mill in 1800s at Chaudière Falls which is now Ottawa, Ottawa Gatineau area, within a generation loggers were exposed from the Madawaska, Rideau and Mississippi rivers. Within two generations they were logging within the eastern end of the big Rideau lakes, to Carleton Place and Perth and up into Calabogie. But that really stripped off the environment that the Algonquins depended on. And so, the very environment which they found sustainability and built their culture within was being splintered by the 1830 s.

Paula Sherman, former co-chief of the Ardoch Omàmiwinini, further explains how the logging practices of the mid- $19^{\text {th }}$ century destroyed the forests that sustained Algonquin people. She explains that the white pines in the forests of the region were harvested for the masts of British ships and for square timber, and that entire forests were burned to access these trees. Consequently, the area became filled with thick black smoke, destroying Algonquin livelihoods: 
$[\ldots]$ so it was burned to the ground to get to that. And of course Algonquin communities and Mississauga communities were caught in the middle of all that and were just living on the periphery [...] and there's oral tradition, and even documentation talking about that. In a lot of the Algonquin territory, there was thick black smoke everywhere from the fires constantly burning. There really wasn't a lot of animals around, not a lot of game around because they're not going to stay in areas where there was always clouds of thick smoke. The sun wasn't really shining through, so the bits of scattered agriculture that Algonquins would have done, corn and things like that - not that we did a lot of that anyway cause a lot of that was gotten in trade - but the little bit of farming that people would have done would have been hampered because of the thick black smoke hanging around the forest. There wouldn't have been a lot of sun shining through. And maybe there would have been some fishing, I don't know how that would have impacted the water (Paula Sherman, 2010b).

Thus, the very beginnings of the manomin that now stands at Mud Lake in Ardoch are rooted in an act of solidarity and support by the people of Alderville for those in Ardoch, who were suffering from the impacts of settler encroachments and colonial resource extraction. Mitchell Shewell, member of AAFNA explains the continuing significance of manomin and the importance of its history:

The wild rice, that's our main food staple, that's why we're here, that's why I' $m$ here, is because of that wild rice. If it wasn't for that wild rice my people wouldn't have stayed here, they wouldn't have stayed in Ardoch, they would have left, because it was such a bad time, with the settlers and all the stuff coming in. So they wouldn't have stuck around. They were starving. And that's why the rice was brought down, was because they were starving. And the people of Alderville realized that.

So it was brought down from the women of Alderville, they were the ones that brought it to us, gave it to us as a gift, so that's really important. So its still today, its there, its there for our taking, its there for us to go and gather, and take care of it. (Mitchell Shewell, 2010)

At the same time, the sharing of manomin by the people of Alderville was also tied to the alteration of the environment and ecology of the Trent and Severn rivers and 
the destruction of traditional livelihoods of Mississauga people in that region in the name of "development" for Ontarians. Mississauga scholar, Leanne Simpson (2008) explains:

Over one hundred years ago, the Federal Government expropriated Mississauga lands and water to complete the Trent-Severn Waterway, a system of locks and canals linking Lake Ontario and Georgian Bay. The waterway was heralded by settler governments as a major advance that would open up access to markets in the south, strengthening the economy to the benefit of all Ontarians and, indeed, all Canadians.

But not for the Mississauga. The ancient travel route was our river highway, leading to a network of travel and trading routes to the north and the west - an ancient travel route that now was physically colonized. No longer could the lifeblood of our Mother run unobstructed through the veins of our lands. No longer could that lifeblood nurture and cleanse our land. Our Elders knew the impact of the waterway would be devastating to our lands, lakes and rivers and especially to our manoomiin, our wild rice. In an attempt to mitigate these impacts, we turned to our friends and our neighbouring nation, the Omàmiwinini. One of our Elders gave manoomiin seeds from Rice Lake to Omàmiwinini Elders who planted those seeds in the Mississippi River, near Ardoch Ontario. The Ardoch community has nurtured and protected those seeds through the past century, so that each fall our community members can harvest our shared manoomiin (9-10).

This connection, of mutual impact and adverse consequences of settler, industrial and developmental encroachment, and of connection and support for both the people of Ardoch and of Alderville was also noted by some research participants representing AAFNA (Perry, 2010; Sherman, 2010c; Shewell, 2010).

The planting of the wild rice in the Mississippi river, near Ardoch, represents a watershed moment that is representative of the history of settler-Indigenous relations in the Ottawa Valley, during which settler governments, private industries and people began to encroach upon Algonquin territory and exploit the natural resources of the region in an unprecedented manner. European economic interests in the area shifted from the fur trade in the $18^{\text {th }}$ century - in which the Omàmiwinini and their traditional relationships 
with the land and animals were "valuable link[s] in the commodity chain" (Smith, 2009: 18 ) - to resource development through lumber and timber extraction beginning in the $19^{\text {th }}$ century and becoming firmly established upriver of Chaudière Falls by the middle of the $19^{\text {th }}$ century (Brascoupé, 2012). As a result, traditional Algonquin livelihoods became threatened by effectively destroying much of the forests in the valley of the Kiji Sibi through intensive cutting practices and the use of fires to clear the brush to reach the white pines, create agricultural lands or make potash as a byproduct (Suffling, Evans, Perrera, 2003; Lawson, 2009). As discussed by Milloy (1991), Sherman (2007) and Smith (2009) Indigenous-settler relations shifted significantly in the Ottawa River Valley, from a relationship of respect and partnership on a nation-to-nation basis, to an assertion of settler dominance over Algonquin people and territory and the destruction of Algonquin livelihoods through intensive resource extraction on traditional Omàmiwinini lands.

This shift in Algonquin-settler relations in terms of resource exploitation also maps onto the shift in Indigenous-settler political relations after the 1800 s, as discussed in Chapter 4 and as outlined by Sherman (2007) in thorough detail in her dissertation. She notes that after the 1800 s, the commitment of British officials to honour the agreements set out in the Royal Proclamation of 1763 began to wane. She explains:

From 1800 to 1850 there was no set policy that settlers or officials could count on in their dealings with Indigenous communities and Nations because Indian policy was in flux in Upper Canada which led to contradictory decisions on the part of many officials who were interacting with Indigenous peoples (Sherman, 2007: 259).

Sherman further notes that although there were no official policies informing settler- 
Indigenous relations during that time period, interactions were nonetheless informed by: ideologies that influenced how officials and settlers approached relations with Indigenous peoples on Indigenous territories; and by the redefinition of space through infrastructure developments (such as the building of colonial roads through which access to Omàmiwinini territory was increased) and land surrenders of Omàmiwinini territory by Mississauga agreements [through the Crawford Purchase (1783), the Rideau Purchase (1819) and the Williams Treaty (1923)], after which settlement also increased through official land appropriations. From 1812 to 1850 , the settler population in Upper Canada increased ten-fold (Miller, 2000), demonstrating the increasing pressure on Indigenous lands. The official responses to the numerous petitions submitted by Algonquin people to Crown officials ranged during this period, sometimes reflecting the commitment to honour agreements set out in the Royal Proclamation, though increasingly demonstrating a policy to discourage Algonquin subsistence activities, such as hunting, gathering and fishing, and to encourage the settlement of Algonquin families onto small tracts of land whereby subsistence would be achieved through agriculture (Sherman, 2007).

Eric L. Smith (2009) explains how in 1830 , the maintenance of the fiduciary relationship between Indigenous peoples and the colonial government became a civil responsibility rather than a military responsibility of the British Crown. Consequently,

[...] during this period, the relationship between the colonial governments and the Omàmiwinini turned from that of 'alliance' to 'irrelevance'. [...] [Thus] relations between the Omàmiwinini and the colonizers were to be defined not by war but by the civilizing peace $[\ldots]$ The remaining indigenous peoples in the expanding colony, who once held the positions of friend [trading partner] and military ally, now occupied the role of ward and subject of the Crown (Smith 2009: 18, quoting Miller, 2000: 116). 
Smith (2009) characterizes the subsequent period - shaped by the significant shift in official governmental policy regarding Indigenous peoples after the $1830 \mathrm{~s}$ - as one of cultural genocide, through which racial difference and hierarchy (white supremacy) were rationalized, and relationships with people, land and "resources" were concurrently changed "to align with the 'industrious and peaceful habits' of the colonists, such as logging, mining and agriculture (19). Smith (2009), like several other writers (Milloy; 1991; Lawrence, 2004; Thobani, 2007) notes the significance of the introduction of "Indian" identity legislation in 1850 (discussed in Section 4.4), through which the colonial government was able to assert control over Indigenous governance and identity, as a tactic towards assimilation and enfranchisement. Smith (2009) further argues that the reconfiguration of Indigenous-settler relations during the 1830s, "along with the establishment of civil 'Indian' administration, marks the birth of the governmentsupported extractive industry as a colonial institution" (Smith, 2009: 19). Thus, Smith (2009) notes that the shift in political relations were directly linked with increasing resource extraction, exploitation and theft.

Brascoupe (2012) links the above shifts with the formation of the Canadian state, noting the change in government policy in the pre-Confederation era from the British policy encouraging Indigenous self-government to the Canadian policy of assimilation. He posits that this shift was crystallized in the Bagot Commission report (1844), wherein methods to "civilize" "Indians" were suggested through assimilation of European livelihoods, property rights and social structures (Huitema, 2000). Similarly, Milloy (1991) argues that it was through Constitutional change, with the passing of the Gradual 
Civilization Act of 1857, the British North America Act (the Canadian Constitution 1867), the Enfranchisement Act of 1869 and the Indian Act (beginning in 1876 and continuing to today) that the colonial government became directly involved in Indian affairs and prioritized development over traditional constitutional relations (such as those embodied in the Royal Proclamation of 1763). Milloy argues that the developmental logic to encourage "industrious," "properly educated," "self-reliant farmers" was cultivated in the pre-Confederation era - the same time period in which colonial agents began to withdraw from their commitments to the Omàmiwinini to protect their traditional hunting lands from settler encroachment. Milloy (1991) writes:

It was the formulation of what might be termed a developmental logic mainly in the pre-Confederation era which both motivated constitutional change and determined the nature of it. Any understanding of the acts of $1857,1869,1876$, and no doubt that of 1951 [all of which discuss the regulation of 'Indian' identity], and of the particular constitutional states they forced upon native people is rooted in the historical evolution of that logic - in the deterministic nature of developmental strategy (147).

Milloy explains that a central component of the developmental logic was a perceived need to shift Indigenous peoples' property relations towards individualized property. Indigenous peoples were encouraged to attain individualized property through individual tenure and through enfranchisement, in which reserve lands would be parceled off for private holdings. In addition to enfranchisement and individual tenure, the colonial developmental strategy "included the more traditional elements of skill training, education, resource development, and general behavioural modification through conversion to the Christian faith" (Milloy, 1991: 147), and later the involvement of the federal government of Canada in Indian governance. Milloy (1991) explains that 
"through its control of native government, the department could now institute all the systems of development it cherished. Under the Act of 1876 it could create for example, individualized land holding, determine the use of resources, and create particular educational systems" $(151-152)^{27}$. Thus, Milloy argues, constitutional change was ultimately guided by a developmental logic that prioritized individual property tenure, resource development and the imposition of social, cultural and political changes.

The political history of Algonquin-settler relations is directly linked with Algonquin access to traditional foods. In an interview conducted for this research, former AAFNA co-chief Paula Sherman explains the ongoing role of the historical legacy of settler colonialism in limiting Indigenous access to their lands and of the government policies and agencies (such as the Ontario Ministry of Natural Resources and the Ministry of Northern Development, Mines and Forestry) that control access to natural resources:

There's a relationship between us [Algonquin people and all of those things coming out of creation and relationships over thousands of years], by trapping or hunting or harvesting, that in itself is a ceremony, is a relationship that has to be maintained, which I think also takes it out of a western context in thinking about it. Which the MNR and none of those people get. They don't understand that I think. [...] MNR policy isn't designed to allow them to experience that. It goes back to the whole entire policy, all of the policies that has Canada has, Ontario has, since we're talking about Ontario in this particular context. I think that all of the policies that Ontario has, all those policies that were developed in the context of settler colonialism, all those policies flow out of the BNA [British North America] Act and flow out of the ways in which things were put under the domain of the MNR [Ministry of Natural Resources].

27 It is important to note that the control of Indian bands only applied to those First Nations who had official status under the Indian Act. As discussed earlier in this thesis, the Ardoch Algonquin First Nation remains a community independent of the Indian Act Band status and structures. Thus, the families who were outside of the control of settler governments had more autonomy in terms of govemance. 
I really think that it's the case, that all of the policies that Ontario has around natural resources are developed in conjunction with settler colonialism. It's not just in Canada, any place that has settler societies has these same policies around controlling land and resources developed. For us, I think it doesn't matter whether it's manomin, it doesn't matter if its moose, or harvesting, trapping, fishing, any of those kinds of things, MNR is trying to control access to our lands, trying to control Algonquin access to our land, so that they can do it.

In fact I've been really thinking about mining as an industry and the ways in which that developed out of settler colonialism and the way in which a lot of the policies, even the policies that the MNR says are for conservation, to me a lot of these policies are developing as a way to allow the mining industry to access Indigenous lands for mining. I was just at that resistance against mining conference that operates in Ontario, and that's one of the things that everyone talked about: that the entire development of mining in Ontario, and the policies that developed around mining, and even the policies that developed around the MNR have been created so that they can control our lands, which in our case were never ceded, we never ceded any lands to Ontario.

[...] Any kind of permits that Mining and Northern Development can issue, that can't happen unless the MNR hasn't already leased permits, land occupation permits and things like that, so the MNR is heavily involved in those two industries. Those two ministries are the ones that are heavily involved in controlling access to lands. In fact the MNR started as a Crown lands department in the $19^{\text {th }}$ century. The MNR was actually enforcing policies of assimilation, that has the responsibility of the Crown lands department early on.

One of the things they were trying to do was force Indigenous peoples into agriculture, through farming

[Geri: through enfranchisement?]

Right. You know after Confederation, the development of the Indian Act, all those things. They're trying to force everyone into farming, so anyone who went out and hunted they would use the Crown lands department to charge them. So the Crown lands department, which became the MNR was actually enforcing assimilation, previous to the provincial police even being created, because the OPP don't exist until 1909 in Ontario. Previous to that the Crown lands department is enforcing those things. So they were really policing Aboriginal peoples, Indigenous peoples prior to the OPP even being created. And now they're still doing it, they're still policing us, they're policing our actions and behaviour in ways that they're not policing the mining industry. I think all those policies that have been created allow the mining industry to get access to our lands. It prevents us to get access but it allows the mining industry to get access (Paula Sherman, 2010c). 
Thus, Paula Sherman (2010c), former co-chief of the Ardoch Algonquin First Nation and Allies, makes further linkages between constitutional change and the appropriation of jurisdiction, access and control over traditional Indigenous territories.

AAFNA community member Mitchell Shewell (2010) further explains how early settler encroachments in the mid- $19^{\text {th }}$ century continue to affect access to manomin today:

[We're connected to] all of the other stuff that goes with it [the wild rice]: the making of canoes, you know all the other foods that go with it. [...]We gathered blueberries to mix with the wild rice that we mixed with the moose meat next, we mix those three together for them not to spoil. And we put them in birch bark baskets so they wouldn't spoil.

$[\ldots]$

I look at things like say...birch bark. Which is not a food, but it is so important to us, it's part of our culture. It allowed us to carry the food we gathered. But yet, today we would have to wait 50 to 100 years for trees to be big enough to make the baskets again. So our culture cannot proceed without birch bark. We can't move forward without it. We can't build our canoes, we can't build our baskets. It built our homes, you know that? That's what we built our homes out of. Those trees are gone and until they allow another 100,150 years for those trees to get big enough to do it again, we can't do it. So we're gonna have to wait another 100 years to be able to gather our foods the way we did.

This idea was also echoed by another research participant who explained that the forests that exist in the Ottawa Valley today are much poorer in biodiversity than those that existed over 150 years ago, and were able to sustain Algonquin families for millenia. Thus, the early impacts of settler encroachment and "development" activities in the Ottawa Valley continue to affect the ways in which Algonquin people access, harvest and store traditional foods such as manomin.

This section has served to explain the deep entrenchment of historical political precedence that influences the current development regime that affects manomin and 
access to manomin by members of the Ardoch Algonquin First Nation and Allies. While this discussion mainly focuses on settler governmental policies and settler governmental relations with Indigenous peoples, the sections that follow demonstrate, as was discussed in Sections 4.5 and 4.6, that although colonial settler relations may have been founded upon colonial laws and authority, they are enacted in various spheres. Thus, manomin is located within a complex set of relations that rest upon a legal and cultural foundation that influences the logic of "development" in the area and ultimately, as will be demonstrated below, influences community access to manomin today.

\subsection{Maintaining access to manomin at Mud Lake}

During the interviews, research participants discussed the events that led to the planting of manomin in Mud Lake in the mid- $19^{\text {th }}$ century and various developments that created challenges to accessing manomin, beginning in the 1950s. However there was a period of approximately a century that was not discussed in detail by research participants. From informal conversations, it seems that the ancestors and relatives of Harold Perry were able to maintain their access to manomin and autonomy over this food for over a century. Beginning in the 1950 s and continuing to today, there have been numerous developments in and around Ardoch that have affected the Algonquin community's access to manomin. These developments are discussed below and include: the use of herbicides to maintain hydro-electric lines (Section 5.3.1); the commercialization of manomin through the Wild Rice Harvesting Act and the subsequent Rice Wars of 1979-1981 (Section 5.3.2); motorboat activity and hydrological management (Section 5.3.3); 
uranium exploration and drilling (Section 5.3.4); the Algonquin Comprehensive Land claim (Section 5.3.5); and, the contemporary food system and social change (Section 5.3.6)

\subsubsection{Herbicide use in hydro-electric lines}

Robert Lovelace noted that Harold Perry has talked of how "during the [Great] Depression his family and other families, and settler families basically relied on the rice to get by" (Robert Lovelace, 2010b). As discussed in Section 1.6.1, and corroborated from the research data, it was not until the 1950s and 1960s that there were any significant changes that affected the ecology of the manomin or Algonquin peoples' access to it. At that time, according to Harold Perry [as reported by Perry (2010) himself, Lovelace (2010b) and Delisle (2001)], the rice fields began to diminish, and the Perry family learned that Agent Orange, a highly toxic combination of 2,4-D (2-4 dichlororphenoxyacetic acid), and 2,4,5-T (2,4,5 trichlorophenoxyacetic acid) was being sprayed one mile from the rice beds, in order to control the vegetation around newly installed hydro-electric transmission lines. In fact, recent investigations by the government of Ontario have revealed that Agent Orange was used in a widespread manner across the province. Private industry operations used Agent Orange to increase efficiency in forestry to "weed out" less valuable broad-leaf trees in Northern Ontario forests (Zlomislic, 2011), and the provincial utility also used the defoliant to clear brush under hydro lines on Crown land from 1950 to 1979 (Canadian Press, 2011). Agent Orange is a well-known defoliant used during the Vietnam War. Harold Perry (2010) 
notes that the manomin beds were set back significantly by the spraying of Agent Orange along the hydro lines, and the rice needed to be reseeded and could not be harvested until the late 1970s when people began to actively gather manomin once again. There was never an investigation to confirm whether the losses incurred by the families of Ardoch resulted from the installation of hydro lines and herbicidal treatment. Delisle (2001) notes that it cannot be definitively determined that the rice was set back by the foliar spraying for the hydro lines or by other factors such as other environmental factors, or natural cycles in the ecosystem.

\subsubsection{Resisting the commercialization of manomin}

The rice wars of 1979-1981 - sparked by the issuing of a license to harvest the wild rice at Mud Lake, Ardoch by the Ontario Ministry of Natural Resources (MNR) to a commercial operation - are described briefly in Section 1.6.2, and in more detail below. The selling of manomin (a traditional food of Anishinaabe people) through the issuing of a license to harvest by an agency of the Government of Ontario, was justified and made legal first with the development of a Wild Rice Management Plan in 1954 and then through the Wild Rice Harvesting Act (WRHA) in 1960, implemented by the Department of Lands and Forests, which later became the MNR (Delisle, 2001).

The Wild Rice Harvesting Act (WRHA) thus represents an important piece of legislation whereby the Ontario government appropriated from Indigenous families and communities the responsibility to determine how manomin is to be managed and who should have access to it, greatly altering the governance of manomin. Delisle (2001) 
notes that participation and support from Indigenous people led to the passing of the WRHA (1960). DeLisle (2001) explains that "[i]n the minds of Aboriginal people, wild rice policy began as a means to protect their interests against encroachments" (46), since settler interest and harvesting of wild rice had become significant beginning in the 1930s. Unfortunately, the WRHA did not have reference to the rights of "Indian pickers" (Avery and Pawlick, 1979 quoted in Delisle, 2001). The WRHA (1960) did however provide for 10 block areas for the use of Aboriginal people only, in the Treaty 3 area of northern Ontario, in Kenora and Dryden districts (the largest wild rice area in Ontario) (see Figure 5.1 below for a map of wild rice stands in Ontario).

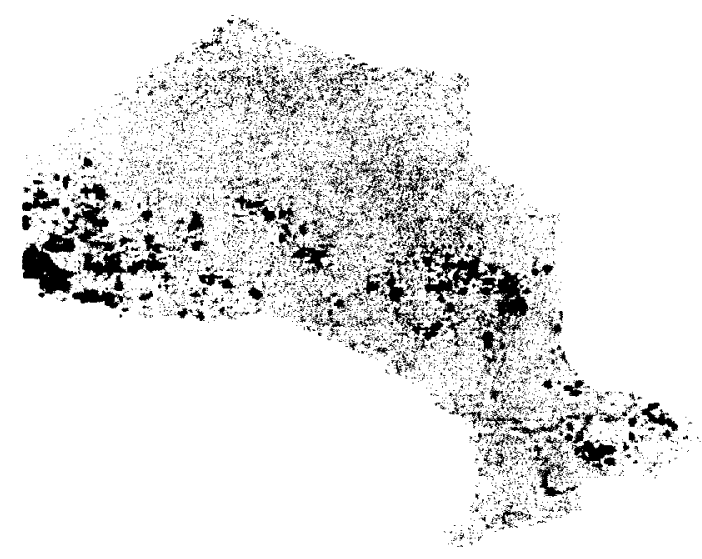

Figure 5.1 - Stands of Wild Rice in Ontario Source: OMNR, 2012

In the late 1970s, after business lobbying efforts to eliminate the block areas, coupled with increases in the efficiency of wild rice harvesting through mechanical and 
commercial harvesting techniques, there was a proposed revision to the Act to eliminate the block areas. Delisle (2001) explains how these proposed changes revealed that Aboriginal rights to wild rice were not as firmly established as many Aboriginal people had thought:

They [Aboriginal people who supported the WRHA] had assumed that the WRHA provided for recognition of their special interest in Manomin. They assumed that it recognized their ownership of Manomin. However, the act did not say, in any manner, that the areas 'belonged' to the Aboriginal people. Rather, as with other resources, the Province considered wild rice to be a Provincial resource to be managed for the benefit of all of the people of Ontario (48).

The MNR thus proposed that these protected block areas be opened up to other users in the areas, in areas that were not commonly used by status "Indians". This was justified by the imperative of economic development to transform the "ineffective" and "wasteful" Indigenous wild rice economy into one that was "effective" and led by "commercial" industry (MNR, 1979 quoted in Delisle, 2001: 50). After protests against the proposal and input about wild rice in the Royal Commission on the Northern Environment (RCNE), the Premier of Ontario at the time declared a five-year moratorium on issuing wild rice licenses to non-Aboriginal harvesters. Part of the moratorium agreement included Ontario's commitment to "extend its efforts to assist Indians to develop appropriate technology and to increase utilization of the available crop" (RCNE, 1979: 104, quoted in Delisle, 2001). As Delisle (2001) notes, though efforts were made to include the Ontario Métis and Non-Status Indian Association (OMNSIA) in the process in which the proposed changed to the WRHA were evaluated, “Ontario's position on Métis and 'nonstatus Indian' people was that they were not 'Indians' under the Indian Act, and therefore 
held rights no different from other citizens of Ontario" (50). Thus, non-Status and Métis access to wild rice on "Crown lands" went unrecognized.

The Rice Wars at Mud Lake (1979-1981) are set amidst a complex period in which Aboriginal rights were being disputed, challenged and defended just prior to the 1982 Canadian constitutional changes in which Aboriginal and Treaty rights were formally recognized (discussed in more detail in Chapter 4). Both Lovelace (2010a) and Delisle (2001) explain that most of the debates surrounding manomin and the Wild Rice Harvesting Act involved the Anishinaabeg of Northwestern Ontario. At the Ardoch

Annual Pow-wow Robert Lovelace (2010a) explains the context of wild rice in 1979:

The Minister of Natural Resources at the time [1979] was James Auld [...] [he] had already confronted some difficulties ... within the last 5 years and the late 1970s in northwestern Ontario because large commercial operations were located in Minnesota which had appropriated wild rice businesses developed from the 1950s on. Some of those were MNR or Aboriginal-Aboriginal operations but most of them were not. In northwestern Ontario it was mostly Manitoba entrepreneurs who were located in northwestern Ontario developing the wild rice there. That got into the liquor trade, that got back into paying almost nothing for Aboriginal people to produce the rice. And Aboriginal people in northwestern Ontario, this was a time, you have to try to imagine, this was a time a lot of Aboriginal people in Canada thought Aboriginal rights were things of the past, long gone. The constitution was not interpreted as including, what was still the British North America Act, was interpreted as still not including any sort of Aboriginal recognition, recognition of Aboriginal rights. But people were asserting that. We were getting smart enough, we were getting smart enough to know that the interpretations of the courts, the interpretation of policy made were wrong. Because historical documents don't exclude aboriginal rights.

In the late summer of 1979, Lanark Wild Rice, owned by Ken and Steve Richardson and Ken Zarecki began a commercial harvest of the wild rice on the Mississippi River, on Mud Lake, near Ardoch Ontario. Delisle (2001) explains that it was at that time that two 
management regimes over the same natural resource came into conflict. She explains

that "[...] a local system of authority and management existed in parallel to a provincial

structure, with both parties presumably unaware of the other. The Mud Lake conflict

represents a collision of these two systems" (Delisle, 2001: 92). Lovelace (2010b)

explains the role that manomin had played in the community around Ardoch prior to

1979:

Well, I think the manomin was seen as the last communal resource in a way. The land began to be divided up in the 1850 s to settlers and at that time Indian people couldn't own land, they couldn't own a piece of land. And they had no access to the land grants that were being given out. And they basically went through a period during settlement really from the War of 1812 on up until the early $20^{\text {th }}$ century of being pushed into the backlands. The land was logged and had been developed for agriculture. And then agriculture declined because the soil was only good for a few decades at the most and then the land gave out. I think the manomin became, it was part of the commons, it was seen as something where people from Alderville came, people from Sharbot Lake came up to Ardoch to harvest wild rice. And the people who were harvesting were the old people, traditional people, the people who remembered their roots, who weren't ready to assimilate. So to harvest rice meant you were an Indian so to speak. And that was a good thing, it was an attachment to the land. It was also an opportunity to do what the old folks did and that was to share with one another and to work together because it's hard work. You know people see each other out harvesting rice and they haven't maybe seen each other all year long. But they see each other out on the lake. So there's that part of the identity. So it really did keep the extended community together as well as the local community and families together. In that way it really did strengthen.

Up until that time, we didn't even know that there was a license to harvest wild rice. Everybody knew that you had to have a fishing license, the government wanted you to have a fishing a license or a hunting license that they regulated those things, but the rice seemed to be one of those things that wasn't regulated by anybody, it was still part of the Indian commons. And in that way it was still very much an Indigenous reality, it was an Indigenous identity.

Lovelace (2010a) provides further context for the Rice Wars at the Ardoch Algonquin 
Annual Pow-wow:

So when a company came in 1979 and was found harvesting rice just down at Ardoch on Mud Lake, it was reminiscent of the loggers and agriculturalists who had come into this area and literally destroyed the environment, it was one more piece of and probably in many ways, it was the last straw. So there was no more avoiding conflict (Lovelace, 2010a).

Thus, a sustained and effective effort to maintain community jurisdiction and autonomy for manomin began. The details of this conflict have been retold for years at a Manoomin Teaching at the AAFNA Annual Manoomin Festival, and are documented by Delisle (2001). They are also detailed briefly in Chapter 6, Section 6.5 in a discussion of how the community has responded to various developments that have affected access to manomin. Paula Sherman (2010b) explains that at that the heart of the conflict between the community members at Ardoch and Lanark Wild Rice and the Ministry of Natural Resources was the commercialization of wild rice. Similarly, Mireille Lapointe (2010), former AAFNA co-chief, explains that the Rice Wars were a conflict resulting from efforts to commodify wild rice:

We don't see manomin as a resource to use for exploitation [...] reasoning it that way encourages us to think of our own sovereignty, our personal sovereignty, and our sovereignty as Indigenous people. And from my perspective, in the ' 80 s when the rice wars happened, why did people rally for that, or do that? Why did they do that? They did it because to allow a company to go in there and to mow down, to savage (and I use the word guardedly) the fields the way they wanted to would have been the end, would have meant that Ardoch was seen as a commodity, the rice would have been seen as commodity. And everything is not a commodity for use and for sale (Mireille Lapointe, 2010).

As Delisle (2001) outlines, Lanark Wild Rice (LWR) was issued a license to harvest by the MNR while the wild rice license moratorium was still in effect as part of a study to determine the feasibility to "develop the wild rice industry in the region" (99) 
and as part of a license held by LWR since 1974 in Lanark County. Over the series of hearings and communications during which the commercial harvest of the wild rice at Mud Lake was contested and defended, the official position of the Ministry of Natural Resources was maintained: that "the province had the responsibility to develop wild rice for the benefit of all of the Citizens of Ontario" by obtaining the "maximum economic benefit" while maintaining a sustainable yield (Delisle, 2001: 117). Thus "development" of the wild rice itself had resulted in one mechanical, commercial harvest of the lake in 1979 , had tied up the community in a legal battle from 1980 to 1982 and in a stand-off in

1981. Thus, at the end of the Rice Wars in 1982:

[...] the MNR was able to maintain their legal authority over the wild rice on Mud Lake through the community's agreement to apply for a license to harvest, the community's functional authority was maintained by MNR withdrawing from their involvement in the managing and harvesting decisions regarding the crop and by providing for a future settlement to be reached at a later date (Delisle, 2001: 137)

Since that time, the MNR has not been directly involved in controlling access to the manomin on Mud Lake, however, as discussed below, the MNR and other government agencies (at the provincial, municipal and federal levels) continue to be involved in other development activities that affect the ecology of manomin.

\subsubsection{Effects of motorboat activity and shoreline and hydrological management}

Nearly all research participants noted that boat traffic and the management of the plant growth around individual properties, cottages and a resort that are alongside the rice fields in Mud Lake pose a significant threat to the ecological viability of manomin. Harold Perry (2010), manomin steward and resident on the Mississippi River just 
upstream from the manomin fields, observes:

Now we have a problem with the big outboards, pontoon boats. There was another huge barge that goes down and tears huge channels through the rice, with no regard to the fact that its our garden. So that I see as a threat, the greatest threat now is the activity and people on that river. They go through there in the spring when there's no channel, when the water's high, and they disturb the seeds that have landed and they roll them up, and lose a lot of seeds that way.

I think at this point we're probably losing a bit of ground because of this activity, so I don't know how long we can hang on there. Its discouraging to me because you know you try, and people just don't care. Some people are ignorant, and we're going to try and correct that but for the most part, they probably just don't care.

During my two visits to the manomin fields on Mud Lake, there was a wide channel in the river (ranging from approximately 4 to 5 metres across to much greater widths at other spots) as well as some other smaller channels cutting through the manomin fields that are in use by various motorized boats (Figure 5.2). Just upstream from the manomin there is a tourist camp with docking space for at least 15 boats, which Harold Perry noted, increases the boat traffic on the river. At the time of my visits to the area, I saw a few large barges docked at the camp in addition to smaller motor boats (see Figure 5.3). 
Figure 5.2: Channels cut by motorized boat traffic through manomin fields on Mud Lake, Mississippi River

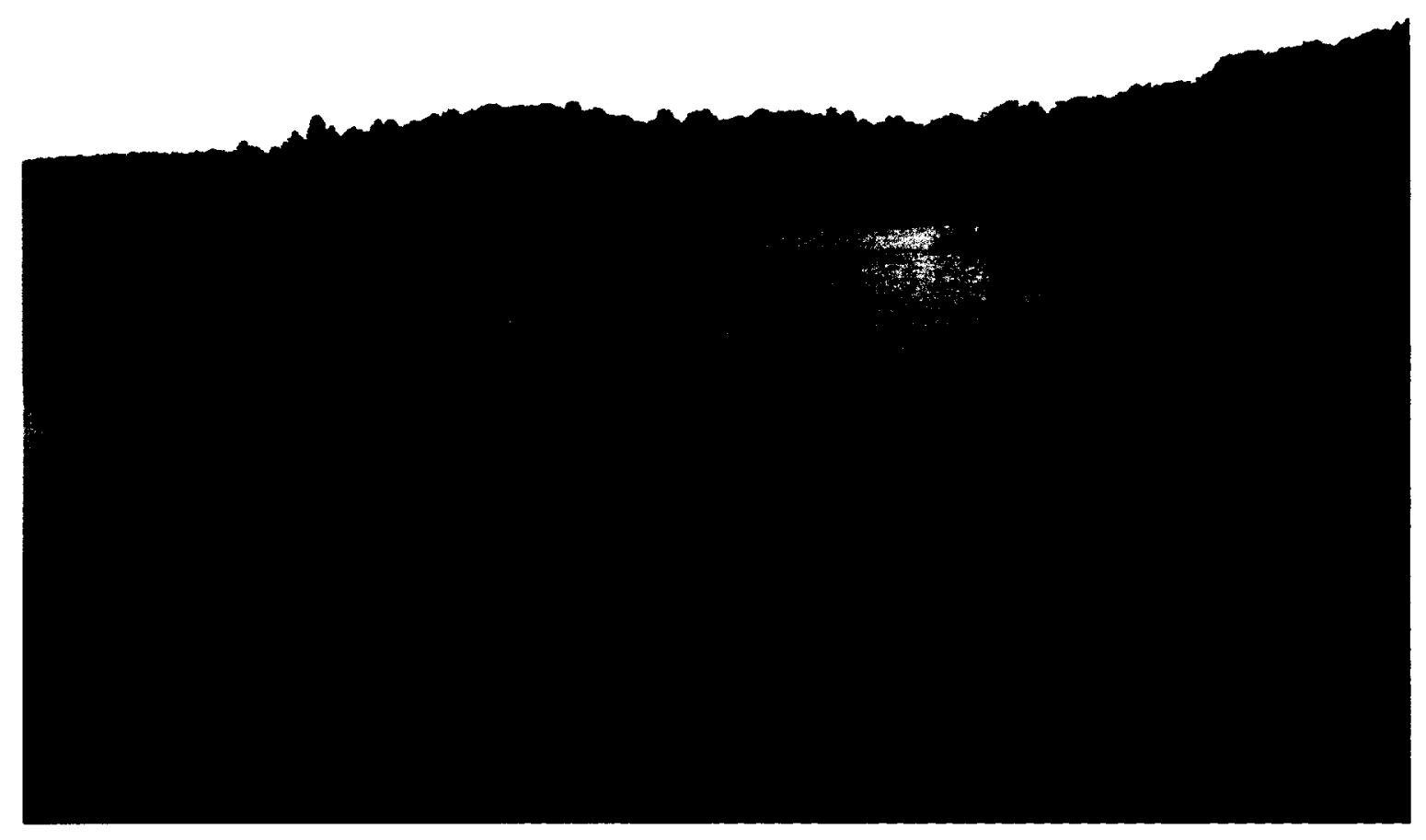




\section{Figure 5.3: Tourist camp}

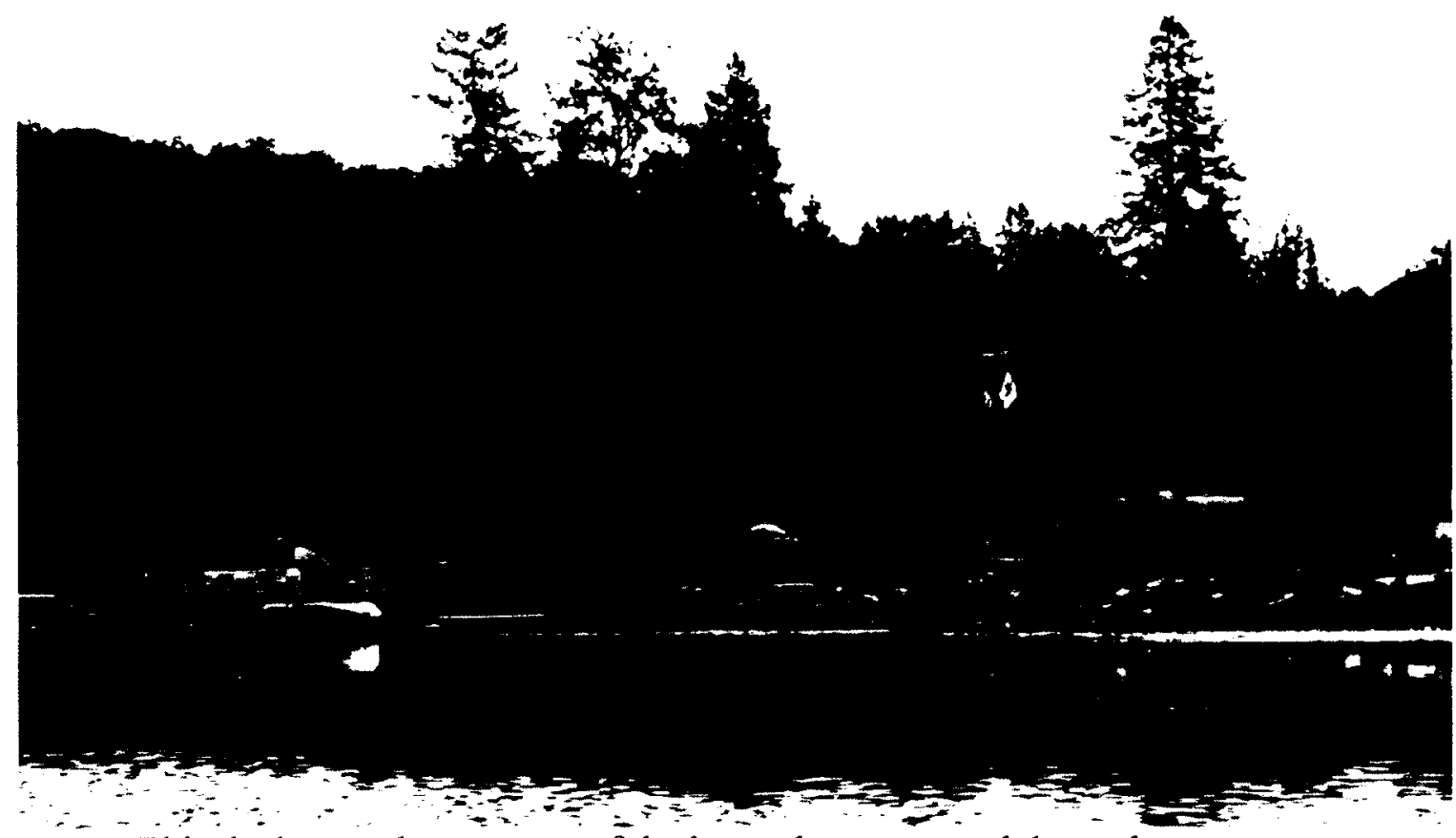

This dock area shows some of the boats that go up and down the Mississippi River through the manomin fields just upstream from the camp.

Research has indicated that wild rice is adversely affected by motor boat traffic, due to damage to plants from propellers, or due to wave action (Tynan, 2000; MDNR, 2008).

Interview participants also indicated that fluctuating water levels resulting from water extraction and dams upstream of the manomin beds have affected the manomin. Paula Sherman (2010c) explains her concerns regarding the fluctuating water levels, and in particular the low water levels that have been observed to adversely affect the ecosystem at Mud Lake: 
I think that consistently, always, aside from these other developments, a huge impact that Harold's always worried about is the level of the water and that's because of a dam right up above it that was put in. [...] At one point we had a meeting with the MNR and we were concerned about the really low levels on manomin, but that wasn't our only concern. We were also concerned about what happens if they drain too much water out of one of those lakes and there's not enough water to shelter it, to provide insulation in the winter. Because turtles and other amphibians burrow into the mud, so what happens in the winter time if there's not that level of water over it. Even if the water freezes, it provides insulation. So what happens to those amphibians if they don't have that level of water protection?

As human beings we're messing with the environment in ways we're not supposed to.

Those are things that we had concerns about. When we had talked to the MNR, they said to us, "how could we measure what happens to amphibians?" Well if we can think about it, it should be an obvious concern to you. This is what I mean by they don't understand. They don't get those concerns. They're like, well there's no way we can measure what the impacts would be on amphibians. Just because you can't measure doesn't mean there's not an impact and that if we've noticed it and we have concerns about it that just means that we're more involved in that landscape than you are. We have more of an understanding and notice the changes that are happening. That's just one example. And the rice, the manomin, it's heavily heavily dependent on balanced water levels. Harold is always very concerned about that in the spring and the fall [...] And he's someone who's constantly on the water. Someone who's out there all the time, always evaluating and looking and he brings those concerns to the Council. So we look to him to advise the Council in that sense because he lives right there and he is always there.

Robert Lovelace (2010b) echoes Sherman's (2010c) concerns regarding the complexity of managing the multiple systems and ecological cycles in a watershed through hydrological control: 
The dams are a perennial problem. I don't know if Harold told you this, but the year that he was charged with hunting illegally while he shot a duck out behind his house... He was charged and he had to take the case, pretty much, it was taken all the way to the Supreme Court. And his right to hunt was substantiated although the case was eventually thrown out because of errors the judge had made - That's sort of the gamble you take. But we had to go through all of this effort all to protect Harold's right to shoot one wounded duck, and that spring the MNR had released water out of the dam above Ardoch, when the ducks had made their nests and were sitting on their eggs, and literally hundreds of nests were washed away. And that's the problem we have, and that's that the MNR tries to manage the water levels in order to feed the water to some power stations further down on the Mississippi, as well as to have cottage levels, maintain lake levels for cottagers on some of the recreational lakes, and in doing so, they can't seem to, they're oblivious to the fact that the birds, they don't do things on the right date, they do things when it's time to do them. And birds are really on Indian time, you know they do things when it feels right or when it's the right thing. They'll take maximum advantage of the extended wetlands in the springtime for nesting and as the summer comes those wetlands dry out and they'll come out to the bigger lakes with their ducklings. But MNR can't understand that. And that's true with the rice too, is that the... that was the thing with the Tay River, we argued that one inch of water on Bob's lake which is a very very extensive lake, but one inch of surface water is hundreds and hundreds, if not thousands of square metres of wetland. Out in the middle of the lake one inch doesn't make a difference but on the edge in those shallows one inch makes one heck of a big difference. They have a hard time getting to that.

That's the problem with the water levels then, so when they raise and lower it throughout the summer time coming down in the Mississippi there, it can really set the rice back. And so we have trouble with that, and we never made any progress with the MNR with that. They say it's their mandate to manage it and they manage it for the reasons they do. And it doesn't fit with... there are so many natural cycles, whether it's amphibians, or turtles or ducks or aquatic plants. There are so many cycles going on at once, they can't manage it. You can't do it. It's basically like using the system like a toilet instead of letting it run its natural courses. So we have some problems with that (Robert Lovelace, 2010b).

The concerns brought forward by members of the Ardoch Algonquin are illustrative of what has been found in the scientific literature. As discussed in Section 1.5, the distribution of manomin is restricted by water depth, where optimal environments are in 
shallow waters ranging from $0.2-1 \mathrm{~m}$. Changes in hydrology, whether by flooding or restricted flow, are likely to negatively affect the seed production of manomin (Pip and Stepaniuk, 1988; Drewes, 2008; MDNR, 2008). Manomin (Zizania sp.) is known to be "intolerant of both low water levels and flooding. Low water levels cause seeds to desiccate, and high water levels force too much energy into shoot elongation" (Wilcox and Meeker, 1991: 1545).

The Mississippi River is managed by Mississippi Valley Conservation (MVC), which works with municipalities and other stakeholders in the watershed to balance ecological integrity with human needs (MVC, 2011). There are numerous water control structures throughout the Mississippi watershed, twelve of which are subject to the Mississippi River Water Management Plan (MRWMP). As described in the MRWMP, water control structures were first put on the river to facilitate the transportation of timber downriver for the settler logging industry in the mid- $19^{\text {th }}$ century, as well as for power generation and the operation of mills. According to the MRWMP (MVC, 2006), today the water control structures serve more complex purposes in recognition of the increase in both permanent and seasonal residents and of the social, economic and ecological potential of the watershed. Thus, the hydrological dams throughout the watershed have multiple purposes, including:

[...] flood protection, low flow augmentation, ice management, recreational access, and erosion control. The dams must also be operated to maintain specific flow and level requirements of fish and wildlife which depend on the lakes, rivers and shorelines, particularly during fish spawning periods. Once all these needs are satisfied, hydro producers also benefit by producing electricity from the flowing water in the system (MVC, 2006: 1). 
As explained previously, the manomin that is cared for, harvested and protected by members of the Ardoch Algonquin First Nation and Allies is at Mud Lake, a tributary of the Mississippi River. Upstream from Mud Lake, are the Kashwakamak Lake dam, Big Gull Lake dam and an overflow weir on Farm Lake and downstream from Mud Lake is the Crotch Lake dam, which is noted as "the most significant reservoir on the Mississippi River system with regards to flood mitigation and low flow augmentation" (MVC, 2006: 14) (refer to Figure 5.4 for a profile of the water control structures near Mud Lake). These dams would have the potential to affect the water levels in Mud Lake throughout the year. 


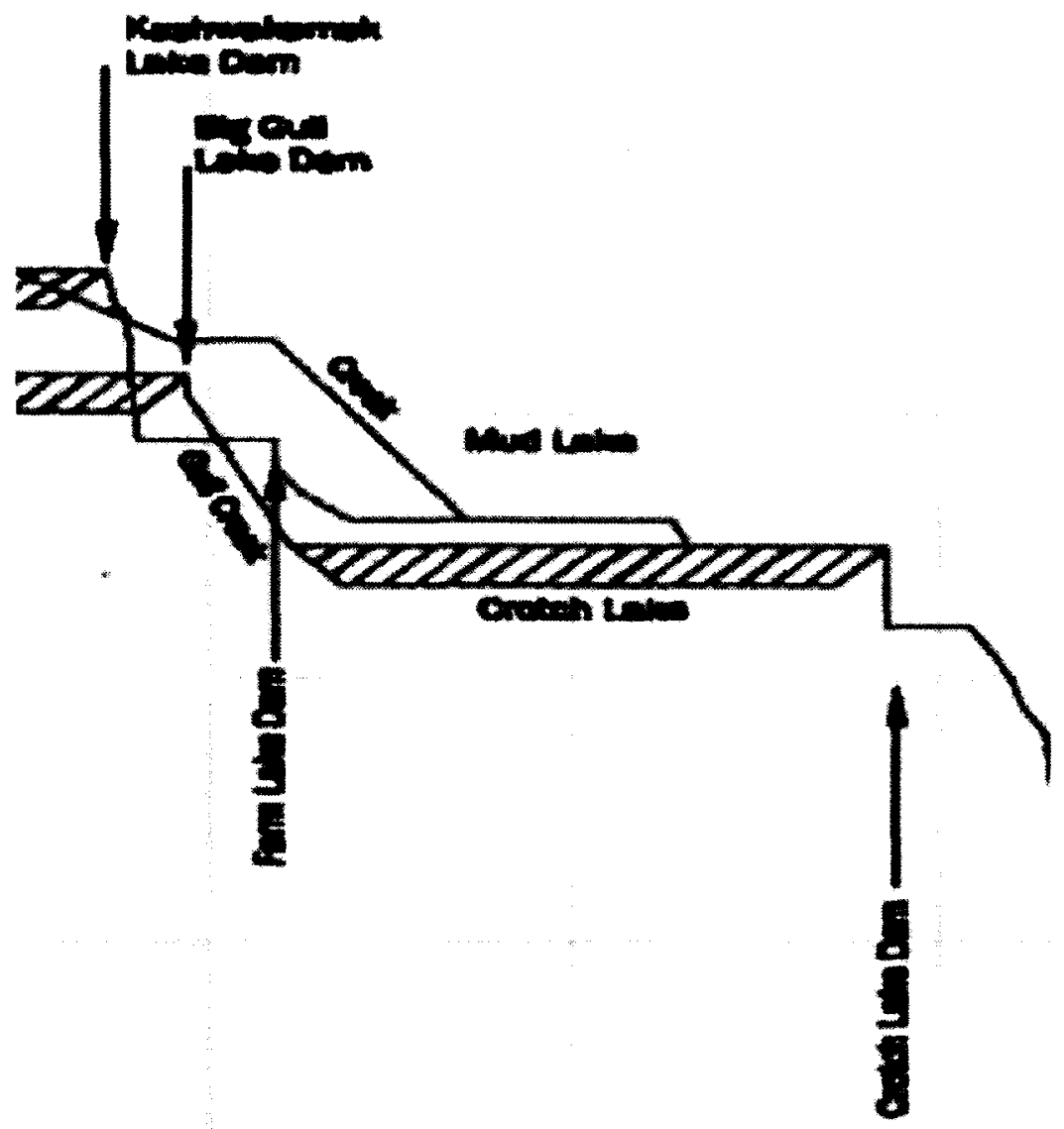

Figure 5.4 - Mississippi River Profile near Mud Lake

Map depicting various dams immediately upstream and downstream from Mud Lake

Source: MVC, 2006: 10

In the Mississippi River Water Management Plan, the harvesting of wild rice at Mud Lake is noted as a socio-economic activity in the region (MVC, 2006: 31) and the rice itself is recognized as a biological resource of significance as a natural heritage site, though not formally designated (MVC, 2006: 20). In developing the Mississippi River Water Management Plan, public consultations were held, including consultations with 
various Aboriginal groups with an interest in the Mississippi River watershed. In response to the comments made by the public regarding concerns over fluctuating water levels, the MRWMP outlines how competing interests for water are to be prioritized:

The overall goal is to maximize the net benefits of the water for the people, fish and wildlife living in, on, near or using the system. Water management within the Mississippi River has evolved to the point where the priorities are as follows (note the priorities vary on importance depending on the time of year, location and circumstances): Flood control; Low flow augmentation; Ecological integrity; Recreation / tourism; and Hydro-generation (MVC, 2006: 24).

Arguably, there are a number of competing interests in the watershed, particularly in terms of ecological integrity, as macrophyte (plant) diversity has been found to be lower in regulated lakes than in unregulated lakes (Wilcox and Meeker, 1991; Hill, Keddy and Wisheu, 1998). Though the Mississippi River Watershed Management Plan aims to prioritize these interests and maximize the net benefits for all (people, fish, wildlife), it is not clear how the interests and concerns of the Ardoch Algonquin First Nation and Allies, with respect to the manomin and the broader ecosystem of the Mississippi River watershed, can be harmonized with the water regulation regime throughout the watershed that has existed since the early 1800 s and continues today.

Mitchell Shewell (2010), member of AAFNA, mentions water management as a development that limits the health of manomin, and the broader ecosystem in the Ottawa River watershed more generally: 
Well, the management of the water, the river, is a constant trouble. You know if they stopped, if they would just leave the river, allow it to stay at the level it wants to be, instead of what they think it should be, it would be healthier [...] The Ottawa watershed is probably one of the dirtiest. And it's because it doesn't flow like it did. There's no rapids to help it take care of itself. It's just stagnant water that flows down the river now. So all of the cottages, it affects the waterway. But people don't care because they're only gonna be there for ten or fifteen years. They're only gonna own that cottage for ten or fifteen years, so as long as the water is up to the dock and they can park their boat they don't care. They don't even see the damage that's being there. Their children will, well they won't even notice it, because when they get there it will be all they know, they'll just know that it looks that way.

\subsubsection{Uranium exploration and mining in the Mississippi watershed: a threat to} manomin, ecosystemic and community health

As described in Chapter 1, the Ardoch Algonquin First Nation and Allies have taken a strong and sustained oppositional stance to uranium exploration and mining in Algonquin territory. They were able to stop uranium exploration in the area on the grounds that the mining "project was approved without any notification or consultation as is required under the Canadian legal system" (Sherman, 2008: 21). This oppositional campaign, though effective, came at great cost to the community and individual members, including those costs associated with a sustained protest and blockade of the mining site, longlasting legal processes, and the incarceration of former AAFNA chief Robert Lovelace.

In the interviews, it was readily apparent that uranium exploration and mining was a form of industrial "development" that was of concern to many of the research participants, in terms of "developments" that affect manomin and access to it. All of the concerns mentioned with respect to uranium mining related to the sustainability (or lack thereof) of mining in terms of ecological, socio-cultural and economic costs, including: 
high water usage (Sherman, 2010c); a lack of understanding of the long-term ecological and geological effects of mining (Shewell, 2010); the health impacts of mining for a radioactive mineral (Shewell, 2010); erosion of Algonquin identity through the further despoliation of Algonquin territory (Sherman, 2010c); local costs borne out for the benefit of international markets (Perry, 2010); and the reality of mining operations as a short-term economic activity in the community (Shewell, 2010).

In Dishonour of the Crown, Paula Sherman (2008) presents the historical and cultural context for AAFNA's opposition to uranium mining in Algonquin territory, along with academic and scientific research that documents the impacts of uranium mining in other Indigenous communities. Sherman (2008) notes four primary impacts of uranium exploration and mining, all of which "directly violate Algonquin law and our responsibility to protect the Natural World" (42): contamination of ground and surface water; release of carcinogenic radon gas and its progeny; habitat loss for wildlife and lack of site and infrastructure remediation; and "social, cultural, and spiritual consequences that can reach across generations" (59). In an interview, Sherman (2010c) elaborates further upon both the physical and social, cultural and spiritual impacts of uranium mining:

One of the things that was talked about a lot [at a conference for communities affected by mining] was the idea that impacts of mining and $[\ldots]$ any of those kind of extractive industries, forestry or any of that, [...] when they're trying to figure what the impacts of things are, they'll look at what can scientifically be measured. You know the scientific impacts to water. And I even talked about that in the Dishonour of the Crown. When the community asked me to do my research, those are things that I tried to focus on too.

When they're drilling with the big drills they can crack aquifers and then uranium leaches into the water and contaminates it, and then the 
uranium has a really adverse, negative effect on human tissue, animal tissue and can cause cancer and other illnesses and disease. And so I talked about that impact to water, and [...] that when they drill [...] radon gas can leach out, and dust goes all over the plant life and animals eat that, [...] it goes all over and it can make its way through the ecosystem, through the fish, and back into us, onto manomin.

So it can leach into the roots of manomin just by being in the water, you know the actual uranium contamination, and the radon can also settle on the water, can settle on the plants. On the one hand it can be impacted, just the roots and the stems of the rice, from the uranium contamination, but then it can also, the radon gas can also settle in the little particles of the plant itself that's above the water, and also cause contamination. and can also affect our physical health [...]

Then I began to think more about the ways in which it affects us culturally and also spiritually [...] And I guess this is more my concern now, is that culturally those kinds of extractions can impact... or even raising the water, lowering the water, not paying attention to the ways in which we interact in the natural world in that sense, right there, around the manomin...the actions that we take, the things that we do impacts the rice itself which in a sense impacts our relationship with it, which is 1 guess the cultural impacts.

$[\ldots]$

If our identity as human beings is bound up with having balanced relationships, and through mining - particularly through the mining industry, but through other extractive industries as well - if over the next one hundred years our land is decimated even more, what kind of identity will our future generations have? That's what it really gets down to, really, in thinking about that, because it's just not enough to physically survive. You need to be able to culturally survive and spiritually survive as distinct peoples. And you can't do that if you don't have your land. And it's not enough to have the land that's all contaminated with uranium. It has to be... you know there's already been 400 years of contamination and bad relationships with the land, so when we think of the kind of development, it's not enough to let the land to minimally exist so that it can be exploited later on, we need to restore the land and restore our relationships, because that's the only way we can restore our... what's important for us is to restore our relationships with our homeland.

As Sherman (2008) explains, there is reason for concern regarding the uranium exploration and the development of a uranium mine in Frontenac County with respect to maintaining the quality of manomin and the ecosystems of which it is a part. 
The specific concerns of the research participants regarding physical contamination of manomin can be further supported through scientific studies examining wild rice contamination. Wild rice species (Zizania aquatica, Z. palustris and Z. latifolia) are known for their ability to sequester and accumulate various contaminants and, in fact, are commonly used for phytoremediation, defined as "the use of plants to cleanup or control many kinds of pollutants including metals, pesticides and oil" (Zhang, Zheng and Sharp, 2010: 1315). Natural stands of wild rice have also been found to accumulate elevated concentrations of contaminants, such as heavy metals and trace metals (including lead, cadmium, arsenic, mercury and cadmium), in vegetative tissues and/or in the grain, beyond concentrations recommended in food health and safety guidelines (Pip, 1993; Nriagu and Lin, 1995; Bennett, Chiriboga, Coleman, and Waller, 2000). Pip (1993) explains that aquatic environments are becoming increasingly contaminated by metals as a result of discharge from effluent (water pollution) and atmospheric depositions (air pollution). Macrophytes (aquatic plants) can absorb metal contaminants through sediments and water via vegetative tissues (roots and shoots), and by aerial deposition or atmospheric absorption in the case of emergent aquatic species (plants growing above water) (Pip, 1993; Bennett et al., 2000). Both Pip (1993) and Nriagu and Lin (1995) note that manomin (Zizania aquatica and Z. palustris) is particularly susceptible to sequestering contaminants given its tendency to grow in "soft and acidic waters" in which "one would expect the trace metals to be mobile and in a more available form to the plants" (Nriagu and Lin, 1995: 224). Some metals are naturally occurring in both the environment and in manomin (such as copper, iron, magnesium, zinc- 
nutritional elements), however, Pip (1993) and Bennett et al. (2000) associate the occurrence of elevated concentrations of trace and heavy metals with water contamination and atmospheric pollution from industrial processes. Thus, manomin appears to be a plant of particular concern with respect to the accumulation of contaminants, such as heavy metals.

The findings of the studies discussed above support the concerns of the Ardoch Algonquin First Nation with respect to uranium mining and its unknown ecological interactions and potentially dangerous effects in terms of contamination of traditional foods, including manomin. As noted by Muscatello, Belknap and Janz (2008), "[u]ranium mining and milling operations have the potential to release trace elements such as $\mathrm{U}, \mathrm{Ni}, \mathrm{As}, \mathrm{Se}$, and Mo [uranium, nickel, arsenic, selenium and molybdenum] and ions (e.g., sulfate, ammonium) into the receiving aquatic ecosystem" (387). Beyond elements associated with uranium, "an almost inevitable consequence of this industry [uranium mining and milling], is an elevation in the concentrations of natural, U-decayseries radionuclides in the environment" (Sheppard and Evenden, 1988: 255). As Sheppard and Evenden (1988) continue to explain "[t]he most important pathways to humans for these radionuclides usually involve direct ingestion or inhalation of contaminated dust particles. However, these radionuclides will also be transmitted through the food chain and the attendant doses are additive to those received from other pathways" (256). In a study of selenium accumulation in aquatic systems downstream of a uranium mine in Saskatchewan, Canada, Muscatello et al. (2008) found that selenium released to surface waters from the mine operations did accumulate and biomagnify up 
the trophic levels of the food chain (from primary producers, through to invertebrates and fish) to the point where selenium concentrations in fish could cause toxicity or negative reproductive effects, even in cases where the water concentrations of selenium were low according to governmental environmental standards (391). Therefore, contamination of wild rice is of concern both due to the effects of direct consumption of the grain by people, and due to the ecosystemic repercussions of contamination of the entire plant, as it is a plant of high ecological and wildlife value. As discussed in Section 1.5, manomin is part of complex trophic (food chain) interactions, as a food for many animals, including insects, waterfowl and people, thus contamination of manomin can have repercussions throughout the food webs in which it is a part.

Thus, the release of uranium, its radionuclide derivatives and its other associated metals have the potential to contaminate manomin, as discussed by members of the Ardoch Algonquin First Nation and Allies [Sherman (2010c); Shewell (2010)]. Though the manomin at Mud Lake is upstream from the Robertsville mine site, the concerns and findings noted above remain significant, as particulates (including dust) from mining increase the pathways of environmental pollution (Petavratzi, Kingman and Lowndes, 2005). These dust particles can become airbome and disperse beyond the mining site:

The effects of dusts on the agriculture and ecology of an area are determined by the concentration of dust particles in the ambient air, their size distribution, the deposition rate and the chemistry. These factors can influence the chemistry of the soil and health of surrounding plants, the meteorological and local microclimate conditions, as well as the penetration rate of dust into vegetation. Apart from vegetation, dust deposition can affect animal communities and woodlands (Petavratzi et al., 2005: 1186).

The authors note that radioactive and carcinogenic dust particles, such as uranium, are of 
particular concern.

\subsubsection{The Algonquin Comprehensive Land Claim and Manomin}

In presenting my proposed research to the Family Heads Council of the Ardoch

Algonquin First Nation and Allies, a number of conditions were set out, one of which was

that if my research is to be based on an analysis of food sovereignty, a discussion of

manomin alone would not suffice, as food sovereignty is maintained and/or challenged by

numerous factors beyond what is directly apparent in discussing manomin. One such

example that was raised was the Algonquin land claim.

Mireille Lapointe (2010) explains how the Algonquin land claim is connected

with food sovereignty and manomin specifically, through the entrenchment of identity

politics in the land claims process:

What you have when you have a land claims process is a definition of terms. And it isn't the Algonquins defining who is an Algonquin so much as the government of Ontario and the federal government. And there are a lot of people who are non-status Indians. Indian communities have forever been determining for themselves their citizenship laws. So you would have citizenship laws for the Migmak and the west coast people and the plains people, and the Northern people and the southern people and all the communities, all the nations had their own ways of looking at citizenship: How do you accept people into your community? How do you expel someone from your community? And all that had to do with self-governance, because the community or the nation decides on its own governance. And really and truly at the local level, Algonquins, [...] so far as I understand, we didn't have national governance like let's say the Blackfoot Confederacy or the Wabenaki Confederacy or the Haudenausaunee Confederacy. The Algonquins had general ways of doing things and communities decided their rules of citizenship. So Ardoch has it rules of citizenship. But when you come to a land claims process the [settler] government starts deciding the rules of citizenship.

So right now what you have is a whole group of non-status Algonquins who have been booted out of the land claims process because 
they're not Algonquin enough. And the politics, if there is anything that brutalizes people within themselves, as a group, is the politics of identity. And the government has done a very efficient job of getting people to fight amongst each other. Because it causes issues, right? Who is an Indian? Like blood quantum. Rejecting people out of communities because they're not Indian enough. Like women who would lose their status for marrying white men, but the converse was not true. And then well, we'll undo that. Well, how the hell do you undo someone losing their identity? Some bureaucrat in Ottawa writes a memo, they've undone it, but lives have been ruined over this. People have committed suicide. It's ruinous these politics.

So the politics of identity continue, continue to cause damage in Native communities. So from my perspective I think we need to become a whole... we need to just refuse to dance the dance.

$[\ldots]$

Land claims by definition are not what aboriginal people want. They are the dance that you need to dance to secure a piece of land because the government wants all the rest. And that's what happening with the Algonquins right now is: how do you secure a portion of land because the government wants and has the rest?

So you want to secure a portion of land. Now who is going to control it, who is going to own it, and who are going to be the Algonquins who have the participation in this? That's the fight that's going on.

Does it have anything to do with personal sovereignty? Oh yah. Because you're letting someone else determine that and you're creating fights between the communities. There's internal dissension all over the damn place. And from my perspective, the whole land claims process needs to be destabilized and fall like a deck of cards all over the ground. And that would be the best thing, to see that fall to the ground and start over with an honest process, a more open process. And a process where people aren't trying to fight each other. That's what we need to do, not fight. Easier said than done though.

It's not good.

Land claims were not designed by Indian people. But if you look at treaties, that's a different story, because treaties, peace and friendship treaties, had a spirit to them, and that's what the Elders will say, the old ones will say. There was a spirit, an intent to these treaties, where people did not give away their land, did not give away their rights, did not give away their sovereignty.

Through the interviews for this research, it is clear that Ardoch leadership is at odds with the land claims process and this is also connected with maintaining access to manomin. 
As Paula Sherman (2010c) explains, the land claim is connected with manomin by virtue of representing a loss of ability on the part of Algonquin people to assert responsibility, and maintain Algonquin identity and relationships in traditional Algonquin territory, which includes the watersheds and ecosystems that affect the health of the manomin fields on Mud Lake. Sherman explains:

What's important for us is to restore our relationships with our homeland. And that means acting in responsible ways in our homeland. That means not allowing uranium exploration, or a land claim that's going to cede our jurisdiction, because that's the same thing. If we cede our jurisdiction through a land claim then we don't have the jurisdiction any longer to maintain our responsibilities in that place (Sherman, 2010c).

In her dissertation, Sherman (2007) further explains that Algonquin identity is dependent upon the ability of Omàmiwinini people to assert "autonomy and jurisdiction within the valley of the Kiji Sibi" as a means to maintain Omàmiwinini responsibilities to the Natural World (148). However, she argues that the land claim process is contingent upon the expectation that Algonquin people "will surrender all claims to the remainder of Omàmìwinini territory forever" (148), thus extinguishing Algonquin jurisdiction and compromising Algonquin identity.

As discussed in Chapter 1, AAFNA leadership withdrew from the land claims process in 1994. In her dissertation, Sherman (2007) explains that AAFNA would not compromise their self-governance by conforming to federal government requirements of adopting "Canadian political structures" by holding elections in the selection of an Algonquin Nation Representative, rather than continuing to use the AAFNA traditional Family Heads Council structure for decision-making (44).

The public discourse that is used in government communications regarding the 
Algonquin land claim do not take account of the concerns raised by Ardoch leadership, as explained above. For example, the Ontario Ministry of Aboriginal Affairs offers the following explanation of the Algonquin land claim:

Canada, Ontario and the Algonquins of Ontario are working together to resolve a comprehensive land claim through a negotiated settlement that will take the form of a modern-day treaty. All three parties are committed to achieving a just and equitable settlement of this claim. Negotiations lead to "win-win" solutions for the benefit of all Canadians (OMAA, 2011b).

Smith (2009) counters that while "the land claim, at first glance may appear to grant land rights to Indigenous nations; in fact, however, the opposite is the case. Paradoxically, the land claim is the 'vehicle through which the Canadian government removes Aboriginal title"' (Lawrence, 2009 quoted in Smith, 2009, with emphasis: 24). Sherman (2007) notes that the land claims process reinforces the legitimacy and primacy [or "authorizing authority" (Thobani, 2007)] of the Ontario and federal governments, and the process "is not seen as Canada's claim to stay in our territory which we never sold nor ceded, but one in which we must be willing to accept the extinguishment of $99 \%$ of our traditional land base of 8.9 million acres" (45). Sherman (2007) further supports the concerns of the Ardoch Algonquin First Nation by explaining that the recommendations of the Royal Commission on Aboriginal Peoples (1996) include a recommendation to eliminate the requirement of compromising traditional governance structures in order to participate in the land claims process, and to eliminate the extinguishment of Aboriginal title as part of the land claims agreement (Sherman 2007:50).

The problems of the land claims process have been widely discussed by numerous politicians, scholars, and Indigenous people (Erasmus, 1989; Gehl, 2005; Smith, 2009). 
Gehl (2005) makes the argument that treaties are negotiated on a nation-to-nation basis, however the land claim process is one that has been devised under guidelines unilaterally drafted by the Canadian federal government, thus echoing Sherman's (2007) concern that the land claims process reflects the domination of settler governments in negotiations. Furthermore, Gehl (2005) notes that the negotiations involve the province of Ontario, thus reinforcing the divide amongst the Algonquin nation, while Algonquin communities continue to live throughout the Ottawa River watershed (in both Ontario and Quebec).

As National Chief of the Assembly of First Nations at the time of writing, Georges Erasmus (1989) explains the fundamental contradictions of the comprehensive claims process in a historical and political context:

The Royal Proclamation of 1763 stated clearly that the Crown should be the only body to deal with First Nations' land, and this had to be done before such land could be used by others. In many parts of the country this issue was never dealt with: [...] land was occupied by settlers without any prior negotiation with the First Nations who had always occupied it.

In theory the comprehensive claims policy promised a solution to this problem; in practice, the way the policy has been administered has been not only unjust, but discriminatory towards and burdensome for our people.

[...] A fundamental problem is that First Nations and the federal government has approached negotiations with different viewpoints and objectives. The government, in its search for finality in all agreements, has viewed the process as one in which an aboriginal group fully cedes, surrenders, and extinguishes all of its rights flowing from its aboriginal title and ownership of the land, in return for which the government returns to aboriginal people some small portion of rights within the land claims agreement.

As First Nations, however, we believe that our aboriginal title includes ownership and jurisdiction over all lands and resources within our traditional areas. For us, claims resolution is a process of determining what land, resources, and jurisdiction will be shared with the governments of Canada. For us, the process is not one of negotiating extinguishment of our aboriginal rights, but of arriving at an equitable agreement on sharing (Erasmus, 1989: 12-13). 
Smith (2009) posits that the divisive outcomes of the Algonquin land claim are visible in the differences in responses between the uranium conflict from 2007 to 2008 and the wild rice wars from 1979 to 1981 . Smith (2009) observes that during the uranium conflict "the presence of solidarity is negligible. The land claim as a discursive structure has produced division within and between Omàmiwinini communities throughout the claim territory [...] The Algonquin land claim corrupts, divides and extinguishes title. It might be one of the more devious colonization schemes to date [...] "(36). Brascoupé (2012) has explained that the problem with the land claims process is that through the development of certainty, it makes access to manomin uncertain.

Thus, the Algonquin comprehensive land claim process has indirect though very important impacts on manomin as it is dividing the Omàmiwinini nation, causing strife between various Indigenous communities, limiting solidarity amongst communities in common struggle, and potentially compromising Algonquin jurisdiction in traditional Algonquin territory in general (and at the manomin site at Mud Lake in particular).

\subsubsection{The Contemporary Food System, Social Change and Manomin}

Another development that was noted to affect access to manomin is the contemporary food system. This food system is pervasive and is, in a certain (though limited) sense, accessible, not restricted by seasonality, relatively cheap (notwithstanding negative externalities not reflected in the market price) and characterized by convenience (Section 1.3.2 describes the contemporary food system in more detail). Many of the research participants from the Ardoch Algonquin First Nation and Allies noted the significance of 
the contemporary food system in creating an alternative to more traditional practices surrounding food. Some research participants emphasized that although the Algonquin food system prior to European contact was sophisticated, nutritious and rooted in sustainable relationships within the local ecosystems, this system must also not be romanticized given how today nearly every one's livelihoods and daily activities are supported by the conveniences of the contemporary food system, which allows for more freedom to pursue other activities.

When asked how manomin is related to food sovereignty, Mireille Lapointe (2010) explains:

Food sovereignty means food independence. Most of us, we don't have it. Because if you think in terms of the ice storm, the first thing that happened in the ice storm is people went and raided the grocery store in Westport. There was very little left in that grocery store because people were really frightened about food.

[...] And sovereignty to me, means independence, but that also comes at a price. It wasn't easy for people to be, to have sovereignty. You can't couch it in these romantic terms, and think that people had their personal sovereignty and food sovereignty and that it was easy. They spent a lot of their day looking for and putting food away. Their life was very complex. Because it was linked to the seasons, it was linked to putting food away, it was linked to living in a simple way so that they could live from season to season. I don't think it was a very ostentatious life. If you look at how we live, its very ostentatious.

And food sovereignty means that you have control over your food production and you are independent in your food production. Very few people have that. And the rice reminds of us of that. And up to a certain point allows us to have that because you can live on wild rice for a long time, if you have to.

Mitchell Shewell (2010) further explains how historical outcomes, such as the change in the forest composition, in conjunction with the contemporary food system and contemporary technologies also affect access to manomin for community members of 


\section{AAFNA:}

Those trees are gone and until they allow another 100, 150 years for those trees to get big enough to do it again, we can't do it [use birch bark to harvest, process and store manomin in the old ways]. So we're gonna have to wait another 100 years to be able to gather our foods the way we did. And do we really want it? Are we gonna tell our youth, by the way, no more Ipods, you're gonna have to go and gather your foods, you can't even go to the grocery store?

We can't even get a basic Canadian to think that we should only buy within a 100 miles of a grocery store. That would be a good way to live, only buy products that are within a hundred miles. But it's really hard to do.

One of the outcomes of the conveniences of the contemporary food system and the structure of contemporary livelihood activities is that there is less incentive and opportunity to connect with food from its growth and care, to harvest and processing, to its storage or preparation. Paula Sherman (2010c) explains her personal challenges in instilling an appreciation for Algonquin culture and identity in her own children and grandchildren, with respect to manomin, language and Mazinaw lake, particularly in terms of the political significance of protecting the manomin: 
We should be teaching these things to our youth and our children. But we can't spend the time that we should be doing that because we're too busy fighting, doing these other things.

I think that it's hard. We do try to find, in between all these things, we try to, I guess, resurrect those things in the sense of, okay we've gone through this whole thing [the rice wars or uranium conflict] and thinking about how significant and important it is that we have to protect it [manomin], so how are we going to inundate our youth and children with that same understanding in thinking about it? That's why we've been trying to, in the summer, really develop a program around connecting them to Mazinaw lake. We have these culture camps where we try to reconnect the youth and the children to that place, to Mazinaw, and to the rice. I think those are some ways in which we're trying to do it. And also resurrect the language in that sense because the language is important for understanding that relationship in a deeply meaningful way. The language is important for that.

I think that the other thing that we're struggling with is how do we put this in terms that youth and... particularly youth....[...] How do we engage youth in these things? How do we make it important for them? How do we share that significance with them so that they understand that connection that they themselves have to that place?

[...] My daughter [...] she's like 'Oh you guys are going ricing, oh I did that, it was kind of boring...' They just don't... maybe it's just where they're at, they're not worried about [...] It's almost like they take that for granted. Yah we understand about the rice and they understand its importance when you talk to them about it. They understand I think, at least superficially, between the pow-wow, which is the Manoomin festival. They all want to go and they all want to dance and participate in it and they hear the Elders and the people talking about the manomin and the relationship of it to the pow-wow (because the pow-wow was created as a way on the $25^{\text {th }}$ anniversary of the rice war in 1980 , which is when the commercial harvesters tried to come in) [...] So they understand that the pow-wow, the manomin festival, is really connected to that struggle. And they're like "Yeah, yeah, we've heard that story". But it doesn't resonate for them. It doesn't resonate for them.

Probably the only thing recently that they can in any way compare to and think about any kind of impacts like that is the mining thing. Because that's something that they experienced. But to go back and try to talk about the struggle for the rice in the 1980s they can't relate to it because they didn't experience it. It's so long ago for them[...] So then how do we engage them in a contemporary sense in this same struggle?

I don't know. I don't really know how to answer that except for, we're continuing to struggle with that ourselves. 
There is clearly a tension that exists in the struggle to maintain spiritual, cultural, political and physical connections with the manomin in Ardoch (and other Algonquin traditions more generally). In their study of the use of Traditional Ecological Knowledge (TEK) in environmental assessments of uranium mining in Athabasca Saskatchewan, Wiles, McEwen and Sadar (1991) observe a similar struggle, describing it as the:

[...] necessity for a healthy social framework that facilitates and encourages participation in these [traditional, land-based] activities [...] Mines and other industries are thus part of the process of social change that is leading to disintegration of traditional culture, even if the environment is not physically degraded, by altering people's patterns of life and hence their relationship with the natural environment (110).

Throughout the environmental assessment process, the authors found:

To be sure, these [traditional] activities require that the health of the physical environment be maintained, a fact recognized and well addressed by standard environmental assessment. Yet the points that were most stressed were the importance of the traditional relationship between the people and the environment, the social structures and conditions that sustain traditional activities in the environment and that fuse the environment with local social practice into a viable culture (Wiles, McEwen and Sadar, 1991, 112).

Throughout my field research, it became clear that the members of AAFNA are engaged with this challenge through multiple approaches, including: assertion of their responsibility and jurisdiction in traditional Algonquin territory, resistance to continuing encroachment and despoliation in the territory, and community-wide cultural events that include traditional practices and celebrate the successes and efforts of contemporary struggles. In the summer of 2010, members of the Ardoch Algonquin First Nation and Allies came together at Mazinaw Lake for the annual AAFNA Culture Camp - Mazinaw Lake is a very significant spiritual and archeological site for Anishinaabe people, known 
for its petroglyphs and ceremonial sites. While having a delicious barbeque lunch of beef burgers, salads and watermelon, Mireille Lapointe turned to me and acknowledged that we may not be sharing "traditional" foods during this meal, but, she explained, "we adapt." We both bit into our burgers and ate good food while sitting in the sun, with good company, beside a magnificent lake.

\subsection{Discussion}

The results of this study indicate that numerous actors, both acting within and outside of the region, are responsible for various developments that affect access to manomin. After reviewing the transcribed interviews, it appears that the actors that are responsible for "developments" that affect manomin can be grouped as individuals, governmental actors (including municipal, provincial and federal governments, agencies and decision-makers) and corporations, though the actions of one group are often facilitated by another. Chapter 6 will examine what the implications might be in terms of settler responsibilities affecting change in Algonquin territory, given their role in developments that affect the AAFNA community's access to manomin.

Another result that emerges from the interview data and a review of academic and popular literature regarding the Ardoch Algonquin First Nation is that "development" - in the form of industrial exploitation of the land - is generally viewed to negatively impact access to manomin (as well as the environment, and thus Algonquin relationships within the Ottawa River watershed). It seems that industrial "development" - in the forms of forestry, logging, commoditization of common property (such as manomin), motorized 
recreation, water management, mining, and comprehensive land claims - is viewed as part of a continuum of 150 years of colonial encroachment and exploitation in the valley of the Kiji Sibi, during which manomin was brought to Ardoch and has since been protected.

However, that is not to say that members of the community understand all forms of development negatively. In the Ardoch Algonquin First Nation Principles of Development, a common definition of development is offered:

Human activity that alters the land to accommodate, social, cultural, spiritual and economic interests is known as development. All communities engage in some form or level of development in order to secure advantages that sustain and enrich the community and its individuals. Altering the land requires conscious and moral decisions that recognize in practice responsibility for the spirit of the land and the future generation who will also be dependent on it (AAFN, n.d.(b): 1).

The document goes on to explain Algonquin people's relationships within the Kiji Sibi watershed, referring to the creation story, concepts of land embedded in Anishnabemowin (the Anishinaabe language), traditional practices and Algonquin people's responsibility to protect their homeland in the context of the occupation of the Algonquin homeland by "people of another origin": "[t]hese people have developed our homeland in such a way as to have it conform to European ideas of land and they have exploited the lands' resources for profit" (AAFN, n.d.(b): 2) Thus, it appears as though it is not development per se to which the Ardoch Algonquin are opposed, but rather the dominant form of development - imposed primarily by the governments of Ontario and Canada - which, is governed by "a strategy of exploitation and regulatory control [and...] which places Algonquin interests behind all others" (AAFN, n.d.(b): 2). This being said, it is all too 
easy to simplify the positions of the Ardoch Algonquin First Nation and Allies, however, in addition to their numerous successes (in terms of resistance to exploitative development), AAFNA has experienced internal strife and division, and conflict with neighbouring Algonquin communities over the years. Section 5.3.6 serves as a reminder that true food sovereignty - or community, or national sovereignty - comes at a high price, given the luxuries and opportunities of contemporary social life.

It is possible to link the AAFNA position on development to their numerous counter-hegemonic approaches to industrial exploitation, opposing and effectively resisting the continual expansion of "development" into Algonquin territory. In the conclusion of this thesis, I will briefly explore how the effects of development discussed in this chapter have shaped this community's political activities, resistance efforts, and other ways that AAFNA have responded to the effects of development on manomin. 


\section{Chapter 6: Conclusion}

In the final chapter of this thesis, I review the questions that have guided this research, and in so doing briefly revisit and summarize the content and findings of the previous chapters while also introducing further analysis and outcomes of the research. I examine how the results of this particular case study - how development has affected one community's access to a traditional food (manomin, wild rice) - highlight the broader context of our contemporary political ecological and political economic reality, which is still rooted in domination and dispossession (both fundamentally colonial relations). By revisiting the results of this research, I hope to further open up dialogue around paths towards more just, respectful and decolonizing relationships - between settlers and Algonquin people (as well as other Indigenous peoples), and ultimately within the very ecosystems, land, air and water upon which we all depend here on Turtle Island (North America).

This chapter begins with a discussion of the limitations of this research in Section 6.1. Section 6.2 reviews the research questions that have guided this research. Section 6.3 summarizes the affects of development as they relate to access to manomin for the Ardoch Algonquin First Nation and Allies - thus providing a critical discussion of "development". Section 6.4 discusses the significance of manomin to the identity of members of the Ardoch Algonquin First Nation. Section 6.5 summarizes AAFNA's responses to the challenges and opportunities of development as they pertain to access to manomin. Section 6.6 begins to examine the implications for settler responsibilities in light of the findings of the research. And finally, Section 6.7 offers concluding thoughts 
on setting out on a decolonizing path.

\subsection{Research Limitations}

My research is, of course, limited by a number of factors. First, the very nature of working with limited time and resources necessarily places constraints on the effectiveness and scope of the research process (i.e., the number of research participants and representation of research participants - most participants are leaders in the community, and youth were not involved in the research, despite my intentions at the outset of the research). Second, members of the Ardoch Algonquin First Nation are quite dispersed geographically as AAFNA, consequently many community members are not always present at AAFNA events, where I primarily sought to make contact with them. Third, the time and resources of AAFNA leadership (who quite generously facilitated my access to the broader community) were limited by the numerous other activities and priorities of the community (not to mention, their respective families). Consequently, many approaches I would have liked to use to recruit more research participants proved impossible $^{28}$.

To my surprise, my research was also constrained by my own limitations as a researcher. The following is a field note made during the Ardoch Manoomin Festival and Pow-wow:

28 The contact information of community members was not available to me, so I was not able to contact community members directly through mail-outs or other forms of communication to inform them of my research. 
I am realizing that the greatest obstacle to my research is, to my surprise, me! I am finding myself to be quite shy and hesitant to approach people not introduced to me directly by Mireille or Paula. I am very aware and self-conscious of being an outside researcher coming into this community. I am, in some ways very uncomfortable with this position and do not want to impose myself on others. I don't want to interrupt the celebrations or take people away from this gathering to talk to them about $m y$ research, $m y$ questions and $m y$ work. I am more interested in simply getting to know people, and to participate, as other settlers are so very welcome to do. (When doing this, just participating, being me, without pursuing my research agenda, I don't feel like an outsider, I don't feel the same kind of self-consciousness, self-awareness, that leads me to think in terms of binaries - insider/outsider, Native/non-Native, research participant/researcher (intruder, neo-colonial spy)). I don't want to impose my own agenda on others.

At the same time, this is the Ardoch Algonquin Manoomin festival! What better time to ask people about manomin?

While these questions interest $m e$, and are the focus of $m y$ research, this research is not for me... not entirely anyways. (September $5,2010)$

The above field note entry demonstrates my somewhat conflicted relationship with my research and my positionality as a researcher. Thus, my research was also limited by my own comfort level and natural inclinations. I found that I was most comfortable approaching individuals about my research when, as mentioned above, they were introduced to me by AAFNA co-chiefs as key knowledge holders about manomin. Most often, one of the co-chiefs explained that I am a student researching with AAFNA, at which point I felt more at ease and welcome to discuss my research and eventually ask if they would be willing research participants. This indicates the importance of establishing relationships of trust - not only for research participants, but also, at least in my case, for the researcher as well.

In sum, this research is constrained by my own efforts to negotiate a balance between respecting community members by not overly imposing myself and my research, 
while also asserting my research agenda and my needs as a student and researcher that has been welcomed into the community, working with finite time and limited resources.

In terms of opportunities to continue with this research, I was unable to explore in depth many of the transnational influences affecting access to manomin, for example, through international trade and research to genetically alter wild rice for new growing and economic opportunities. Biopiracy and biocolonialism are other significant and fascinating areas that impact Anishinaabe people's ability to maintain their responsibilities with respect to this sacred food, and both warrant a fuller investigation, though this falls beyond the scope of this particular project.

\subsection{Reviewing the Research Questions Guiding this Study}

Through this research I have intended to answer the following primary research question: How has the Ardoch Algonquin First Nation and Allies'access to manomin been affected by development? Chapter 4 sets the historical context of "development" in the Ottawa valley by providing an overview of Algonquin-settler relations from 1603 to present day through a lens of colonial history. I posit that this history serves as the foundation for contemporary development projects in traditional and unceded Algonquin territory. Chapter 5 addresses the above research question directly by presenting the results of primary research data collected from interviews, participant observation and participatory research approaches. A summary of these results is offered below in Section 6.2 and through Figure 6.2, a diagram depicting the various developments and the direction of change of these developments on AAFNA's access to manomin. These results inform a 
critical discussion of "development" in Section 6.2, where development is demonstrated to be part of ongoing colonial processes that continue to marginalize Algonquin people and Indigenous peoples by limiting their livelihood activities through the exploitation of their traditional territories and increasing barrier to maintaining their relationships, responsibilities and jurisdiction within these territories.

In addition to the above primary research question, there have also been secondary research questions that have guided this research. A secondary question includes, how have AAFNA responded to the challenges or opportunities of development? In beginning to address this question, I will provide a brief overview of how manomin is linked with identity for members of AAFNA in Section 6.3. AAFNA's responses to the challenges and opportunities of development have been alluded to throughout this thesis, and are elaborated upon further in Section 6.4, and are also summarized in Figure 6.3.

Drewes and Silbernagel (2004) present a model of the drivers that influence the extent and distribution of wild rice. Following their integrative approach to studying the dynamic system of wild rice distribution, Figures 6.2 and 6.3 are presented to illustrate the circumstances under which the extent of wild rice landscapes are increasing or decreasing (Drewes and Silbernagel 2004: 378). Drewes and Silbernagel assert that:

[...] approaching wild-rice landscapes from a systems perspective [allows for the recognition of] the natural system or land base that supports the landscape, the social systems relating to cultural knowledge and beliefs about this landscape, and the interaction between these two systems that is manifested through cultivation (381).

The authors offer a conceptual model "to identify the influences of natural and cultural drivers on wild-rice distribution" through a visual account of the "direction of change 
(increasing or decreasing wild rice) and the drivers influencing this change" (382). While Drewes and Silbernagel do not account for "other external sociological factors such as economics, management and land use that influence this landscape" (381) this research has taken these factors into account. The figure below is an illustration of Drewes and Silbernagel's (2004) conceptual model:

\section{Figure 6.1: Conceptual model of wild rice distribution}

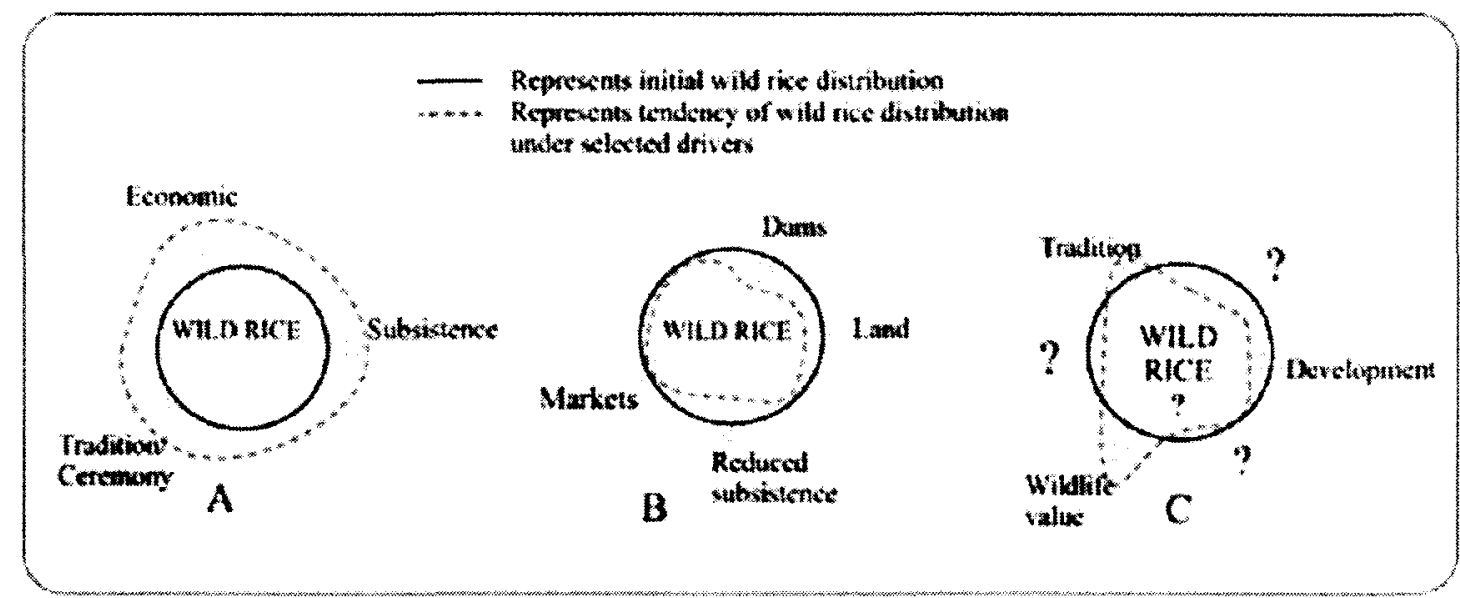

Source: Drewes and Silbernagel, 2004

:Influence of natural and cultural drivers on wild-rice distribution during three different time periods. (A) Pre-settlement (pre-1850s); during this time wild-rice distribution was expanding and natural drivers were relatively stable. (B) By the 1970s wild-rice distribution had begun to decline and the supporting land/water base had undergone significant changes, along with a change in dominant culture. (C) Today (2004) we recognize that multiple natural and cultural drivers are influencing wild-rice distribution, but the overall direction is unclear (Drewes and Silbernagel, 2004: 382).

Following this approach to research, Figures 6.2 and 6.3 serve to illustrate and summarize the drivers (challenges or opportunities) that affect access to manomin for the Ardoch Algonquin First Nation and Allies in terms of development (as discussed in Chapter 5 and Section 6.2), as well as AAFNA's responses to these drivers which further influence 
access to manomin (as discussed in Section 6.4).

Another research question that guided this research is, what are the implications of these findings for settler responsibilities? A summary of each chapter of this thesis serves as a starting point to consider this question (Section 6.5). Finally further avenues for exploration of the implications for settler responsibilities are offered in order to move towards paths to decolonization in Section 6.6.

\section{3 "Development" and the Ardoch Algonquin First Nation and Allies' access to} manomin

Chapter 5 outlines and documents which developments have occurred in the area that have affected manomin, whether by improving access to manomin, or by inhibiting and creating barriers that limit access to manomin. Figure 6.2 below, summarizes the findings of Chapter 5 by illustrating the various drivers that influence access to manomin and their direction of change.

Figure 6.2 illustrates that nearly all of the "developments" identified by research participants have limited (or have a significant potential to limit) the capacity of members of AAFNA to continue to access manomin. With respect to access to manomin, it appears that "development" has presented more challenges than opportunities, constraining and/or threatening the health and viability of manomin (and therefore the community's access to it) rather than enabling its access. The exception to this observation is the very development through which manomin was introduced to Mud Lake by Harold Perry's ancestors in Alderville: the intensive settlement, industrial exploitation of resources in the 
Ottawa Valley in the $19^{\text {th }}$ century, which threatened, limited and destroyed Algonquin livelihoods at the time and led to the planting of wild rice in Mud Lake in response to those challenges. The potential effects of climate change on the rice at Mud Lake is another potential driver linked to development (through the production and consumption of fossil fuels) that was outside of the scope of this research.

By examining how access to manomin has been affected by the challenges and opportunities of development for the Ardoch Algonquin First Nation and Allies, this research reveals a key finding: that development is for the most part interpreted by research participants as settler encroachment in Algonquin territory and economic exploitation of "natural resources." In the words of the Ardoch Algonquin First Nation, as set out in their Principles of Development, development is a way to alter the Algonquin homeland "to have it conform to European ideas of land" and the exploitation of "the land's resources for profit" (AAFN, n.d.(b): 2). Extending from this understanding, development can be further understood as a continuation of colonial relations through which settler governments and individuals continue to assert jurisdiction and responsibility in unceded Omàmiwinini and Indigenous territory, through colonial discourses, governance, and control of "resources". 
Figure 6.2: Developments that affect AAFNA's access to manomin on Mud Lake

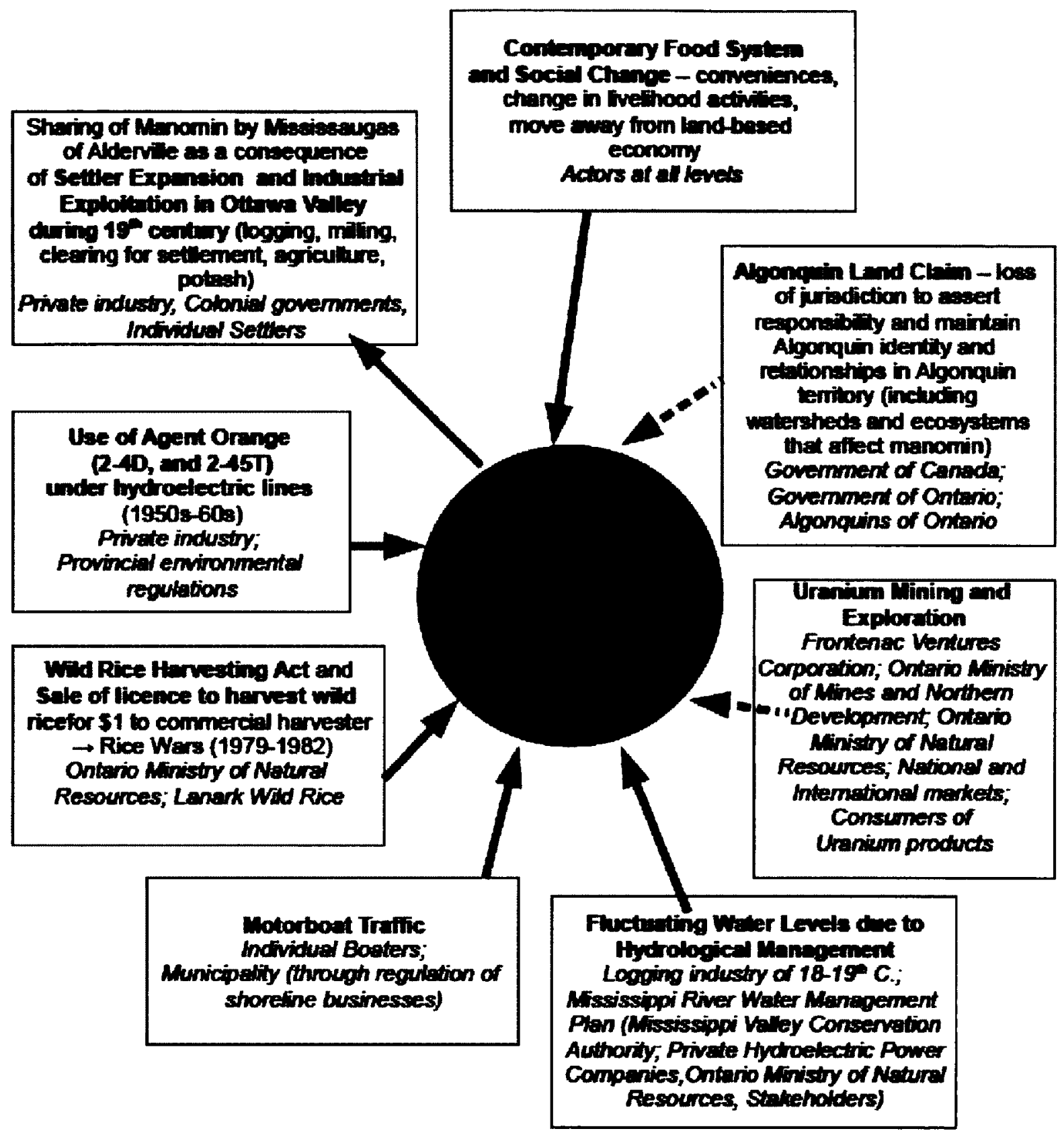

The yellow boxes summarize the main developments discussed in Chapter 5 that have affected access to manomin. The actors that influence each development are italicized. The arrows indicate the direction of change of access to manomin, where the red arrows indicate an increase in access to manomin and blue arrows indicate reduced access to manomin for members of AAFNA. Dashed arrows indicate a significant potential change in access to manomin. 
Academic definitions of development (as discussed in Section 2.3.1) can be summarized as: part of the ongoing project of colonialism which seeks to impose a particular, historically and culturally mediated social-political economic regime under the guise of universality, growth and progress (Esteva and Prakash,1998); the result of capital flows from place to place (Katz, 2004) and discourse which serves to construct the subjects of development (in this case the Ardoch Algonquin First Nation and Allies) as primordial, static and in need of the technology and expertise in order to progress towards a particular goal (clearly, a value-laden notion) (Escobar, 1996). As is affirmed in this study, development must be understood as ongoing colonial processes enacted through all of the mechanisms and political technologies mentioned above. Development continues to marginalize and dispossess Algonquin people by limiting their livelihood activities, their cultural and spiritual practices and traditions, their political autonomy, their responsibilities and their jurisdiction.

It is important to note that the forms of "development" identified in this research that have limited AAFNA's access to manomin are not the only forms of development possible, but rather they reflect the dominant hegemonic values at play in the region. As discussed in Section 5.4, not all developments are necessarily limiting to Algonquin livelihoods and/or healthy ecosystems. On the contrary, the Ardoch Algonquin First Nation acknowledge that "all communities engage in some form or level of development in order to secure advantages that sustain and enrich the community and its individuals" (AAFN, n.d.(b): 2). Of greater significance are the values and moral decisions that guide the forms of development - in this case, we see that the dominant settler or Euro- 
Canadian values that inform development directly conflict with the very values that determine how manomin and its surrounding environment is managed and cared for by the Ardoch Algonquin First Nation and Allies.

As discussed in Section 4.5, colonialism is enacted through numerous and diverse strategies. Similarly, a significant result that emerges from this research is that, much like colonialism, development is far from a monolithic process, rather, development takes on numerous forms, and has varied potential. Also, the actors that are responsible for the myriad developments that affect AAFNA's access to manomin are varied, from governments in different jurisdictions, to corporations, to individuals, each acting at a variety of spatial and temporal scales. Development also affects individuals differently depending on their particular context. As such, a variety of discourses have emerged in this research regarding how development has affected access to manomin. As mentioned previously, generally development is viewed to have created numerous challenges to accessing manomin and continuing with traditions associated with the harvest, care, processing, preparation, sharing and ceremonial use of manomin by members of the Ardoch Algonquin First Nation and Allies. However, across research participants the outcomes of development are discussed in ways that range from understanding development as a challenge to traditional Anishinaabe practices, to framing it as part of ongoing colonial processes, to appreciating how developments have supported improved standards of living for Algonquin people in some senses (e.g., decreasing time spent producing, gathering, harvesting, processing, storing and preparing basic necessities such as food; and creating access to contemporary technologies). 
Of course, though the effects of development have mainly created challenges, or have limited access to manomin, the Ardoch Algonquin First Nation and Allies have responded to these challenges through various strategies that oppose and resist the destruction of their livelihoods and cultural practices, and the dispossession and loss of jurisdiction in their traditional homeland (as has been the case for Algonquin people since the $18^{\text {th }}$ century).

\section{4 "It's in our blood": AAFNA Identity and Manomin}

It is clear that manomin is of profound importance to the identity of AAFNA as a community and to individuals as Algonquin people. During interviews, manomin was said to be central to the identity of the Ardoch Algonquin First Nation and its members in numerous ways, including: as a connection to identity as Anishinaabek people; central to the Anishinaabe migration story (where it was prophesized that they should travel to the land where food grows on water-manomin), as a reminder of the Original Instructions, the Anishinaabe concept of Mino-Pimaadiziwin (discussed in Sections 1.1 and 1.6) and the responsibilities and relationships that have been maintained in the territory since time immemorial. Manomin was also said to be central to a connection to family and ancestors - as descendants of those Algonquins who had lived in Ardoch; and, as a connection with traditions, the land and Ardoch. Furthermore, manomin is identified as: a connection to Indigenous identity and being "Indian" (Lovelace, 2010); as a reminder of the community's ongoing triumphs over assimilation; as a symbol and a reminder towards the goal of personal, community and Indigenous sovereignty, as well as food sovereignty; 
as a cause of cultural revitalization; and as a source of politicization of the community. Additionally, manomin provides a connection to the spiritual world; a connection to the community of AAFNA itself, and also to the wider, extended community (such as Alderville and other Anishinaabe communities); and, a connection to other Indigenous nations (both across Turtle Island and around the globe).

The interviews provide numerous anecdotes that speak to each of these points from various perspectives. The following quotations serve to illustrate the importance of manomin to the identity of members of AAFNA, in their own words. Mitchell Shewell (2010) explains the historical and ancestral connections to wild rice and how these connections continue to influence AAFNA's stances to protect the area:

When people talk about the Ardoch they recognize the rice right from the start, because if it wasn't for the rice, the people wouldn't have been in Ardoch. They stayed in Ardoch because of the rice, so that's who we are, it's in our blood. They say that, they say it's in our blood, because we are what we eat, and that food was the main food through the whole winter. Like I say, without it we wouldn't have survived [...] That's who we are [...]

I think that we get, we're very protective over it. So as long as it's there we will protect that area. As long as the wild rice is there for us to go and gather we will do what we have to do to protect that area, so that's what the wild rice does. That's part of us. If you take it away, we're not who we are.

Similarly, Paula Sherman (2010c) explains that manomin is fundamental to Algonquin conceptualizations of autonomy or jurisdiction in the Valley of the Kiji Sibi, in a historical, cultural and spiritual sense: 
When I think of autonomy, I think that manomin is very very seriously at the centre of that in the same way, particularly because it has, as something that we have knowledge of, it goes back to the creation, the actual creation of Anishinaabe people. And also that in that autonomy and trying to understand it, we see that, really that our autonomy and jurisdiction is based on thousands of years of living in that place, of our ancestors, and that knowledge being passed down to us. It's really of thinking about, maybe the way to think about it is to think of why it is that we have autonomy, why do we have jurisdiction in that place? It's not to say that we own the land, or that that's our sovereign place, in the construction of western notions of nationhood. The only reason that we have jurisdiction in that place is so that we can maintain our relationships and responsibilities there [...] and our autonomy and jurisdiction exists within the idea of Piwadiziwin, that relationship.

So to me manomin is critically significant and important and our ability to [maintain our relationships] is heavily connected to that. And it's not just politically significant, or important in the sense that we think of politics and governments. It's more the case that it's significant in a spiritual and cultural way that connects us to that place. Because part of what happens over those thousands of years is that as a distinct people with a distinct identity and a distinct language you develop a historical identity in connection with that place. So the very fabric of who we are as human beings is all bound up in that place, its bound up with manomin, its bound up in Mazinaw, its all connected to those places, so you can't really separate them out from each other.

In the following quotation from Robert Lovelace (2010b), he explains the significance of the successes during the Rice Wars and their implications for the community's reconnection with Algonquin knowledge and identity: 
I guess, when you look at the situation, we shouldn't have been able to win that fight. We were disorganized and outnumbered, we didn't have any guns, the police had guns. We didn't know very much, they had all the information at the time. So some people think that the spirits of the rice and the spirits of the lake were behind our success. The idea that things... in the old language, things are animate, they have spirits... you know for so many years, the rice was an important part of Indian peoples' sustenance, that it wasn't ready to give itself up.

And I think people think that we were woken up by the rice. And things have changed a lot since then. People know much more who they are, they're much more capable of standing up for what they, for who they are and also for their Indianness and for those values that they see that are intrinsic in their families, and in the culture, what's left of it. [...] It has helped, as I said the rice woke us up and we began to research, we began to think about these things, and also, as we became more and more attuned and awoken to the issues in front of us, the more we understood when we looked at our Indigenous knowledge what we thought was maybe even insufficient, or sort of colloquial knowledge, those things became much more important. And we began to understand what we knew better, what was taught to us as children and so people could then celebrate the things that their grandparents had told them that at one point they didn't think was worth anything.

It caused us to take a stand on a lot of things. We also, you know once you have a reputation of fighting and winning, you want to keep it up. So we took on issues around the Tay River. And you know what's interesting, we looked at forest stuff, we got involved in forest stuff to some extent, but most importantly we got involved in water.

Mireille Lapointe (2010) further elaborates on the political consequences of the relationship with manomin: 
I think that those political stances, the political stance that we have taken, comes from that original life that we have undertaken, that original relationship that we have with manomin. Because if you are going to have manomin in your community, and you are going to be respecting manomin, and respecting the right of the community members to have access to that, then it means that it belongs to the community, it doesn't belong to one individual, so all of us have access to it. Which means that one individual does not have a right to make tons of money from it and keep it to him or herself.

So it means you have a mindset and you have a way of looking at things that instructs you when looking at manomin. Well that same mindset, that same worldview, that same way of looking at things, if you're consistent, will apply itself to all other situations that arise, situation smokes, situation mining and whatever other situation that arises.

If we're honest and if we see that integrity of thought and integrity of action is important to us then our worldview on manomin informs everything else that we do.

The relationship of members of the Ardoch Algonquin First Nation with manomin is rooted in physical, historical, ancestral, cultural, spiritual and political connections, which inform the governance, practices and political activities of AAFNA. From the above quotations, it becomes clearer how this relationship with manomin is tied to a broader connection with Algonquin laws, including AAFNA's Principles of Development (discussed in Section 5.4).

Given the significance of manomin to the identity of members of AAFNA and how it informs their actions, it should then come as no surprise that the developments summarized above (which have mostly limited access to manomin and threatened its viability) have been resisted, opposed, challenged and negotiated in various capacities.

As discussed previously, the forms of development that have limited (or presented a significant risk to) access to manomin are diverse. There are numerous actors involved across different scales and jurisdictions (ranging from neighbouring individuals to 
municipal, provincial and federal governments, to international governments and actors). As such, AAFNA's strategies and responses to these challenges have thus also been diverse, creative and varied.

\subsection{AAFNA's responses to the challenges of "development"}

As explained in Section 3.1.5, this research goes beyond the "impact model" of development to an examination of the processes and interactions through which developments are constituted and negotiated across time and place. As such, AAFNA's responses to development are an important part of this research.

There are some notable observations that emerge in considering how has AAFNA responded to the challenges and opportunities of development? First, is the obvious observation that "development" has been a process that has been negotiated, resisted, reworked and in some cases embraced by members of the Ardoch Algonquin First Nation and Allies. It is also clear from the results of this research that the Algonquin Nation, and the Ardoch Algonquin First Nation more specifically, have responded to the challenges of development in countless ways, drawing on various strategies to oppose, resist and adapt to the challenges of "development" since the arrival of colonial agents and settlers in Algonquin territory (as discussed in Chapter 4).

The oppositional responses of AAFNA (with respect to maintaining access to manomin) can be deconstructed in terms of the framework presented in Section 2.3.2 that draws on the insights of both Katz (2004) and Brascoupé (2010) to distinguish between oppositional practices as resilience (associated with pre-contact history), reworking 
(reflecting negotiations throughout the contact period) and resistance (decolonization). In this framework, resilience is associated with sustaining practices that allow people to endure in an oppressive context. Reworking is associated with efforts to redistribute the landscape of power and resources without necessarily challenging the status quo. Resistance is characterized by actions that directly challenge the dominant powers or hegemony, which in this context can be summarized as colonial domination over Indigenous peoples. As is discussed in Section 2.3.2, decolonizing practices can be understood to be integral to each of the categories above, weaving through many oppositional practices of varying natures, though it is through resistance practices that the violent marginalization of Indigenous peoples can be directly confronted and transformed into a new context of respect and decolonization.

Many of the responses of the Ardoch Algonquin First Nation and Allies' to the challenges and opportunities of development (both in general and more specifically as they relate to manomin) have been alluded to throughout the previous chapters of this thesis. While some of these oppositional practices have been in response to developments that directly impact access to manomin, other oppositional practices are indirectly related to protecting and maintaining access to manomin (i.e. by asserting jurisdiction and responsibility in Algonquin territory, or protecting the broader ecosystems of which manomin is a part).

AAFNA's responses to the challenges of development that can be understood as resilience include: the ongoing celebration of community, culture, history, traditions and accomplishments (through the annual pow-wow known as the Manoomin Festival); 
continuing to harvest, process and manage manomin using traditional techniques; and, the revitalization of Algonquin identity and re-connection with Indigenous rights after the Rice Wars. Instances of reworking as a response to the challenges of accessing manomin due to development include: AAFNA's assertion of their access and jurisdiction in unceded territory (Crown lands) as in the cases of clearing ground on Pine Lake for a community centre; continuing to participate in traditional activities, such as hunting, fishing, trapping and wild rice harvesting without seeking permits from Ontario authorities; and defending rights to do so in the courts (discussed in Section 1.6.3). Other instances of reworking as opposition include: the educational efforts for children, youth and other community members (including settler allies) regarding Algonquin culture, history, traditions (e.g., Mazinaw Lake culture camp, Pow-wow and annual manomin teaching). acts of resilience and reworking can nurture the stronger oppositional stances of resistance, as noted by Katz (2004). Sherman (2008) echoes this thought:

While some Omàmiwinini people continue to find it difficult to make that connection, others have entirely transformed their lives as a result of the recognition that they have responsibilities as human beings within our homeland. Opposition to development has been one of the outcomes of this re-envisioning of Algonquin relationships with the land (16-17).

AAFNA has also resisted various developments that have limited or posed serious threats to their access of manomin. Examples of AAFNA's resistance include: AAFNA's participation in various actions including road blockades, Wild Rice Hearings and asserting their Algonquin jurisdiction and responsibility with respect to manomin in other capacities (described in Section 1.6.2) in response to the commodification and "theft" of manomin by the Ontario Ministry of Natural Resources and by Lanark Wild Rice (the 
commercial harvester) during the Rice Wars. During the uranium mining conflict that began in 2007, AAFNA also resisted the despoliation of the ecosystems in which manomin exists, by mounting their 4-pronged strategy of community education, direct action (blockades of mine site), research, and exploration of legal options and political solutions (discussed in Section 1.6.3). AAFNA has also engaged in political and legislative processes to assert their responsibility and jurisdiction in traditional Algonquin territory in order to oppose other harmful developments (such as opposing Omya's overdrawing of water from a tributary of the Ottawa River through the Environmental Review Tribunal). This political engagement is another example of AAFNA's resistance to harmful developments in the Valley of the Kiji Sibi and extinguishment of Algonquin jurisdiction in the territory. Finally, AAFNA's refusal to participate in the Algonquin comprehensive land claim, a political process that is argued to compromise Algonquin jurisdiction in the Ottawa Valley, is another example of resistance, as it delegitimizes the land claim process and permits the ongoing assertion of Algonquin responsibility and jurisdiction within unceded Algonquin territory (discussed in Section 5.3.5). AAFNA's maintenance of traditional governance (Ka-Pishkawandemin) can be conceptualized as both resilience and resistance as it provides a connection to traditional activities and values, while also highlighting the unjust terms of exclusion to participate in the Algonquin land claim. These responses are depicted in Figure 6.3 below.

Though not discussed in earlier portions of this thesis, AAFNA has engaged in other numerous examples of oppositional acts and stances to address the challenges to access to manomin posed by development. Most notably, AAFNA has absolutely refused 
to commoditize manomin in any way. During field research at the Silver Lake Pow-wow, I observed community leaders discuss that they would not use manomin to raise money for community activities (i.e. through the pow-wow raffle as they do with canoes and other prizes). This is particularly significant given that AAFNA is financially independent and raises their own funds due to their independence from governmental funding supports for Indian Band (status) First Nations (as AAFNA is a non-status community and does not receive funding from Aboriginal Affairs and Northern Development). Consequently they must raise funds for their community events, programs and governance operations without a tax base and mostly drawing on contributions from individual community members and their supporters. Their absolute refusal to commoditize manomin, I argue is another instance of resistance to the overarching logic of exploitative and commodifying development. The diversity of Algonquin responses to development reveal the consistent strength and distinction of Algonquin values from dominant settler ideology and practice. 
Figure 6.3: AAFNA's responses to developments to protect manomin on Mud Lake

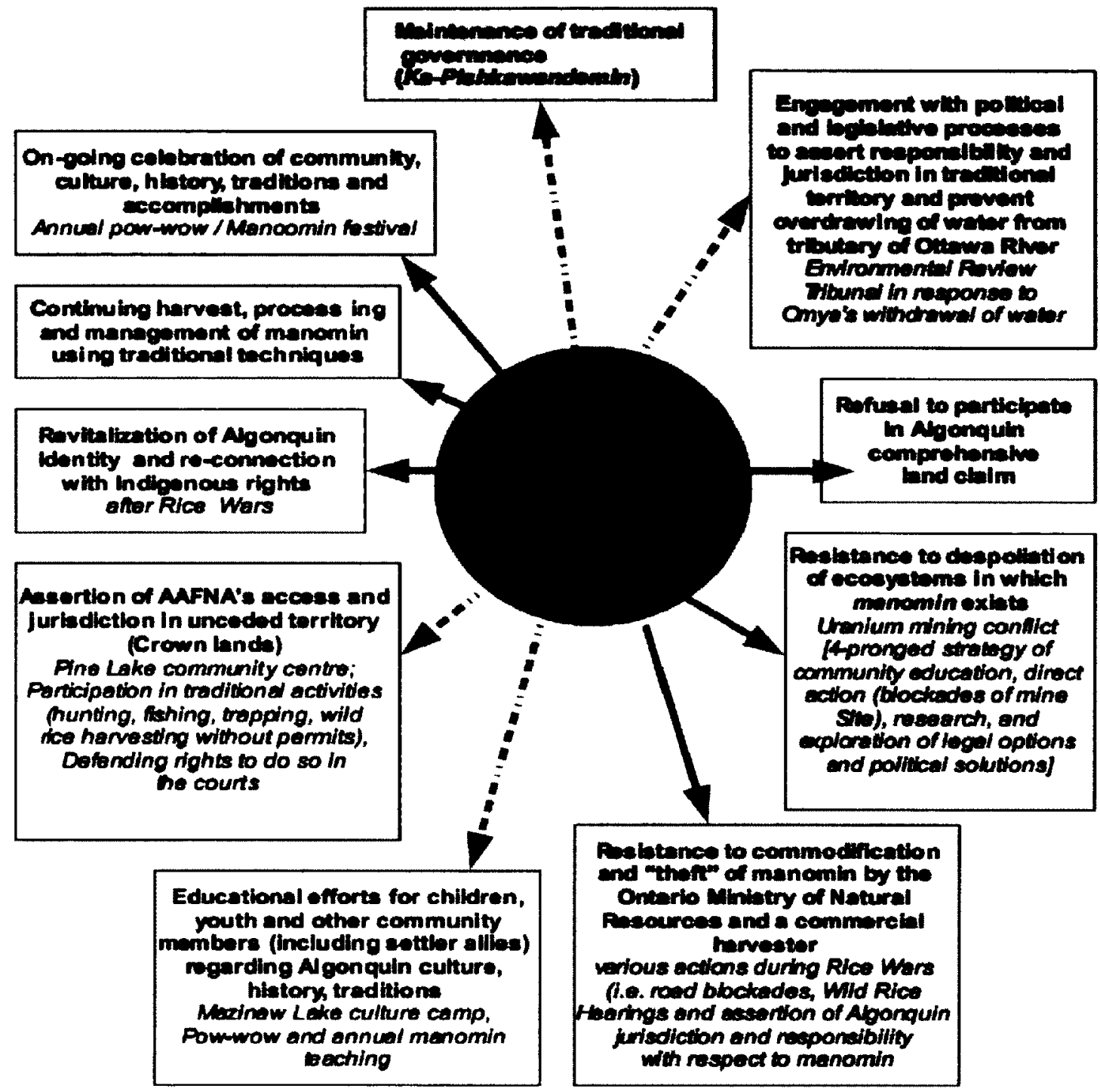

The boxes summarize the main oppositional practices discussed in Section 6.5. The blue boxes represent oppositional practices characterized as resilience. The yellow boxes represent oppositional practices characterized as reworking. The pink boxes represent oppositional practices characterized as resistance. The purple box represents an oppositional practice characterized as both resilience and resistance. Specific examples of how the oppositional practices are italicized. The arrows indicate the direction of change of access to manomin, where the red arrows indicate an increase in access to manomin and blue arrows indicate reduced access to manomin for members of AAFNA. Dashed arrows indicate a significant potential change in access to manomin. 


\subsection{Where do non-Indigenous people fit in? Implications for Settler Responsibilities}

As discussed, another secondary research question that has guided this research has been, in light of the findings, what are the implications for settler responsibilities? While this question has not been dealt with explicitly in the body of this thesis, there has been much discussion that serves to point to some possible answers to this question. A summary of the preceding chapters begins to offer some answers to the above question by pointing towards ways to realign Algonquin-settler relations towards relationships of respect that are rooted in the responsibilities agreed to and established through the very historical agreements that enabled initial settlement in the Ottawa Valley from the $18^{\text {th }}$ century onward, first by Europeans and later by immigrants of numerous nationalities.

In examining this question, the first insight revealed through this research is that there is a need to adopt decolonizing practices in beginning to explore the very question of settler responsibilities. Chapter 2 of this thesis begins by explaining this imperative through a discussion of the historical connection of research and academic inquiry with colonial projects. By introducing the concept of deconstructing and decolonizing the production of knowledge through a project of "unmapping" (Razack, 2002, p. 5), I present how research can be part of a decolonizing project, which reveals, confronts, challenges and undermines colonial histories and logic (which silence and erase Indigenous histories, knowledges, treaties and agreements).

By also rooting this research in political ecology (and drawing on insights from poststructural, postcolonial and critical feminist theory) the links between power, ecology 
and socio-economic-political factors are teased out. The approaches of political ecology are applied throughout the research by deconstructing "development" and resistance, taking account of multi-scalar interactions (at various temporal and spatial scales), exploring the ways in which capitalism and colonialism are mutually constitutive and examining the consequence of nature as a social production.

Moving on from the recognition that the asking of the question itself must be rooted in decolonizing practices, Chapter 3 examines the question of how to begin to ask the research questions themselves (i.e. questioning the very doing of the research itself). Chapter 3 explains how a commitment to decolonizing practices have guided the very way that this research has been conducted, by drawing on Indigenist and decolonizing, post-colonial, critical feminist, critical post-structural and critical ethnographic methodologies. Many of these methodologies challenge traditional approaches to research by approaching research through a critical, reflexive, flexible and explicitly political approach that aims to confront, challenge and transform 500 years of colonial, oppressive relations on Turtle Island by decentering Euro-centric ways of knowing and committing to a readiness to learn from myriad ways of knowing, doing and practicing. Rooting research in respect, accountability, reciprocity and transparency have been overarching goals of this research, and have also led to a dedication to acknowledge and celebrate the strengths and accounts of the histories of the Ardoch Algonquin First Nation. Through both Chapters 2 and 3, this thesis reveals that in attempting to even learn about Indigenous-settler relations and histories, and subsequent settler responsibilities through a focus in a particular place and community, one must approach 
the research with an engagement with the deep historical precedents of colonial settlerIndigenous relations, particularly settler domination and Euro-Canadian undermining and erasure of Indigenous histories and knowledges. In other words, we must dig deep to learn what is not readily or widely taught, discussed or celebrated in the common accounts of the history of our homes, in order to learn and appreciate the many different accounts of history and of place and to gain a more nuanced understanding of the workings of power, domination, subordination and contestation that are at work in Indigenous-non-Indigenous relations.

Thus, I argue that one implication of the outcomes of this study is that the journey to examining settler responsibilities in the case of Algonquin settler relations in the Ottawa Valley begins with taking personal responsibility to acknowledge, engage with and challenge complex colonial histories while simultaneously forging respectful and accountable relationships through the research and learning process. A large part of this involves cultivating the capacity to listen, to be open to learning new accounts of the same story from a different voice and a different perspective, and unlearning and undermining the very historical foundations of our social and political organizations and structures (also known as our national myths) (Battiste, 2000b; Razack, 2002; Mackey, 2005). Learning to listen involves a careful and critical effort to take direction from Indigenous peoples themselves, and a willingness and openness to learn from different ways of knowing, learning and doing. The consequences of undertaking this kind of learning and questioning are great, as is seen through discussion of the outcomes of Chapters 4 and 5. 
In Chapter 4, the results of the research point to further implications for settler responsibilities, as it is argued that settler governments and individuals have not upheld their side of the agreements that first allowed Euro-Canadian (and later other migrants) to settle in the valley of the Kiji Sibi. This lesser told history becomes apparent by learning from Algonquin (and other Indigenous) accounts of history [through both primary (first hand) and secondary sources]. These alternative accounts of history confront dominant historical discourses, which often erase Algonquin history in the territory and reinforce the legitimacy of colonial law, consequently engaging with these alternative accounts challenge the very foundations of contemporary legal and political structures. As outlined in Chapter 4, the terms and spirit of the Friendship Treaty of 1701 (as represented in the wampum belt held by Algonquin Elders), the Royal Proclamation of 1763 and the Treaty of Niagara of 1764 (British colonial legal agreements) have not been upheld in the Ottawa Valley by settler governments, agents, nor the majority of Canadian citizens since 1772 (beginning with the first Algonquin petition submission). In her essay, Picking Up the Wampum Belt as an Act of Protest, former AAFNA co-chief Paula Sherman (2010a) explains the consequences of the neglect of the Friendship Treaty of 1701: 
Over the centuries, as European interest in North American lands passed to the British, and then to Canada, understandings of this agreement [the Friendship Treaty] and the relationship it represented, faded from memory. This resulted in unbalanced relationships between Omamawinini people, European officials, and settlers. Without the principles and protocols for relating that were embedded in the Friendship Treaty, Omamawinini lands were appropriated and used to facilitate settlement and an economic base for the emerging Canadian nation. As the process proceeded over hundreds of years, many lands and watersheds within the homeland of the Omamawinini were people were transformed from living breathing entities imbued with spirituality into exploitable resources that would be used to support the needs of particular human beings (115).

As I present in Chapter 4, "Canada is the result of settler societies established through conquest and the appropriation of Indigenous lands and resources" (Sherman, 2010: 116) through the exercise of colonial judicial processes and the neglect of historical agreements. The implications of these findings are very significant and monumental in scope, as they undermine the very foundation of the Canadian political and judicial system (including the legitimacy and functions of all aspects and jurisdictions of Canadian government and legislation), and also undermine the "rightfulness" or legitimacy of settlement across Algonquin territory by non-Indigenous people. Moreover, these findings also affirm ongoing Algonquin jurisdiction in the Valley of the Kiji Sibi.

While discussing AAFNA's assertion of Algonquin jurisdiction and responsibility in the Valley of the Kiji Sibi during the uranium conflict of 2007, Sherman (2010) explains that AAFNA challenged the authority of the Ontario government to "issue mining claims that had never been ceded or surrendered to Canada" (123). She elaborates: 
We took this argument a bit further, to insist that our jurisdiction extended beyond the reserves or crown land to include those lands that had been appropriated and transferred to the domain of private property. While we certainly respected the rights of our neighbours to enjoy their land and homes, we believe that this right is one of occupation and not of actual ownership of the Earth.

Actual ownership of the Earth does not reside with human beings. Our jurisdiction is therefore not about ownership in the sense of control and domination, but is instead about relationships and responsibilities. Jurisdiction is a necessary mechanism to maintain our relationships with the Natural World around us. In a very real sense, our identity as people is tied to our relationships with the land (Sherman, 2010: 123).

Former co-chief Mireille Lapointe (2010) explains in an interview that knowledge of this history, these agreements left unhonoured, creates responsibility for those who have begun to learn about this history:

Once you have knowledge of something, then you are responsible for that knowledge. Wherever you take it and whatever you do with it. Once you know something and you've experienced it, then you become responsible for this. So the kids I teach in Native studies, I teach them that 'You are now responsible for the knowledge you have'. There's no turning back from that. You know better, you know to go and get information. You know that we are not the authors of our misery on a national scale.

In taking direction from members of AAFNA, it then becomes clear that an implication for settler responsibilities that comes out of this research is the imperative to acknowledge that fundamental agreements between settlers and Algonquin people have not been honoured and continue to be violated on an ongoing basis.

From a genuine and sincere recognition of this reality, other responsibilities must flow in order to address the inconsistencies with these agreements. One example of individual settlers upholding their responsibilities as residents in the Algonquin homeland was expressed in the alliances built between Omàmiwinini people and their neighbours during the uranium conflict of 2007 with Frontenac Ventures Corporation and the 
Government of Ontario. According to Sherman (2010a):

In a very real sense, what developed between the Omamawinini people and our neighbours as a result of this conflict was a continuation of the original relationship begun hundreds of years ago. That relationship, which has been neglected and tossed aside, now looked promising. As our neighbours began to acknowledge that they were living in the homeland of the Omamawinini people, they began to think about Canada's relationship with Indigenous peoples. People, who barely knew we existed previous to this protest, began to see Canada and its history in a new light. They began to critically analyse what was happening around them (122).

Thus, as Sherman (2010a) presents, a consequence of recognizing the historical account offered in Chapter 4 requires a drastic (but attainable) re-framing of Algonquin-settler relations that is rooted in the spirit of the agreements through which European settlement in the territory was made possible during the $18^{\text {th }}$ and $19^{\text {th }}$ centuries. This reframing of relations implicates our governments, our political organizations and laws, and indeed, settlers as individuals and communities.

Another implication for settler responsibilities is apparent through examining the previous research questions: how has access to manomin been affected by development? And how have members of AAFNA responded to the challenges of development? Chapter 5 and Figure 6.2 illustrate the numerous ways that access to manomin for the Ardoch Algonquin First Nation and Allies has been affected by development. As discussed, many of the consequences of development create challenges to which members of AAFNA have had to respond in order to maintain their access and cultural practices to care, harvest, process, prepare, eat, share and store manomin. AAFNA's responses to the challenges of developments are summarized in Section 6.2 and in Figure 6.3, above. What is apparent in examining the developments that affect AAFNA's access to manomin 
is that there are numerous actors who are responsible for developments that limit AAFNA's access to manomin. These actors work at and across various scales and political jurisdictions. Not surprisingly then, AAFNA's responses are also diverse and target actors at various scales and across varying jurisdictions [i.e., their educational efforts target children and youth of the community; the building of the community centre at Pine Lake challenges the jurisdiction of "Crown lands" (and the authority of the Ontario Ministry of Natural Resources) and asserts Algonquin jurisdiction in the territory; while rejection of the Comprehensive Land Claims process challenges federal and provincial jurisdiction to set the terms of negotiations with respect to Algonquin identity, governance and cessation of title].

What does this imply for settler responsibilities? What I hope to reveal through this analysis is that settlers are implicated in various ways in whether access to manomin is limited or maintained, for example as individual boaters that cut through the wild rice fields, or collectively through our governments' policies that claim jurisdiction over Algonquin "resources" (such as the wild rice itself through the Wild Rice Harvesting Act) or to unceded Algonquin territory (through the issuing of mining rights). As such the implications for settler responsibilities are many. They can be far-reaching and significant, and hold potential for renewed and emancipatory change towards a movement that confronts our colonial history and our ongoing colonial present. For example, in Section 5.3.5, the Algonquin Comprehensive Land Claim is shown to potentially and significantly limit AAFNA's access to manomin and their ability to assert responsibility in the region to protect the manomin and its surroundings. Thus, an 
engagement with the problems of the land claim process is one possible responsibility that emerges from this particular example.

Similarly, the avenues through which to act on these responsibilities are also many. By examining the particular case of the Ardoch Algonquin First Nation and Allies' access to manomin, the complexity of interactions that affect access to this food source (which is of cultural, spiritual, physical and ecosystemic value) is underscored. Just as members of AAFNA have responded to the challenges of development through numerous and diverse avenues, there are many ways that settlers (as individuals, political agents and corporate actors) can confront the injustices and challenges that have been discussed throughout this study. What cannot be highlighted enough is that in taking up responsibility and confronting our collective history of injustice, one must be engaged in a process which seeks to listen, learn, engage in genuine dialogue and one must take direction from Algonquin people themselves. One must learn to work within Algonquin people's visions of relationships rooted in respect and responsibility. (Of course, this path is not simple as there is no single "Algonquin people's vision of relationships rooted in respect and responsibility" and is therefore more of a negotiated process, rather than a foreseeable end-state). What is important here is that there are numerous ways in which to become engaged in this process, as individuals, as neighbours, as political and civic agents, and as shareholders and businesses, amongst others.

A final implication of this research is illustrated through the understanding that this particular case study, which examines an Algonquin community's access to one of many traditional foods, is only one entry point that reveals the ongoing colonial relations 
between Indigenous peoples and settlers. The lens of manomin sheds light on the incredible number of processes that are at play when maintaining Indigenous cultural practices and identity. These processes include the challenges and limitations created by uneven power relations that marginalize and constrain Algonquin people (such as the regulation and control of Indigenous governance, identity, cultural practices, territory, and exploitation of the land, water and creatures across Indigenous territories), and the oppositional and sustaining practices through which Algonquin identity, responsibilities and relationships are protected and maintained. Paula Sherman explains the implications of this for herself and her community in recounting her and AAFNA's experience of slamming into "the colonial wall" during the uranium conflict:

Because identity is also I think is developed in conjunction with colonialism, it's really developed juxtaposing all of that too. Because there's no, you can't escape colonialism at this point. You can't. There's nothing you can do to escape. This became really crystal clear to me around the uranium issue, in thinking about really coming to understand and to know what it meant to be Algonquin in the sense that we cannot allow that development to happen because to do so would violate Algonquin law and would violate our relationship in that place as Algonquin people. So here we are at the point of really in our hearts understanding what that means...that it can't happen. Because otherwise it compromises who we are as human beings, so here we are at the point where after these 400 years of struggling to even still be here, to physically exist, we're at a point of spiritually and culturally existing and understanding what that meant. So in a sense that's a positive thing, that we had come back to such an extent that we understand what that relationship means, and we understood Algonquin law to that sense in understanding that uranium exploration can't happen otherwise it violates those things that over those thousands of years our ancestors have done to protect that place and our relationship with that place, with the Kiji Sibi and particularly with manomin in that place, specifically for us. So here we are at that point of understanding that, and feeling positive about ourselves in the sense of understanding that, but then we're dragged into court and told that what we understand to be the truth doesn't matter. That all that matters is Canadian law. 
So to me, to be standing there and have the judge tell us that who we are doesn't matter, that our culture, our language, our relationship with manomin in that place, none of that matters, all that matters is that Frontenac Ventures be allowed to drill for uranium. So to reach that point of philosophically understanding once again, what our ancestors wanted us to know, to come to that point of understanding that and then slam into that wall, that colonial wall, of that judge in the court room, who actually said to Bob and I that we should know better, we're educated Indians, that we benefited from this system of education. So for us to stand up against Ontario law was to have been a very criminal act and really, I think, he proved to us that he was just not...that he was the epitome of settler colonialism. He was the epitome of what it meant to be indoctrinated to see Canada in a particular way that alienated us and our knowledge and our history in that place. None of that mattered. What was important was that the mining industry had access to our lands. And that whatever policies had to be developed to allow that to happen, that would happen. That's the message that we got from that right?

So how do we...and so in thinking about that now, it's not only thinking about how do we develop and create a sense of identity in our youth and children who understand their relationship with manomin, but how can they do that and carry that forward in time when it leads them to the same place that it led us, to being sentenced in court. So that's just something that we're struggling with, how do we bring that forward in that sense?

Because it seems to be, the more you actually articulate Algonquin law and live within Algonquin law the more you're going to hit the colonialist settler, colonial wall. The more you're going to slam into that because that violates Algonquin law. So to me that's the point that we're struggling with right now. How do we rectify that? (Paula Sherman, 2010c).

Therefore, the implication here is that our colonial past remains with us today, not merely as an artifact of this history, but as an ongoing process which maintains, reinforces and further entrenches the domination and control of settler Canadians through the marginalization, dispossession and oppression of Indigenous peoples across Turtle Island, and in the Ottawa Valley or the valley of the Kiji Sibi, more specifically.

While this conclusion may seem overly simple or obvious, I stand firm in my belief that this understanding is not widely enough appreciated, taught nor challenged, in 
that our collective colonial past and present is so rarely confronted in a way that truly contests and resists the ongoing dispossession and marginalization of Anishinaabe and Indigenous peoples on whose homelands we have been residing. These ongoing colonial relations furthermore constrain all of us in a cycle of violence, conflict, greed and unbalanced relationships. Beyond contesting the ongoing dispossession and marginalization of Anishinaabe and other Indigenous peoples, there is little commitment to decolonization through efforts to recognize the autonomy, self-determination, jurisdiction and responsibility of Indigenous peoples in their territories, through law, policy and/or other important but informal practices, at collective or individual levels.

In sum, the implications of this research for settler responsibilities are many, and include (but are certainly not limited to): the imperative to ask our questions and to learn in a fundamentally different way than has been traditionally done in the past; the imperative to learn, acknowledge and take responsibility for our colonial histories and broken promises and agreements; the imperative to learn, acknowledge and take responsibility for the specific ways we are implicated in limiting the livelihood activities, cultural practices, jurisdiction, responsibility and identity of our Indigenous (Algonquin) neighbours; and the imperative to learn, acknowledge and take responsibility for the reality that we are not beyond colonial relations of domination, dispossession and marginalization.

\subsection{Towards a decolonizing journey}

The above implications are hugely significant, and lead me to ask another slew of questions: What next? How do we take up these responsibilities? And if we begin to 
take up the responsibilities that are revealed through this research, we must learn, we must acknowledge and we must act. But how do we act? Towards what end?

For me, the question that follows acknowledging all of the above implications for settler responsibilities is: How do I individually, and how do we as settler allies, collectively pursue a path towards decolonization, to genuinely confront, oppose, resist and transform our colonial histories and ongoing colonial, oppressive relationships?

In beginning to explore these new questions beyond what has already been discussed in Section $6.5, \mathrm{I}$ would like to highlight that the ways we can begin to do so must be diverse, creative and numerous, just as the very processes and impacts of development and colonialism and the oppositional responses of the Ardoch Algonquin First Nations and Allies are diverse, creative and numerous.

Members of AAFNA whom I interviewed echoed this perspective of respect for diverse approaches. Robert Lovelace (2010) explains:

So people really do, people have to stand up and fight, they have to claim their humanity again, both settlers and Aboriginal people. We're all victims of colonialism, colonialism is a mind-set both for those who were colonized and those who were colonizers. The only way to challenge it is to do that, is to challenge it at all levels.

How do we do that? Some people write papers, some people teach, some people live back you know on the land, my neighbours, we all, we trade and we barter with one another, you know in those small ways we afford each other an economy that's not self-reliant but reminds us of, that sustainability might be possible. I don't know. And some people go to Toronto and get arrested in the summer time because they simply want to shout out their concern and their grievances.

Robert Lovelace (2010) also suggests that a fundamental restructuring of our political borders to reflect bioregional boundaries would be another part of decolonizing our relations on/with this land. Brascoupé (2012) similarly emphasizes the importance of 
settlers working together "to decolonize Anishinaabe lands and the natural world" through a physical unmapping of the environment by removing developments (such as dams) that limit Indigenous peoples' access to their traditional territory. I will leave other concrete suggestions on how to move forward on a decolonizing path to those who are better situated to do so, as I am still learning to listen, to ask, and to take direction with critical thought and analysis, and am only best situated to explore concrete ways forward for myself.

There is a growing body of work which seeks to illuminate ways to move towards a journey of decolonization, to engage in Indigenous solidarity, to become an ally in Indigenous struggles and to collaborate in settler-Indigenous alliances (some written examples include Barron, 2000; Battiste, 2000b; Tuhiwai Smith, 2000; Collins, 2004; Simpson, 2004; Lawrence and Dua, 2005; Regan, 2005; Lovelace, 2009; Barker; 2010; Christian and Freeman, 2010; Davis, 2010; Davis and Shpuniarsky, 2010; Gehl, 2010; Sherman, 2010a; Gehl, 2011; Walia, 2012). Many of these works have been referred to throughout this thesis. I cannot do justice to the breadth of this important work here. What I do know, through this research, is that we all have an important part to play in this effort towards decolonization, liberation from oppressive relationships and a more just and respectful future. Mireille Lapointe (2010) explains: 
We should, from all of the efforts of government and politicians and the Church and the education establishment, all these institutions, it amazes me that we still exist. That this notion, this belief, these ways of being and thinking, and language are still here. And we are, we're still here. And we're still here for a purpose.

And its not to moralize, and its not to show that we're better than anyone else, but I think we have a role, and that's it, we have a role. If that role is yet to be determined, maybe, maybe not. Maybe its an evolving role.

I think that to put on us the guardianship of the earth, on Indigenous people - because you see white people, you hear white people doing that - and I think its immensely wrong and I don't want to use the word unfair, but its misplaced, and I think its misguided in many ways. And the reason I say that is that I believe, one of my deepest deepest held beliefs is that of the medicine wheel, and for me there is a place on the medicine wheel for all creatures, all beings, all things. We all sit on the medicine wheel, somewhere on there, but we all do, and we all have our role. And to think that, to ascribe to Indigenous people of guardianship of the earth is to in fact to absolve yourself, to absolve oneself of one's responsibilities because then that responsibility belongs to someone else.

When in point of fact, if you eat, drink and breathe, that responsibility belongs to all of us who eat, drink and breathe. But if we think in terms of roles for people, I think our role is to be hard headed, to be steadfast in our beliefs, in the medicine wheel, not to forget the Original Instructions, if we have any role at all, I think that's one of them.

For me that's how I see it. It's that we remember. We need to remember in our collective conscious the Original Instructions. Because if we don't this place becomes a giant factory, the earth becomes a giant factory. And that's not what I want, and that's not what the Original Instructions say to me.

I firmly believe that there is a learning opportunity and beyond that, a responsibility, for all of us to better understand how we can better live on this land, respecting our neighbours, upholding the agreements and promises that allowed European, and later other immigrants, to settle in the region, and re-orienting our lives, livelihood and economic activities to better protect the ecosystems which sustain all life in the valley of the Kiji Sibi.

The Ardoch Principles of Development offer an alternative model of how we 
might pursue development, or in other words how we could organize "human activity that alters the land [to] sustain and enrich the community and its individuals". The Ardoch Principles of Development include the following principles: Walking lightly on the land; Taking only what is needed; Listening to the Elders; Knowing the land; Protecting the land; Honouring the relationship between the land and the people; Protecting the people and the sacred relationship to the land; and Making relations. The Principle of "Making Relations" speaks meaningfully to the question of how to begin the journey toward taking responsibility for our implications (if not direct participation) in the ongoing dispossession of Algonquin and other Indigenous peoples:

The beauty of this world is expressed in its many colours and forms and in the complexity of its meanings and spirits. There are many human beings beyond the Algonquin community who share recognition of the abiding responsibility we have to our homeland and the greater world. We need to respect these people as brothers and sisters and work with them in mutually supportive ways. We need to listen to good advice when it is given in a respectful way as though it is given by a brother or sister (AAFN, n.d.: 4, emphasis in original).

This principle (as well as all of the others) contains wisdom of relevance to nonIndigenous or settler neighbours as well. As AAFNA has suggested: "We need to respect these people as brothers and sisters and work with them in mutually supportive ways. We need to listen to good advice when it is given in a respectful way as though it is given by a brother or sister" (AAFN, n.d.: 4). Through this research the richness and complexity of our histories and the many ways our actions are intertwined in one another's lives has been underscored for me. Perhaps most importantly, through this work I have been taught ways to seek more justice, equity and freedom as I continue forward living in Algonquin territory or in other Indigenous peoples' territories across Turtle Island. 
I have been so incredibly fortunate to have been supported by members of the Ardoch Algonquin First Nation in undertaking this research, and to have been granted the opportunity to sit with individuals from the community, ask my questions, listen and learn. It is my hope that I have done their commitments, words and work the respect it is due. Chi Migwetch for this opportunity. 


\section{REFERENCES}

Abu-Lughod, Lila. (1993). Writing Women's Worlds: Bedouin Stories. Berkeley: University of California Press.

Adelson, Naomi. (2005). The Embodiment of Inequity: Health Disparities in Aboriginal Canada. Canadian Journal of Public Health. 96(Suppl. 2), S45-61

Amnesty International. (2009, August). 'Pushed to the Edge' The Land Rights of Indigenous Peoples in Canada. Amnesty International. Retrieved from http://www.amnesty.ca/amnestynews/upload/AMR200022009.pdf [Accessed October, 30, 2010]

Alfred, Taiaiake. (2004). Warrior Scholarship: Seeing the University as a Ground of Contention. In D.A. Mihesuah and A.C. Wilson (Eds.), Indigenizing the Academy: Transforming Scholarship and Empowering Communities (pp. 88-99). Lincoln: University of Nebraska Press.

Anderson, Kim. (2008). Notokwe opikiheet - 'Old-lady raised': Aboriginal women's reflections on ethics and methodologies in health research. Canadian Woman Studies/Les Cahiers de la femme. 26(3-4), 6-12

Aboriginal Peoples Television Network [APTN] National News. (2010, November 12). Canada finally backs UN indigenous declaration. APTN National News. Retrieved from http://aptn.ca/pages/news/2010/11/12/canada-finally-backs-unindigenous-declaration/ [Accessed January 12, 2011].

Ardoch Algonquin First Nation [AAFN]. (2007, June 23). Statement on Uranium Mining. Ardoch Algonquin First Nation. Retrieved from Ardoch Algonquin First Nation, News http://www.aafna.ca/Uranium mining.html [Accessed November 3, 2010]

Ardoch Algonquin First Nation [AAFN]. (n.d.(b)). Principles of Development. [Handout].

Assembly of First Nations [AFN]. (2010, November 12). National Chief Welcomes Canada's Endorsement of UN Declaration on the Rights of Indigenous Peoples: Respect, Partnership and Reconciliation will Guide Work to Improve the situation of First Nation Peoples and Build a Stronger Canada. Assembly of First Nations. Retrieved from Press Releases and Media Advisories, www.afn.ca/cmslib/general/10-1112\%20UND\%20press\%20release Fe\%20(2).pdf [Accessed February 24, 2011] 
Avery K., and T. Pawlick. (1979). Last Stand in Wild Rice Country. Harrowsmith. 19(7), 33-55, 107.

Ballamingie, Patricia \& Sherrill Johnson. (2011). The Vulnerable Researcher: Some Unanticipated Challenges of Doctoral Fieldwork. The Qualitative Report. 16(3), 711-729.

Barker, Adam. (2010). From Adversaries to Allies: Forging Respectful Alliances between Indigenous and Settler Peoples. In Lynne Davis (Ed.), Alliances (pp.316-333). Toronto: University of Toronto Press.

Barnett, Clive. (2006). Postcolonialism: Space, Textuality, and Power. In S. Aitken \& G. Valentine (Eds.), Approaches to Human Geography (pp. 147-160). Thousand Oaks: Sage

Barron, Jennifer. (2000). In the Name of Solidarity: The politics of Representation and Articulation in Support of the Labrador Innu. Capitalism, Nature, Socialism, ll(3), 87-112.

Baskin, Cyndy. (2008). Indigenous youth exploring identities through food security in Canada and Brazil. MAI Review, 3(5), 1-11.

Battiste, Marie. (2000a). Maintaining Aboriginal Identity, Language, and Culture in Modern Society. In Marie Battiste (Ed.), Reclaiming Indigenous Voice and Vision. Vancouver: UBC Press.

Battiste, Marie. (Ed.). (2000b). Reclaiming Indigenous Voice and Vision. Vancouver: UBC Press.

Baviskar, Amita. (2008). Introduction: Contested Grounds: Nature, Culture and Power. In Amita Baviskar (Ed.), Contested Grounds: Essays on Nature, Culture and Power (pp. 1-12). New Delhi: Oxford University Press.

Bell, Avril. (2008). Recognition or ethics? De/centering and the legacy of settler colonialism. Cultural Studies, 22(6), 850-869.

Bennett, James P. , Esteban Chiriboga, John Coleman, and Donald M. Waller. (2000). Heavy metals in wild rice from northern Wisconsin. The Science of the Total Environment, 246, 261-269.

Blay-Palmer, Alison and Betsy Donald. (2008). Food Fear: Making Connections. In Alison Blay-Palmer (Ed.), Food Fears: From Industrial to Sustainable Food Systems. Burlington: Ashgate Publishing Limited. 
Bodirsky, M. and J. Johnson. (2008). Decolonizing Diet: Healing by Reclaiming Traditional Indigenous Foodways. Cuizine: The Journal of Canadian Food Cultures, $1(1)$. Retrieved from http://www.erudit.org/revue/cuizine/2008/v1/n1/019373ar.html [Accessed January $20,2010]$

Brascoupé, C. (1999). Reflections of a Native American Farmer. In G Cajete (Ed.), $A$ People's Ecology: Explorations in Sustainable Living (pp. 151-174). Santa Fe: Clear Light Publishers.

Brascoupé, Simon. (2010, November 26). Personal Communication. Ottawa, Ontario.

Brascoupé, Simon. (2012, February 11). Personal Communication. Ottawa, Ontario.

Braun, B. and N. Castree. (Eds.). (2001a) Social Nature: Theory, Practice and Politics. Malden, USA: Blackwell Publishers.

Braun, B. and N. Castree. (2001b). Preface. In N. Castree and B. Braun (Eds.), Social Nature: Theory, Practice, and Politics (pp. Xi-xiv). Malden, USA: Blackwell Publishers.

Braun, Bruce. (2002). The Intemperate Rainforest: Nature, Culture and Power on Canada's West Coast. Minneapolis: University of Minnesota Press.

Brien, Donna Lee. (2009). Climate Change and the Contemporary Evolution of Foodways. M/C Journal, 12(4). Retrieved from http://journal.mediaculture.org.au/index.php/mcjournal/article/viewArticle/177 [Accessed April 6, 2010]

Bron, Ian and Zachary Houle. (2001). Eastern North America, 1763. Canada In the Making. Retrieved from Aboriginals: Treaties and Relations: 1763-1791, [http://www.canadiana.ca/citm/themes/aboriginals/aboriginals3 e.html [Accessed November 23, 2010]

Bryant, Raymond L. (2001). Political Ecology: A Critical Agenda for Change? In N. Castree and B. Braun (Eds.), Social Nature: Theory, Practice, and Politics (pp. 151 - 169). Malden, USA: Blackwell Publishers.

Butler, Judith. (1990). Gender Trouble: Feminism and the Subversion of Identity. New York: Routledge.

Butler, Judith. (1992). Contingent Foundations: Feminism and the Question of 'Postmodernism'. In J. Butler and J. W. Scott (Eds.), Feminists Theorize the Political (pp. 3-21). New York: Routledge. 
Butler, Judith. (2004). Undoing Gender. London: Routledge.

Cahill, Caitlin. (2007). The Personal is Political: Developing new subjectivities through participatory action research. Gender, Place \& Culture: A Journal of Feminist Geography, 14(3), 267-292.

Cajete, Gregory. (Ed.). (1999a). A People's Ecology: Explorations in Sustainable Living. Santa Fe: Clear Light Publishers.

Cajete, Gregory. (1999b). Indigenous Foods, Indigenous Health: A Pueblo Perspective. In G. Cajete (Ed.), A People's Ecology: Explorations in Sustainable Living (pp. 79-102). Santa Fe: Clear Light Publishers.

Cajete, Gregory. (2000). Native Science: Natural Laws of Interdependence. Clear Light: Santa Fe.

Cajete, Gregory. (2002). Indigenous Knowledge: The Pueblo Metaphor or Indigenous Education. In Marie Battiste (Ed.), Reclaiming Indigenous Voice and Vision. Vancouver: UBC Press.

Cameron, Jenny and Katherine Gibson. (2005). Participatory action research in a poststructuralist vein. Geoforum, 36, 315-331.

Canadian Press. (2011, February 28). Agent Orange 'widely used' in Ontario. $C B C$ News, Canada. Retrieved from http://www.cbc.ca/news/canada/toronto/story/2011/02/28/agent-orangeontario.html [Accessed April 28, 2011].

Castree, Noel. (2001). Socializing Nature: Theory, Practice and Politics. In N. Castree and B. Braun (Eds.), Social Nature: Theory, Practice, and Politics (pp.1-21). Malden, USA: Blackwell Publishers.

Cizek, P. (1992). Guardians of Manomin: A case study of Indigenous resource management of wild rice. University of Guelph. Unpublished Master's Thesis.

Christian, Dorothy and Victoria Freeman. (2010). The History of a Friendship, or Some Thoughts on Becoming Allies. In Lynne Davis (Ed.), Alliances (pp. 376-390). Toronto: University of Toronto Press.

Churchill, Ward. (1996). From a Native Son: Selected Essays on Indigenism 1985-1995. Cambridge, MA: South End Press.

Churchill, Ward. (1997). A little matter of genocide : holocaust and denial in the Americas, 1492 to the present. San Francisco: City Lights Books. 
Cloke, Paul, Ian Cook, Philip Crank, Mark Goodwin, Joe Painter and Chris Philo. (2004). Practising Human Geography. Ten Thousand Oaks, California: Sage Publications.

Collins, Patricia Hill. (2002). Black Feminist Thought: Knowledge, Consciousness and the Politics of Empowerment. New York: Routledge. (Original work published 1990)

Constitution Act, 1982 being Schedule B to the Canada Act 1982 (U.K.), 1982, c. 11

Comtassel, Jeff. (2008). Toward Sustainable Self-Determination: Rethinking the Contemporary Indigenous-Rights Discourse. Alternatives, 33,105-132.

Cotterill, Pamela. (1992). "Interviewing Women: Issues of Friendship, Vulnerability, and Power." Women's Studies International Forum, 15, 593-606.

Cox, Kenneth, W. (1993). Wetlands: A Celebration of Life: Final Report of the Canadian Wetlands Conservation Taskforce. Sustaining Wetlands Issues, Paper, No.1993-1.

Crush, Jonathan. (1995). Imagining Development. In J. Crush (Ed.), The Power of Development (pp. 1-26). New York: Routledge.

Davis, Lynne. (Ed.). (2010). Alliances: Re/Envisioning Indigenous-non-Indigenous Relationships. Toronto: University of Toronto Press.

Davis, Lynne and Heather Yanique Shpuniarsky. (2010). The Spirit of Relationships: What We Have Learned about Indigenous/Non-Indigenous Alliances and Coalitions. In Lynne Davis (Ed.), Alliances: Re/Envisioning Indigenous-nonIndigenous Relationships (pp.334-347). Toronto: University of Toronto Press.

DeLisle, S. (2001). Coming out of the shadows: Asserting identity and authority in a layered homeland: the 1979-1982 Mud Lake wild rice confrontation. Queen's University. Unpublished Master's thesis.

Denevan, William M. (1989). Hispanic Land and Peoples: Selected Writings of James J. Parsons. Boulder, Colorado: Westview.

Drewes, Annette and Janet Silbernagel. (2004). Setting up an integrative research approach for sustaining wild rice (Zizania palustris) in the Upper Great Lakes Region of North America. In Tress, Tress, Fry and Opdam (Eds.), From Landscape Research to Landscape Planning: Aspects of Integration, Education and Application (Vol. 12) (pp. 377-386). Heidelberg: Springer. 
Drewes, Annette (Dray) Louise. (2008). Sustaining a ricing culture: An integrated landscape approach to understanding harvest, distribution and management of wild rice (Zizania palustris) across the Upper Great Lakes Region. University of Wisconsin - Madison. Unpublished Doctoral dissertation.

Erasmus, Georges. (1989). Introduction: Twenty Years of Disappointed Hopes. In Boyce Richardson (Ed.), Drumbeat: Anger and Renewal in Indian Country. Toronto: Summerhill Press and Assembly of First Nations.

Escobar, Arturo. (1996). Constructing Nature: Elements for a Poststructural Political Ecology. In R. Peet and M. Watts, (Eds.), Liberation Ecologies: Environment, Development, Social Movements (pp. 46-68). New York: Routledge.

Esteva, Gustavo and Madhu Suri Prakash. (1998). Grassroots Post-modernism: Remaking the Soil of Cultures. New York: Zed Books.

Fausto-Sterling, Anne. (2000). Sexing the Body: Gender Politics and the Construction of Sexuality. New York: Basic Books.

Foreign Affairs and International Trade Canada [FAITC]. (2012). Trade Negotiations and Agreements. Retrieved from http://www.international.gc.ca/tradeagreements-accords-commerciaux/agr-acc/index.aspx?view=d [Accessed April $13,2012]$

Forum for Food Sovereignty. (2007). Nyéléni 2007. Retrieved from www.nyeleni.org [Accessed November 30 2009]

Frankenberg, Ruth. (1995). Growing Up White: Feminism, Racism and the Social Geography of Childhood. Feminist Review, 45, 51-84.

Froc, Kerri A. (2010). Multidimensionality and the Matrix: Identifying Charter Violations in Cases of Complex Subordination. Canadian Journal of Law and Society, 25(1), 21-50.

Gallagher, Colin. (2003). 'Quit Thinking Like a Scientist!' In Jill Oakes et. al. (Eds.) Native Voices in Research (pp. 183-190). Winnipeg: Aboriginal Issues Press.

Gehl, Lynn. (2005). 'Oh Canada! Your Home is Native Land': The Algonquin Land Claim Process. Atlantis, 29(3),148-150.

Gehl, Lynn. (2010). Maan Piinde'eng: A Debwewin Journey Through the Algonquin Land Claims and Self-Government Process. Trent University. Unpublished Doctoral Dissertation. 
Gehl, Lynn. (2011). Ally Bill of Responsibilities. Canadian Dimension 45(1),12-13.

Gezon, Lisa L and Susan Paulson. (2005). Place, Power, Difference: Multiscale Research at the Dawn of the Twenty-first Century. In Paulson, S. and L. L. Gezon (Eds.), Political Ecology Across Spaces, Scales and Social Groups (pp.1-16). London: Rutgers University Press.

Gibson-Graham, J.K. (2006). A Postcapitalist Politics. Minneapolis: University of Minnesota Press.

Gramsci, Antonio. (1971). Selections from the prison notebooks of Antonio Gramci ( Trans. and Eds. Quintin Hoare and Geoffrey Nowell Smith). New York: International Publishers.

Green, Jeff. (2007, May 3). Ottawa Algonquin Community Drops Out of Land Claim Process. Frontenac News. Retrieved from www.frontenacnews.ca/2007/may_3/ottawa_algonquins [Accessed December 9, 2010]

Green, Jeff. (2010, June, 10). Frontenac Ventures Still Beating the Bushes for Funding". Frontenac News. Retrieved from www.frontenacnews.ca/2010/1023 jun 10/uranium 10-23.html [Accessed December 9, 2010]

Green, Joyce. (2009, May). Inclusion or Transformation? Indigenizing the Academy. Unpublished paper presented at Congress 2009, Ottawa, Ontario. Retrieved from http://fedcan.ca/index.php?action=artikel\&lang=en\&id $=203$ [Accessed January 4, 2011]

Gregory, Derek. (2001). (Post)Colonialism and the Production of Nature. In N. Castree and B. Braun (Eds.), Social Nature (pp. 84-111). Oxford: Blackwell.

Harper, Stephen. (2008). Statement of Apology - to former students of Indian Residential Schools. Retrieved from Indian and Northem Affairs Canada, www.ainc-inac.gc.ca/ai/rqpi/apo/sig-eng.pdf [Accessed November 18 2010]

Harrison, Paul. (2006). Poststructuralist Theories. In S. Aitken and G. Valentine (Eds.), Approaches to Human Geography (pp. 122-135). Thousand Oaks: Sage.

Hart, Gillian. (2004). Geography and development: critical ethnographies. Progress in Human Geography, 28(1), 91-100.

Harvey, David. (2003). The New Imperialism. New York: Oxford University Press.

Hay, Iain. (2005). Qualitative Research Methods in Human Geography ( $2^{\text {nd }}$ ed.). New York: Oxford University Press. 
Henderson, James (Sakej) Youngblood. (2000a). Ayukpachi: Empowering Aboriginal Thought. In Marie Battiste (Ed.), Reclaiming Indigenous Voice and Vision. Vancouver: UBC Press.

Henderson, James (Sakej) Youngblood. (2000b). The context of the State of Nature. In Marie Battiste (Ed.), Reclaiming Indigenous Voice and Vision. Vancouver: UBC Press.

Hessel, Peter. (1993). The Algonkin nation: the Algonkins of the Ottawa Valley: an historical outline. Arnprior, Ontario: Kichesippi Books.

Hill, Nicholas M., Paul A. Keddy and Irene C. Wisheu. (1998). A hydrological model for predicting the effects of dams on the shoreline vegetation of lakes and reservoirs. Environmental Management, 22(5), 723-736.

Hoggart, Keith, Loretta Lees and Anna Davies. (2002). Researching Human Geography. London: Arnold.

Hornborg, Alf and Mikael Kurkiala. (1998). Voices of the Land. In A. Hornborg and M. Kurkiala (Eds.), Voices of the Land: Identity and Ecology in the Margins. Lund: Lund University Press.

Huitema, Marijke E. (2000). Land of which the savages stood in no particular need": Dispossessing the Algonquins of South-Eastern Ontario of their Lands, 17601930. Queen's University. Unpublished Master's Thesis.

Hunt, Alan. (1990). Rights and Social Movements: Counter-Hegemonic Strategies. Journal of Law and Society, 17(3), 309-328.

Indian and Northern Affairs Canada [INAC]. (2010a). The Royal Proclamation of 1763. Indian and Northern Affairs Canada. Retrieved from Welcome to INAC NT Region, Education, Youth Buzz, Negotiating Land Claims and Self-Government, http://www.ainc-inac.gc.ca/ai/scr/nt/edu/bzz/nls/ryp/index-eng.asp [Accessed March 13, 2010]

Indian and Northern Affairs Canada [INAC]. (2010b). Frequently Asked Questions: Canada's Endorsement of the United Nations Declaration on the Rights of Indigenous Peoples. Indian and Northern Affairs Canada. Retrieved from Aboriginal Peoples and Communities, International Activities, www.aincinac.gc.ca/ap/ia/dcl/faq-eng.asp [Accessed November 11, 2010]

Indigenous Peoples' Solidarity Movement of Ottawa [IPSMO]. (n.d.) Mission - Basis of Unity / Base d'unité. Retrieved from IPSMO homepage, www.ipsmo.org [Accessed March 3, 2010] 
Jackson, Peter. (2001). Making sense of qualitative data. In Melanie Limb and Claire Dwyer (Eds.), Qualitative methodologies for human geography (pp. 199-214). London: Arnold.

Johnston, Josée, Andrew Biro and Norah, MacKendrick. (2009). Lost in the Supermarket: The Corporate-Organic Foodscape and the Struggle for Democracy. Antipode, 41(3), 509-532.

Katz, Cindy. (2004). Growing Up Global: Economic Restructuring and Children's Everyday Lives. Minneapolis: University of Minnesota Press.

Kitchenuhmaykoosib Inninuwug and Ardoch Algonquin First Nation. (2008, July 7). Court of Appeals Calls on Ontario to Negotiate with KI and Ardoch. Community Coalition Against Mining Uranium (CCAMU). Retrieved from http://www.ccamu.ca/court-of-appeal-070708.htm [Accessed December 9, 2010]

Kindon, Sara. (2005). Participatory Action Research. In Iain Hay (Ed.), Qualitative Research Methods in Human Geography (2 ${ }^{\text {nd }}$ ed.) (pp. 207-220). New York: Oxford University Press.

Kinew, Kathi Avery. (1995). Manito Gitigaan : governing in the Great Spirit's garden : wild rice in Treaty \# 3. University of Manitoba. Unpublished Doctoral dissertation.

Koschade, Bettina (2003). 'The Tay River Watershed 1s Our Responsibility': The Ardoch Algonquins and the 2000-2002 Environmental Review Tribunal Hearings. Queen's University. Unpublished Master's Thesis.

Kobayashi, Audrey L. (1994). Women, Work and Place. Montreal: McGill-Queen's University Press.

Kuokkanon, Rauna. (2009, May). The Logic of the Gift as a Process of Decolonization. Unpublished paper presented at Congress 2009, Ottawa, Ontario. Retrieved from http://fedcan.ca/index.php?action=artikel\&lang=en\&id=203 [Accessed January 4, 2011]

LaDuke, Winona. (2005). Recovering the Sacred: The power of naming and claiming. Toronto: Between the Lines.

LaDuke, Winona. (2006). The People Belong to the Land. In Jerry Mander and Victoria Tauli-Corpuz (Eds.), Paradigm Wars: Indigenous peoples resistance to globalization (pp. 23-25). San Francisco: Sierra Club Books.

LaPointe, Mireille. 2010 (October 12). Personal Interview. Westport, Ontario. 
Lawrence, Bonita. (2004). Real Indians and others: Mixed blood urban Native peoples and Indigenous nationhood. Vancouver: UBC Press.

Lawrence, Bonita and Enakshi Dua. (2005). Decolonizing Antiracism. Social Justice, $32(4), 120-143$.

Lawrence, Bonita and Kim Anderson. (Eds.). (2005). Special Issue: Indigenous Women: the State of our Nation. Atlantis, 29(2).

Lawson, James. (2009, May). Aboriginal Dispossession in the Emergence of a Capitalist Resource Extractive Region: the Ottawa Valley, 1800-1830s. Unpublished paper presented at the Annual Meeting of the Canadian Political Science Association, Carleton University, Ottawa, ON. Retrieved from http://www.cpsa-acsp.ca/papers-2009/Lawson.pdf [Accessed January 28, 2012]

Ley, David and Alison Mountz. (2001). Interpretation, representation, positionality: issues in field research in human geography. In Melanie Limb and Claire Dwyer (Eds.) Qualitative methodologies for human geography (pp. 234-250). London: Arnold.

Little Bear, Leroy. (2000). Jagged Worldviews Colliding. In Marie Battiste (Ed.), Reclaiming Indigenous Voice and Vision. Vancouver: UBC Press.

Ljunggren, David. (2009, Sept 25). Every G20 nation wants to be Canada, insists PM. Reuters. Retrieved from Reuters.com, www.reuters.com/article/idUSTRE58P05Z20090926 [Accessed November 18 2010]

Lorde, Audre. (1984). Sister Outsider: Essays and Speeches. Trumansburg NY: Crossing Press.

Lovelace, Bob (Robert). (n.d.). An Algonquin History. Ardoch Algonquin First Nation (AAFNA). Retrieved from http://www.aafna.ca/history.html [Accessed February $10,2009]$

Lovelace, Robert. (2008, Dec 2). Ardoch Algonquin First Nation (AAFN) Press Release: $\mathrm{Re}$ : Uranium exploration activities in Algonquin homeland. Community Coalition Against Mining Uranium (CCAMU). Retrieved from http://www.ccamu.ca/aafn120208.htm [Accessed December 9, 2010]

Lovelace, Robert. (2009). Prologue: Notes from Prison: Protecting Algonquin Lands from Uranium Mining. In Julian Agyeman, Peter Cole, Randolf Haluza-DeLay, Pat O'Riley (Eds.), Speaking for Ourselves: Environmental Justice in Canada. Vancouver: UBC Press. 
Lovelace, Robert. (2010a, September 5). Manomin Teaching. Workshop at AAFNA Manoomin Festival, Plevna Community Hall.

Lovelace, Robert. (2010b, November 22). Personal Interview. Sydenham, Ontario.

Mackey, Eva. (2005). The House of Difference: Cultural Politics and Identity in Canada. New York: Routledge.

Majaury, Heather. (2005). "Community Voices: Living Inside Layers of Colonial Division: A Part of the Algonquin Story". Atlantis. 29.2

Martin, Biddy and Chandra Talpade Mohanty. (1986). Feminist Politics: What's Home Got to Do with It? In Teresa de Lauretis (Ed.), Feminist Studies/Critical Studies (pp. 191-212). Bloomington, Indiana: Indiana University Press.

Marx, Karl. (1990). Capital: A Critique of Political Economy. Trans. Ben Fowkes. Penguin Books: Toronto. (Original work published 1867)

McClintock, Anne. (1997). No longer in a Future Heaven: Gender, Race and Nationalism. In Anne McClintock, Aamir Mufti and Ella Shohat (Eds.), Dangerous Liaisons: Gender, Nation and Postcolonial Perspectives. Minneapolis: University of Minnesota Press.

McGregor, Stephen. (2004). Since Time Immemorial: "Our Story" : the story of the Kitigan Zibi Anishinàbeg. Maniwaki, Québec: Kitigan Zibi Education Council and Anishinabe Printing

McIntosh, Peggy. (1988). White Privilege: Unpacking the Invisible Knapsack. In White Privilege and Male Privilege: A Personal Account of Coming to See Correspondences through Work in Women's Studies (Working Paper 189). Wellesley, MA: Wellesley College Center for Research on Women.

McNally, David. (2006). Another World is Possible: Globalization \& Anti-Capitalism $\left(2^{\text {nd }}\right.$ ed). Winnipeg: Arbeiter Ring Publishing.

Metcalf Foundation. (2008). Food Connects Us All: Sustainable Local Food in Southern Ontario. Retrieved from: Metcalf Foundation, www.metcalffoundation.com/p_resources_pub [Accessed December 10, 2010]

Mihesuah, D.A. and A.C. Wilson (Eds.). (2004). Indigenizing the Academy: Transforming Scholarship and Empowering Communities. Lincoln: University of Nebraska Press. 
Milburn, M.P. (2004). Indigenous Nutrition: Using Traditional Food Knowledge to Solve Contemporary Health Problems. American Indian Quarterly, 28(3 \& 4), 411-434.

Miller, J.R. (1991). Introduction. In J.R. Miller (Ed.), Sweet Promises: A Reader in Indian-White Relations in Canada. Toronto: University of Toronto Press.

Miller, J.R. (2000). Skyscrapers hide the Heavens: A History of Indian White Relations in Canada. Toronto: University of Toronto Press.

Milloy, John S. (1991). The Early Indian Acts: Developmental Strategy and Constitutional Change. In J.R. Miller (Ed.), Sweet Promises: A Reader in IndianWhite Relations in Canada. Toronto: University of Toronto Press. .

Mining Watch Canada. (2010, January 5). Ontario's New Mining Act Leaves Gaping Holes. Mining Watch Canada. Retrieved from http://www.miningwatch.ca/en/ontario-s-new-mining-act-leaves-gaping-holes [Accessed December 9, 2010]

Minnesota Department of Natural Resources [MDNR]. (2008). Natural Wild Rice in Minnesota. Retrieved from http://files.dnr.state.mn.us/fish wildlife/legislativereports/20080215 wildricestud y.pdf [Accessed November 24, 2010]

Mississippi Valley Conservation [MVC]. (2006). Mississippi River Water Management Plan: Final Report. Retrieved from MVC Water Management, http://www.mvc.on.ca/water-management/special [Accessed November 18, 2011]

Mississippi Valley Conservation [MVC]. (2011). Mississippi Valley Conservation. Retrieved from http://www.mvc.on.ca/home [Accessed November 18, 2011]

MNR [Ministry of Natural Resources]. (1979, April 19). Deputy Minister Policy and Priorities Office, Submission to Cabinet: Ontario's Position on Wild Rice, D.W. Simkin, Acting Director, Policy Coordination Secretariat (Ontario Archives RG1AA2 Box 169, file: Policy Coordination Secretariat (1) no. 4, 1979)

Moekli, J. and B. Braun. (2001). Gendered Natures: Feminism, Politics and Social Nature. In N. Castree and B. Braun (Eds.), Social Nature: Theory, Practice, and Politics (pp.112-132). Malden, USA: Blackwell Publishers.

Mohanty, Chandra Talpade. (1986). Under Western Eyes: Feminist Scholarship and Colonial Discourses. Boundary 2 12(3), 333-58. 
Mohanty, Chandra Talpade. (2002). 'Under Western Eyes' Revisited: Feminist Solidarity through Anti-capitalist Struggle. Signs: Journal of Women in Culture and Society, $28(2), 499-535$.

Monture-Angus, Patricia. (1995). Thunder in My Soul: A Mohawk Woman Speaks. Halifax: Fernwood Publishing.

Morrison, D. (2008). Final Activity Report. B.C. Food Systems Network and Working Group on Indigenous Food Sovereignty. Retrieved from http://www.indigenousfoodsystems.org/content/bc-food-systems-networkworking-group-indigenous-food-sovereignty-final-report [Accessed October 12, 2010]

Muscatello J.R., A.M. Belknap and, D.M. Janz. (2008). Accumulation of selenium in aquatic systems downstream of a uranium mining operation in northern Saskatchewan, Canada. Environmental Pollution, 156, 387-393.

Nagar, Richa, Victoria Lawson, Linda McDowell, Susan Hanson. (2002). Locating globalization: feminist (re)readings of the subjects and spaces of globalization. Urban Studies, 78, 257-284.

Nash, Catherine. (2004). Postcolonial geographies: spatial narratives of inequality and interconnection. In P. Cloke, P. Crang and M. Goodwin (Eds.), Envisioning Human Geography (pp. 104-127). London: Arnold.

Nast, Heidi J. (1994). Women in the Field: Critical Feminist Methodologies and Theoretical Perspectives: Opening Remarks on 'Women in the Field'. The Professional Geographer, 46(1), 54-66.

National Farmers Union [NFU]. (2010). "Free Trade": Is it working for farmers? Comparing 1988 to 2010. Retrieved from www.nfu.ca [Accessed April 13, 2012].

Nriagu, Jerome O., and Tser-Sheng Lin. (1995). Trace metals in wild rice sold in the United States. The Science of the Total Environment, 172, 223-228.

Oakes J., R. Riewe, A. Edmunds, A. Dubois \& K. Wilde. (Eds.). (2003). Native Voices in Research. Winnipeg: University of Manitoba: Aboriginal Issues Press.

Oelke, E., P.R. Bloom, R.A. Porter, Q. Liu. (1999). Wild Rice Plant Development and Seed Physiology. In L. Williamson, L. Dlutkowski, A. McCammon Soltis (Eds.), Wild Rice Research and Management: Proceedings of the Wild Rice Research and Management Conference. Odanah, Wisconsin: Great Lakes Indian Fish and Wildlife Commission: . 
Office of Nutrition Policy and Promotion [ONPP]. (2007). Income-related household food security in Canada. Ottawa, ON: Health Canada.

Omya. (2010). Omya in Canada. Retrieved from Omya North America, locations, Perth, ON http://www.omyana.com/internet/us/q2wcontent.nsf/04fa7deb65dc84f9c1256a6200552c10/e6ef6de 76bb7a9e3c125769300513791? OpenDocument [Accessed Dec 9, 2010]

Ontario Ministry of Aboriginal Affairs [OMAA]. (2009a). Claim History. Retrieved from Aboriginal Affairs, Land Claims, Algonquin Land Claim, http://www.aboriginalaffairs.gov.on.ca/english/negotiate/algonquin/history.asp [Accessed March 30, 2011]

Ontario Ministry of Aboriginal Affairs [OMAA]. (2009b). Overview: What is the Algonquin Land Claim About?. Retrieved from Aboriginal Affairs, Land Claims, Algonquin Land Claim, http://www.aboriginalaffairs.gov.on.ca/english/negotiate/algonquin/overview.asp [Accessed December 9, 2010]

Ontario Ministry of Aboriginal Affairs [OMAA]. (2011a). Claim Map. Retrieved from Aboriginal Affairs, Land Claims, Algonquin Land Claim, http://www.aboriginalaffairs.gov.on.ca/english/negotiate/algonquin/map.asp [Accessed February 20, 2012]

Ontario Ministry of Aboriginal Affairs [OMAA]. (2011b, March). Update on the Algonquins of Ontario Land Claim Negotiations. Retrieved from Aboriginal Affairs, Land Claims, Algonquin Land Claim, http://www.aboriginalaffairs.gov.on.ca/english/negotiate/algonquin/update.asp [Accessed February 20, 2012]

Ontario Ministry of Natural Resources [OMNR]. (2012). Wild Rice Stand. Retrieved from Carleton University library, GIS, Geospatial Data http://www.library.carleton.ca/find/gis/geospatial-data/wild-rice-stand [Accessed April 24, 2012].

Pain, Rachel. (2004). Social Geography: Participatory Research. Progress in Human Geography, 28(5), 652-663.

Paulson, Susan, Lisa L. Gezon and Michael Watts. (2003). Locating the Political in Political Ecology: An Introduction. Human Organization, 62(3), $205-217$.

Paulson, Susan, Lisa L. Gezon and Michael Watts. (2005). Politics, Ecologies Genealogies. In Paulson, S. and L. L. Gezon (Eds), Political Ecology Across Spaces, Scales and Social Groups (pp. 17-40). London: Rutgers University Press. 
Pawlick, Thomas F. (2009). The War in the Country: How the Fight to Save Rural Life Will Shape Our Future. Toronto: D \& M Publishers.

Pesticide Action Network Asia and the Pacific [PANAP]. (2004). Primer on People's Food Sovereignty. Retrieved from Nyeleni 2007, Food Sovereignty, Papers and Articles from http://www.nyeleni.org/spip.php?rubrique46. [Accessed January $12,2011]$

Perry, Harold. (2010, September 6). Personal Interview. Ardoch, Ontario.

Peoples' Food Policy Project [PFPP]. (2012). Peoples' Food Policy Project: creating food policy from the ground up. Retrieved from http://peoplesfoodpolicy.ca/foodsovereignty [Accessed April 13, 2012]

Petavratzi E., S. Kingman, I. Lowndes. (2005). Particulates from mining operations: A review of sources, effects and regulations. Minerals Engineering, 18, 1183-1199.

Phare, Merrell-Ann. (2009). Denying the Source: the crisis of First Nations water rights. Surrey, British Columbia: Rocky Mountain Books.

Pip, Eva and Jeffray Stepaniuk. (1988). The effect of flooding on wild rice, Zizania aquatica L. Aquatic Botany, 32, 283-290.

Pip, Eva. (1993). Cadmium, Copper and Lead in Wild Rice from Central Canada. Archives of Environmental Contamination and Toxicology, 24, 179-181.

Power, Elaine. (2005). Individual and Household Food Insecurity in Canada: Position of Dietitians of Canada. Canadian Journal of Dietetic Practice and Research, 66(1), 43-46.

Pratt, Minnie Bruce. (1984). Identity: Skin Blood Heart. In Ellen Bulkin, Minnie Bruce Pratt, and Barbara Smith (Eds.), Yours in Struggle: Three Feminist Perspectives on Anti-Semitism and Racism (pp. 11-63). New York: Long Haul Press.

Ramsar. (n.d.). Wetland Ecosystem Services - an Introduction. Ramsar Ecosystem Services Factsheets Retrieved from www.ramsar.org/cda/ramsar/display/main/main.jsp?zn=ramsar\&cp=1-30103^24258_4000_0_ [Accessed Dec 4, 2010]

Razack, Sherene. (2002). When Place Becomes Race. In Sherene Razack (Ed.), Race, Space, and the Law: Unmapping a White Settler Society. Between the Lines: Toronto 
Reading, J.L., A. Kmetic and V. Gideon. (2007). First Nations Wholistic Policy and Planning Model: Discussion Paper for the World Health Onganization Commission on Social Determinants of Health. Assembly of First Nations.

Regan, Paulette. (2005, January 20). A Transformative Framework for Decolonizing Canada: a Non-Indigenous Approach. Unpublished paper presented at Indigenous Governance Doctoral Student Symposium, University of Victoria. Retrieved from Research, Indigenous Governance www.web.uvic.ca/igov/research [Accessed March 15, 2012]

Robbins, P. (2005). QResearch is theft: environmental inquiry in a postcolonial world. In Gill Valentine and Stuart Aitken (Eds.), Approaches to human geography (pp. 311-324). London: Sage Press.

Rose, Gillian. (1997). Situating knowledges: positionality, reflexivities and other tactics. Progress in Human Geography, 2 I(3), 305-320.

Roulet, Nigel. (2000). Peatlands, Carbon Storage, Green House Gases, and the Kyoto Protocol: Prospects and Significance for Canada. Wetlands, 20(4), 605-615.

Royal Commission on Aboriginal Peoples [RCAP]. (1996). Report of the Royal Commission on Aboriginal Peoples. Ottawa: Libraxus.

Royal Commission on the Northern Environment [RCNE]. (1979). Chapter 3: Economic Realities in an Untamed Land. In A Background Paper on Behalf of the Royal Commission on the Northern Environment (Ontario Archives RG1-8 file: Royal Commission on the Northern Environment 1979).

Sabra, Samah. (2008). Re-Imagining Home and Belonging: Feminism, Nostalgia, and Critical Memory. Resources for Feminist Research, 33(1/2), 79-102.

Said, Edward W. (1993). Culture and Imperialism. New York: Vintage Books.

Sauer, Carl. (1952). Agricultural Origins and Dispersals. New York: American Geographical Society.

Sheppard, S.C., W.G. Evenden. (1988). Critical compilation and review of plant/soil concentration ratios for uranium, thorium and lead. Journal of Environmental Radioactivity, 8(3), 255-285.

Sherman, Paula. (2007). Indawendiwin: Spiritual Ecology as the Foundation of Omàmìwinini Relations. Trent University. Unpublished Doctoral Dissertation.

Sherman, Paula. (2008). Dishonour of the Crown: The Ontario Resource Regime in the Valley of the Kiji Sibì. Winnipeg: Arbiter Ring Publishing. 
Sherman, Paula. (2010a). Picking Up the Wampum Belt as an Act of Protest. In Lynne Davis (Ed.) Alliances: Re/Envisioning Indigenous-non-Indigenous Relationships. Toronto: University of Toronto Press.

Sherman, Paula. (2010b, September 5). Manomin Teaching. Workshop at AAFNA Manoomin Festival, Plevna Community Hall.

Sherman, Paula. (2010c, October 18). Personal Interview. Peterborough, Ontario.

Shewell, Mitchell. (2010, September 15). Personal Interview. Kingston, Ontario.

Shiva, Vandana. (2000). Stolen Harvest: The hijacking of the global food supply. Cambridge: South End Press.

Simpson, Leanne. (2004). Anticolonial Strategies for the Recovery and Maintenance of Indigenous Knowledge. American Indian Quarterly, 28(3 \& 4), 373-382.

Simpson, Leanne. (2008). Foreword. Dishonour of the Crown: The Ontario Resource Regime in the Valley of the Kiji Sibi. Winnipeg: Arbiter Ring Publishing.

Smith, Eric Lloyd. (2009). Resource Extraction, Crown land, and the land claim process: Omàmiwinini resistance in the Mississippi watershed. Carleton University, Ottawa. Unpublished paper.

Smith, Neil. (1996). The New Urban Frontier: Gentrification and the Revanchist City. New York: Routledge.

Statistics Canada. (2008, November 13). Study: The role of natural resources in Canada's economy. The Daily. Retrieved from http://www.statcan.gc.ca/dailyquotidien/081113/dq081113b-eng.htm [Accessed December 13, 2010]

Stevenson, Winona. (1999). "Colonialism and First Nations Women in Canada". In Enakshi Dua and Angela Robertson (Eds.) Scratching the surface: Canadian antiracist feminist thought. Toronto: Women's Press.

Stevenson (Wheeler), Winona L., 2000. Decolonizing Tribal Histories. University of California, Berkeley. Unpublished doctoral dissertation.

Steward, Julian. (1972). Theory of Culture Change: The Methodology of Multilinear Evolution. Urbana: University of Illinois Press. (Original work published 1955).

Suffling, Roger, Michael Evans and Ajith Perera. (2003). Presettlement forest in southern Ontario: Ecosystems measured through a cultural prism. The Forestry Chronicle, 79(3), 485-501. 
Tanakiwin. (2009). Frequently Asked Questions. Retrieved from Tanakiwin, Algonquin Nation in present day Ontario, http://www.tanakiwin.com/faq.htm [Accessed December 9,2010$]$

Tarnocai, C. (1980). Canadian wetland registry. In C.D.A. Rubec and F.C. Pollett (Eds.) Proceedings of a workshop on Canadian wetlands. Environ. Can., Ecol. Land Class. Series No. 12. Ottawa, Ont., 9-21.

Tickell, A. and J. Peck. (2003). Making Global Rules: Globalization or Neoliberalization. In J. Peck, H. Wai-chung Yeung (Eds.), Remaking the Global Economy (pp. 163-181). London: Sage.

Thobani, Sunera. (2007). Exalted Subjects: Studies in the Making of Race and Nation in Canada. Toronto: University of Toronto Press.

Tuhiwai Smith, Linda. (2000). Decolonizing Methodologies: Research and Indigenous Peoples. New York: Zed Books.

Tynan, T. (2000). Testing the effects of motorboats on wild rice (Zizania palustris var. interior). Unpublished paper presented at Proceedings of the Wild Rice Research and Management Conference. Great Lakes Indian Fish and Wildlife Commission, 7-8 July 1999, Carlton, Minnesota, pp.192-205.

United Nations [UN]. (2008). United Nations Declaration on the Rights of Indigenous Peoples. Retrieved from United Nations, UN Permanent Forum on Indigenous Issues, www.un.org/esa/socdev/unpfii/documents/DRIPS en.pdf [Accessed November 18 2010]

Walia, Harsha. (2012). Decolonizing together: Moving beyond a politics of solidarity toward a practice of decolonization. Briarpatch Magazine, 4l(1), 27-30.

Watts, M. and R. Peet. (2004). Preface, and Liberating Political Ecology. In R. Peet and M. Watts (Eds.), Liberation Ecologies: Environment, development, social movements (2nd Edition) (pp. xiii-xviii; 3-47). New York: Routledge.

Weir, Allison. (2008). Home and Identity: In Memory of Iris Marion Young. Hypatia, $23(3), 4-21$.

Wilcox, Douglas A., and James E. Meeker. (1991). Disturbance effects on aquatic vegetation in regulated and unregulated lakes in northern Minnesota. Canadian Journal of Botany, 69, 1542-1551.

Wiles, Anne, John McEwen and M. Husain Sadar. (1999). Use of traditional ecological knowledge in environmental assessment of uranium mining in the Athabasca Saskatchewan. Impact Assessment and Project Appraisal, 18(2), 107114. 
Wilson, Angela Cavender. (2004). Reclaiming Our Humanity: Decolonization and the Recovery of Indigenous Knowledge. In D.A. Mihesuah and A.C. Wilson (Eds.), Indigenizing the Academy: Transforming Scholarship and Empowering Communities (pp. 69-87). Lincoln: University of Nebraska Press.

Windfuhr, M. and J. Jonsen. (2005). Food Sovereignty: Towards democracy in localized food systems. Warwickshire: ITDG Publishing.

Woodley, Ellen, Eve Crowley, Jennie Dey de Pryck and Andrea Carmen. (2006). Cultural indicators of Indigenous Peoples' food and agro-ecological systems. Retrieved from FAO, International Indian Treaty Council http://www.fao.org/sard/common/ecg/3045/en/Cultural Indicators paperApril200 8.pdf [Accessed March 23, 2011]

Wylie, John W. (2006). Poststructuralist Theories, Critical Methods and Experimentation. In S. Aitken and G. Valentine (Eds.), Approaches to Human Geography (pp. 298-310). Thousand Oaks: Sage.

Vayda, Andrew and Roy Rappaport. (1967). Ecology, Cultural and Noncultural. In J. Clifton (Ed.) Introduction to Cultural Anthropology (pp. 477-497). Boston: Houghton Mifflin.

Vukov, Tamara. (2003). Imagining Communities Through Immigration Policies: Governmental regulation, media spectacles and the affective politics of national borders. International Journal of Cultural Studies, 6(3), 335-353.

Zedler, Joy B. and Suzanne Kercher. (2005). Wetland Resources: Status, Trends, Ecosystem Services and Restorability. Annual Review of Environmental Resources, 30, 39-74.

Zhang, B. Y., J. S. Zheng, R. G. Sharp. (2010). Phytoremediation in Engineered Wetlands: Mechanisms and Applications. Procedia Environmental Sciences, 2, $1315-1325$.

Zlomislic, Diana. (2011, Feb 7). Star Exclusive: Agent Orange 'soaked' Ontario teens. The Toronto Star News. Retrieved from http://www.thestar.com/news/canada/article/940243--star-exclusive-agent-orangesoaked-ontario-teens [Accessed April 28 2011]. 